Technical Report

August 1994

\title{
Meteorological and Oceanographic Data Collected during the ASREX 91 Field Experiment
}

\author{
by
}

Nancy R. Galbraith

Anand Gnanadesikan

George H. Tupper

Bryan S. Way

Upper Ocean Processes Group

Woods Hole Oceanographic Institution

Eugene A. Terray

Department of Applied Ocean Science and Engineering

Woods Hole Oceanographic Institution
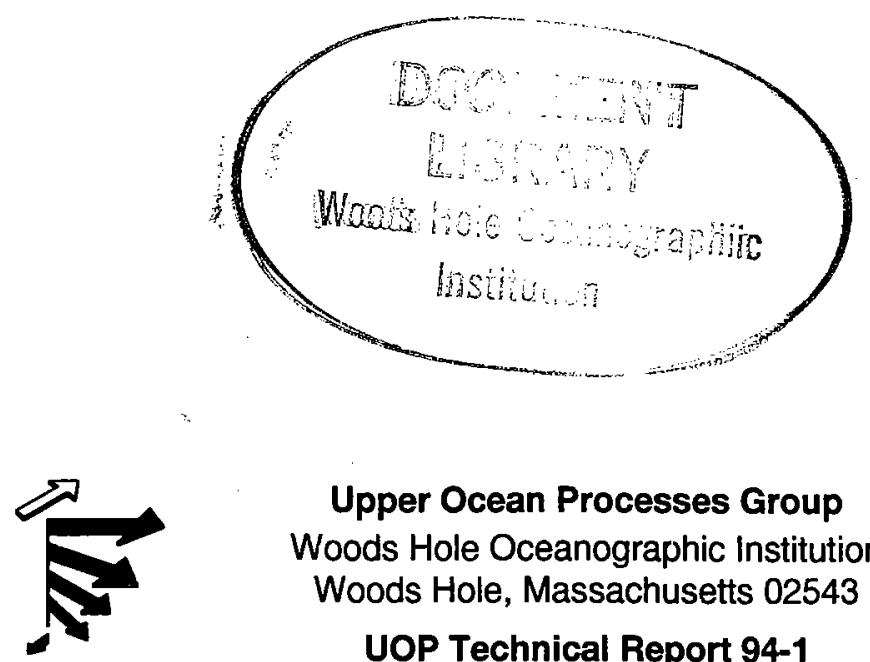

Upper Ocean Processes Group

Woods Hole Oceanographic Institution

Woods Hole, Massachusetts 02543

UOP Technical Report 94-1 


\title{
Meteorological and Oceanographic Data Collected during the ASREX 91 Field Experiment
}

by

\author{
Nancy R. Galbraith \\ Anand Gnanadesikan \\ George H. Tupper \\ Bryan S. Way \\ Upper Ocean Processes Group \\ Woods Hole Oceanographic Institution \\ Eugene A. Terray \\ Department of Applied Ocean Science and Engineering \\ Woods Hole Oceanographic Institution
}

August 1994

\section{Technical Report}

Funding was provided by the Ocean Acoustics Program (Code 324OA) of the Office of Naval Research under contract N00014-91-J-1891.

\begin{abstract}
Reproduction in whole or in part is permitted for any purpose of the United States Government. This report should be cited as Woods Hole Oceanog. Inst. Tech. Rept., WHOI-94-18.
\end{abstract}

Approved for public release; distribution unlimited.

\section{Approved for Distribution:}

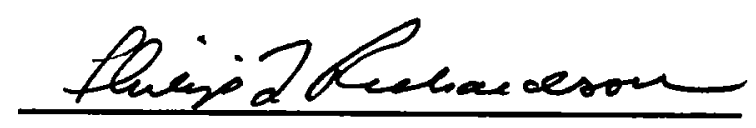

Philip L. Richardson, Chair

Department of Physical Oceanography 


\begin{abstract}
The 1991 Acoustic Surface Reverberation Experiment (ASREX 91) took place in November and December off the coast of British Columbia. As part of this experiment, three moorings were deployed to characterize the environmental background. The moorings consisted of a meteorological/oceanographic mooring designed to measure surface meteorology, current and temperature in the upper 120 meters, and nondirectional wave parameters and two wave moorings which were instrumented with pitch-roll buoys to characterize the directional wave spectrum. This report presents results from these three moorings. The conditions seen during the experiment were extremely rough, with wind speeds at $3.4 \mathrm{~m}$ above the water surface reaching a maximum of $22 \mathrm{~m} / \mathrm{s}$ and wave heights reaching a maximum of over 10 meters. The air-sea flux of heat was strongly cooling, and the mixed layer deepened over the course of the experiment from approximately 40 to approximately 70 meters. Spectra of the temperature showed a strong semidiurnal tidal signal associated with temperature excursions of several degrees $C$. The velocity signal showed strong inertial oscillations with amplitudes of $30-50 \mathrm{~cm} / \mathrm{s}$ Weaker low-frequency and semidiurnal tidal signals were also seen. The waves were very strong with significant wave heights of 5-6 meters persisting for up to 2 weeks at a time. Waves were generally out of the south or the west.
\end{abstract}





\section{Table of Contents}

List of Figures $\mathbf{v}$

List of Tables vi

1. Introduction 1

2. Mooring Information 1

\section{Data Presentation}

3.1 Meteorology during ASREX 91 8

3.2 Temperature and Density Structure during ASREX 91

References 
Appendix 3: CTD Cast Information 111

Appendix 4: Seatex Mooring Failure Report. .112

Appendix 5: MATLAB Routine for Calculating Wave Direction .......114 


\section{List of Figures}

2.1 Map of ASREX Site

pages

2.2 Discus Mooring Diagram

2.3 Seatex Mooring Diagram

2.4 Endeco Mooring Diagram

3.1.1-3 IMET and VAWR Meteorological Variables

3.1.4-5 VAWR Meteorological Variables

14-16

3.1.6-10 Heat Flux from VAWR

17-18

3.1.11-15 Wind Stress from VAWR

19-23

3.1.16 Autospectra of Meteorological Variables

3.1.17 Precipitation from IMET

3.2.1 Contour Plot of Temperature

3.2.2-11 Temperature Time Series and Spectra

3.2.12 Temperature Profiles, Deployment Cruise CTDs

3.2.13 Salinity Profiles, Deployment Cruise CTDs

3.2.14 Density Profiles, Deployment Cruise CTDs

3.2.15 Temperature Profiles, Recovery Cruise CTDs

3.2.16 Salinity Profiles, Recovery Cruise CTDs

3.2.17 Density Profiles, Recovery Cruise CTDs

3.3.1-5 Subsurface Velocity Vectors (Low-Frequency)

3.3.6 Progressive Vector Diagrams

51.55

3.3.7-10 Velocity Time Series and Spectra

3.4.1 Wave Parameters from Seatex Buoy

$57-60$

3.4.2 Evolution of Wave Field vs. Frequency

65

3.4.3 Wave and Wind Direction

66

3.4.4 Comparison of Three Buoys

$67-68$

69

3.4.5-38 Directional Wave Spectra

70-103

A.4.1 Schematic of Seatex Mooring Attachment 


\section{List of Tables}

2.1 Locations and durations of the three moorings 2

2.2 Instrumentation on the Discus mooring 7

3.1.1 Meteorological sensor specifications, VAWR 11

3.1.2 Meteorological sensor specifications, IMET 12

3.1.3 Schematic of VAWR sensor averaging periods 13 


\section{Introduction}

The 1991 Acoustic Surface Reverberation Experiment (ASREX 91) was designed to study processes causing degraded acoustic transmission in high sea states. The experiment took place in late 1991 and early 1992 off the coast of British Columbia. In support of this experiment, a group from the Woods Hole Oceanographic Institution deployed three moorings designed to provide the environmental background for the acoustic measurements made by other investigators. These moorings measured the meteorology, temperature structure over the top 120 meters of the water column, current velocity over the top 20 meters, and the directional wave spectrum. The resulting data set provides an opportunity to examine the wintertime deepening of a mixed layer, and to evaluate the importance of surface gravity waves for this process.

\section{Mooring Information}

The mooring operations took place onboard the University of Washington's R/V Thomas G. Thompson. Deployment was on Voyage 4, sailing out of Seattle on 29 October 1991. Recovery was on Voyage 5, also sailing from Seattle, on 5 January 1992. The moorings were sited about $350 \mathrm{~km}$ west of Vancouver Island. Table 2.1 lists the location and duration of the three moorings. Figure 2.1 shows a bathymetric map of the area around the experiment site. A list of cruise participants appears in Appendix 1, and the chronology of the cruises is described in Appendix 2. 
Table 2.1: Locations and durations of the three moorings

\begin{tabular}{|c|c|c|c|c|}
\hline Buoy & Deployment & Recovery & Latitude & Longitude \\
\hline $\begin{array}{l}\text { Discus Buoy } \\
\text { (WHOI-920) }\end{array}$ & $9110 \overline{31} 21: 09$ & $92010714: 18$ & $4913.45 \mathrm{~N}$ & $13151.88 \mathrm{~W}$ \\
\hline $\begin{array}{l}\text { Seatex } \\
\text { (WHOI-921) }\end{array}$ & 911101 05:50 & $\begin{array}{l}\text { Surface Buoy } \\
\text { 911204 19:00 } \\
\text { Mooring: } \\
\text { 920107 23:11 }\end{array}$ & $4909.10 \mathrm{~N}$ & $13153.30 \mathrm{~W}$ \\
\hline $\begin{array}{l}\text { Endeco } \\
\text { (WHOI-923) }\end{array}$ & $91110204: 50$ & 920108 18:04 & $4908.25 \mathrm{~N}$ & $13147.42 \mathrm{~W}$ \\
\hline
\end{tabular}

On 1 December 1991, telemetry data from System Argos revealed that the Seatex buoy had gone adrift. The buoy was recovered on 4 December by the Canadian destroyer HMCS Huron. Upon recovery it was found that the Seatex buoy appeared to have been intentionally detached from the mooring and the surface tether had been cut. Information about this incident is given in more detail in Appendix 4.

The WHOI moorings were designed by and set by members of the Upper Ocean Processes Group (UOP) and the Ocean Acoustics Lab (OAL) at Woods Hole. Mooring diagrams are in figures 2.2 through 2.4. A summary of the instrumentation on the discus mooring is given in table 2.2. 


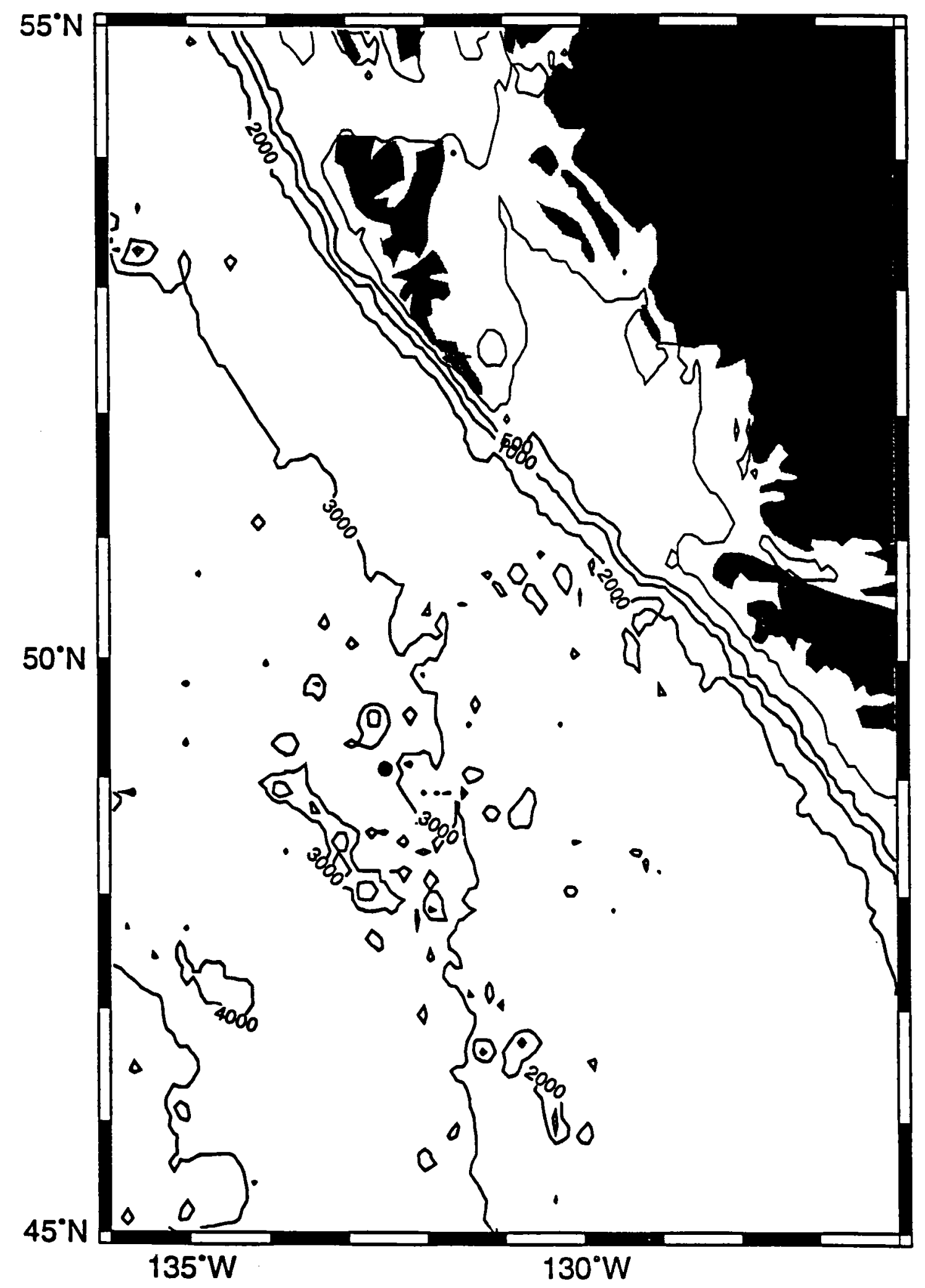

Figure 2.1: Map of ASREX 91 Experiment Site 


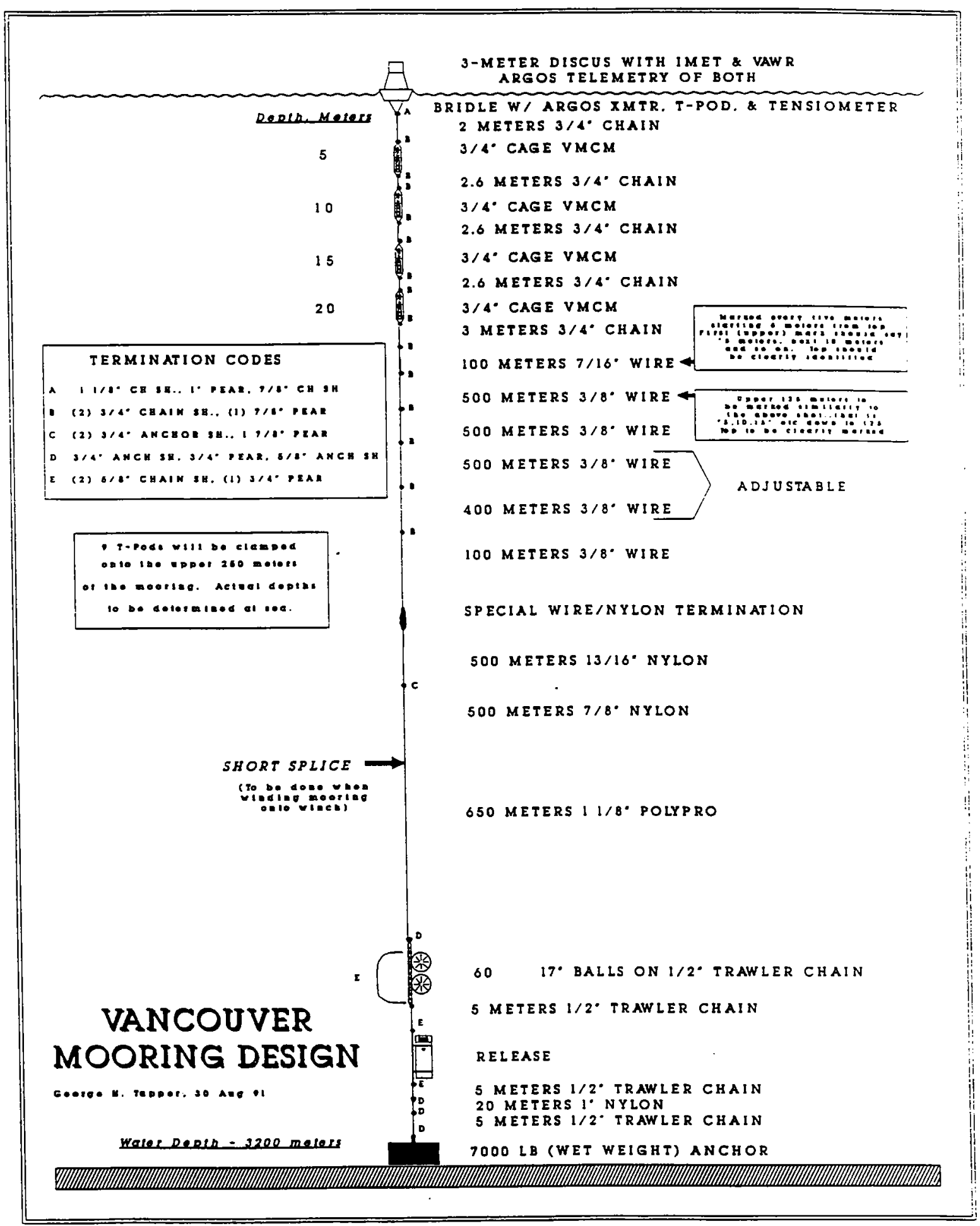

Figure 2.2: Mooring Diagram. Discus Mooring. 


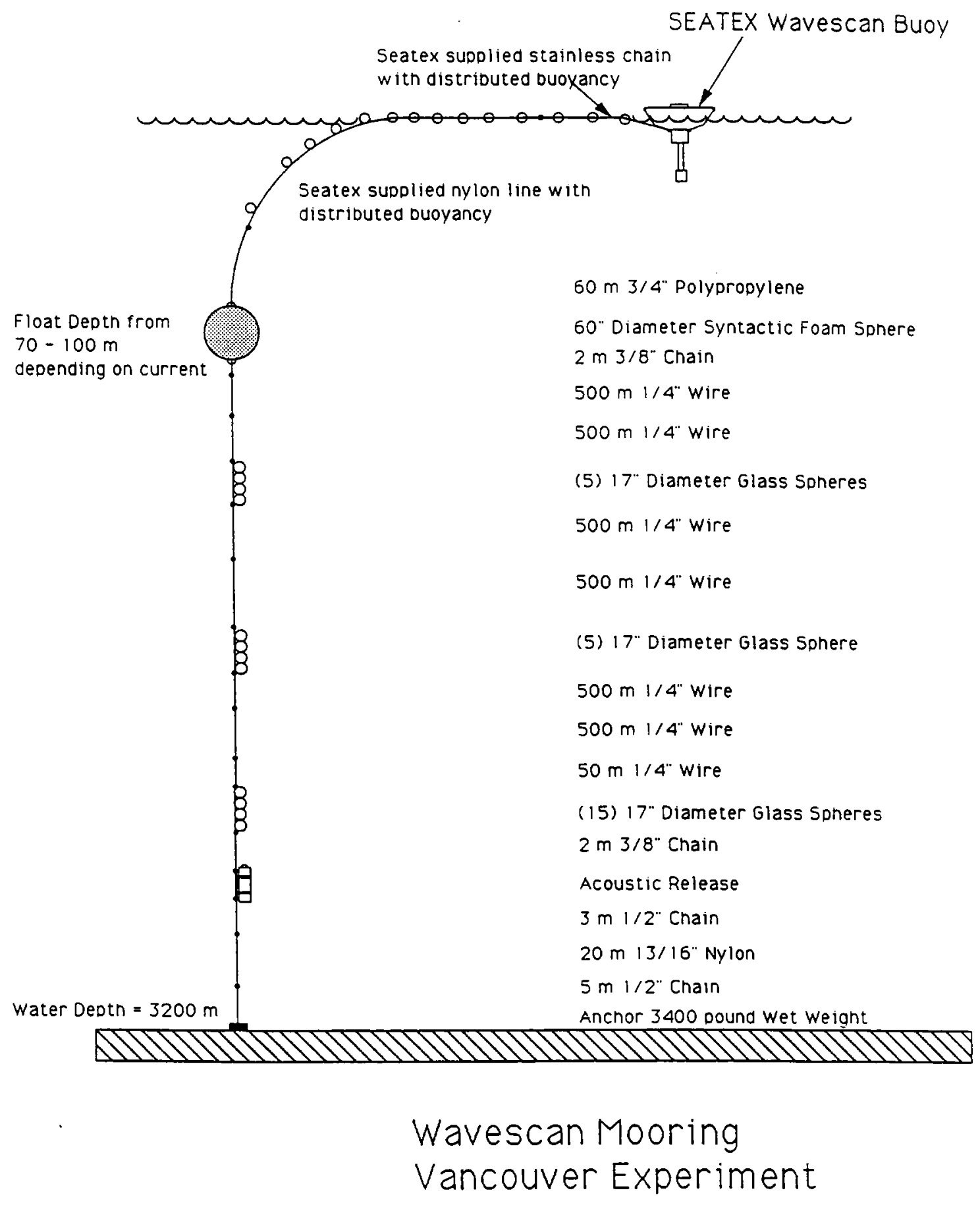

Figure 2.3: Mooring Diagram. Seatex Mooring. 


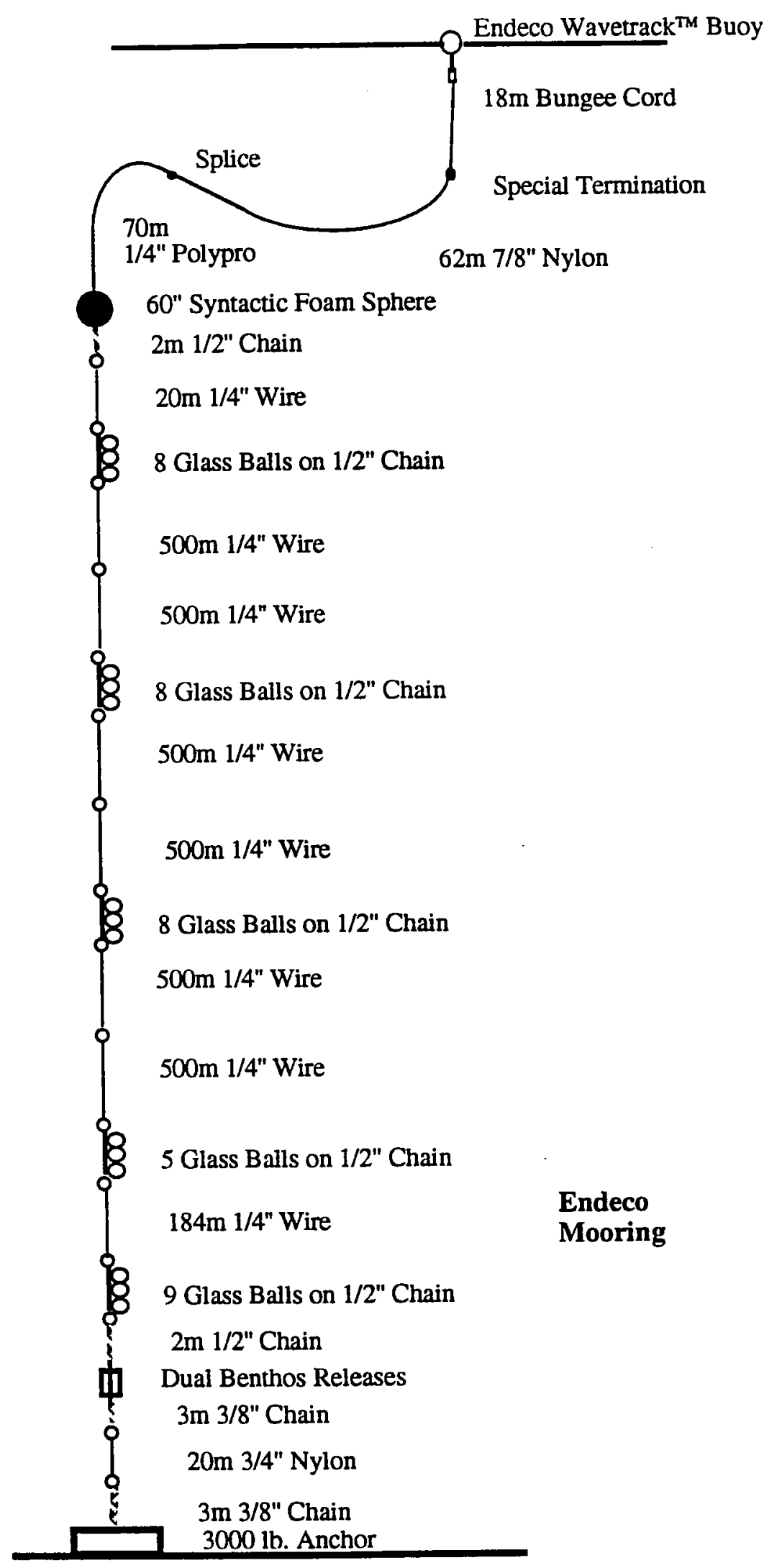

Figure 2.4: Mooring Diagram. Endeco Mooring. 
Table 2.2: Instrumentation on the Discus mooring

$\begin{array}{llll}\begin{array}{c}\text { Instrument } \\ \text { Type }\end{array} & \begin{array}{c}\text { Serial } \\ \text { Number }\end{array} & \begin{array}{l}\text { Sample } \\ \text { Rate(sec) }\end{array} & \begin{array}{c}\text { Depth } \\ \text { (meters) }\end{array} \\ \text { VAWR } & 0723 & 900 & \text { Surface } \\ \text { IMET } & 3699 & 60 & \text { Surface } \\ \text { TPOD } & 1405 & 450 & 2 \\ \text { VMCM } & 0201 & 112.5 & 5 \\ \text { VMCM } & 0773 & 1125 & 10 \\ \text { VMCM } & 0873 & 112.5 & 15 \\ \text { VMCM } & 3702 & 1125 & 20 \\ \text { TPOD } & 3662 & 450 & 40 \\ \text { TPOD } & 3700 & 450 & 60 \\ \text { TPOD } & 3667 & 450 & 80 \\ \text { TPOD } & 3705 & 450 & 100 \\ \text { TPOD } & & 450 & 120\end{array}$




\section{Data Presentation}

\subsection{Meteorology during ASREX 91}

\section{Meteorological Observations}

Meteorological data was recorded using a Vector-Averaging Wind Recorder (VAWR) with a 15 minute record rate. A second meteorological instrument package, an Improved Meteorological (IMET) system, also recorded data for a period of about one month, but its battery power, normally recharged by solar panels, failed as a result of too little sunlight on 5 December 1991 at midnight. The IMET system had a one minute record rate.

Tables 3.1.1-3.1.2 summarize the sensors, their accuracy, and the sampling strategy for each of the packages. Table 3.1.3 shows a schematic of how the VAWR sampled each sensor during the 15 minute recording interval. Note that while the wind and radiation sensors recorded over the entire interval, the relative humidity and barometric pressure are sampled for a very short period of time in the middle of the recording interval.

A check of the time base for the VAWR found 392 missing or incorrect clock counts. The data was interpolated over these gaps. The final processed data file had a total of 6455 records at 15 minute intervals between 91-11-01 00:07:30 UTC and 92-01-07 08:07:30 UTC. Figure 3.1.1 through 3.1.5 show time-series of meteorological data recorded by the VAWR and IMET. Displayed are wind velocity north and east, sea temperature, air temperature, barometric pressure, relative humidity, short wave and long wave radiation. IMET data is represented with a dashed line, and VAWR data with a solid line. A magnetic variation of $21.4^{\circ}$ was applied to the data from both instruments. 
The IMET data were found to agree very well with the VAWR data in general, although several small, systematic differences were found. The VAWR recorded wind speeds about $9 \%$ higher than the IMET. The IMET relative humidity was found to be about $1 \%$ higher than the VAWR with rms differences of order $1-2 \%$. The barometric pressure also showed a systematic offset, with the VAWR being about $0.8 \mathrm{MB}$ lower than the IMET. Except for the wind sensors, these differences were within the sensor specifications. Comparison of these differences with meteorological observations taken aboard the Thompson was made, but the differences were not resolvable. For purposes of the flux calculations reported here, the VAWR data will be taken as correct.

\section{Air-Sea Fluxes}

Fluxes of momentum, sensible heat, and latent heat for the Vancouver data site were computed from the meteorological variables using the stabilitydependent bulk aerodynamic formulae of Large and Pond (1981; 1982). The net shortwave radiation is computed using an albedo of 0.06 . The net longwave radiation is estimated using sea surface temperature. air temperature and the mixing ratio from Clark et al., 1974. This formula also includes a cloud-correction function which depends on the cloud cover. The cloud cover $\mathrm{n}$ was estimated from the incoming shortwave radiation. by comparing the observed radiation to clear-sky radiation predicted from astronomical theory (List,1984) assuming some atmospheric transmission coefficient. An atmospheric transmission coefficient of 0.7 was used, and compared well with observed short wave radiation from the VAWR during the few clear-sky days over the course of the deployment. Night- 
time values of cloud cover were estimated by linear interpolation between the nearest two daytime values.

Time series of the heat fluxes computed from the VAWR are shown in Figures 3.1.6 through 3.1.10. From top to bottom, the sensible, latent, net shortwave, net long wave and total heat flux in $\mathrm{W} / \mathrm{m}^{2}$ are shown. Figures 3.1.11 through 3.1.15 show the wind stress time series computed from the VAWR. From top to bottom, the eastward wind stress, northward wind stress, wind stress magnitude, wind stress direction (towards), and the nondimensional stability parameter $z / L . L$ is the Monin-Obhukhov length $-c_{p} T_{*}^{3} / \kappa g Q$, (where $c_{p}$ is the specific heat, $\mathrm{T}$ is the temperature, $\mathrm{u}^{*}$ the friction velocity, $\mathrm{g}$ is gravity, $\mathrm{K}$ is the Von Karman constant, and Q is the heat gained by the atmosphere from the ocean) are shown. Large negative values of $\mathrm{L}$ mean that the atmospheric boundary layer is convectively unstable, so that the shear of the velocity is reduced from a logarithmic profile.

Figure 3.1.16 shows the rotary spectrum of the wind stress (solid represents clockwise rotation, dashed counterclockwise rotation), and the spectrum of the sea-surface temperature, air temperature, shortwave radiation, barometric pressure and relative humidity. Other than the shortwave radiation, which shows a distinct set of peaks at the first, second, and third harmonics of the diurnal frequency, there are no significant peaks.

Figure 3.1 .17 shows the precipitation measured by the IMET system. The sensor used was an R.M Young self siphoning rain gauge, which emptied itself upon reaching a level of $5 \mathrm{~cm}$. Over the course of the deployment, the gauge emptied itself 2 times, on 3 November and 16 November. 


\begin{tabular}{|c|c|c|c|}
\hline Parameter & Sensor Type & Accuracy & Record Time \\
\hline Wind Speed & $\begin{array}{l}\text { R.M. Young } \\
\text { 3-cup } \\
\text { Anemometer }\end{array}$ & $\begin{array}{l}+1-2 \% \\
\text { above } \\
0.7 \mathrm{~m} / \mathrm{s}\end{array}$ & Vector Averaged \\
\hline $\begin{array}{l}\text { Wind } \\
\text { Direction }\end{array}$ & $\begin{array}{l}\text { Integral Vane } \\
\text { w/vane follower } \\
\text { WHOI/EG\&G }\end{array}$ & $\begin{array}{l}+/-1 \text { bit } \\
5.6 \text { degrees }\end{array}$ & Vector Averaged \\
\hline Insolation & $\begin{array}{l}\text { Pyranometer } \\
\text { Eppley 8-48 }\end{array}$ & $\begin{array}{l}+/-3 z \\
\text { of reading }\end{array}$ & $\begin{array}{l}\text { Averaged over } \\
\text { record interval }\end{array}$ \\
\hline $\begin{array}{l}\text { Long Wave } \\
\text { Radiation }\end{array}$ & $\begin{array}{l}\text { Pyrgeometer } \\
\text { Eppley PIR }\end{array}$ & $+/-10 \%$ & $\begin{array}{l}\text { Averaged over } \\
\text { record interval }\end{array}$ \\
\hline $\begin{array}{l}\text { Relative } \\
\text { Humidity }\end{array}$ & $\begin{array}{l}\text { Vaisala } \\
\text { Humicap 0062HMP }\end{array}$ & $+/-2 \% \mathrm{RH}$ & $\begin{array}{l}3.515 \text { Seconds } \\
\text { Average } \\
\text { Note } 1\end{array}$ \\
\hline $\begin{array}{l}\text { Barometric } \\
\text { Pressure }\end{array}$ & $\begin{array}{l}\text { Paroscientific } \\
\text { Model 216-B-101 }\end{array}$ & $\begin{array}{l}+/-0.2 \\
\text { mbars } \\
\text { wind }<20 \mathrm{~m} / \mathrm{s}\end{array}$ & $\begin{array}{l}2.636 \text { Seconds } \\
\text { Average } \\
\text { Note } 1\end{array}$ \\
\hline $\begin{array}{l}\text { Sea } \\
\text { Temperature }\end{array}$ & $\begin{array}{l}\text { Thermistor } \\
\text { Thermometrics } \\
4 \text { \& } 25 \text { degrees } C\end{array}$ & $\begin{array}{l}+/-0.005 \\
\text { degrees C }\end{array}$ & $\begin{array}{l}\text { Averaged over } \\
1 / 2 \text { record time } \\
\text { Note } 2\end{array}$ \\
\hline $\begin{array}{l}\text { Air } \\
\text { Temperature }\end{array}$ & $\begin{array}{l}\text { Thermistor } \\
\text { Yellow Springs } \\
\text { \#44034 } \\
5 \mathrm{~K} \text { \& } 25 \text { degrees C }\end{array}$ & $\begin{array}{l}+1-0.2 \\
\text { degrees } \mathrm{C} \\
\text { wind }>5 \mathrm{~m} / \mathrm{s}\end{array}$ & $\begin{array}{l}\text { Averaged over } \\
1 / 2 \text { record time } \\
\text { Note } 3\end{array}$ \\
\hline
\end{tabular}

\section{Notes :}

1. Relative Humidity and Barometric Pressure are averaged in the middle of the recording interval for the time noted.

2. Sea temperature is measured during the first half of the recording interval.

3. Air temperature is measured during the second half of the recording interval.

Table 3.1.1: Meteorological Sensor Specifications. Vector Averaging Wind Recorder (VAWR) Deployed on Discus Buoy. 
IMET (Improved Meteorological Record) (60 second record interval)

\begin{tabular}{|c|c|c|c|}
\hline Parameter & Sensor Type & Accuracy & Record Time \\
\hline Wind Speed & $\begin{array}{l}\text { R. M. Young } \\
\text { propeller } \\
\text { Anemometer }\end{array}$ & $\begin{array}{l} \pm 2 \% \\
\text { above } \\
0.7 \mathrm{~m} / \mathrm{s}\end{array}$ & $\begin{array}{l}\text { Scalar average } \\
\text { over } 1 \mathrm{~min}\end{array}$ \\
\hline Wind Direction & $\begin{array}{l}9 \text { bit encoder } \\
\mathrm{KVH} \text { compass }\end{array}$ & $\begin{array}{l} \pm 1 \text { bit } \\
0.7 \text { degrees }\end{array}$ & $\begin{array}{l}\text { Scalar average } \\
\text { over } 1 \mathrm{~min}\end{array}$ \\
\hline Insolation & $\begin{array}{l}\text { Pyranometer } \\
\text { Eppley PSP }\end{array}$ & $\begin{array}{l} \pm 3 \% \\
\text { of reading }\end{array}$ & $\begin{array}{l}\text { Averaged over } \\
\text { record interval }\end{array}$ \\
\hline $\begin{array}{l}\text { Long Wave } \\
\text { Radiation }\end{array}$ & $\begin{array}{l}\text { Pyrgeometer } \\
\text { Eppley PIR }\end{array}$ & $\pm 10 \%$ & $\begin{array}{l}\text { Averaged over } \\
\text { record interval }\end{array}$ \\
\hline $\begin{array}{l}\text { Relative } \\
\text { Humidity }\end{array}$ & $\begin{array}{l}\text { Rotronics } \\
\text { MP-100F }\end{array}$ & $\pm 2 \% \mathrm{RH}$ & $\begin{array}{l}\text { Averaged over } \\
\text { record interval }\end{array}$ \\
\hline $\begin{array}{l}\text { Barometric } \\
\text { Pressure }\end{array}$ & Air DB1-A & $\begin{array}{l} \pm 0.2 \mathrm{mbars} \\
\text { wind }<20 \mathrm{~m} / \mathrm{s}\end{array}$ & $\begin{array}{l}\text { Averaged over } \\
\text { record interval }\end{array}$ \\
\hline $\begin{array}{l}\text { Sea } \\
\text { Temperature }\end{array}$ & PRT 1k & $\begin{array}{l} \pm 0.005 \\
\text { degrees C }\end{array}$ & $\begin{array}{l}\text { Averaged over } \\
\text { record interval }\end{array}$ \\
\hline Air Temperature & PRT 1k & $\begin{array}{l} \pm .005 \\
\text { degrees } C \\
\text { wind }>5 \mathrm{~m} / \mathrm{s}\end{array}$ & $\begin{array}{l}\text { Averaged over } \\
\text { record interval }\end{array}$ \\
\hline
\end{tabular}

Table 3.1.2: Meteorological Sensor Specifications. Improved Meteorological system (IMET) Deployed on Discus Buoy. 

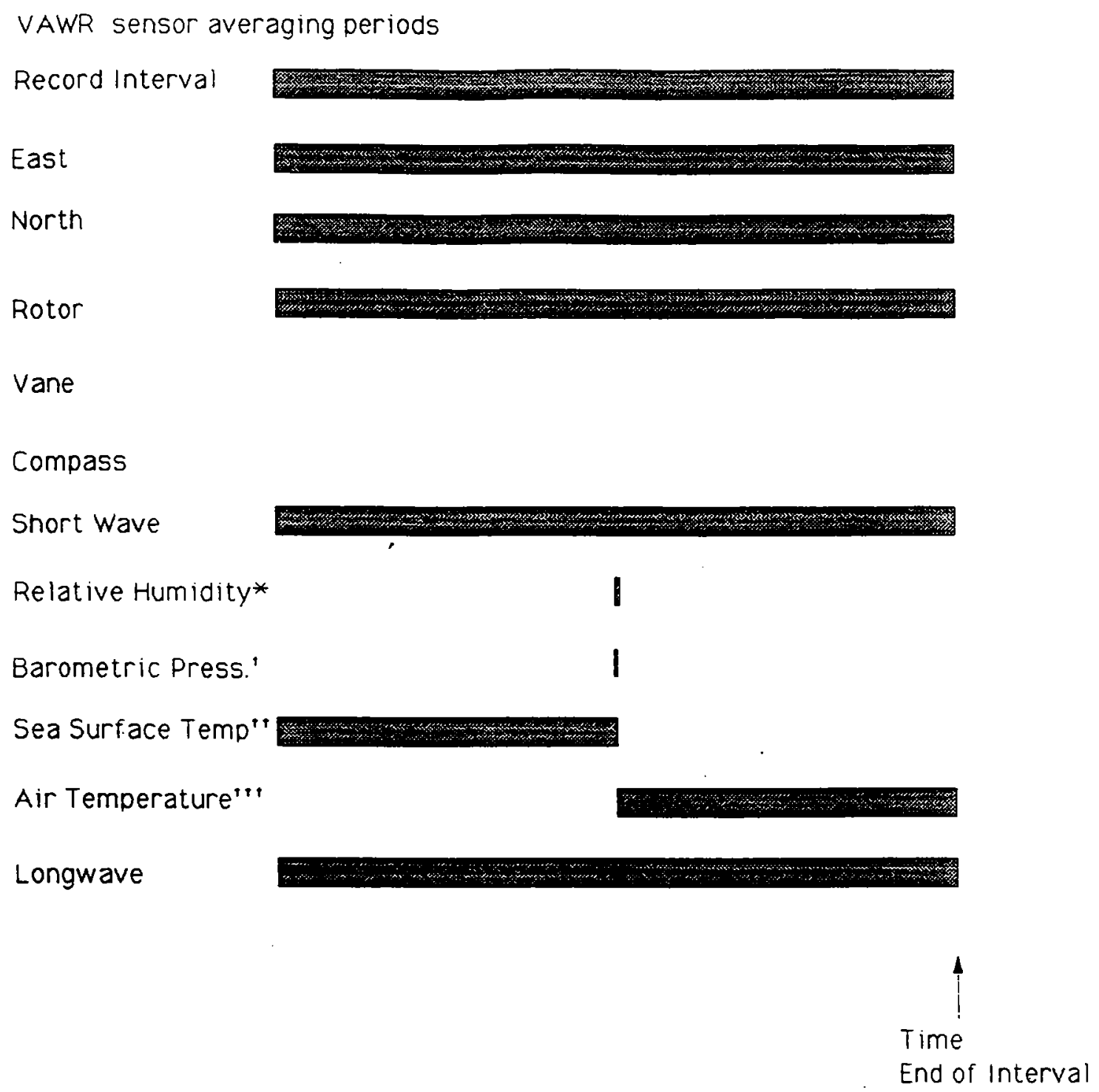

* Relative humidity sensor is on for 7 seconds and counted for 3.515 seconds

' Barometric Pressure sensor is on for 4.39 seconds and counts for 2.636 seconds

"Sea surface temperature is averaged during the first half of the record rate Actual averaging interval is half the record rate minus 1.7578125 seconds (delay and settle time from SST to AT)

"Air temperature is counted for the second half of the averaging interval. The air temp average interval is half the record rate minus 1.7578125 .

Recorded compass and vane information is the last sample taken in the record interval.

Table 3.1.3: Schematic of VAWR Sensor Averaging Periods. 


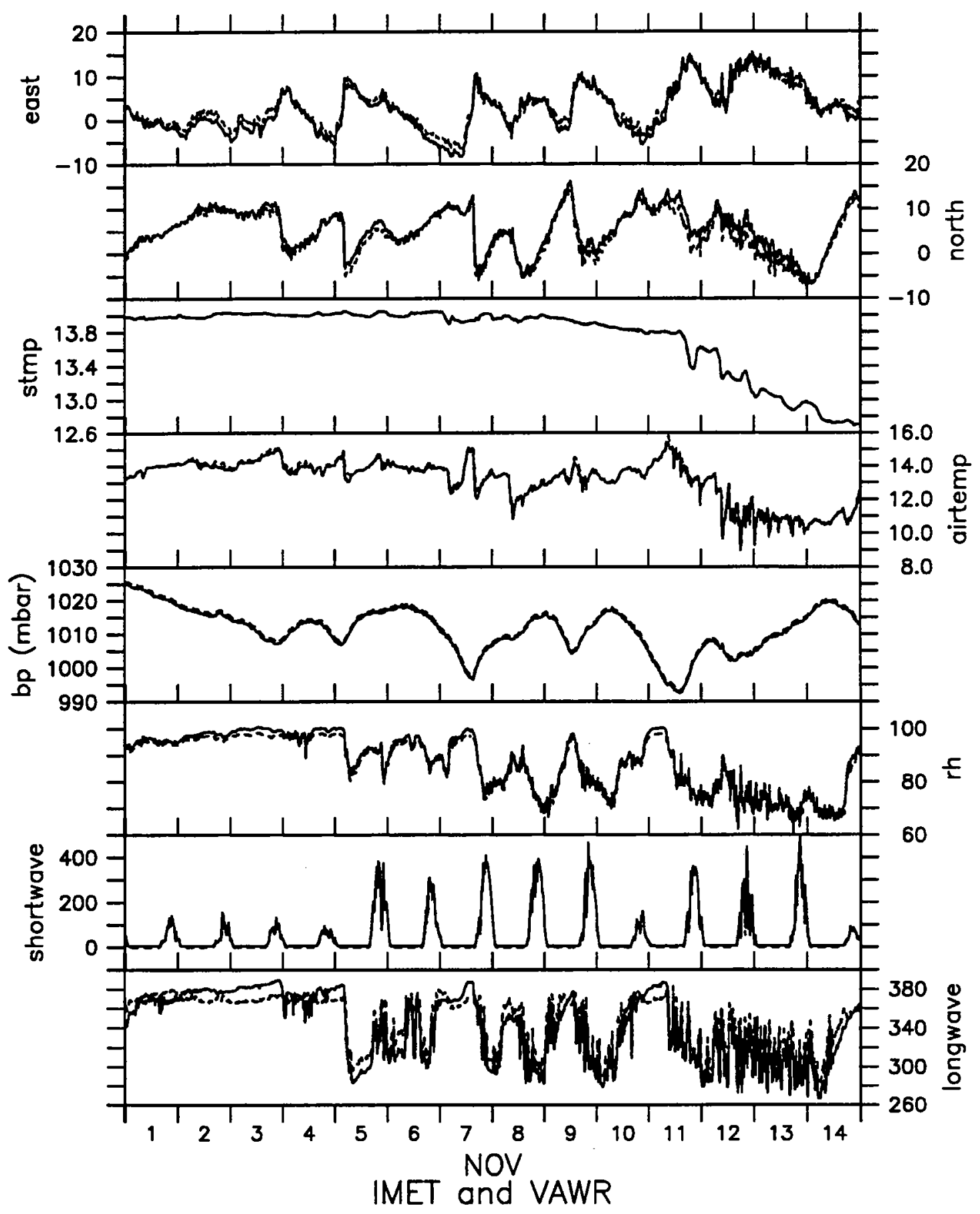

Figure 3.1.1 VAWR and IMET Meteorological Time Series. IMET data is dashed, VAWR data is solid line. 


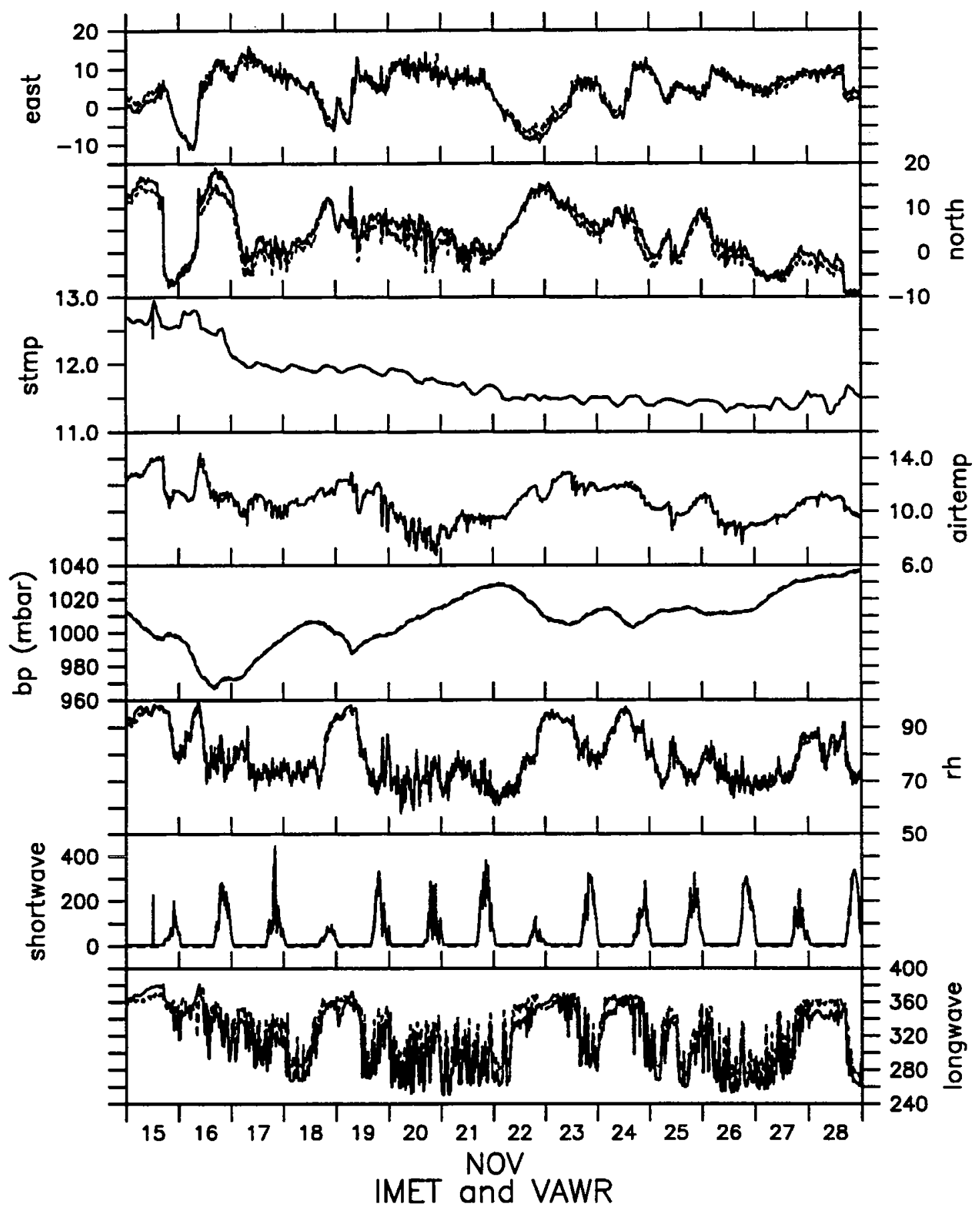

Figure 3.1.2 VAWR and IMET Meteorological Time Series. IMET data is dashed, VAWR data is solid line. 


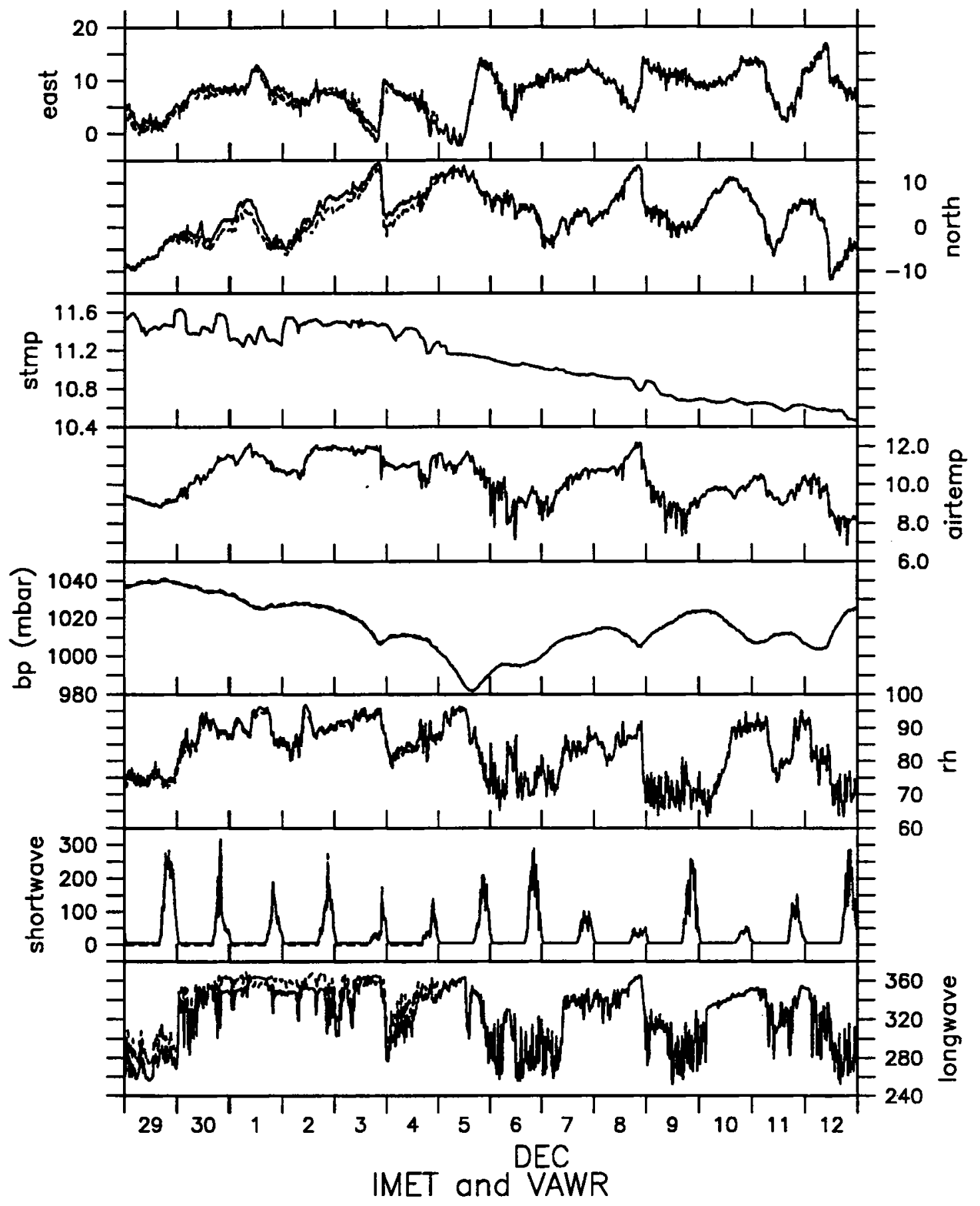

Figure 3.1.3 VAWR and IMET Meteorological Time Series. IMET data is dashed, VAWR data is solid line. IMET failed on December 4 at 2359 UTC. 


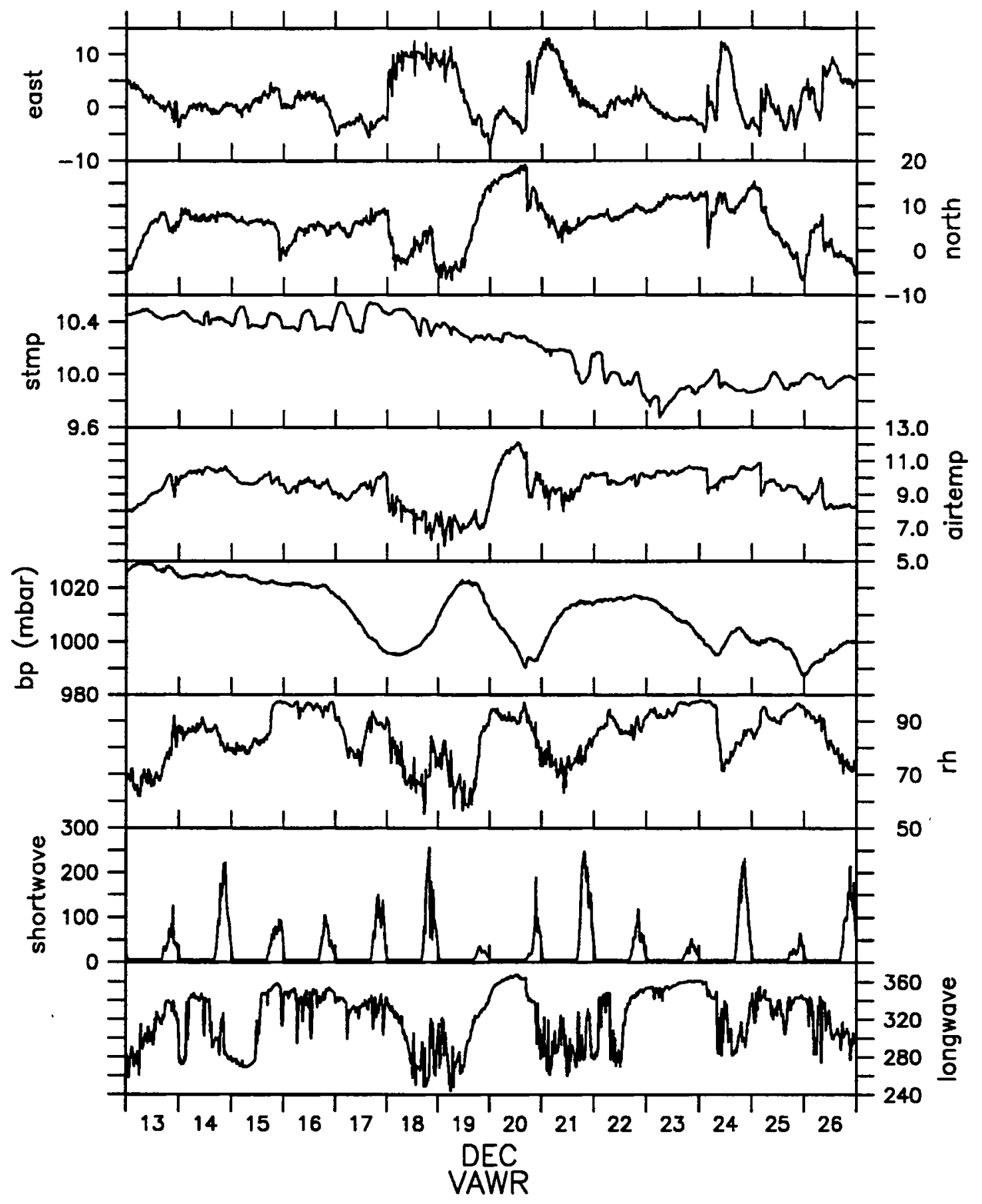

Figure 3.1.4 VAWR Meteorological Time Series. 


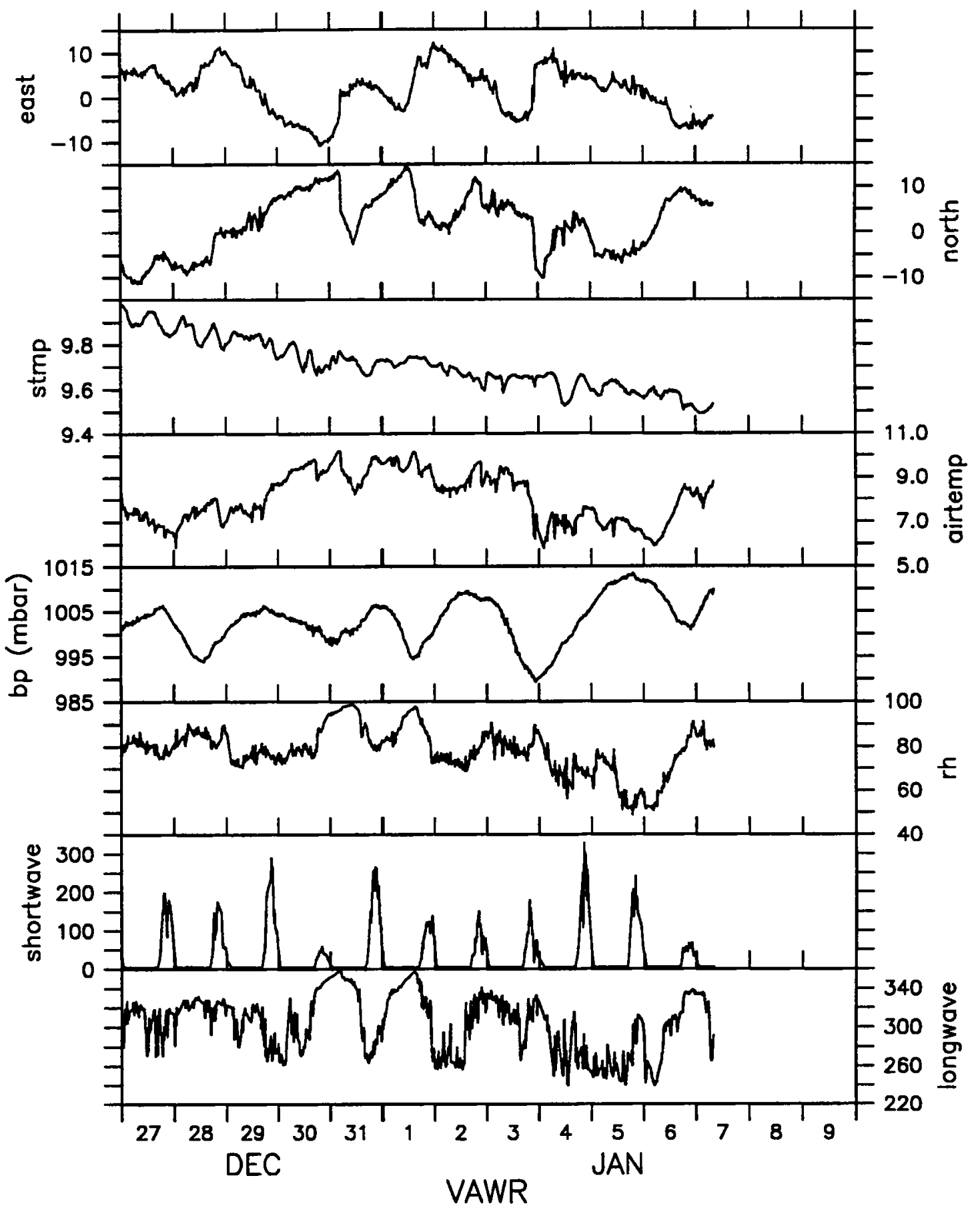

Figure 3.1.5 VAWR Meteorological Time Series. 


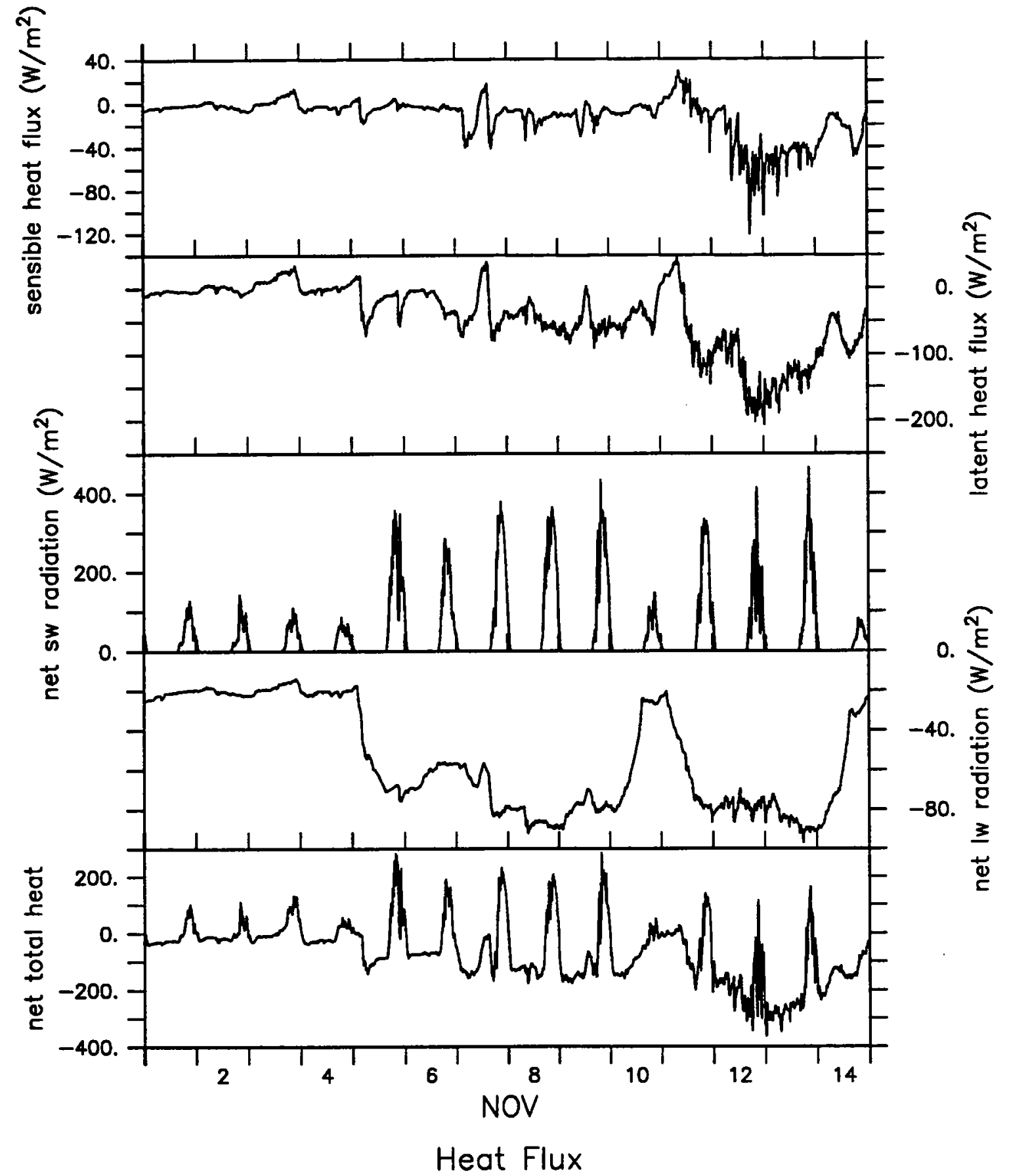

Figure 3.1.6 Heat Flux Time Series from VAWR. 


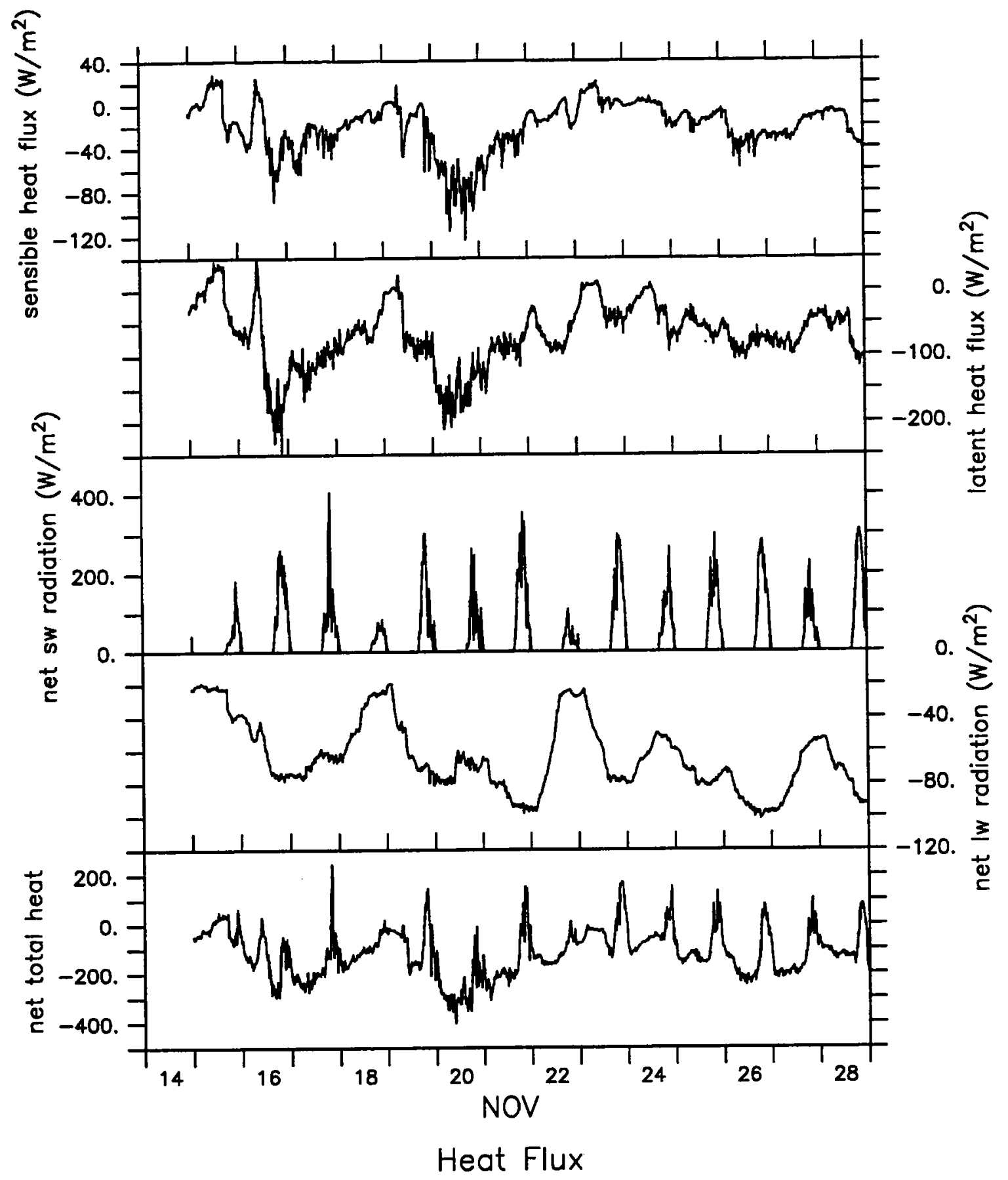

Figure 3.1.7 Heat Flux Time Series from VAWR. 


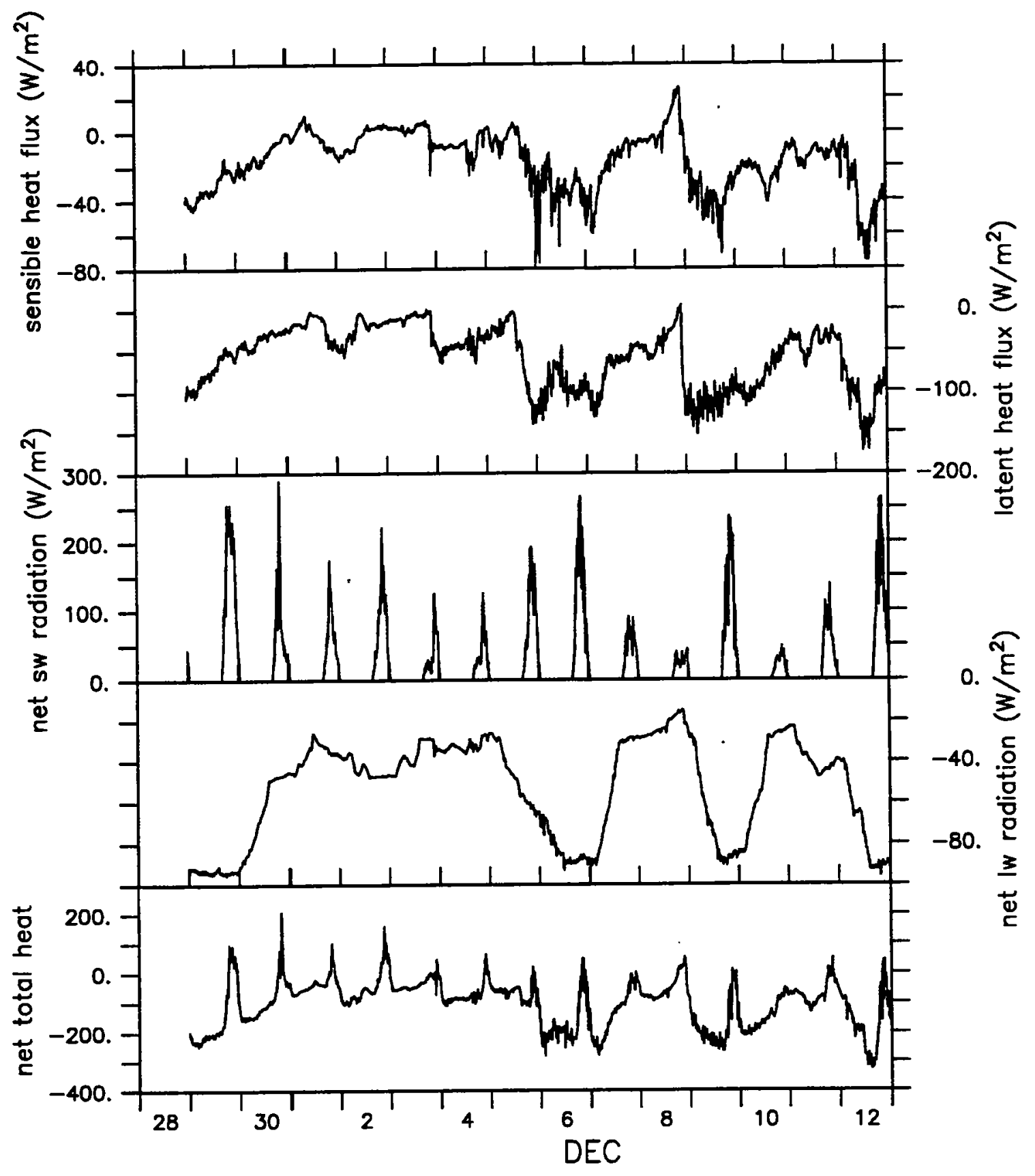

Heat Flux

Figure 3.1.8 Heat Flux Time Series from VAWR. 


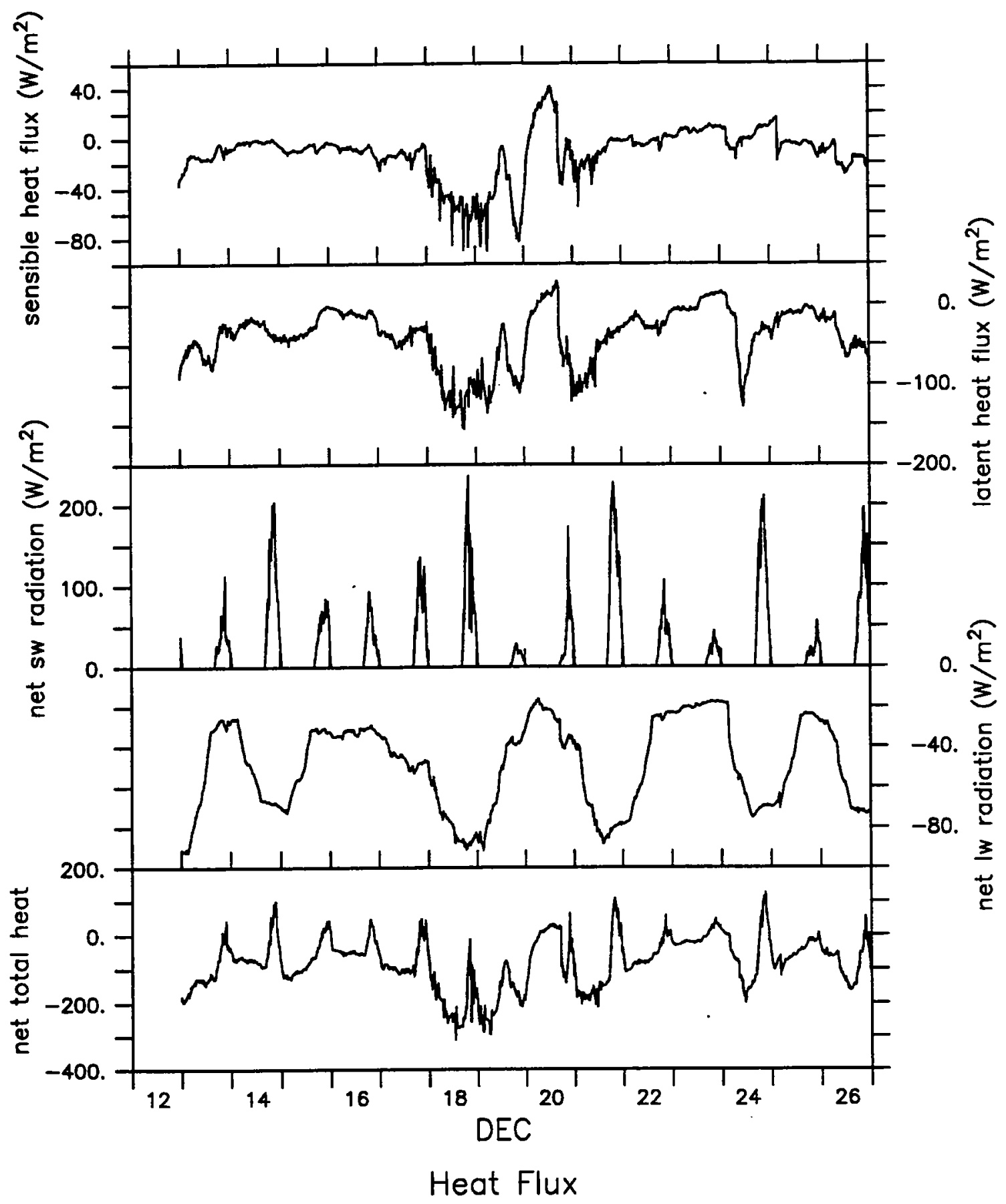

Figure 3.1.9 Heat Flux Time Series from VAWR. 


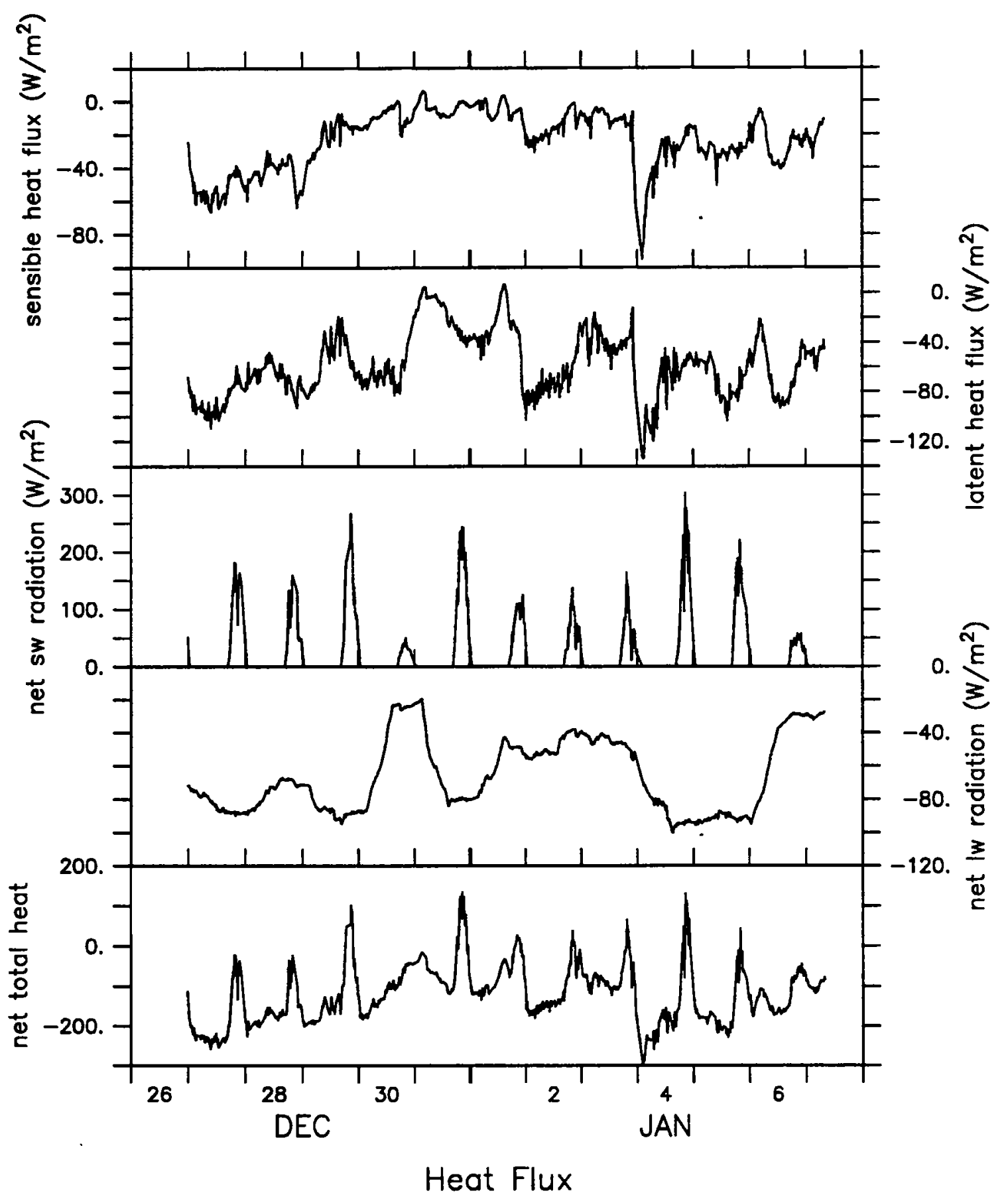

Figure 3.1.10 Heat Flux Time Series from VAWR. 


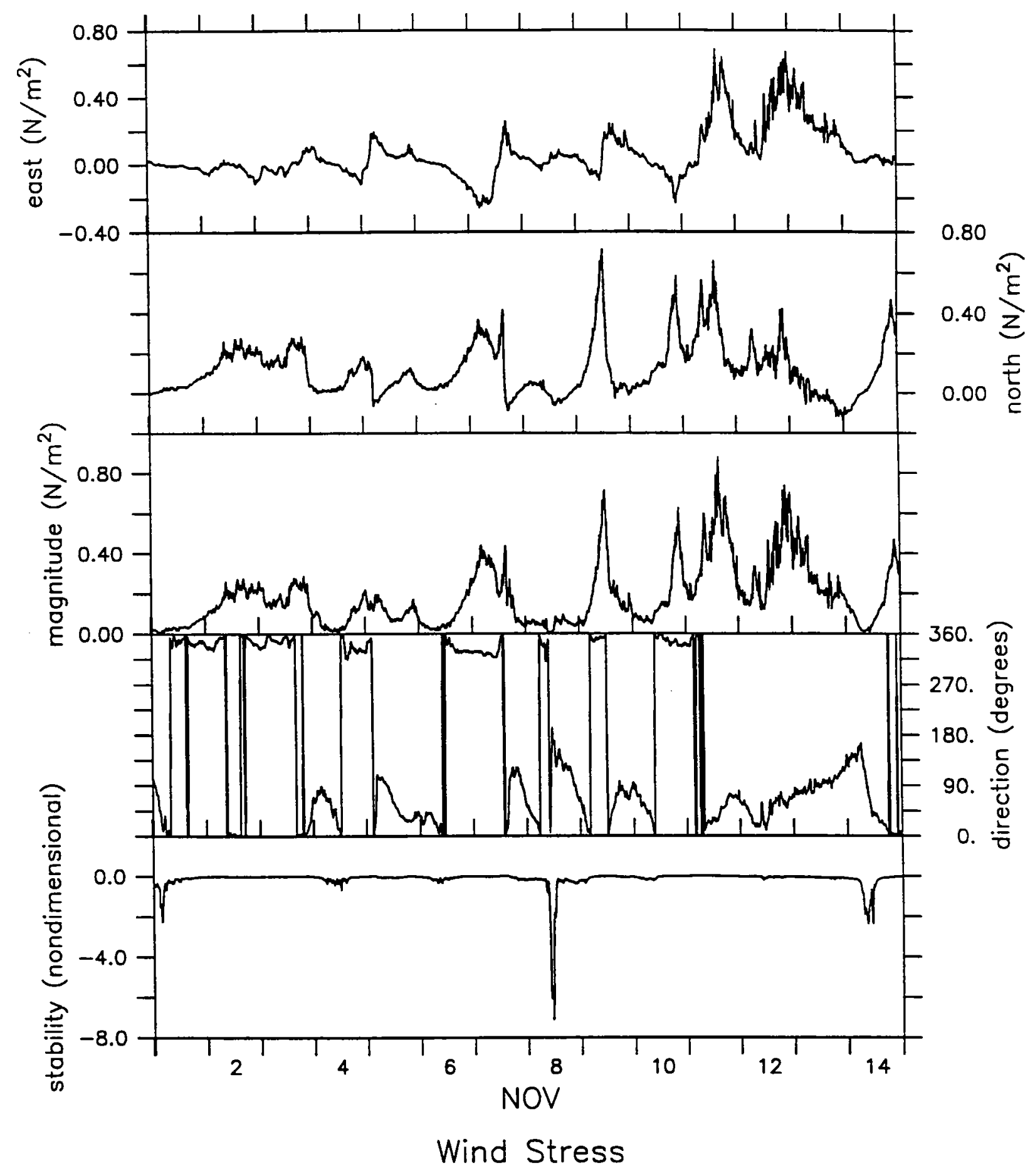

Figure 3.1.11 Wind StressTime Series from VAWR. 


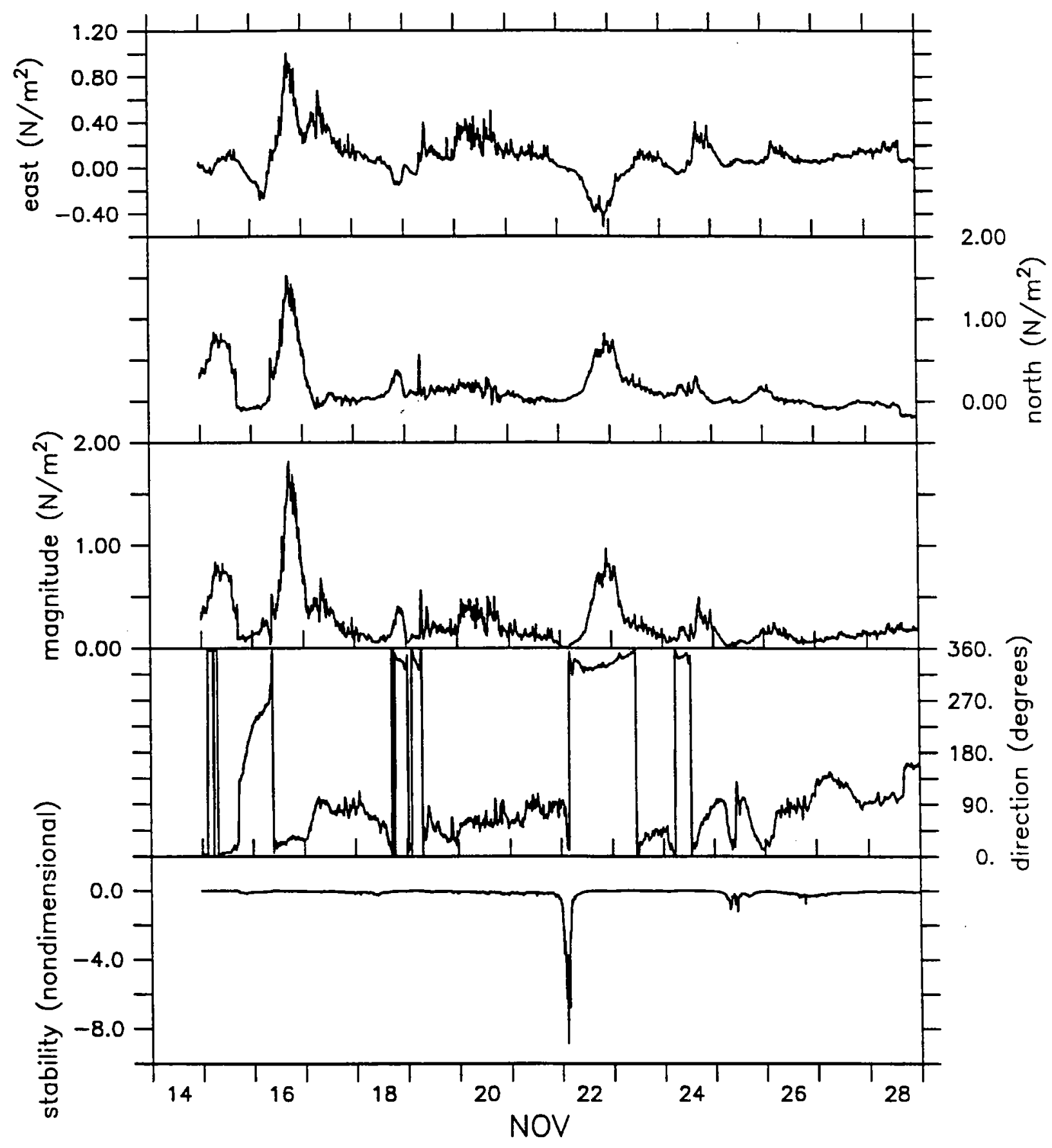

Wind Stress

Figure 3.1.12 Wind Stress Time Series from VAWR. 


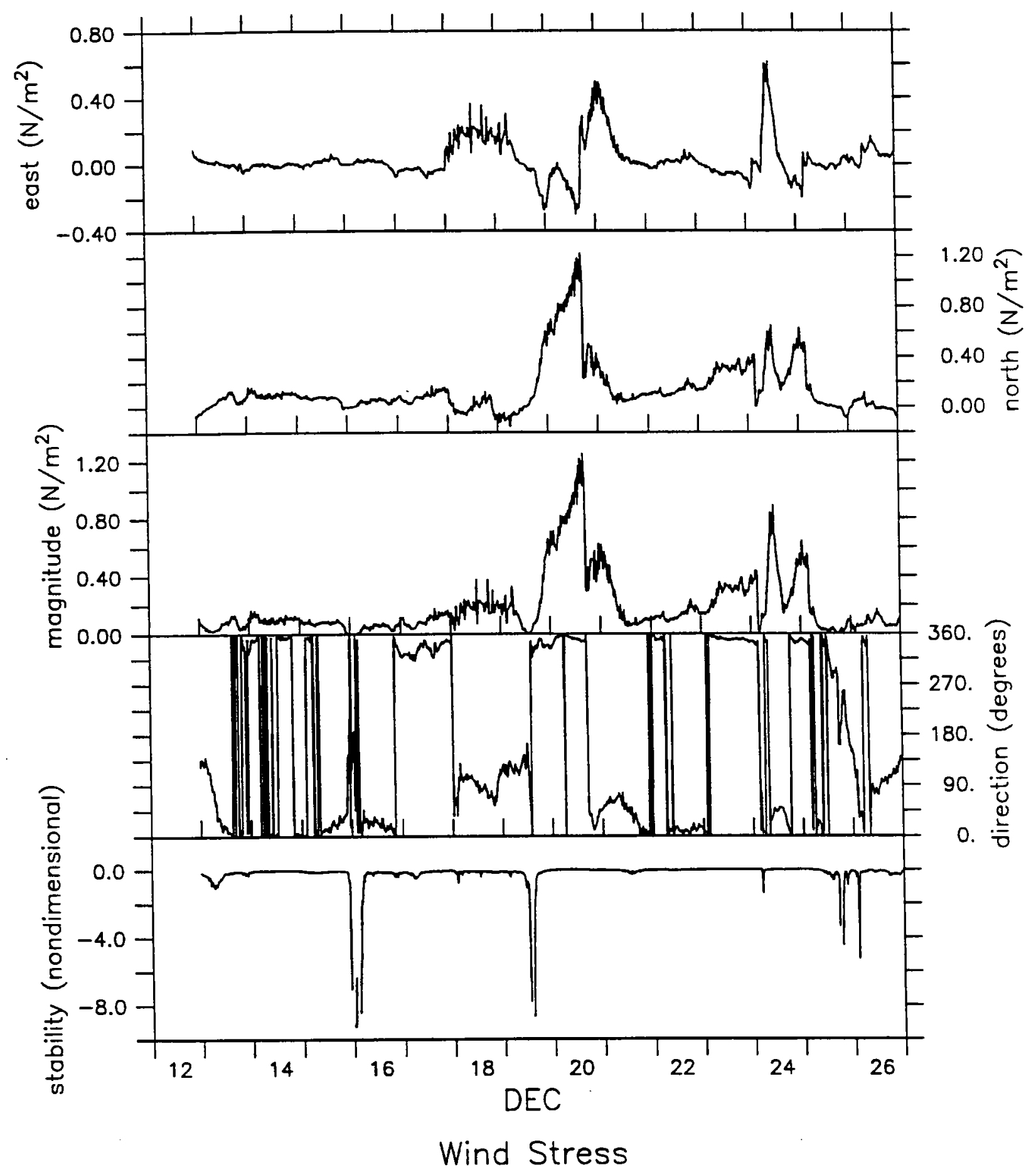

Figure 3.1.13 Wind Stress Time Series from VAWR. 


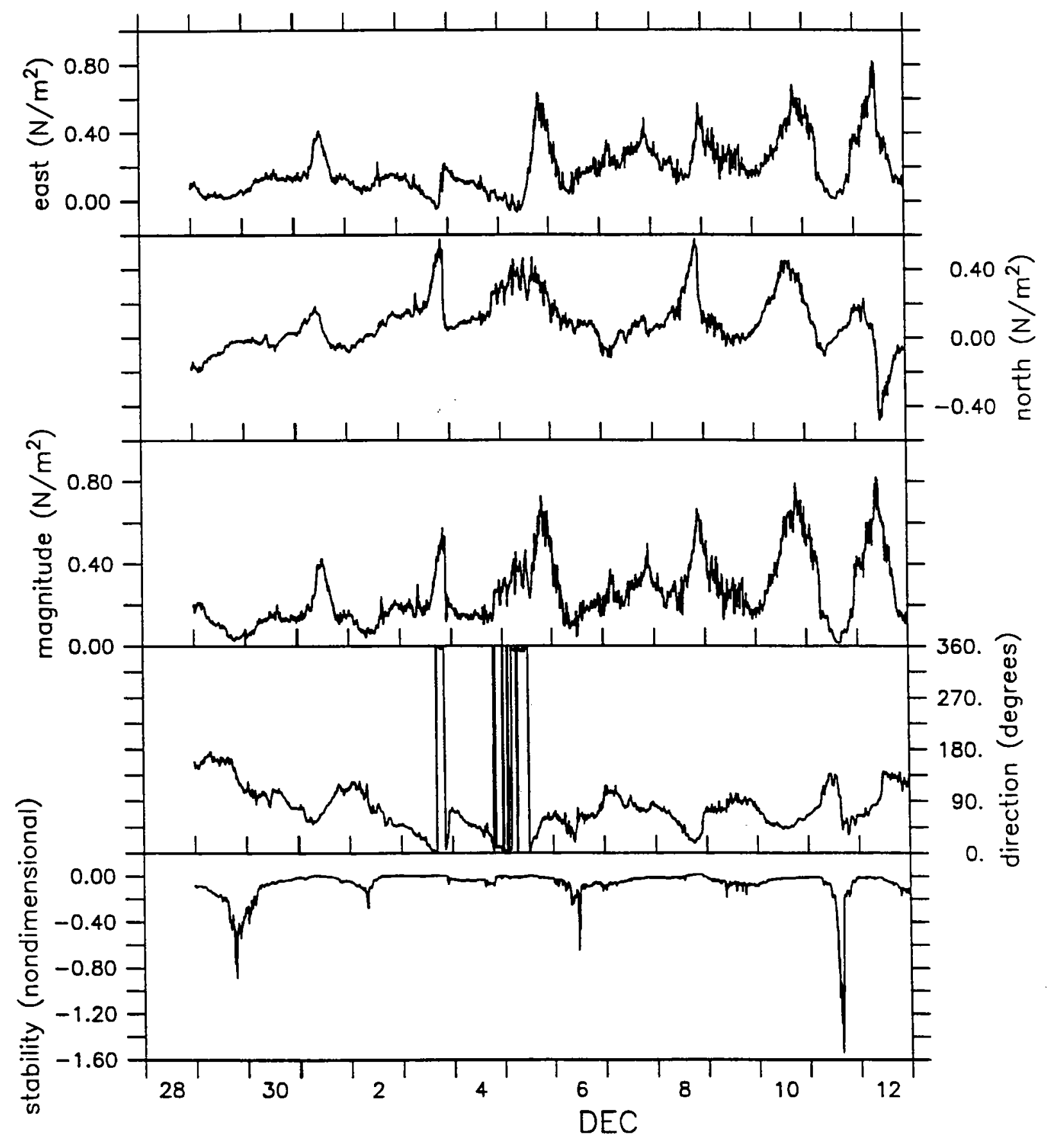

Wind Stress

Figure 3.1.14 Wind Stress Time Series from VAWR. 


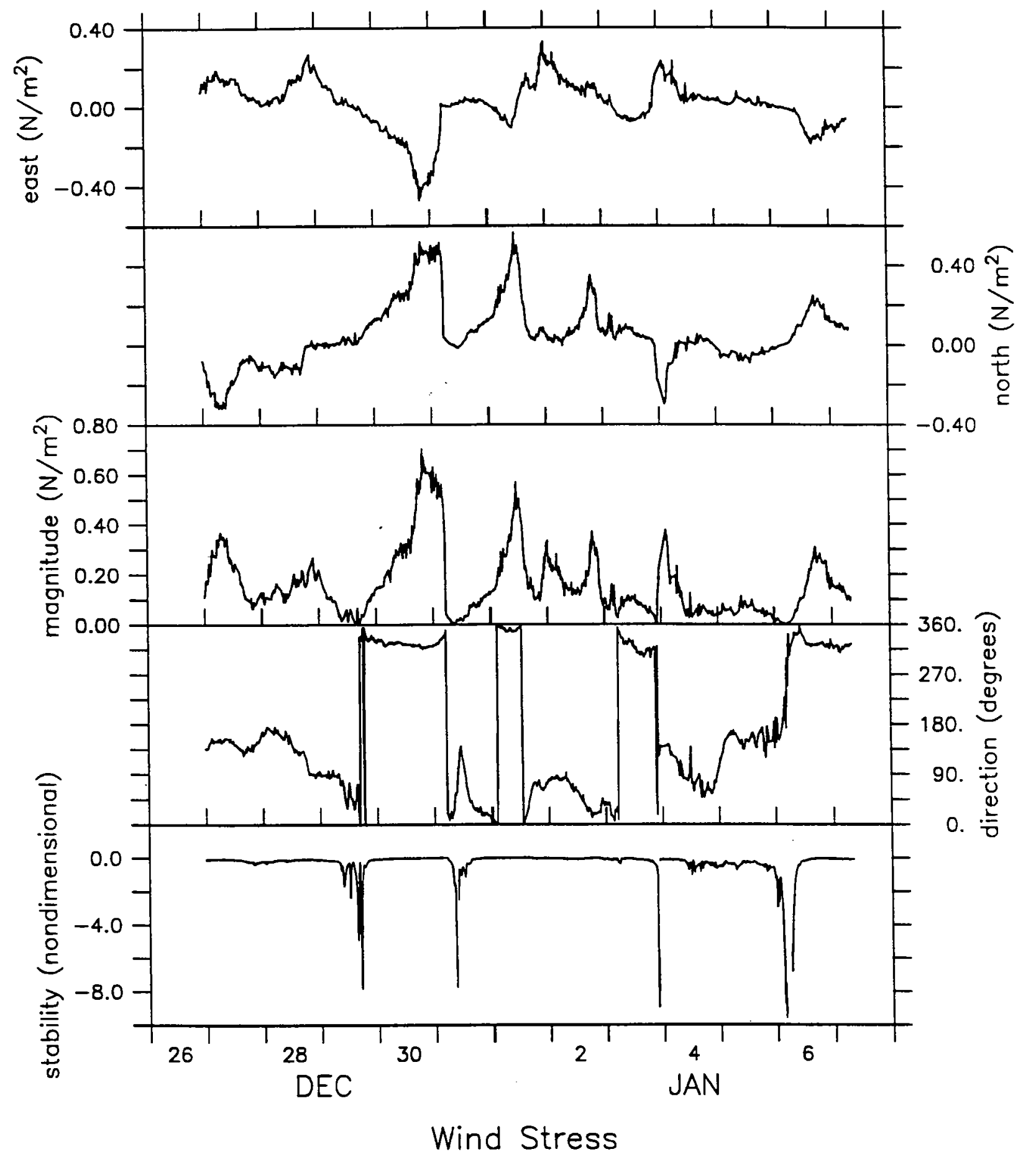

Figure 3.1.15 Wind Stress Time Series from VAWR. 

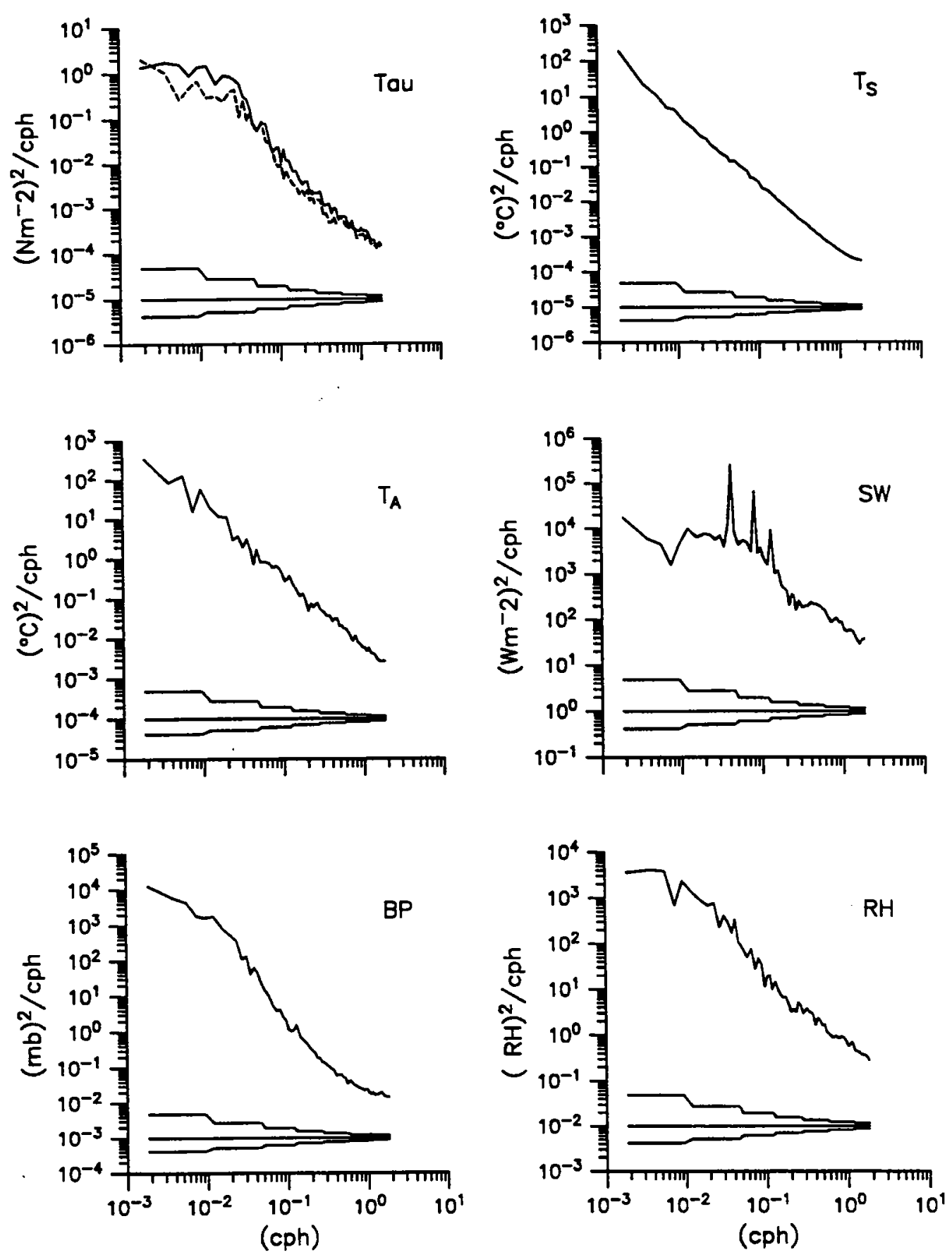

Figure 3.1.16 Autospectra of wind stress, air temperature, barometric pressure, sea surface temperature, insolation, and relative humidity . Rotary autospectra are shown for wind stress; solid curves show the clockwise component, and dashed curves show the counter-clockwise component. 

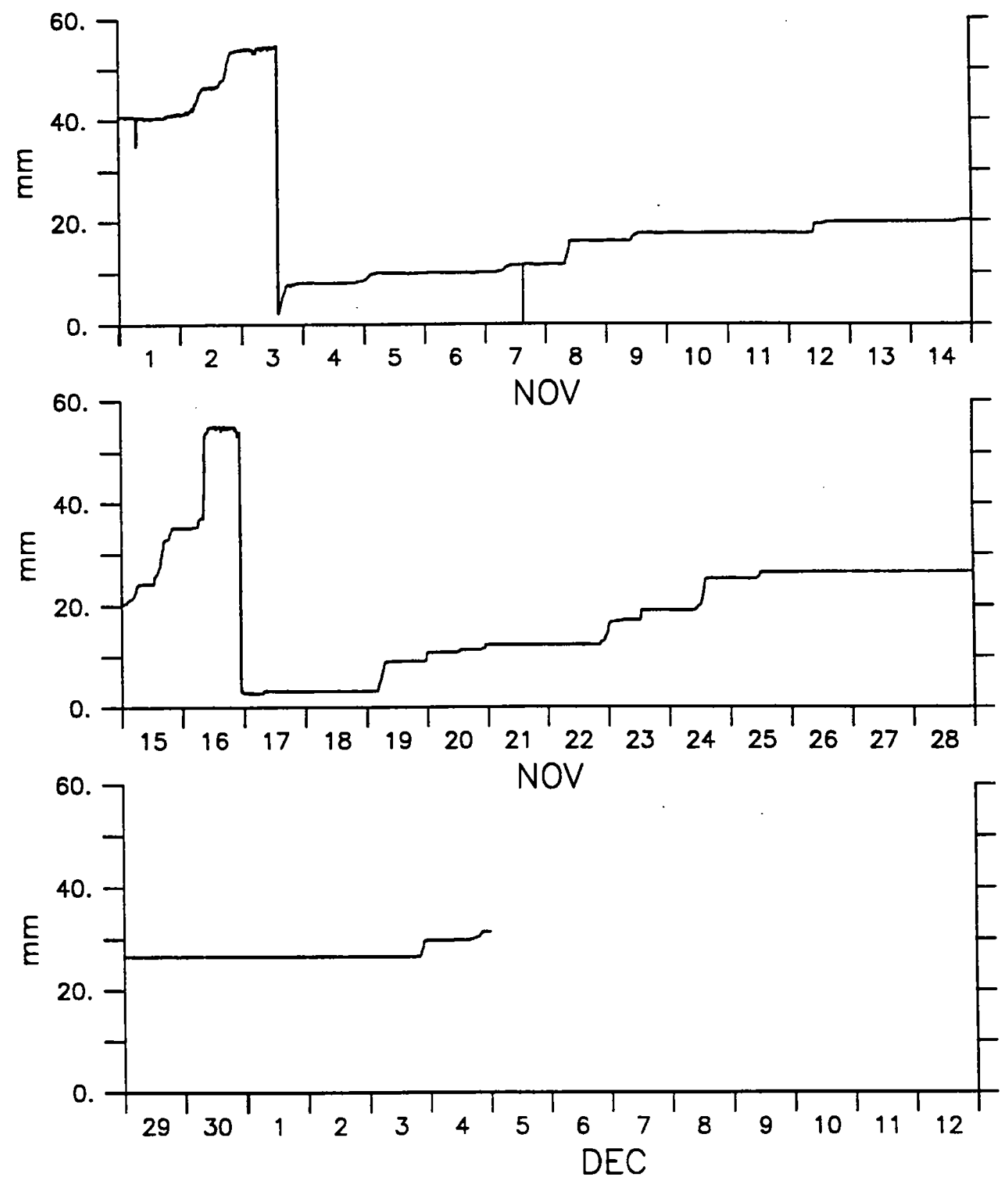

IMET Precipitation

Figure 3.1.17 Cumulative Precipitation in $\mathrm{mm}$ measured by IMET system using an R.M. Young self siphoning rain gauge. Rain gauge drains when level reaches a critical value. 


\section{2 Temperature and Density Structure during ASREX 91}

Sea temperatures were measured by the VAWR, by six Brancker temperature recorders (TPODs) at depths of 2, 40, 60, 80, 100, and 120 meters, and by four Vector Measuring Current Meters (VMCMs) at 5, 10, 15, and 20 meters. VMCMs recorded data every 112.5 seconds, and TPODs recorded every 450 seconds.

Each temperature sensor was calibrated in the lab before and after the experiment, with the exception of TPOD 3700 , which did not recieve a postcruise calibration. Because data comparisons for the shallow instruments looked good using pre-cruise calibrations, all but Brancker 3662, at $60 \mathrm{~m}$, were processed with pre-cruise calibrations.

Figure 3.2.1 is a contour plot of all the temperature data from the moored array instruments. Data was filtered using a 24-hour running mean to remove the semidiurnal tide signal, and subsampled at 900 second intervals to produce a uniform time-series for the contour plot.

Time-series and spectra of temperature at each depth are presented in figures 3.2.2 through 3.2.11. In the upper frame of each of these plots, temperature is represented along the $y$ axis and time (UTC) along the $\mathrm{x}$ axis. The lower frame contains the spectra. The long arrows on the lower frames indicate the frequency of the semidiurnal tidal peak and the short arrows show the frequency of the Coriolis peak. Confidence limits are displayed at the bottom of the frame. Captions indicate instrument type and depth. Unlike the previous plot, 
the data here is not smoothed, so that the strong signals associated with the semidiurnal tides are readily visible.

CTD casts were taken to a depth of about 375 meters. Five casts were taken before deployment of the moored array, and two casts were taken after recovery. Information on CTD cast dates and locations is contained in Appendix 3. Profiles of CTD temperature, salinity, and density are shown in figures 3.2 .12 through 3.2.17. These plots show that over the course of the deployment, the mixed layer depth increased from about 40 meters to about 80 meters as indicated by the temperature data alone.

The temperature records in the upper 40 meters of the water column show relatively little short-time variability. The temperature records at $60,80,100$ and 120 meters show strong peaks at the frequency of the semidiurnal tide. The tidal signal appears to be strongest near the top of the main thermocline. 


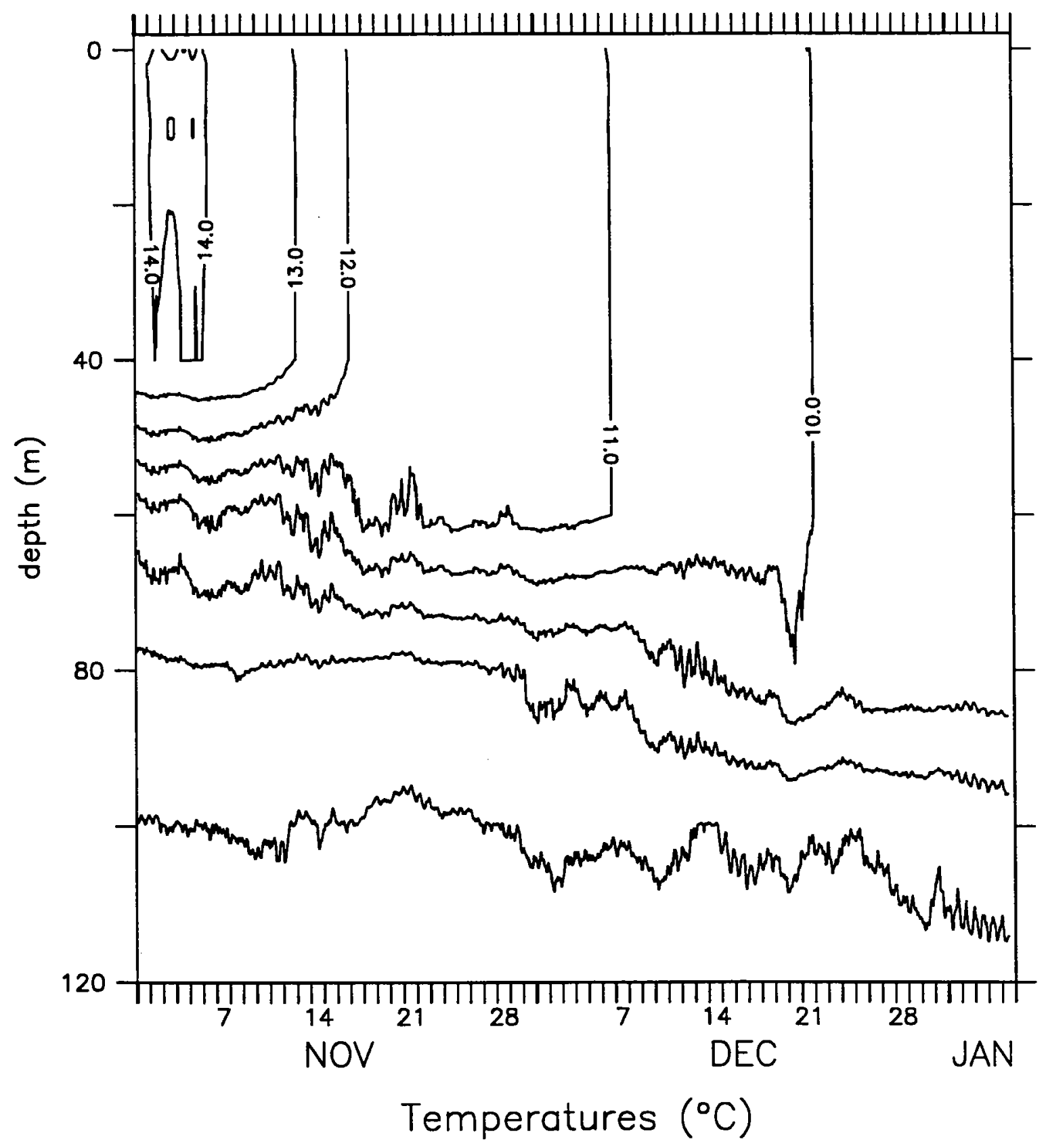

Figure 3.2.1 Temperature Contours from data at $0,2,5,10,15,20,40,60$, 80,100 , and120 meters. Data is filtered over 24 hours and decimated to 15 minutes per record before plotting. 


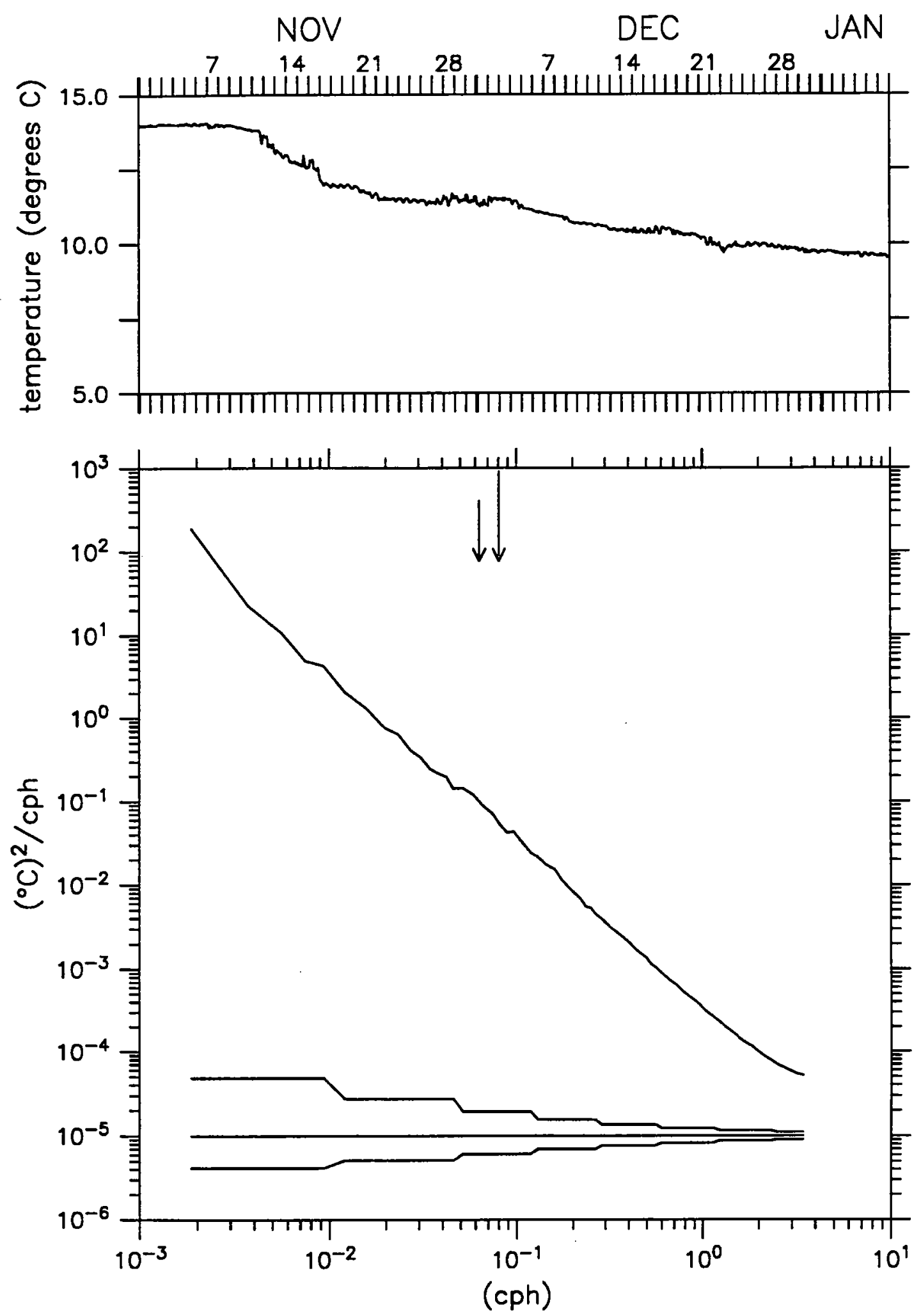

tpod3699 at $2.0 \mathrm{~m}$

Figure 3.2.2 Temperature Time Series and Spectra at $2 \mathrm{~m}$. Long arrow indicates semi-diurnal tidal frequency, short arrow indicates coriolis frequency. 


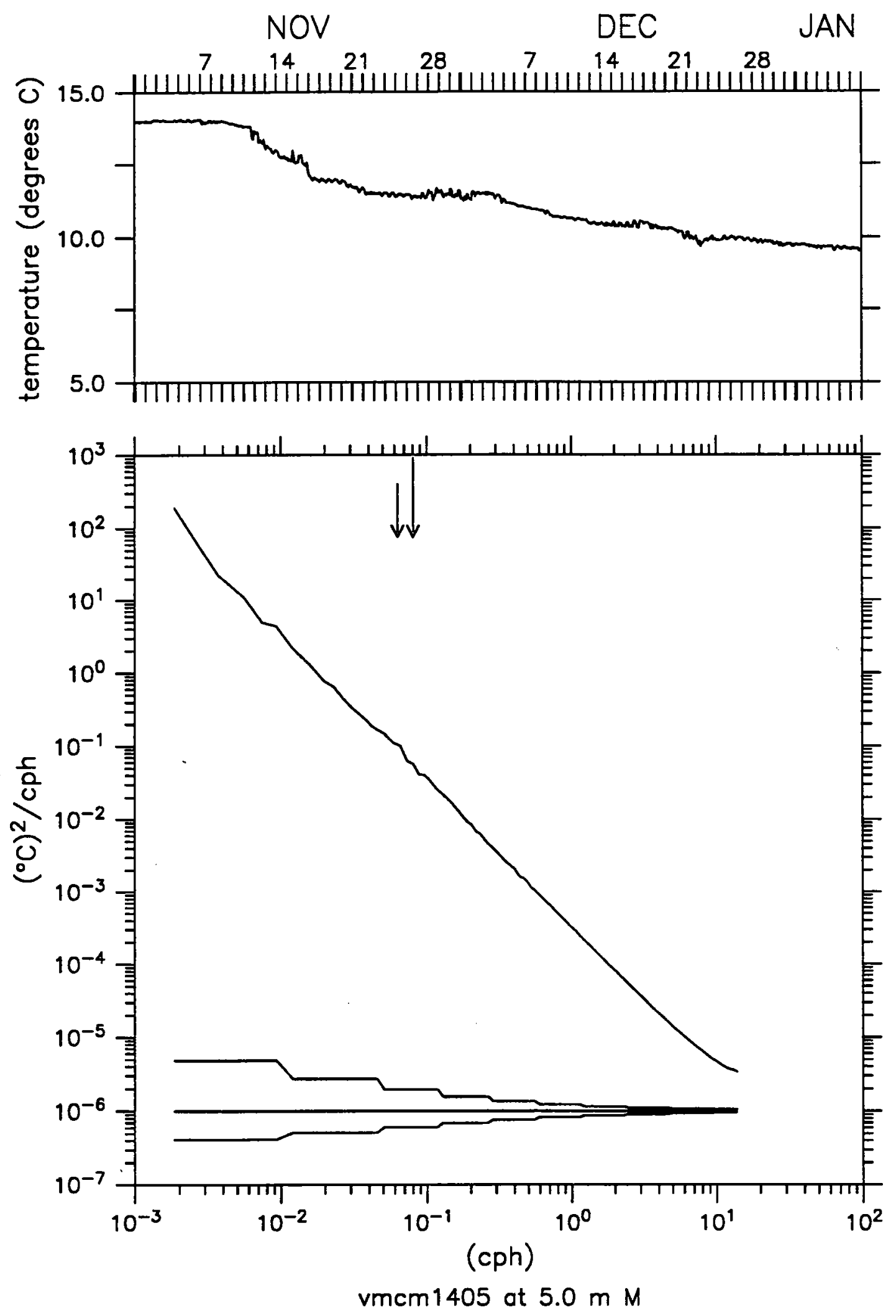

Figure 3.2.3 Temperature Time Series and Spectra at $5 \mathrm{~m}$. Long arrow indicates semi-diurnal tidal frequency, short arrow indicates coriolis frequency. 


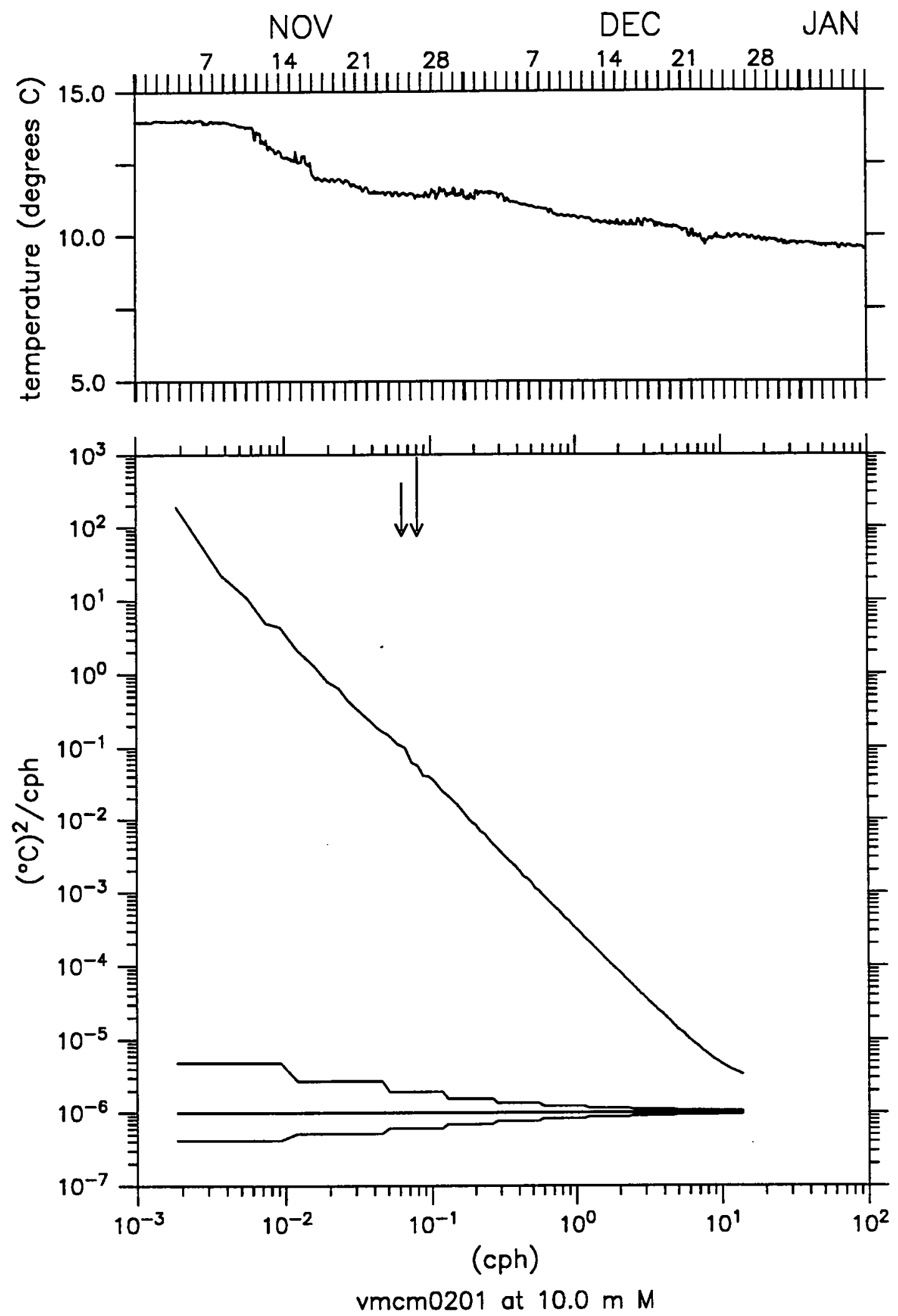

Figure 3.2.4 Temperature Time Series and Spectra at $10 \mathrm{~m}$. Long arrow indicates semi-diurnal tidal frequency, short arrow indicates coriolis frequency. 


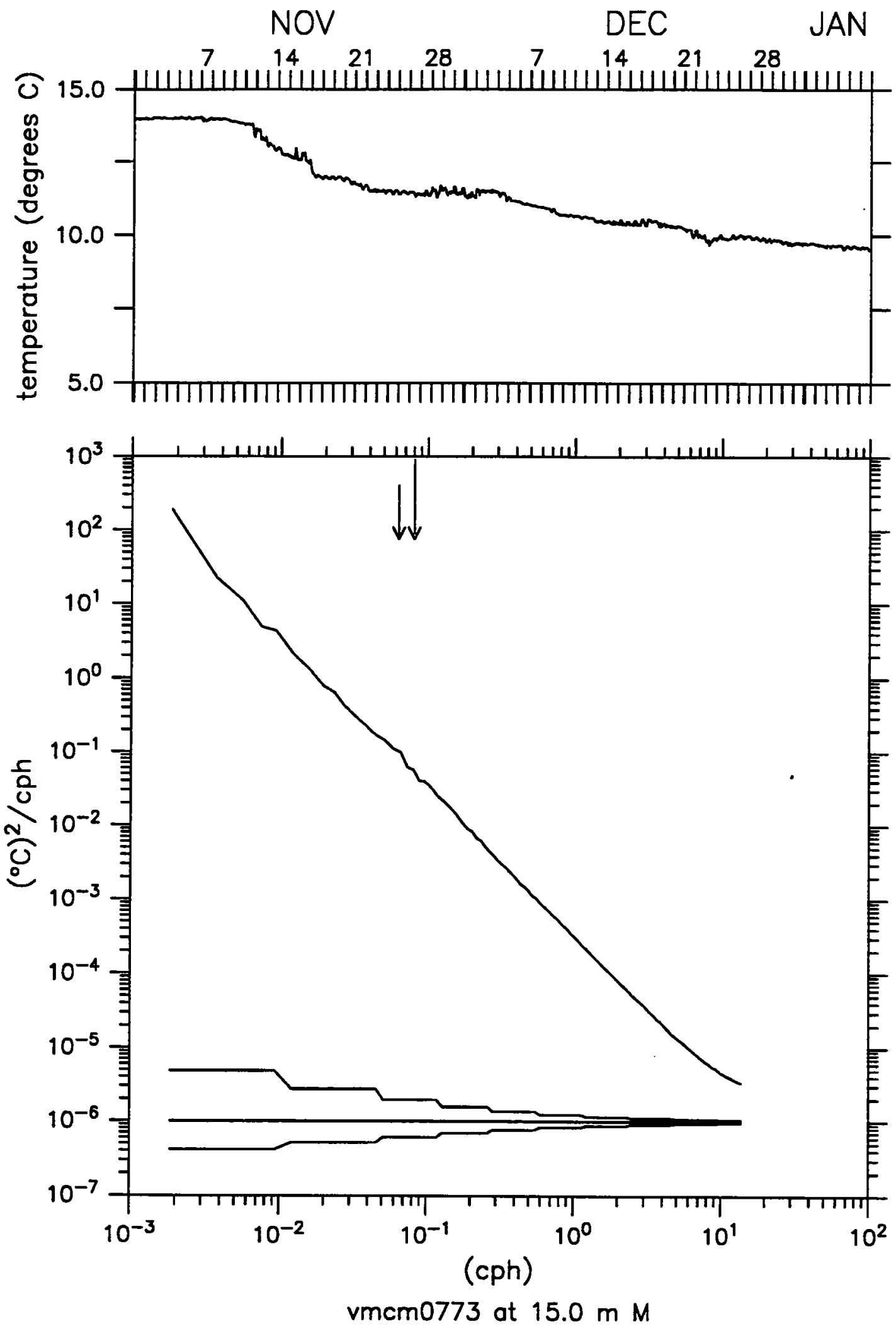

Figure 3.2.5 Temperature Time Series and Spectra at $15 \mathrm{~m}$. Long arrow indicates semi-diurnal tidal frequency, short arrow indicates coriolis frequency. 


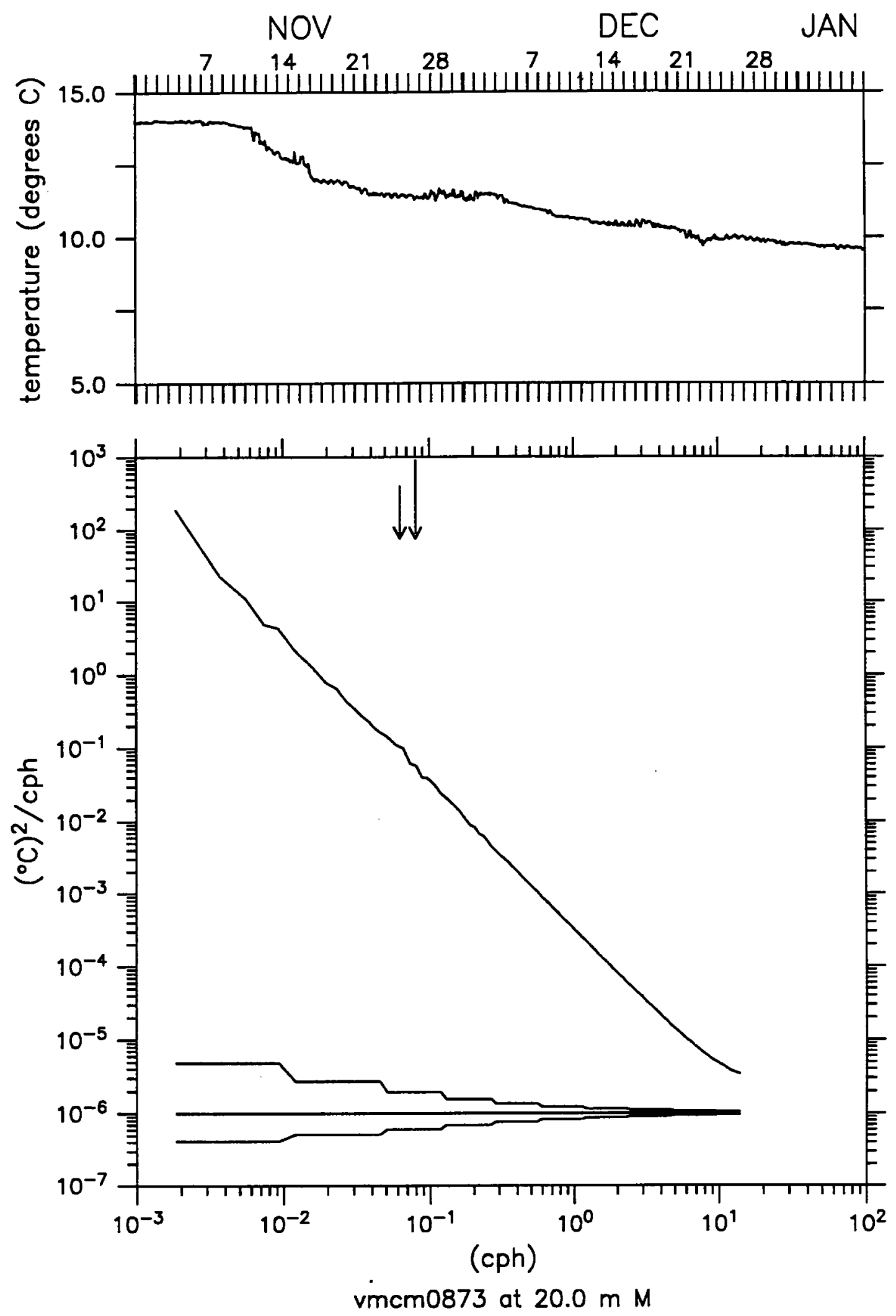

Figure 3.2.6 Temperature Time Series and Spectra at $20 \mathrm{~m}$. Long arrow indicates semi-diurnal tidal frequency, short arrow indicates coriolis frequency. 


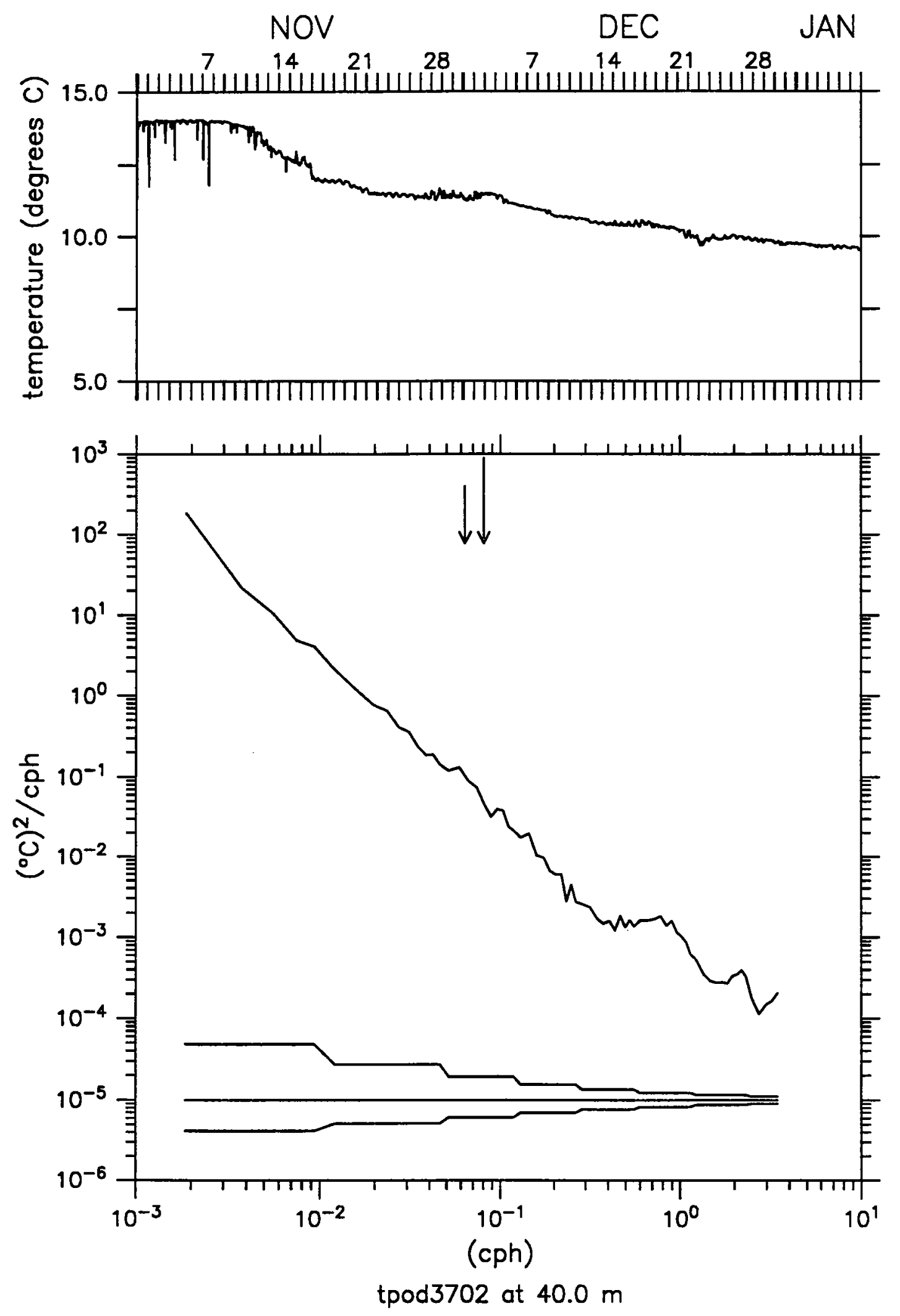

Figure 3.2.7 Temperature Time Series and Spectra at $40 \mathrm{~m}$. Long arrow indicates semi-diurnal tidal frequency, short arrow indicates coriolis frequency. 


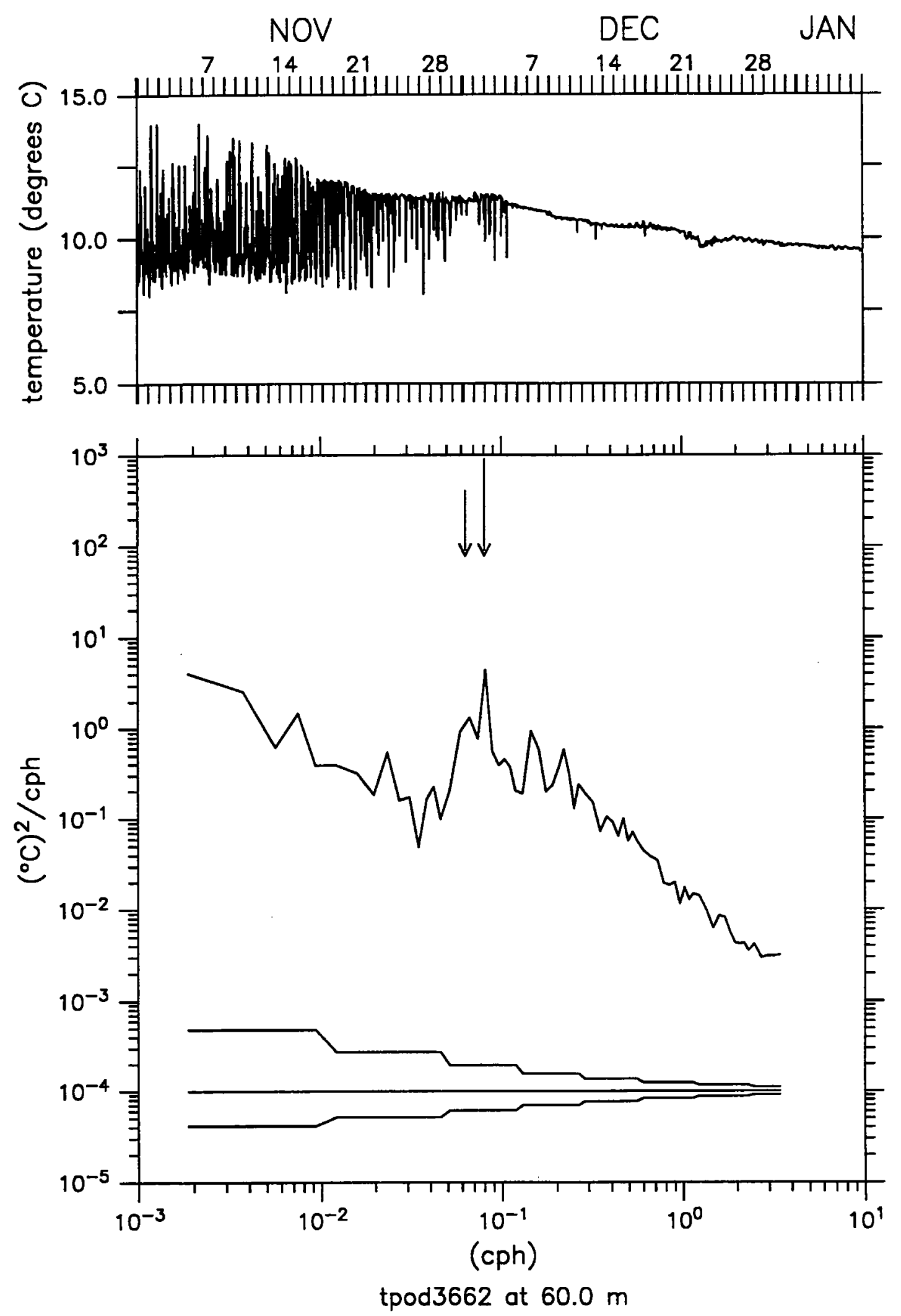

Figure 3.2.8 Temperature Time Series and Spectra at $60 \mathrm{~m}$. Long arrow indicates semi-diurnal tidal frequency, short arrow indicates coriolis frequency. 

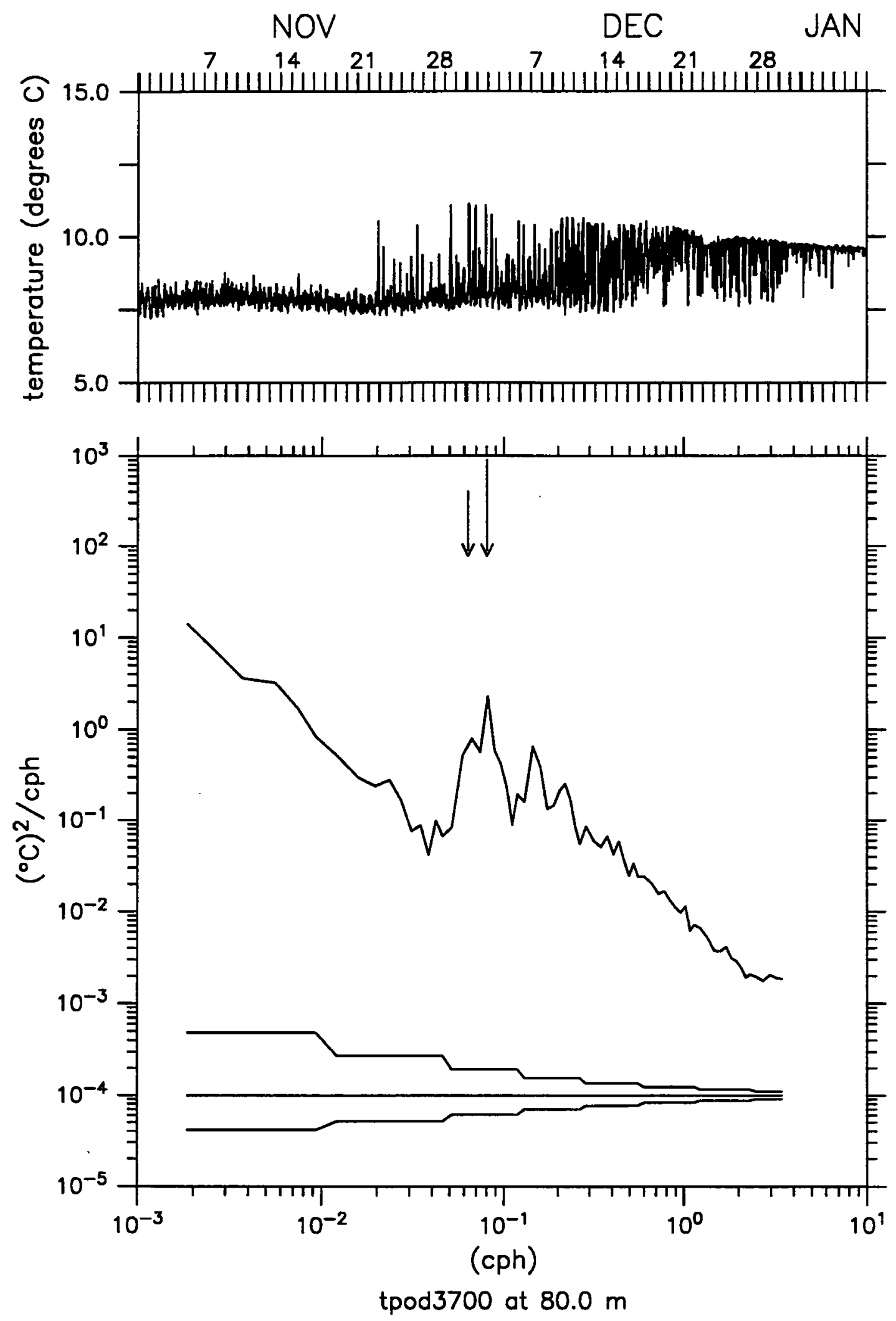

Figure 3.2.9 Temperature Time Series and Spectra at $80 \mathrm{~m}$. Long arrow indicates semi-diurnal tidal frequency, short arrow indicates coriolis frequency. 


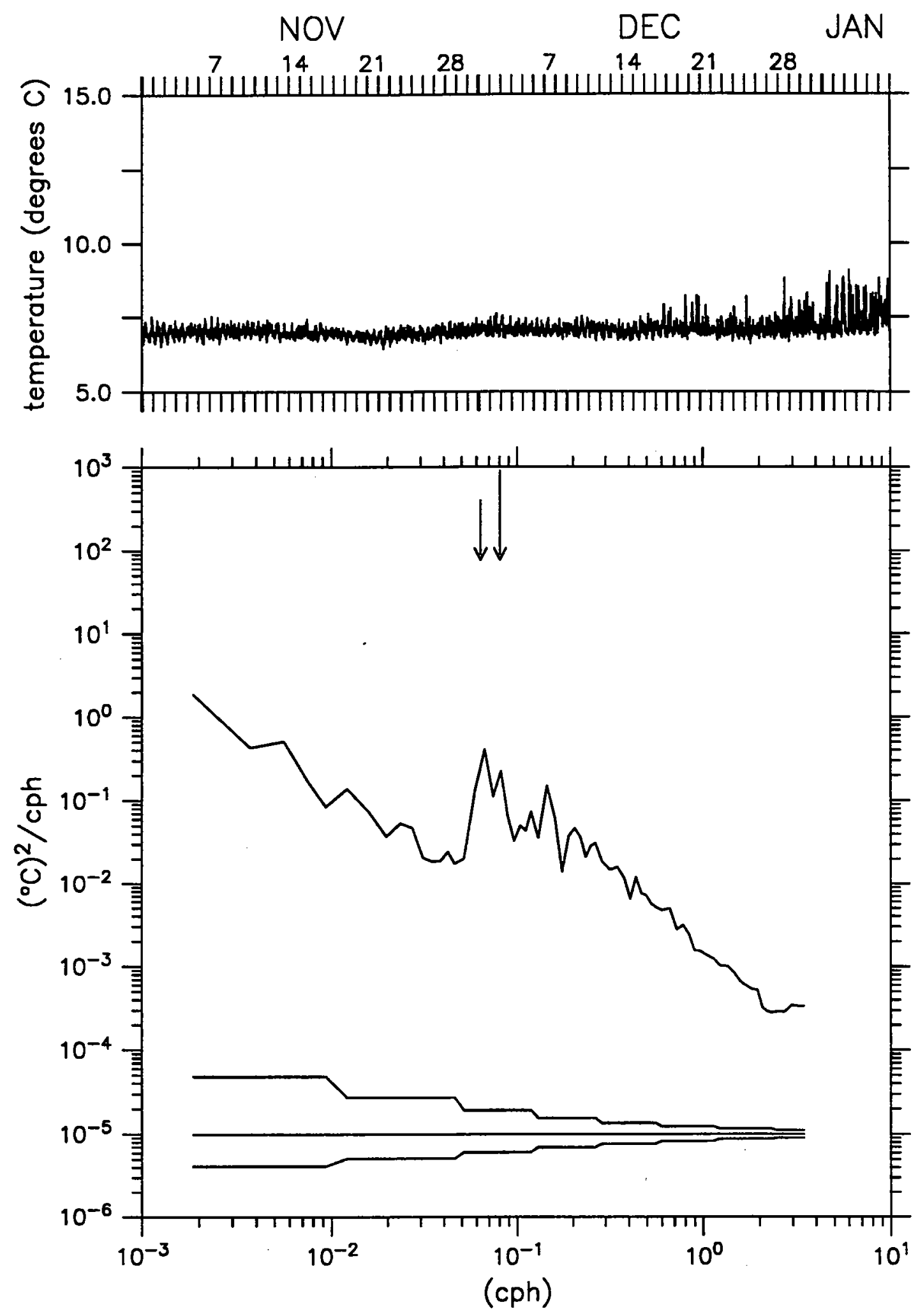

tpod3667 at $100.0 \mathrm{~m}$

Figure 3.2.10 Temperature Time Series and Spectra at $100 \mathrm{~m}$. Long arrow indicates semi-diurnal tidal frequency, short arrow indicates coriolis frequency. 


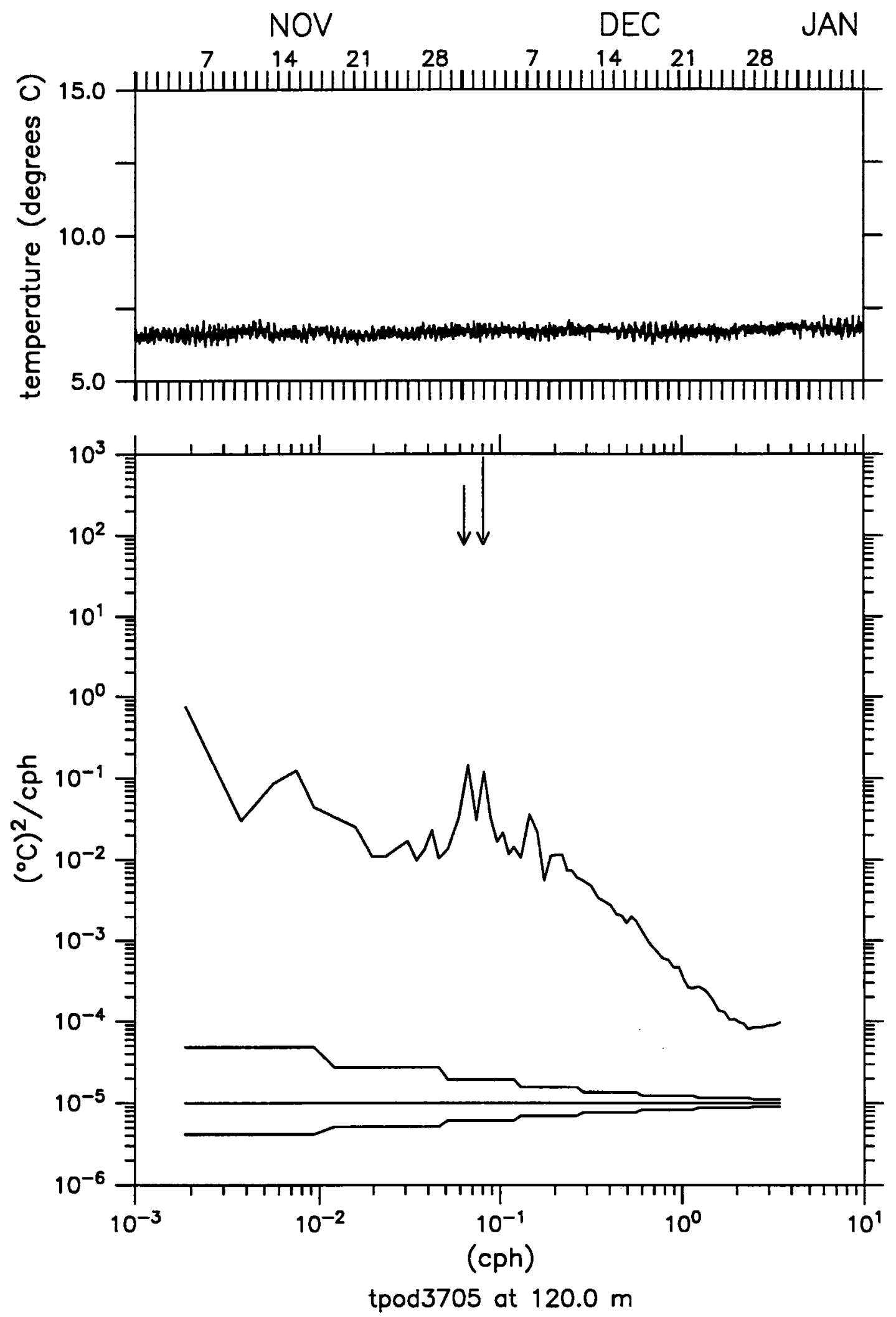

Figure 3.2.11 Temperature Time Series and Spectra at $120 \mathrm{~m}$. Long arrow indicates semi-diurnal tidal frequency, short arrow indicates coriolis frequency. 


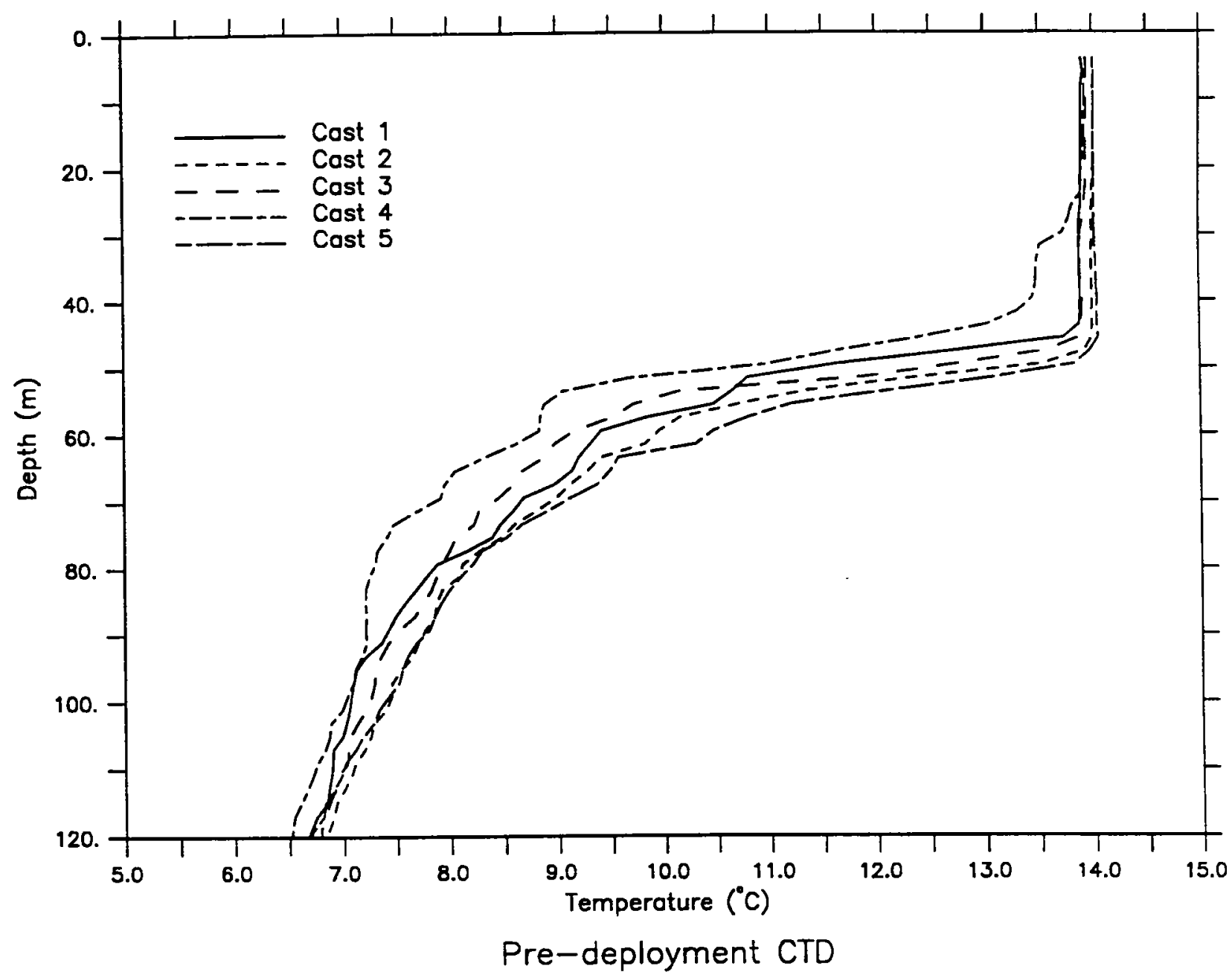

Figure 3.2.12 Temperature profiles from pre-deployment CTD casts taken on Thompson Cruise 4, leg 1 . Cast 1 is solid, cast 2 is short dash, cast 3 is long dash, cast 4 is a short chain, cast 5 is a long chain. 


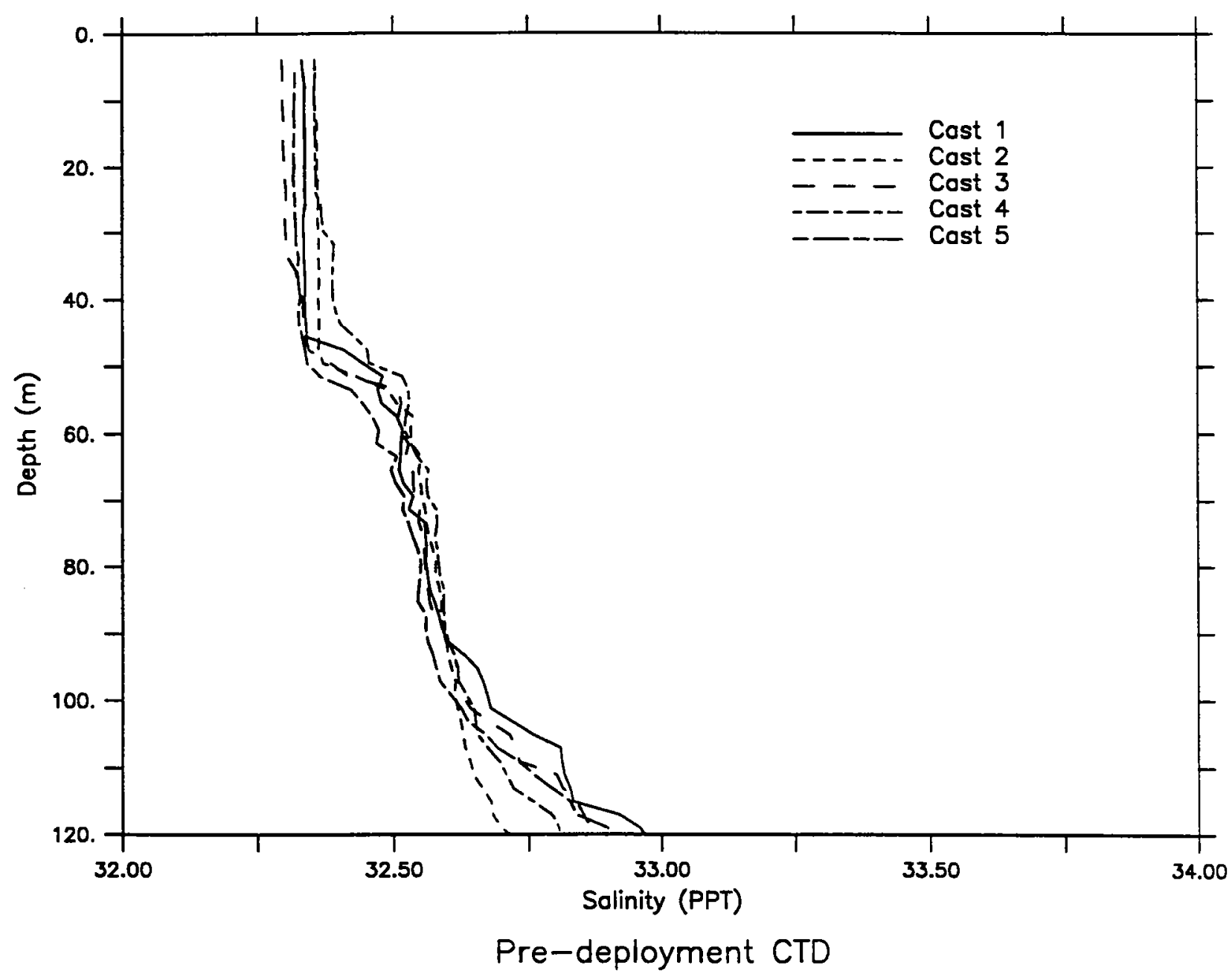

Figure 3.2.13 Salinity profiles from pre-deployment CTD casts taken on Thompson Cruise 4 , leg 1 . Cast 1 is solid, cast 2 is short dash, cast 3 is long dash, cast 4 is a short chain, cast 5 is a long chain. 


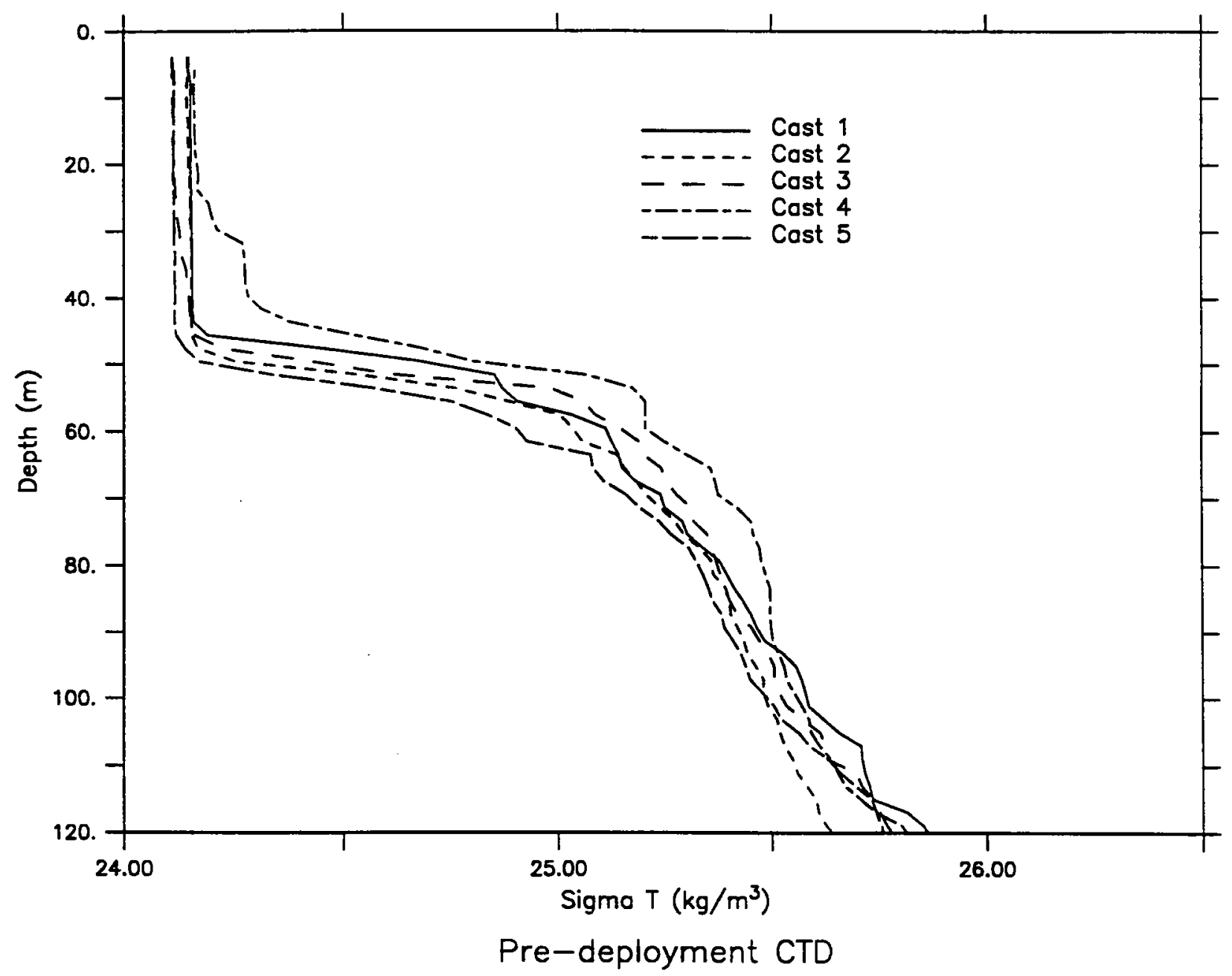

Figure 3.2.14 Density profiles from pre-deployment CTD casts taken on Thompson Cruise 4, leg 1 . Cast 1 is solid, cast 2 is short dash, cast 3 is long dash, cast 4 is a short chain, cast 5 is a long chain. 


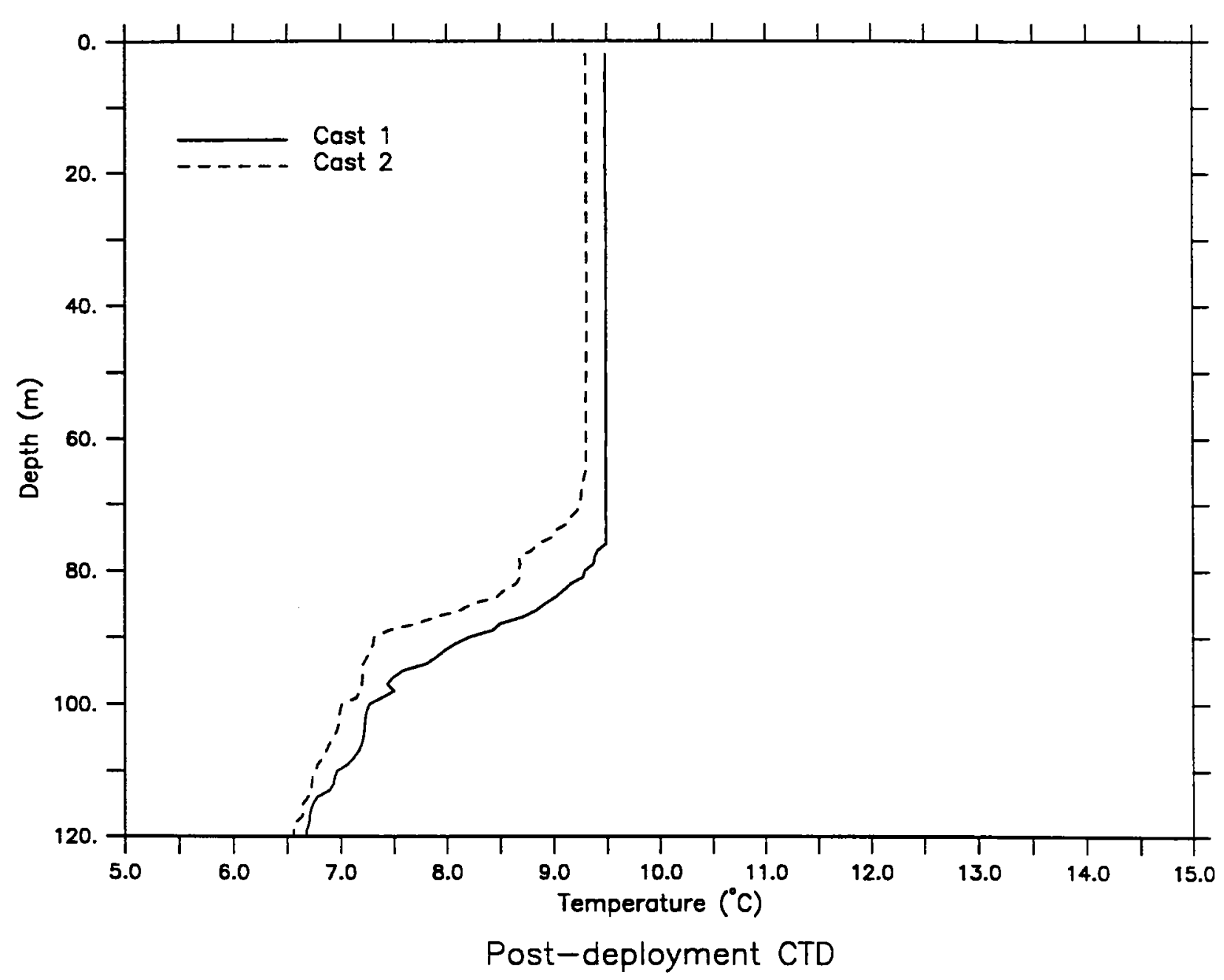

Figure 3.2.15 Temperature profiles from post-deployment CTD casts taken on Thompson Cruise 4, leg 2. Cast 1 is solid, cast 2 is dashed. 


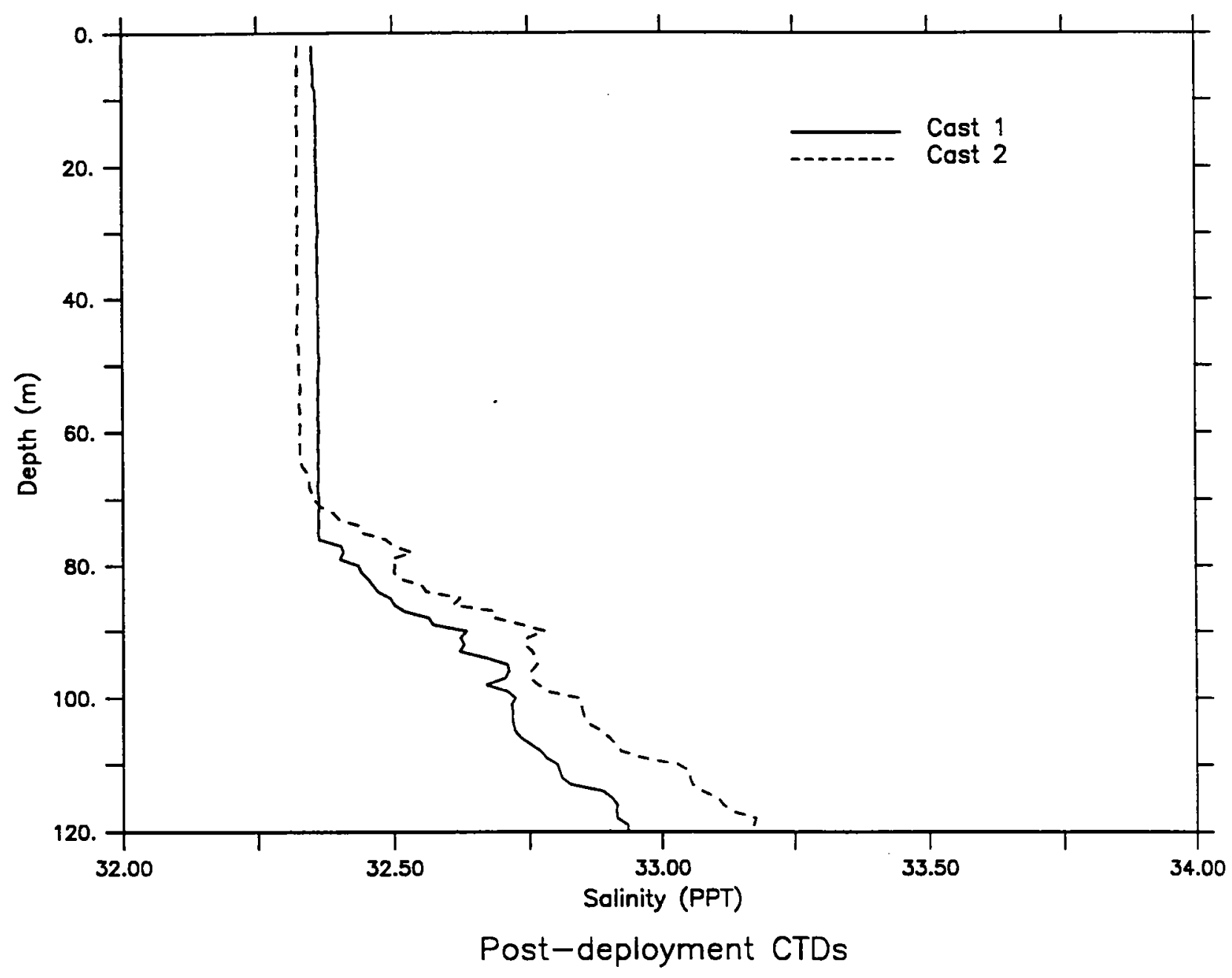

Figure 3.2.16 Salinity profiles from post-deployment CTD casts taken on Thompson Cruise 4, leg 2. Cast 1 is solid, cast 2 is dashed. 


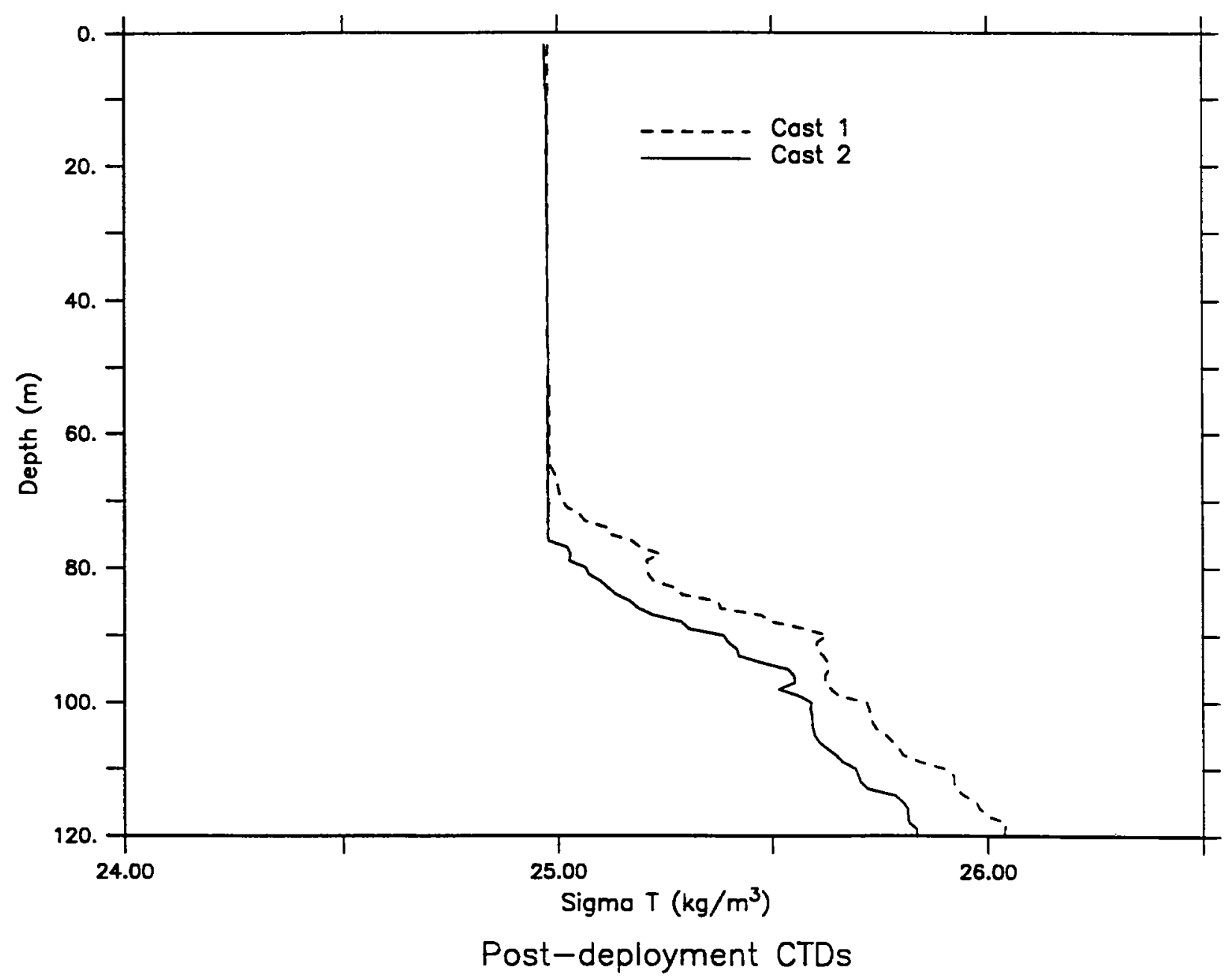

Figure 3.2.17 Density profiles from post-deployment CTD casts taken on Thompson Cruise 4, leg 2. Cast 1 is solid, cast 2 is dashed. 


\subsection{Current Velocities during ASREX 91}

Currents were measured by VMCMs at $5,10,15$, and 20 meters. The current meters recorded at a rate of once every 112.5 seconds. A time-base checking program was used to correct missing data and data with invalid timewords before any further processing was carried out. The final data set consists of 51713 reconds beginning at $0000 \mathrm{Z} 1$ November, 1991 and concluding at $0801 Z$ on 7 January, 1992.

Time series stick-plots of the water vectors at each depth are in figures 3.3.1 through 3.3.5. Data was filtered over a 48 hour period and decimated to 2 hours for the vector plots. Northerly velocities are represented by vectors pointing toward the top of the page.

Progressive vector plots for all four VMCMs are in figure 3.3.6. Velocity data was filtered over 8 hours and decimated to 4 hour values before plotting.

Figures 3.3.7 through 3.3.10 are combined time-series and spectra for currents at each depth. These plots show unfiltered data. The upper frame for each plot represents the north and east velocities along the vertical axes and time (UTC) along the horizontal axis. The lower frame contains the spectra, with a solid line indicating the clockwise component and a dashed line indicating the counter-clockwise component. As for temperature plots, the frequency of the Coriolis parameter and the semidiurnal tide are shown on the plots, and confidence limits are displayed. There are significant peaks associated with both the tide and Coriolis frequency. 

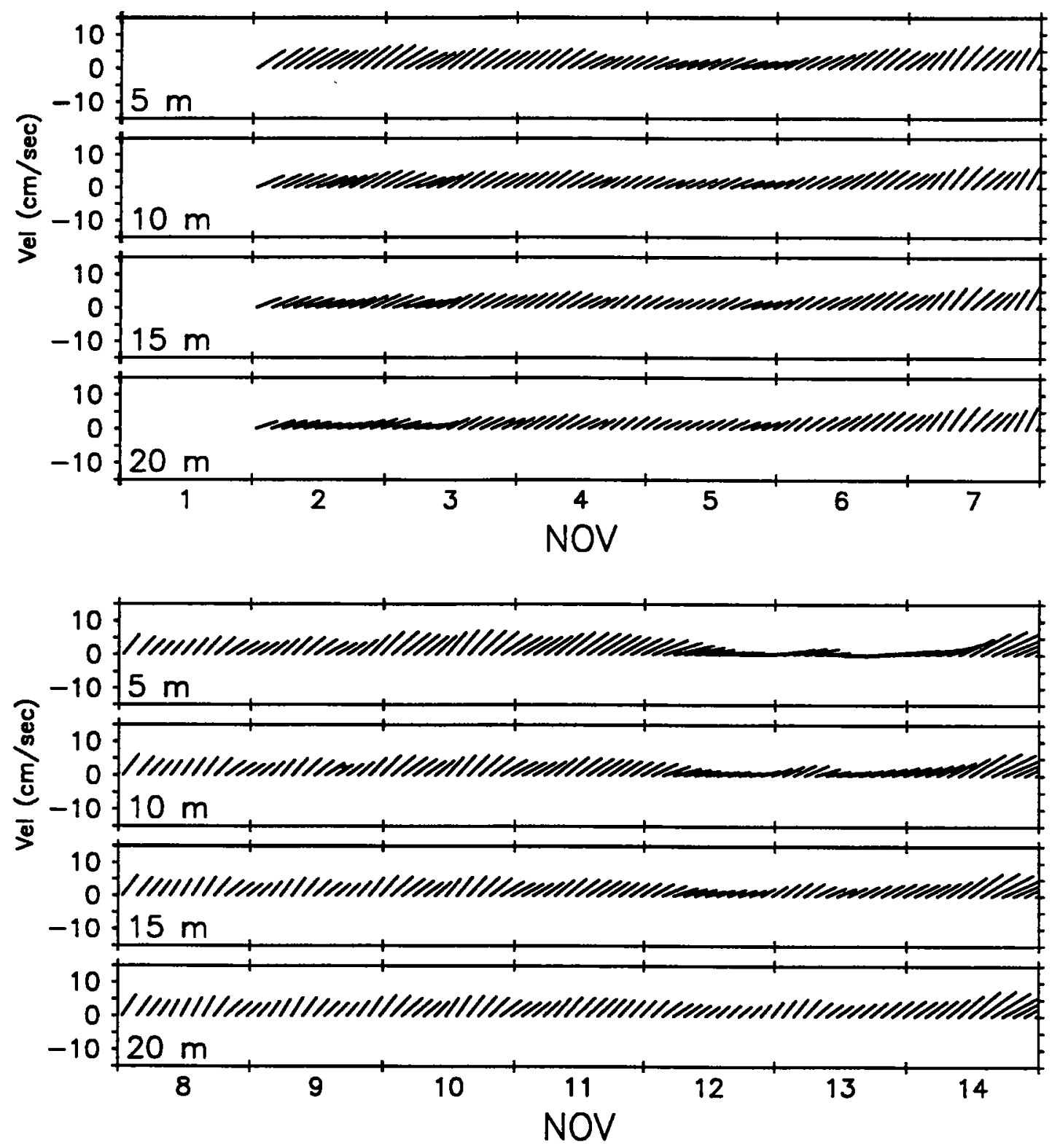

VMCM Water Velocities

Figure 3.3.1 Sub-surface velocity vectors at 4 depths. Northerly component is toward top of page. Data is averaged over 48 hours and subsampled to 2 hours before plotting. 

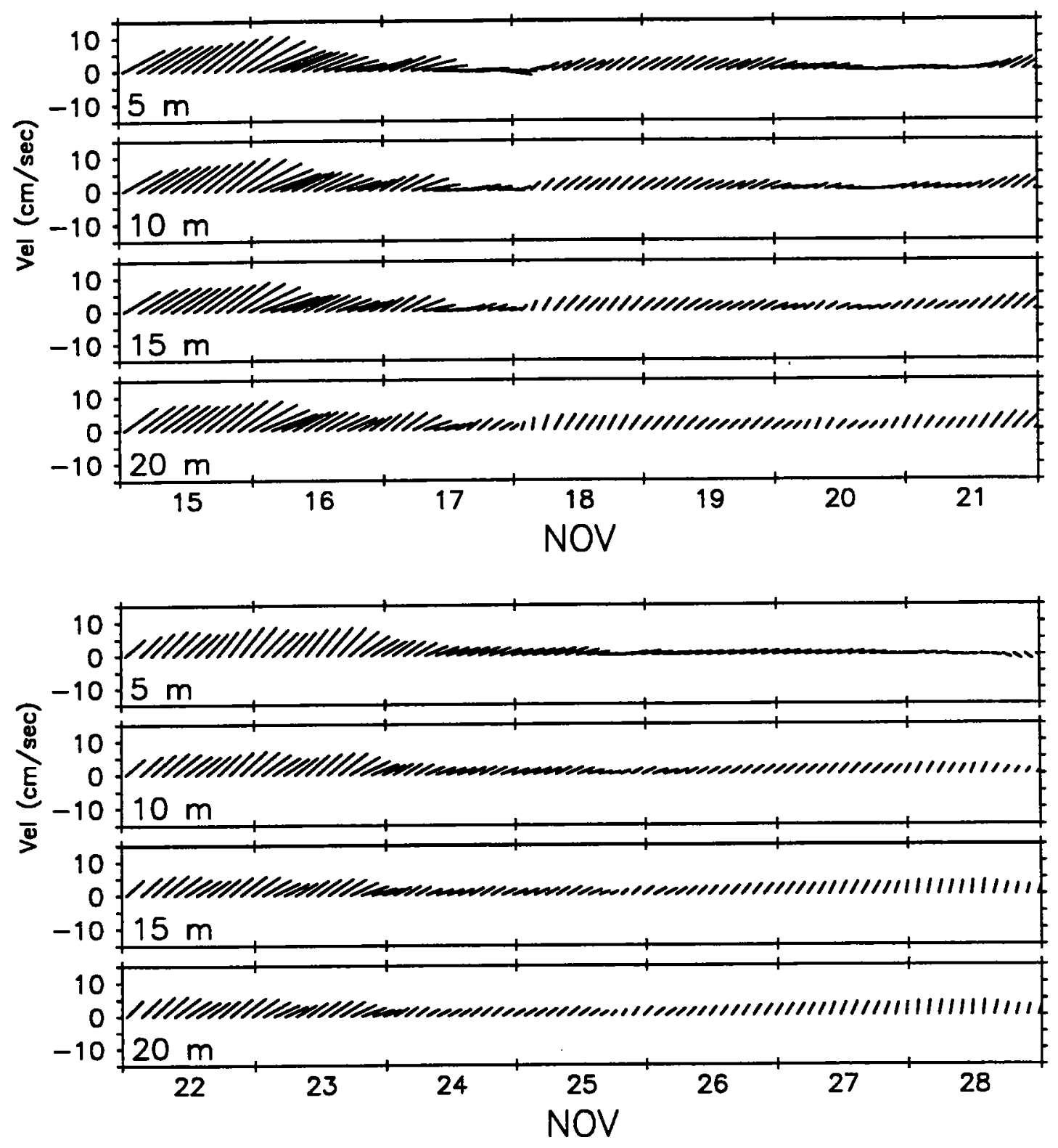

VMCM Water Velocities

Figure 3.3.2 Sub-surface velocity vectors at 4 depths. Northerly component is toward top of page. Data is averaged over 48 hours and subsampled to 2 hours before plotting. 

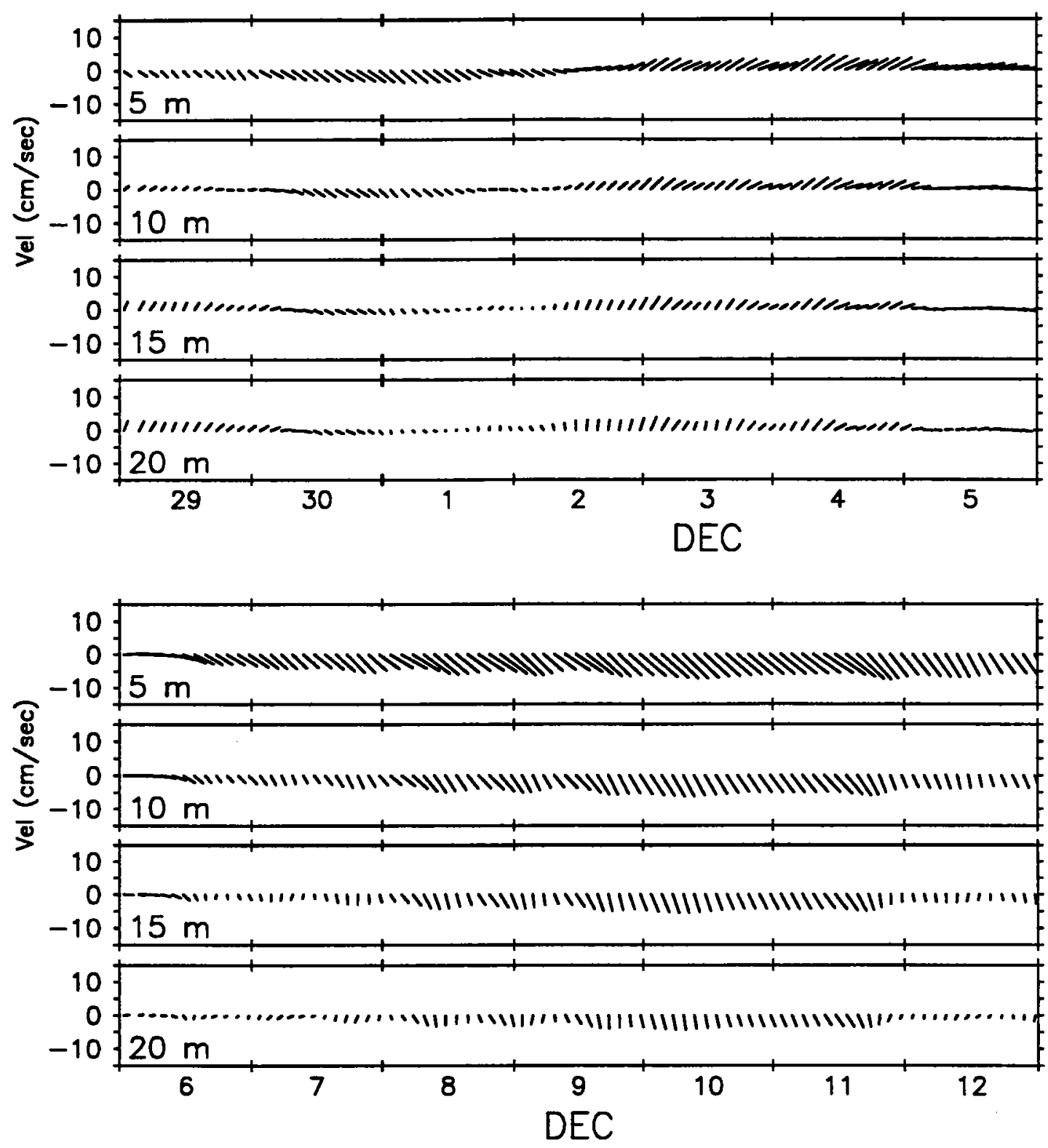

VMCM Water Velocities

Figure 3.3.3 Sub-surface velocity vectors at 4 depths. Northerly component is toward top of page. Data is averaged over 48 hours and subsampled to 2 hours before plotting. 

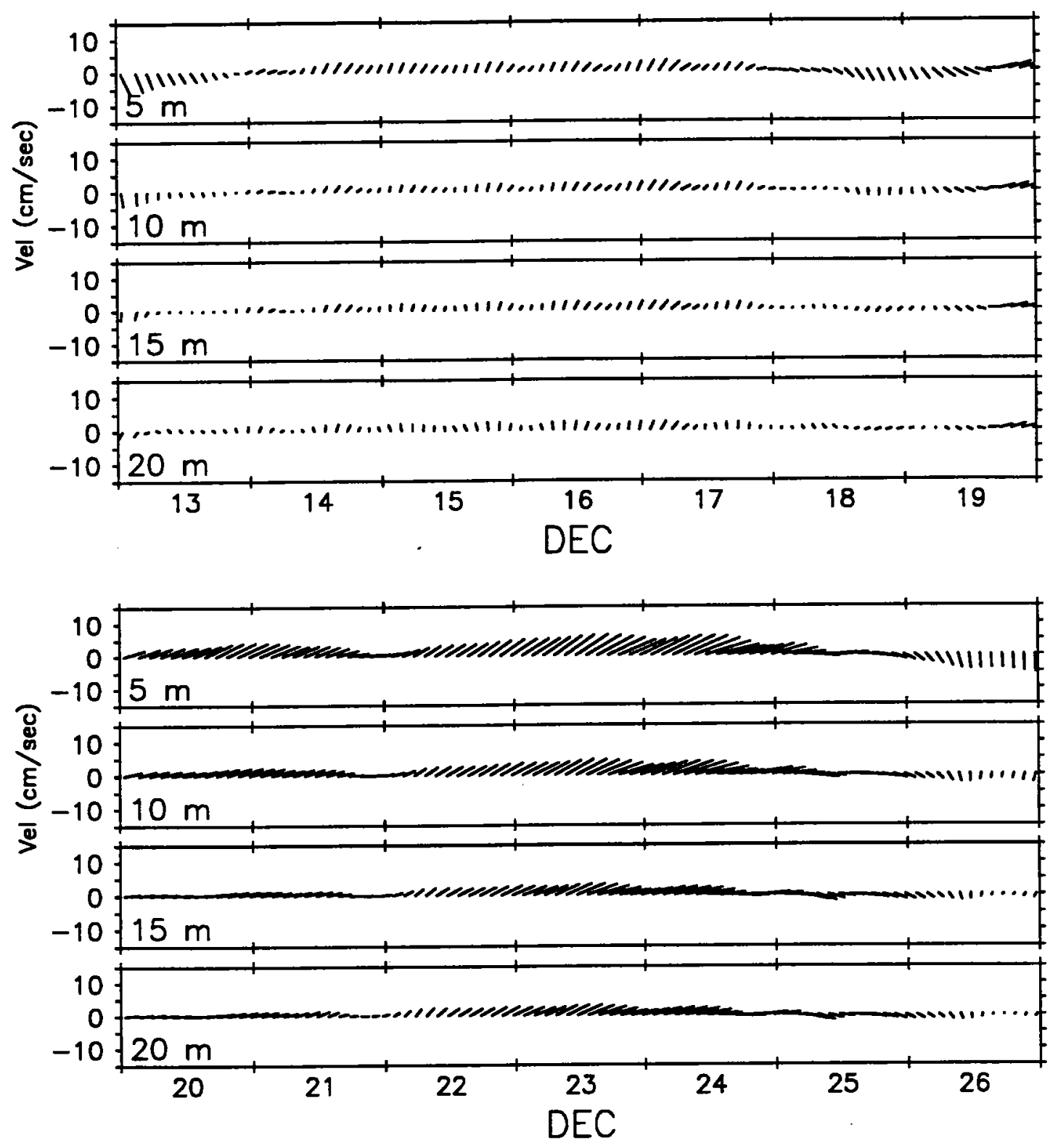

VMCM Water Velocities

Figure 3.3.4 Sub-surface velocity vectors at 4 depths. Northerly component is toward top of page. Data is averaged over 48 hours and subsampled to 2 hours before plotting. 

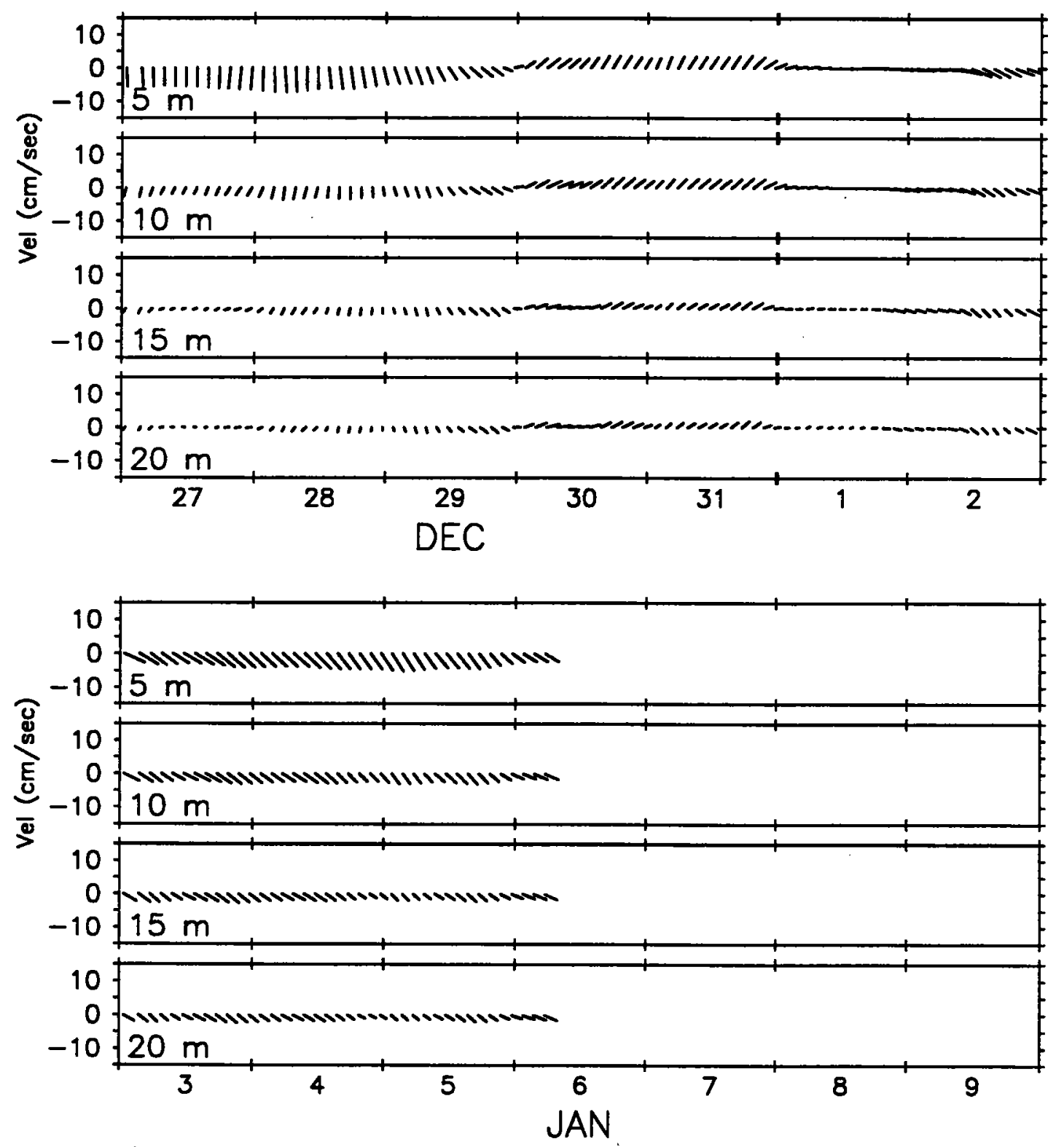

VMCM Water Velocities

Figure 3.3.5 Sub-surface velocity vectors at 4 depths. Northerly component is toward top of page. Data is averaged over 48 hours and subsampled to 2 hours before plotting. 

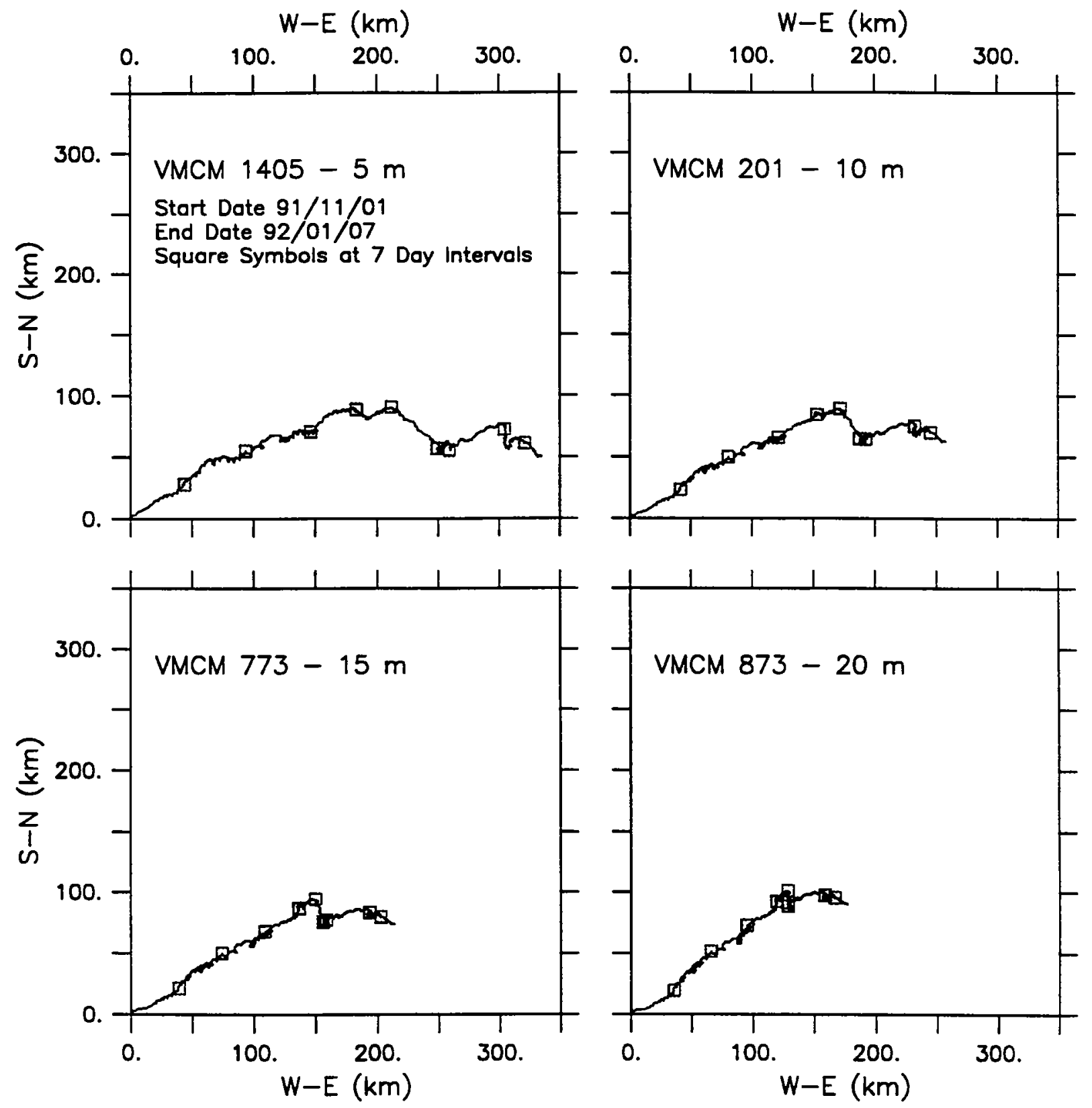

Figure 3.3.6 Progressive water velocity vectors, constructed from velocities averaged over 4 hours. 

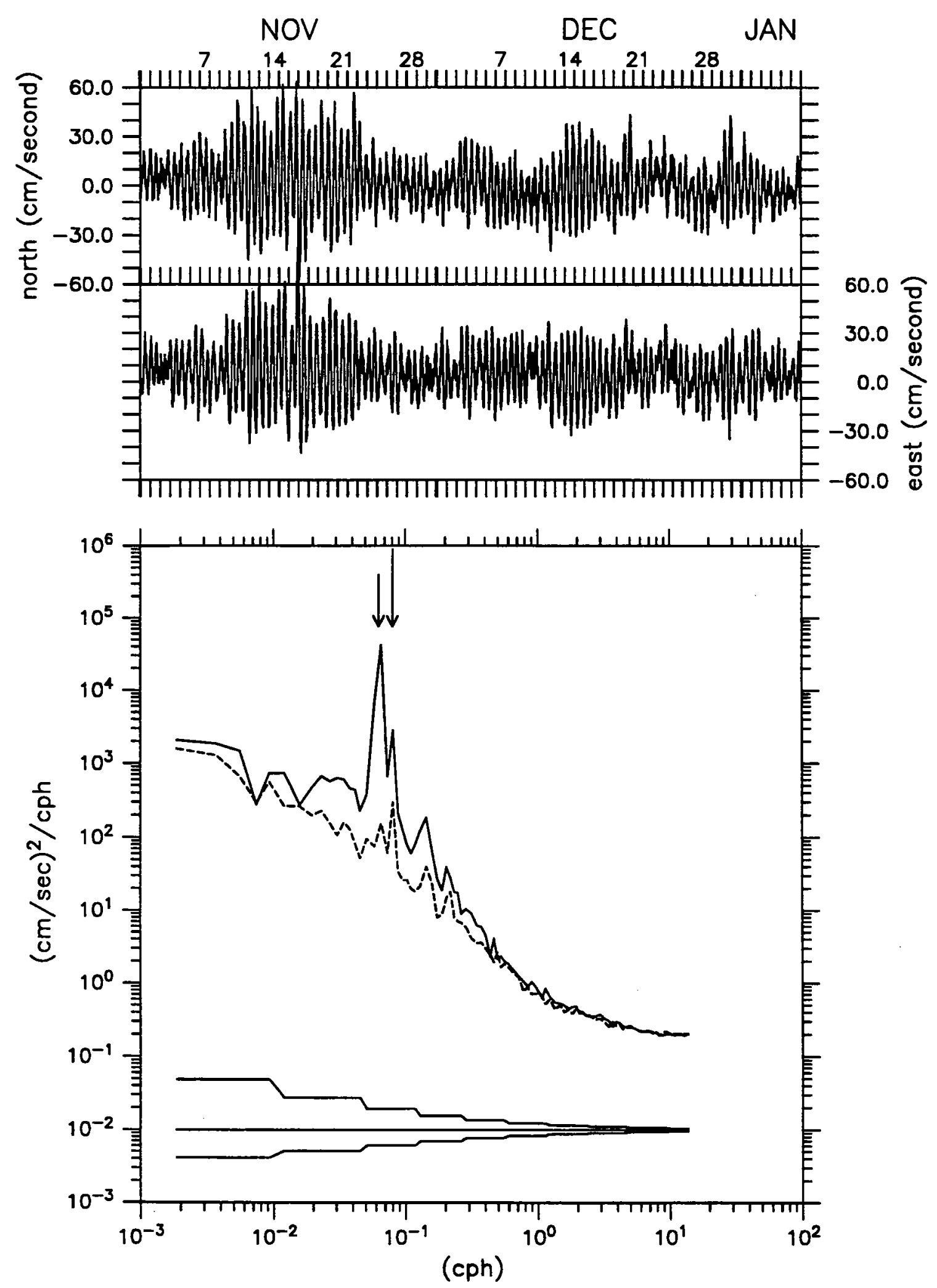

vmcm 1405 at $5.0 \mathrm{~m} \mathrm{M}$

Figure 3.3.7 Water Velocity Time Series and Spectra at $5 \mathrm{~m}$. Solid curves show the clockwise component, and dashed curves show the counterclockwise component. Long arrow indicates semi-diurnal tidal frequency, short arrow indicates coriolis frequency. 

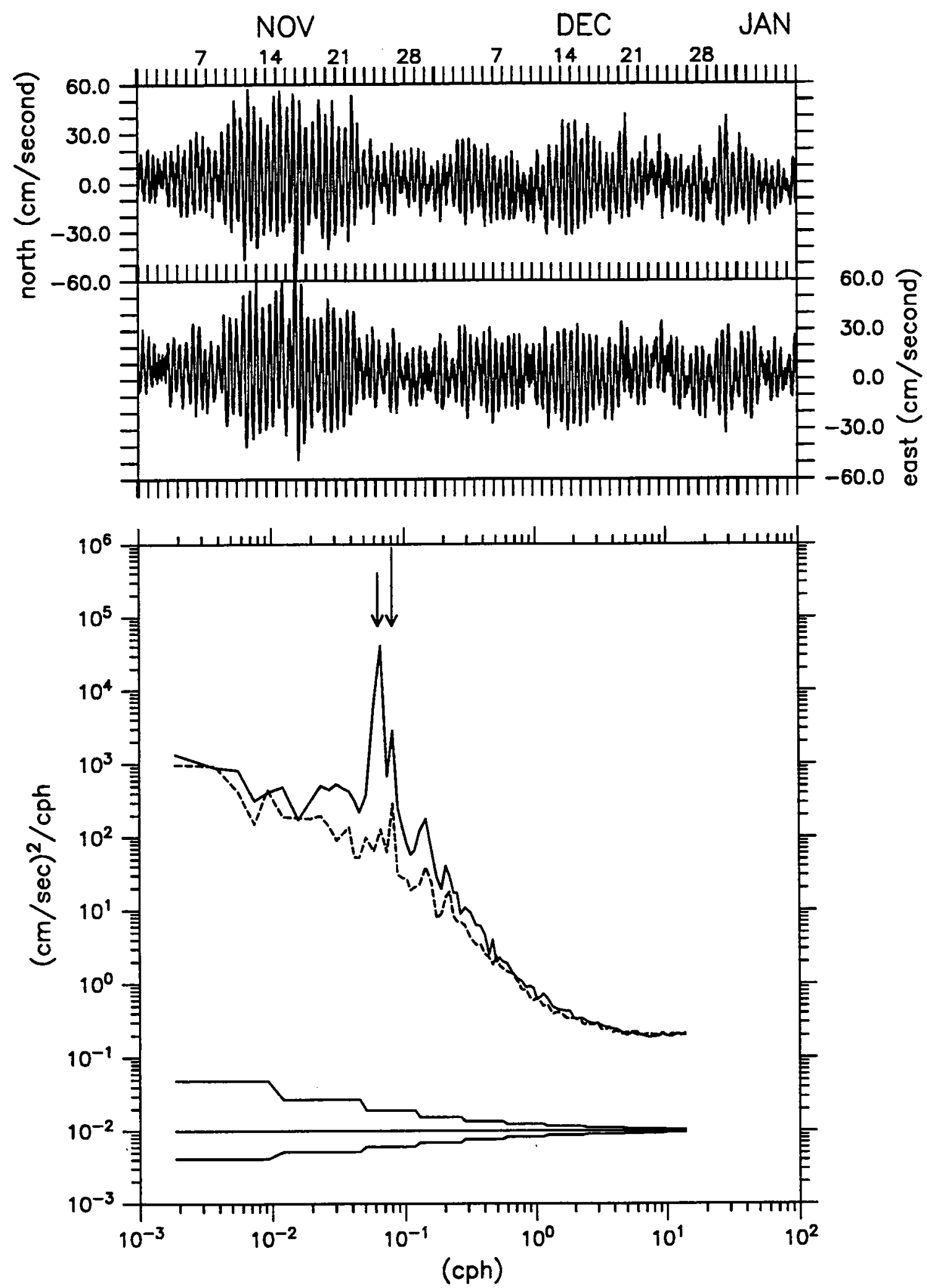

vmem0201 at $10.0 \mathrm{~m} \mathrm{M}$

Figure 3.3.8 Water Velocity Time Series and Spectra at $10 \mathrm{~m}$. Solid curves show the clockwise component, and dashed curves show the counterclockwise component.Long arrow indicates semi-diurnal tidal frequency, short arrow indicates coriolis frequency. 

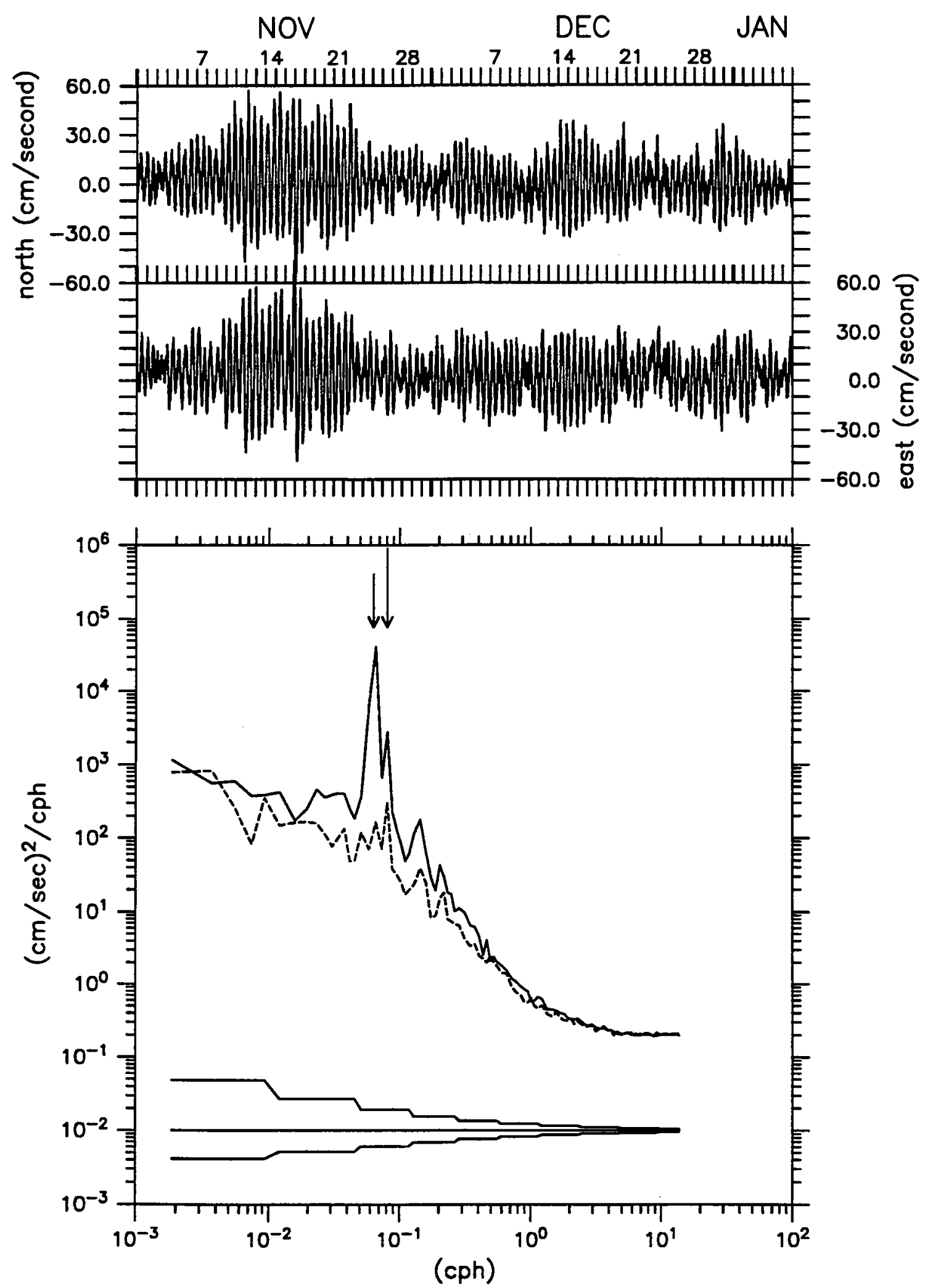

vmcm0773 at $15.0 \mathrm{~m} \mathrm{M}$

Figure 3.3.9 Water Velocity Time Series and Spectra at $15 \mathrm{~m}$. Solid curves show the clockwise component, and dashed curves show the counterclockwise component. Long arrow indicates semi-diurnal tidal frequency, short arrow indicates coriolis frequency. 

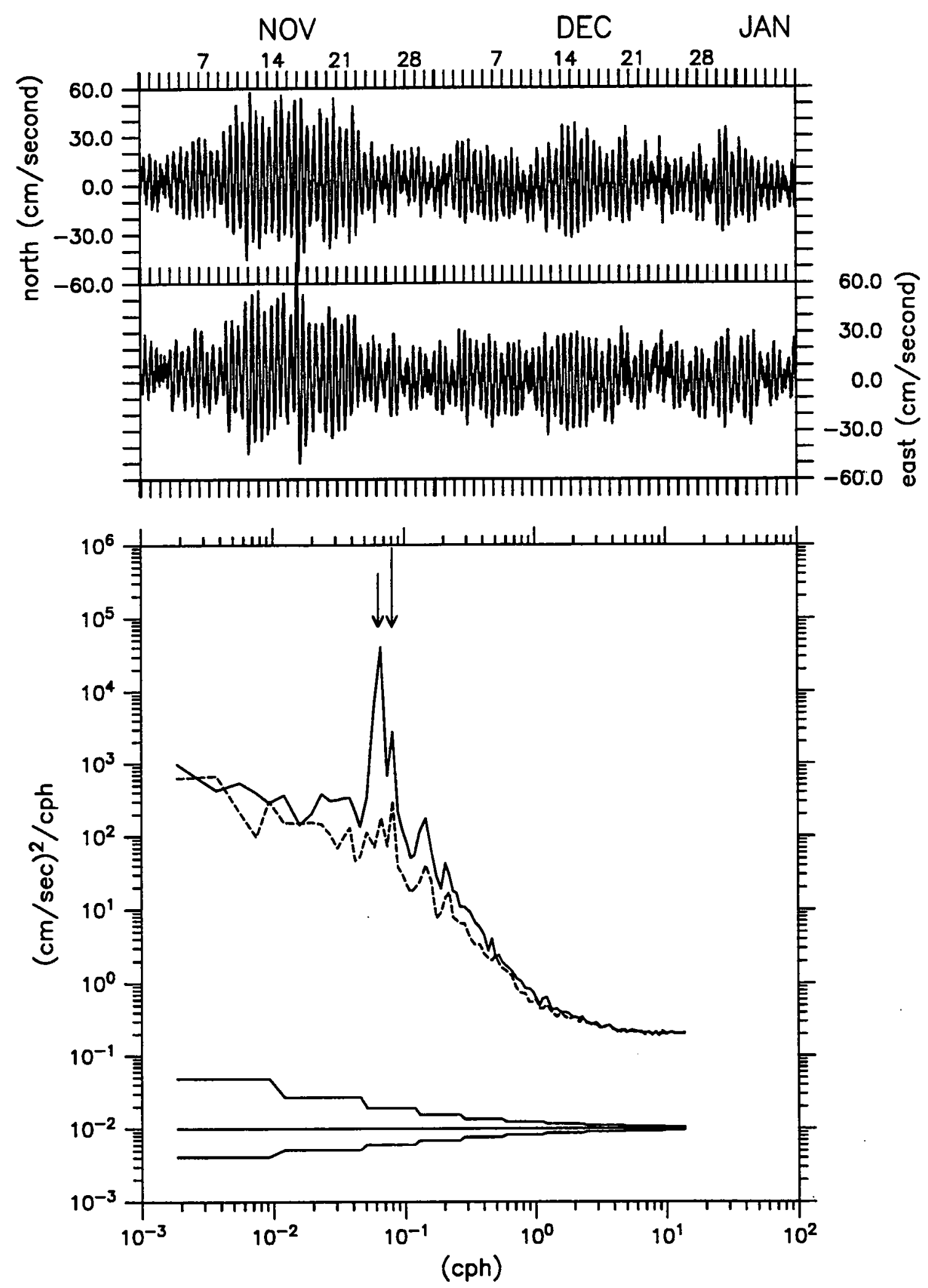

vmcm0873 at $20.0 \mathrm{~m} \mathrm{M}$

Figure 3.3.10 Water Velocity Time Series and Spectra at $20 \mathrm{~m}$. Solid curves show the clockwise component, and dashed curves show the counter-clockwise component. Long arrow indicates semi-diurnal tidal frequency, short arrow indicates coriolis frequency. 


\subsection{Measurement of Ocean Surface Gravity Waves During ASREX 91}

During the experiment, wave-measuring sensors were deployed on three buoys by the Upper Ocean Processes Group. The discus buoy from which the meteorological measurements were made was also outfitted with a Datawell Hippy 40 in the well, measuring heave, pitch, and roll. The buoy recorded 900 seconds of data at $4 \mathrm{~Hz}$ every 6 hours, and wrote the data to the IMET system. Data was acquired beginning on 31 October every 6 hours until the IMET system went down due to low battery on 5 December 1991. The directional response of this buoy is still being studied. Although an initial characterization of the response is presented in Gnanadesikan and Terray (1994), there are still major gaps in our understanding of the transfer function at low frequencies. Directional spectra from this buoy will therefore not be presented in this report.

Two dedicated pitch-roll buoys were also deployed during ASREX. The first of these buoys to be deployed was a Wavescan ${ }^{\mathrm{TM}}$ made by Seatex A/S of Trondheim, Norway. A Datawell Hippy 120 sensor on this buoy 2048 samples heave, pitch and roll at a rate of $1 \mathrm{~Hz}$ every 3 hours. Buoy heading was recorded simultaneously from a two-axis fluxgate compass. The time series of good data from this buoy begins at $0600 Z$ on November 1 November, 1991 and continues until $1800 Z$ on 4 December 1991 when it was recovered by the HMCS Huron. The Wavescan buoy is described in more detail in Barstow et al., 1991. As noted in Gnanadesikan and Terray (1994) the response of the Seatex buoy to surface gravity waves is the best studied and may be easily corrected by modelling the buoy as a damped harmonic oscillator. The Seatex was thus taken as the standard against which other buoys were compared. 
The second pitch/roll buoy was a Wavetrack ${ }^{\mathrm{TM}}$ manufactured by Endeco/YSI of Marion MA. This buoy measured vertical acceleration using a gimballed accelerometer and two electrolytic tilt sensors. The buoy recorded 2048 samples of heave, north tilt, and east tilt at a rate of $2 \mathrm{~Hz}$ every 12 hours. The time series of good nondirectional data from this buoy begins at $0000 \mathrm{Z}$ on 3 November 1991 and continues until $1200 \mathrm{Z}$ on 8 January. The directional response of this buoy has been studied by Gnanadesikan and Terray (1994), who found that it is not as simple as that of the Seatex buoy. This report will present some directional results from the Endeco buoy, but will not present an exhaustive listing of the spectra.

Figure 3.4.1 shows time series of wave parameters measured from the Seatex buoy. Figure 3.4.1a and 3.4.1b show time series of the significant wave height and period, computed as follows. The period between successive zero-up crossings of the sea-surface height was defined as corresponding to a single wave. The height of this wave was defined as the difference between the maximum and minimum surface heights. The period of the wave was defined as the time interval between the sucessive zero-up-crossings. The significant wave is defined as the height of the highest $1 / 3$ of the waves. The significant wave period is the mean period of the highest $1 / 3$ of the waves. The height of the largest wave seen during the 2048 second observing period is shown in Figure 3.4.1c. During the deployment we see that the waves were in general quite large, with a peak significant height of 10.03 meters at $1800 \mathrm{Z}$ on 16 November 1991 . The largest wave seen during the entire deployment (15.97 meters in height) was seen at this time. 
Figure 3.4.2 shows the evolution of the energy in the surface wave field as a function of frequency over the course of the ASREX 91 experiment. Contours are $\log _{10}$ spectral density, The heavy dashed lines show some of the clearly identifiable events corresponding to locally generated windsea for which the frequency of the peak of the spectrum increases with time. The straight heavy solid lines show identifiable swell propagation events for which the frequency of the peak of the spectrum decreases with time.

Directional wave spectra were calculated using the Maximum Entropy Method of Lygre and Krogstad (1986). Corrections to the measured direction of orientation due to buoy tilt were calculated and applied. The tilts were then rotated into geographic coordinates. The spectra and cross-spectra of the heave and tilt were calculated with corrections being made for sensor response and buoy transfer function. The resulting heave and tilt spectra, quadrature spectrum of heave and north and east tilt, and cospectrum of north and east tilt were input to the Maximum Entropy routine of Lygre and Krogstad, and directional spectra were produced. The MATLAB code used to produce these spectra is given in Appendix 5. If the resulting spectra are integrated over frequency, one may get a sense of how the wave energy depends on direction. Figure 3.4.3a shows a contour plot of the wave energy as a function of direction measured from the Seatex buoy over 1 November- 21 November. The plot shows the direction from which the waves were propagating. $3.4 .3 \mathrm{~b}$ shows the wind direction during this time period. Figures $3.4 .3 \mathrm{c}$ and $\mathrm{d}$ repeat $3.4 .3 \mathrm{a}$ and $\mathrm{b}$ for 21 November to 5 December. During the deployment, the winds were generally from the west and the south, and the wave climate seems to mirror this fact. The directional distribution wave energy in general reflects the wind direction, but there are some clear cases where there are differences. 
Figure 3.4.4 shows comparisons of wave parameters measured from the the Seatex, Endeco and Discus buoys during the month of November, 1991. In all plots the data from the Seatex buoy is shown as a solid line, that from the Endeco as open circles and that from the discus as an $\mathrm{x}$. Figure 3.4.4a shows the significant wave height measured from the three buoys and $3.4 .4 \mathrm{~b}$ shows the frequency at the peak of the spectrum. The agreement between the three buoys is excellent with the standard deviation of the difference between the Seatex and Endeco buoys being $0.25 \mathrm{~m}$ and the standard deviation of the difference between the Seatex and discus buoys being $0.34 \mathrm{~m}$.

Wave directions were computed from the Seatex and Endeco buoys at various frequencies. Figure $3.4 .4 \mathrm{c}$ and 3.4.4d. Figure $3.4 .4 \mathrm{c}$ shows the direction associated with the spectral peak from the Seatex and Endeco buoys. The two buoys agree most of the time, but show occasional differences. Gnanadesikan and Terray (1994) argued that these differences were most likely due to uncertainties in the buoy transfer function. Figure 3.4.4d shows the wave direction in a frequency band from $0.25-0.33 \mathrm{~Hz}$. The dashed line shows the wind direction. Clearly in this band, the waves track the wind very closely.

Figures 3.4.7-3.4.38 show a subset of the Seatex directional wave spectra. Four spectra are shown on each day (eight were taken) at 00,06,12, and 18Z. 
ASREX 91:Significant Wave Height (Seatex Buoy)

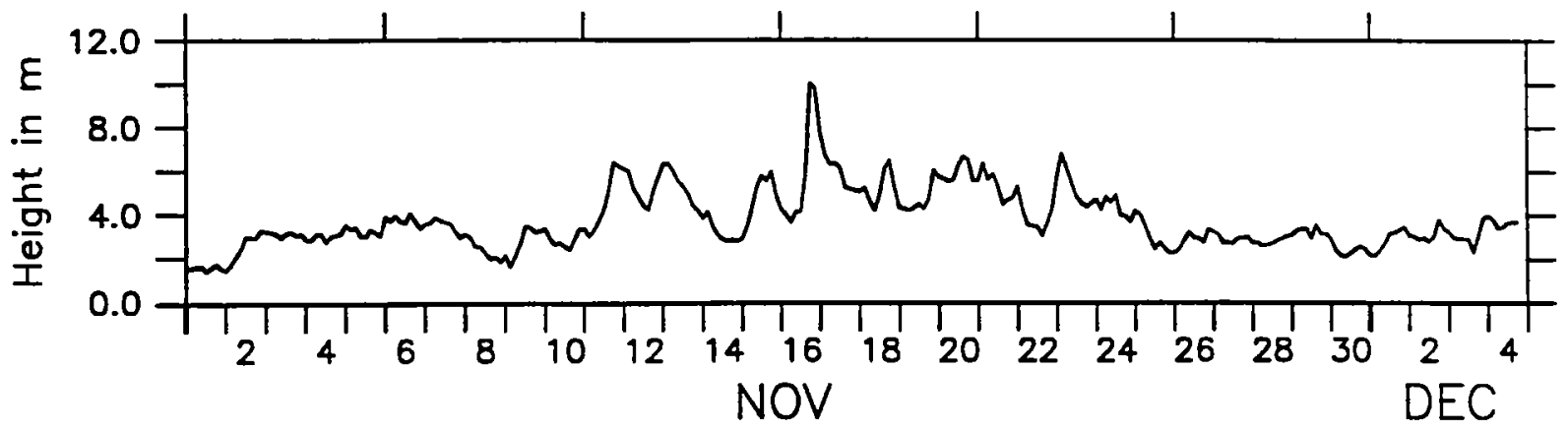

(a)

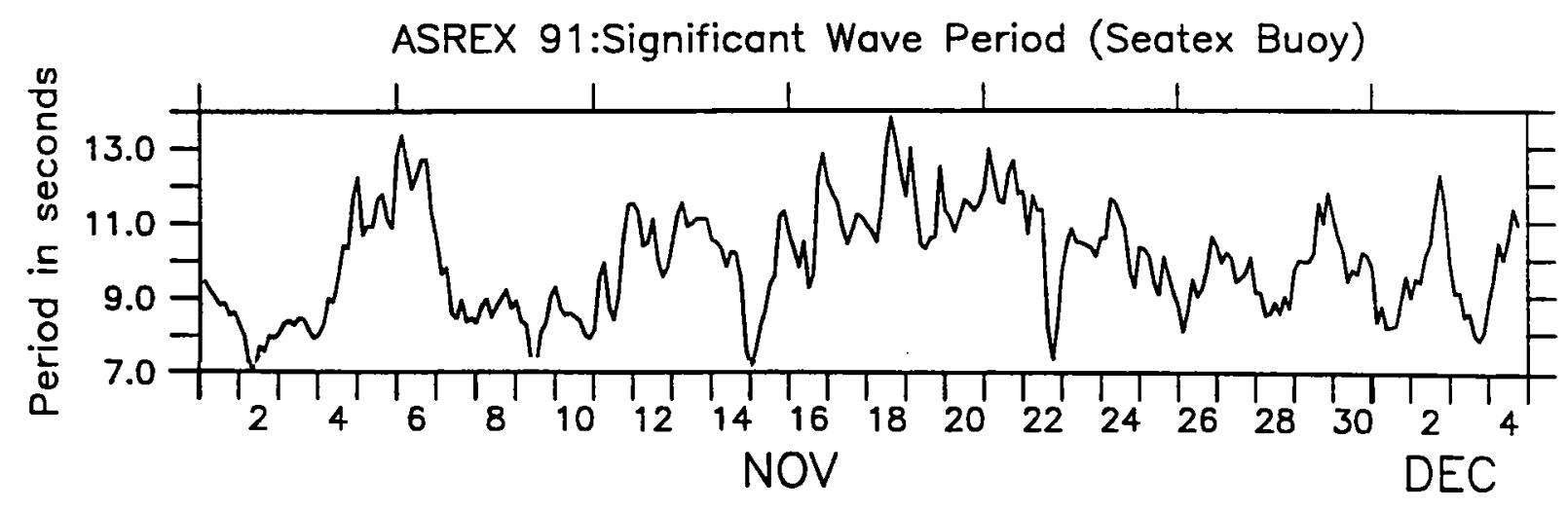

(b)

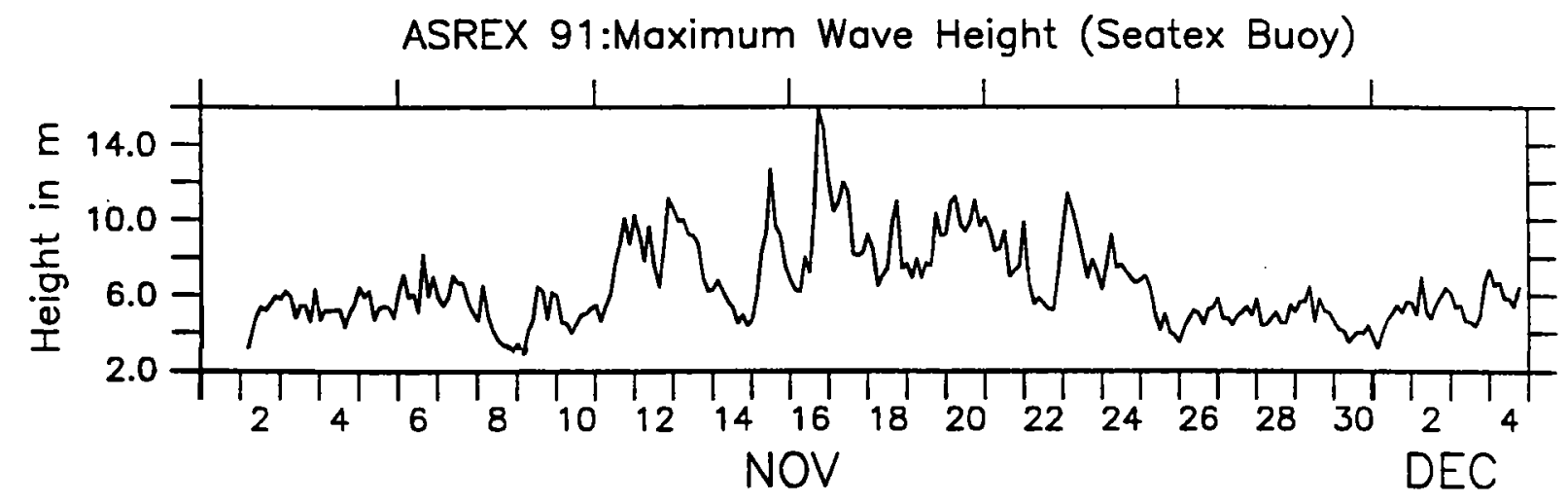

(c)

Figure 3.4.1: Wave parameter time series from Seatex Buoy. 
ASREX 91: $\log _{10}$ Surface Wove Energy vs. Frequency (Seatex)

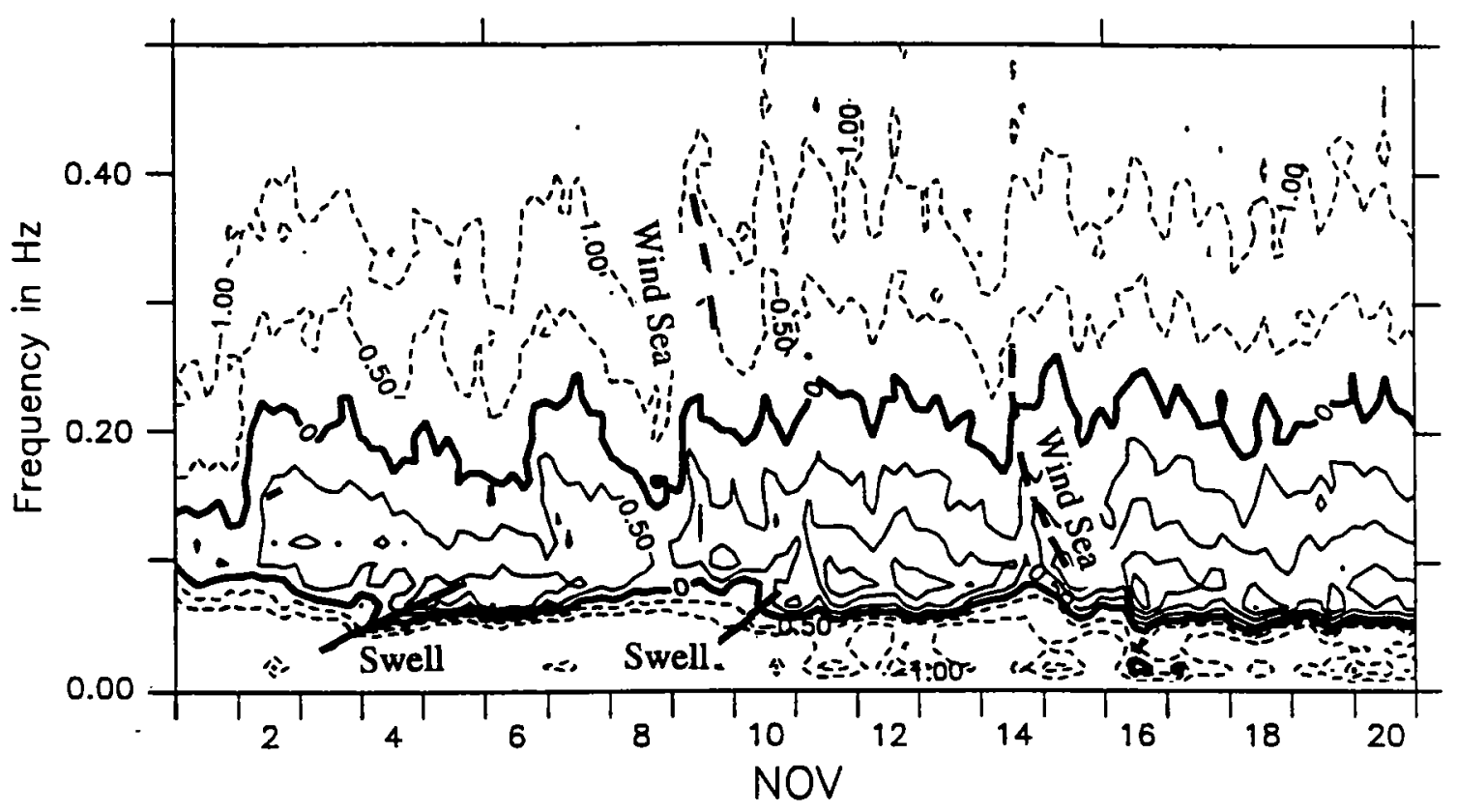

(a)

ASREX 91:Log 10 Surfoce Wove Energy vs. Frequency (Seatex)

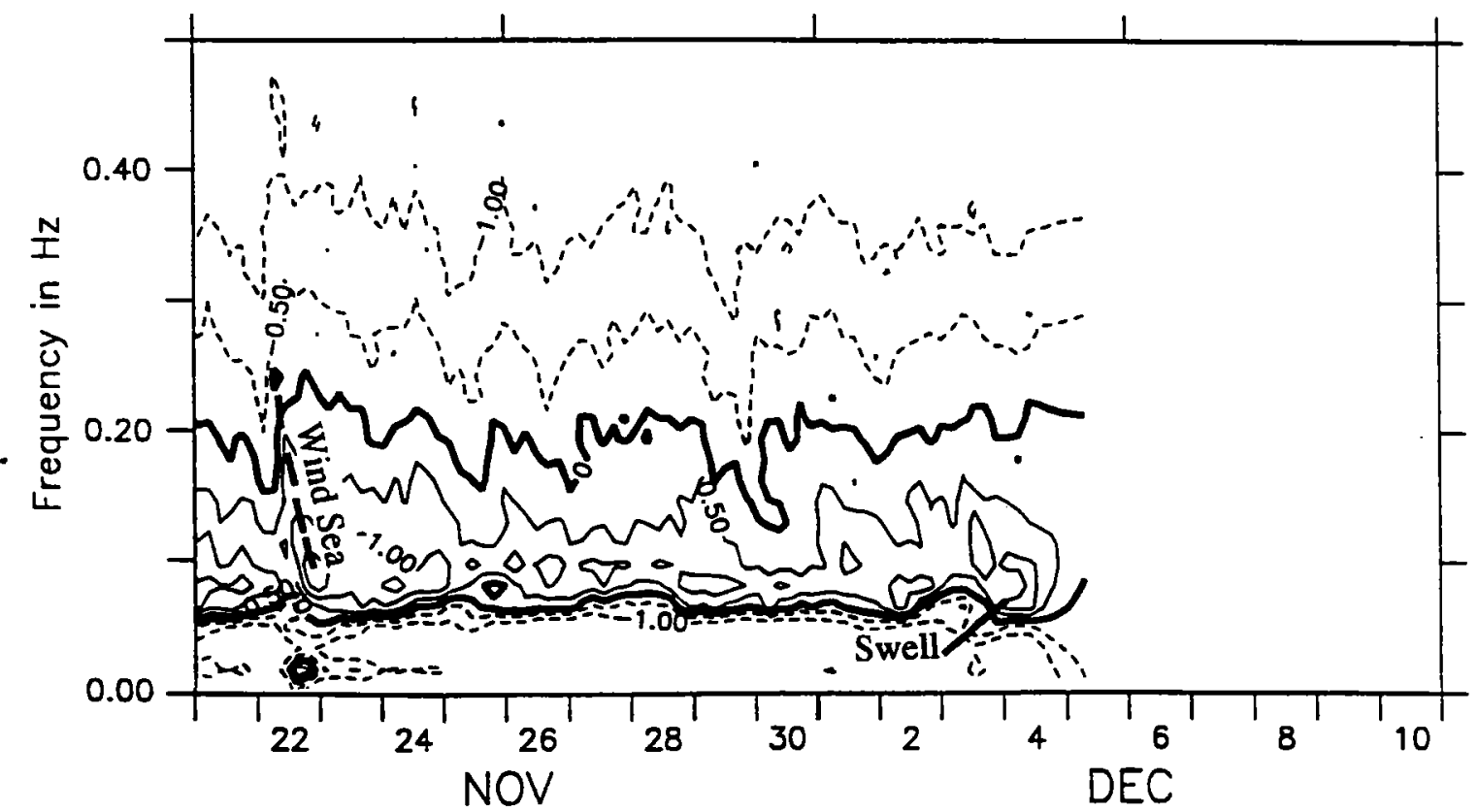

(b)

Figure 3.4.2: Evolution of wave field vs frequency during ASREX 91. Data are taken from the Seatex buoy and run from 0300Z 1 November 1991 through $1800 \mathrm{Z} 4$ December 1991 . (a) Contours of $\log _{10}$ spectral density $1-$ 21 November. (a) Contours of $\log _{10}$ spectral density 21 November - 5 December. 


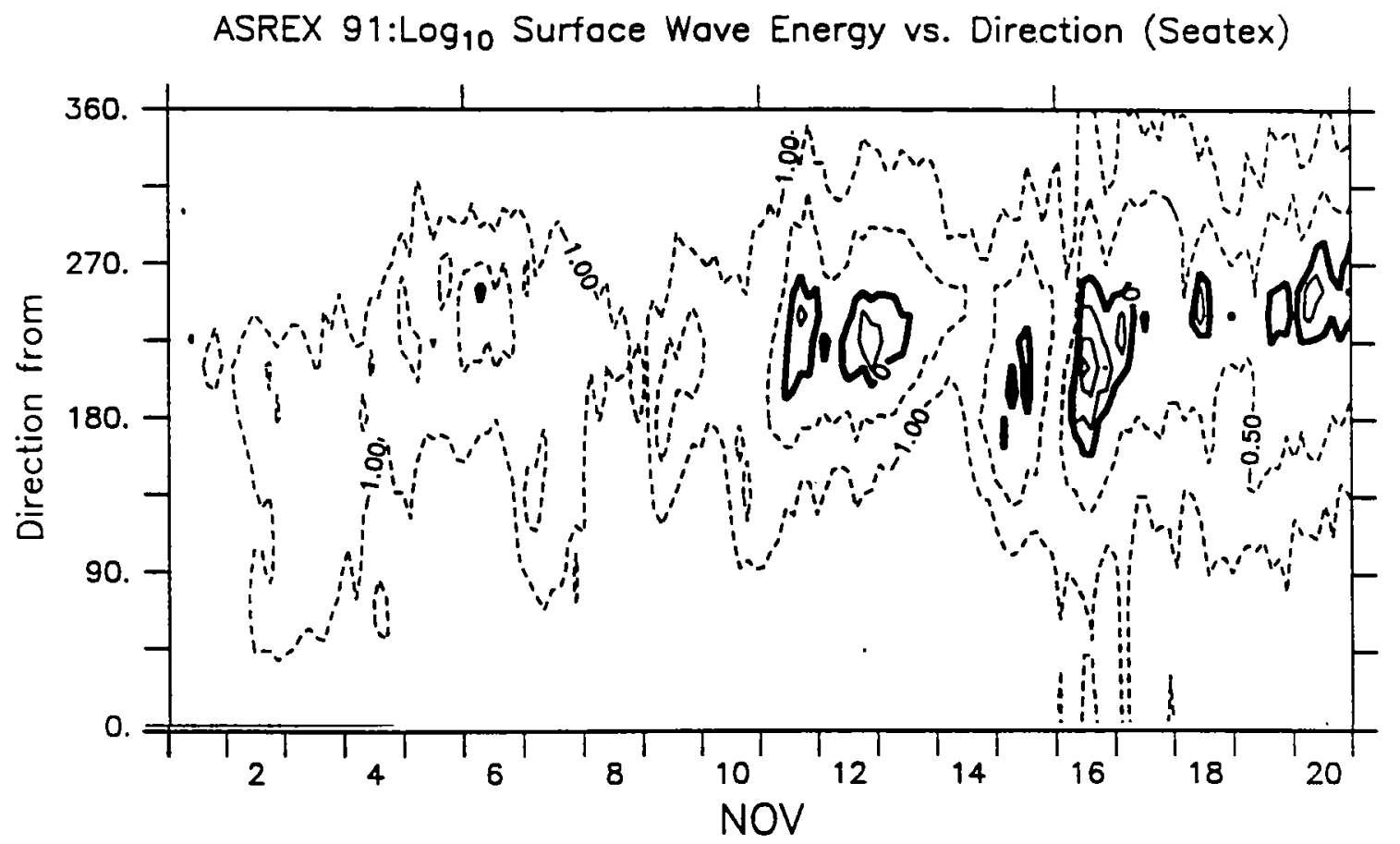

(a)

Wind Direction

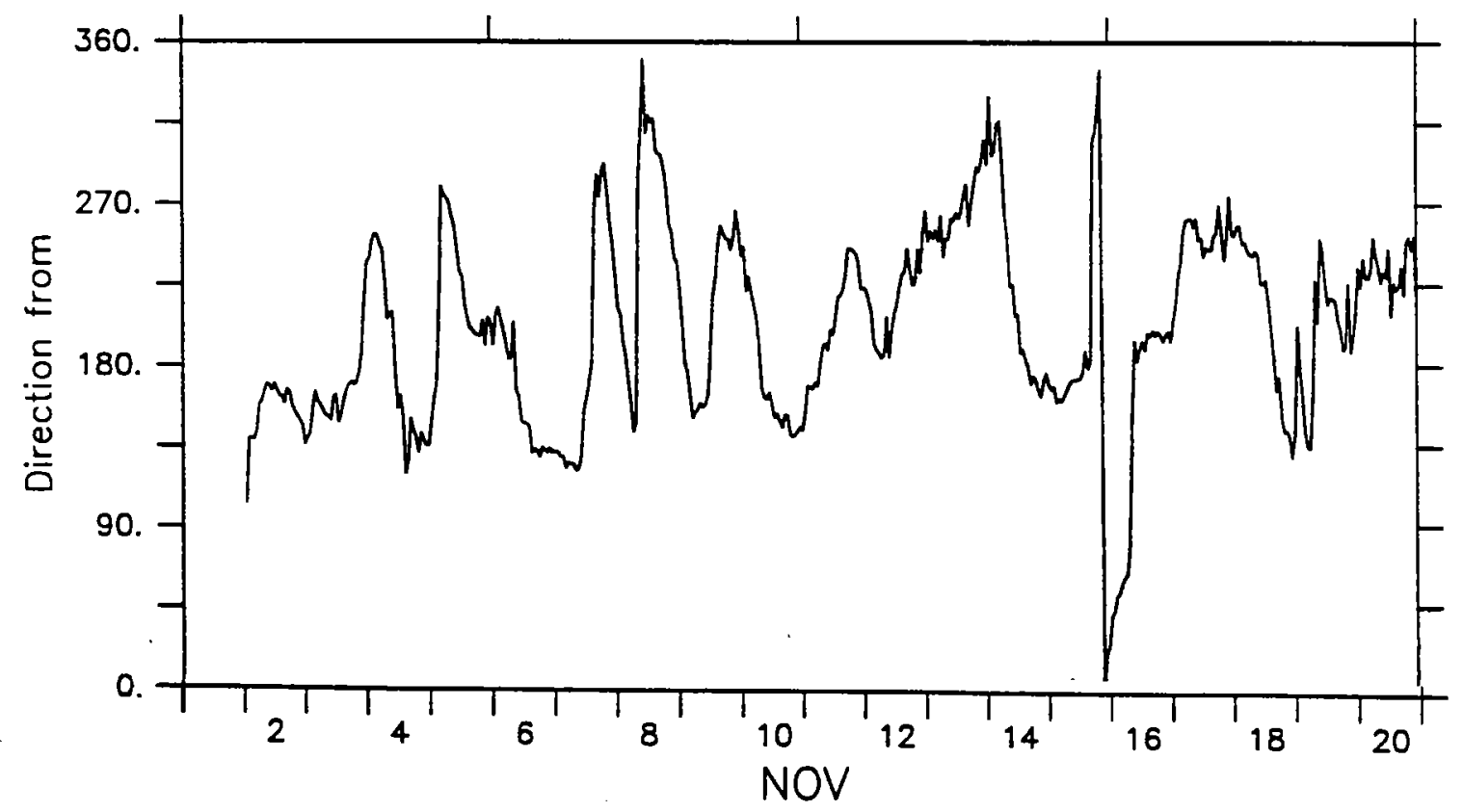

(b)

Figure 3.4.3: Directional Wave Evolution during ASREX 91 from Seatex buoy. (a) $\log _{10}$ wave energy vs. direction 1 - 21 November. (b) Wind direction 1 - 21 November. (c) $\log _{10}$ wave energy vs. direction 21 November - 5 December. (c) Wind direction 21 November - 5 December. 


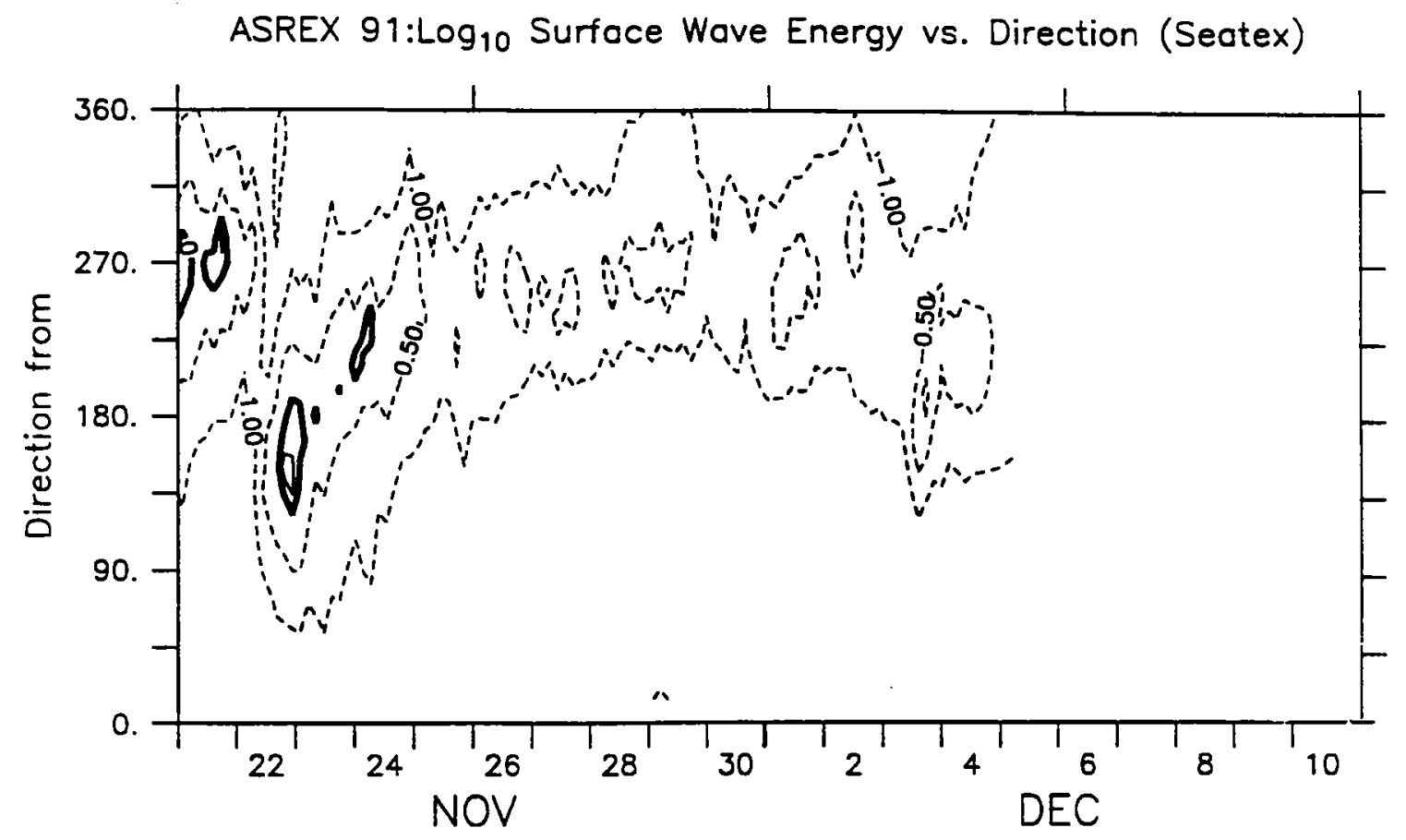

(c)

Wind Direction

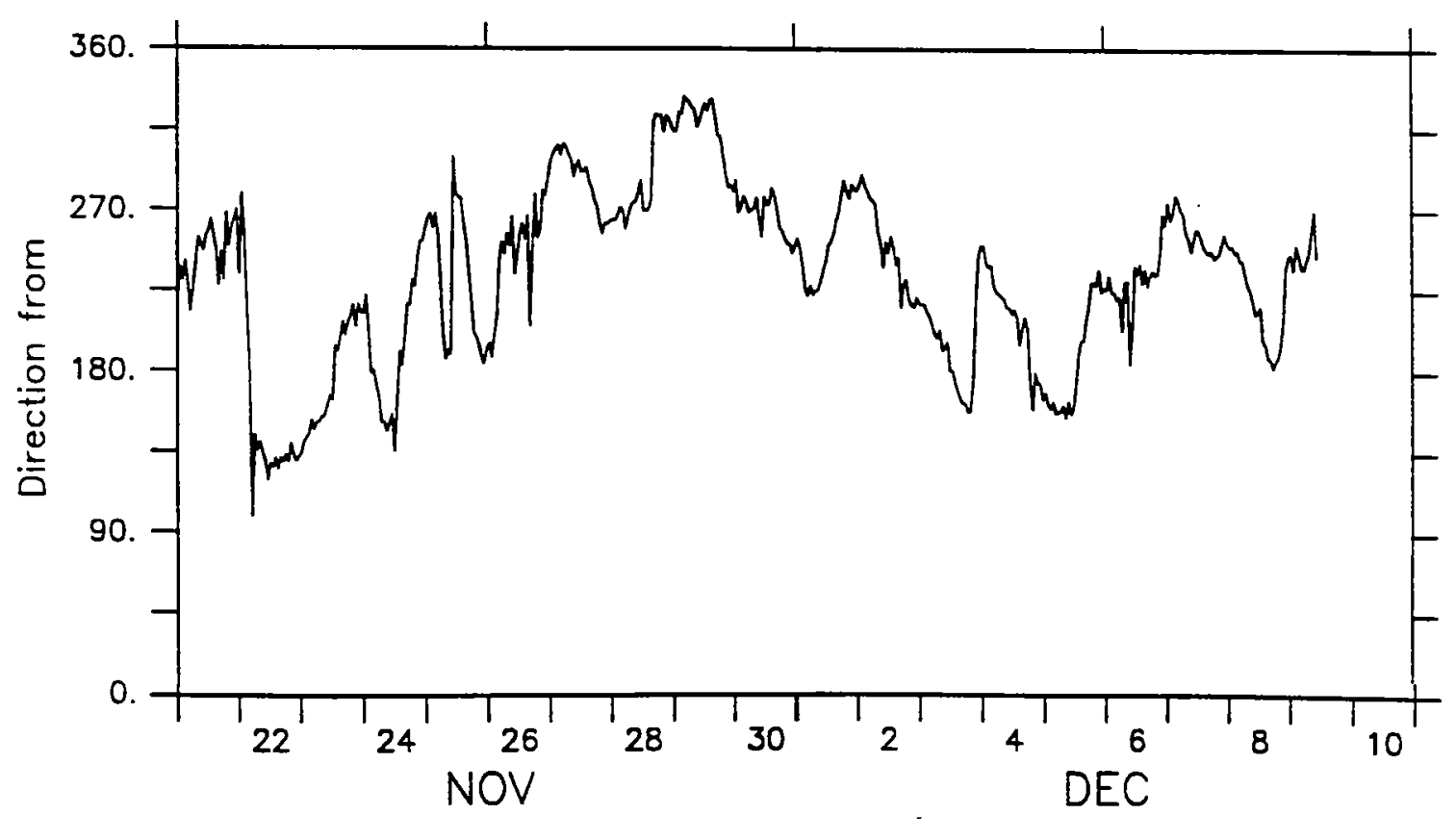

(d)

Figure 3.4.3 (continued) 
Significant Wave Height

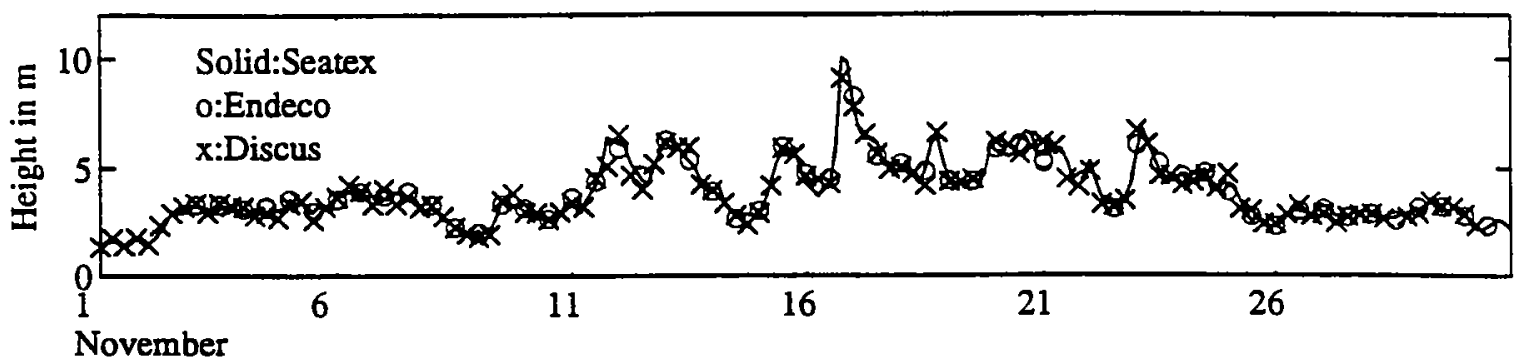

(a)

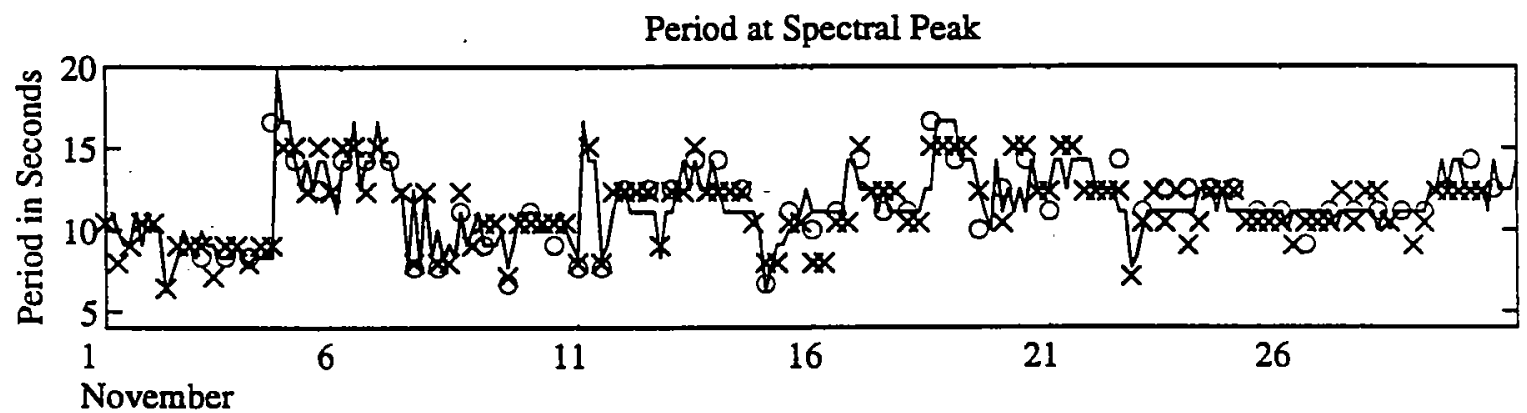

(b)

Direction at Spectral Peak

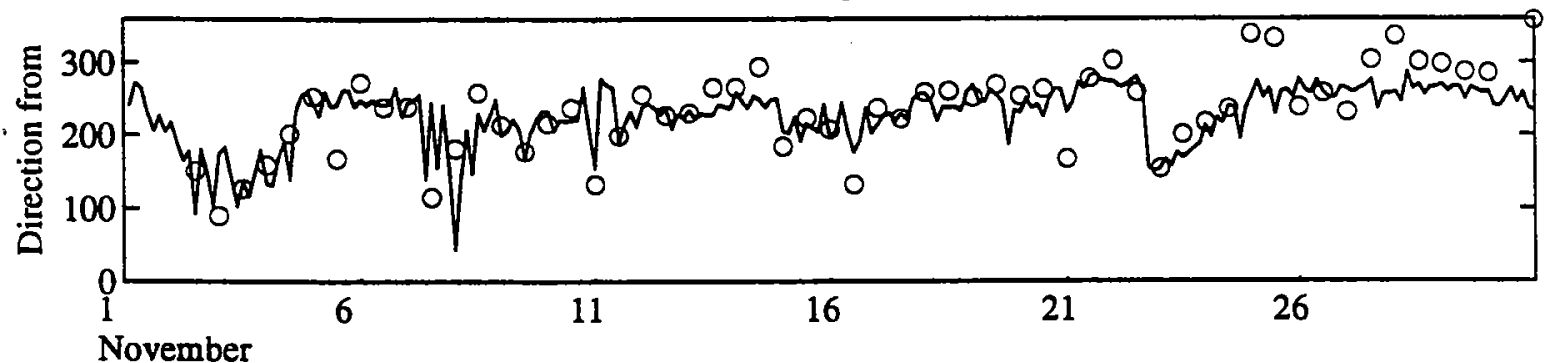

(c)

Direction between .25 and $.33 \mathrm{~Hz}$

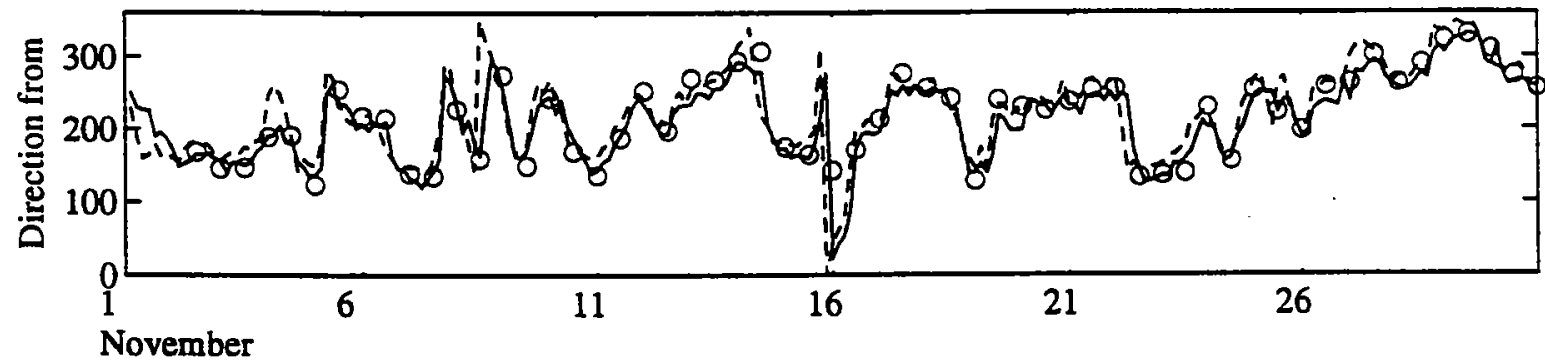

(d)

Figure 3.4.4: Wave parameters from three buoys. Solid: Seatex, o: Endeco, x: Discus. (a) Significant wave height in $\mathrm{m}$. (b) Period of spectral peak in s. (c) Direction at spectral peak. (d) Direction of waves with 3-4 seconds period, dashed line is wind direction. 


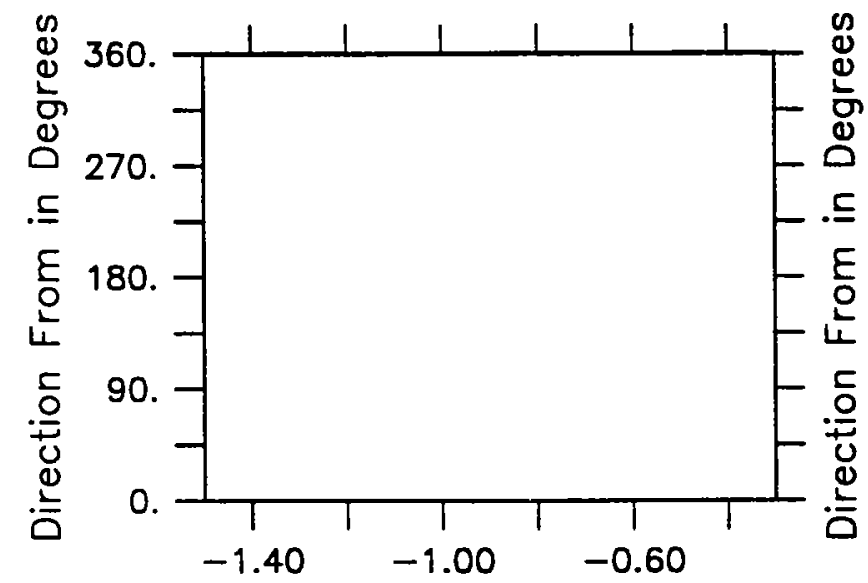

$\log _{10}$ Frequency in $\mathrm{Hz}$

November $1,199100 Z$

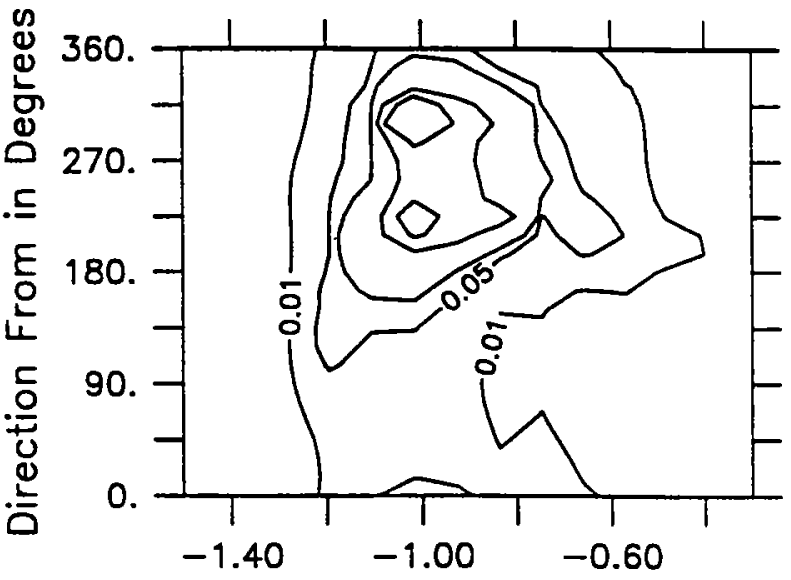

$\log _{10}$ Frequency in $\mathrm{Hz}$

November $1,199106 Z$

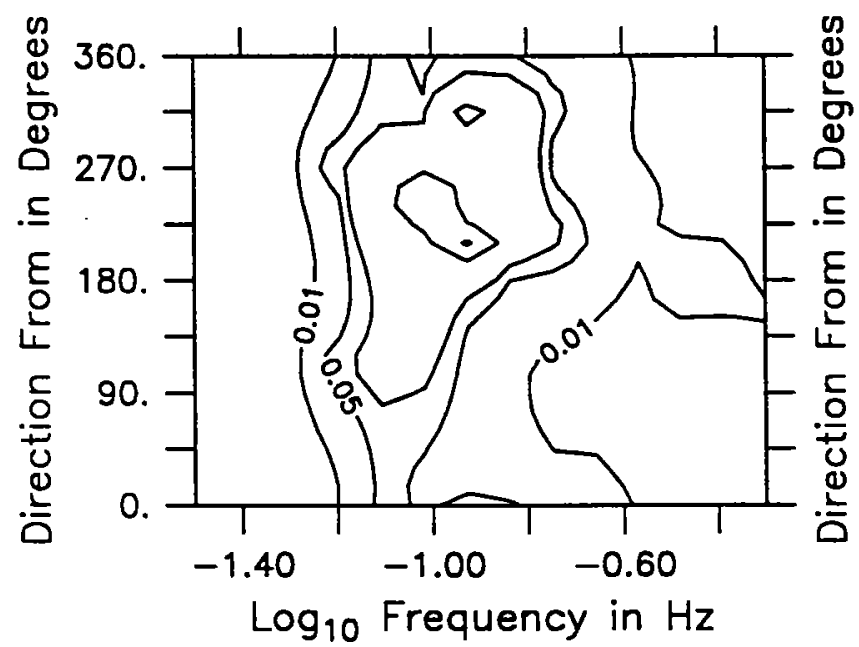

November 1,1991 $12 Z$

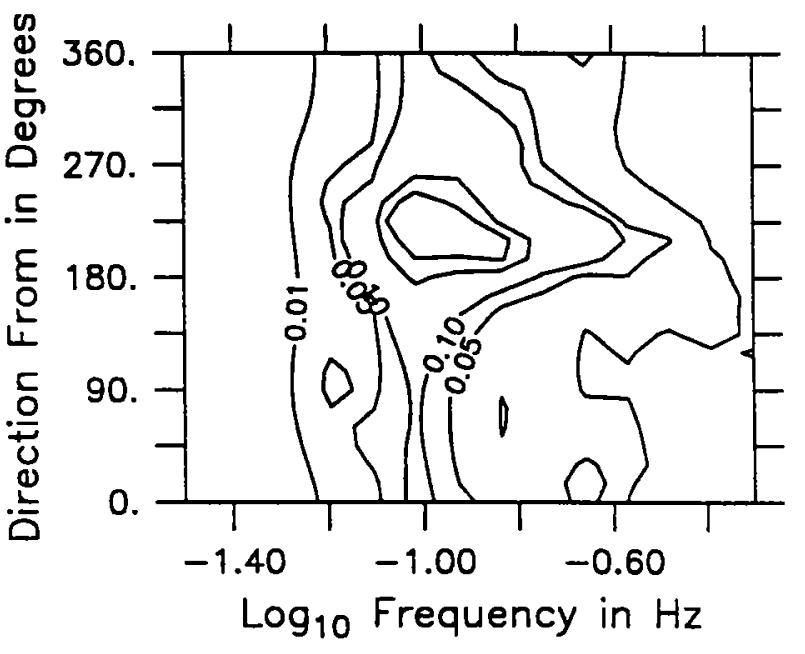

November 1,1991 $18 Z$

Figure 3.4.5: Directional wave spectra, Seatex buoy. Contours are 0.01, 0.05, $0.1,0.5,1,5,10,50,100,500$. 


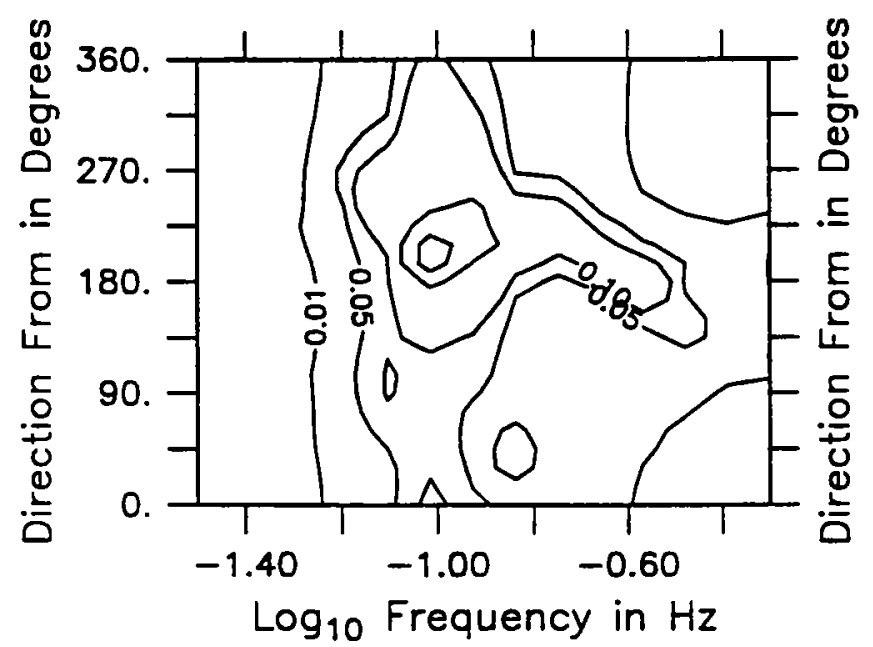

November 2,1991 OOZ

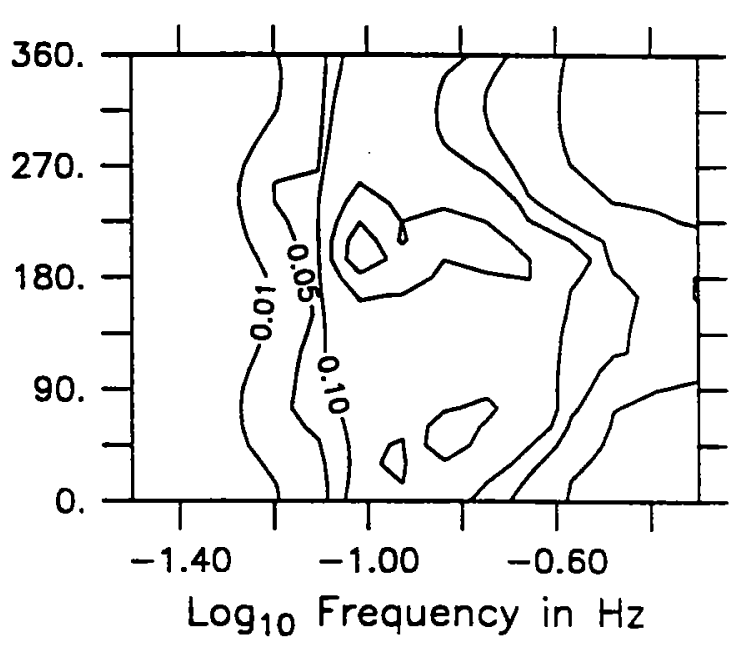

November 2,1991 $06 Z$

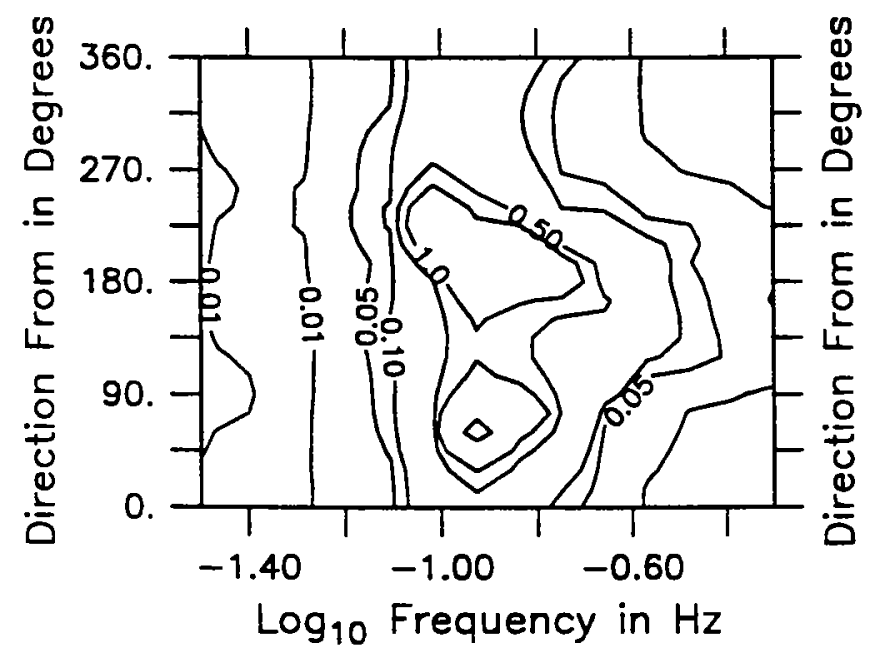

November 2,1991 $12 Z$

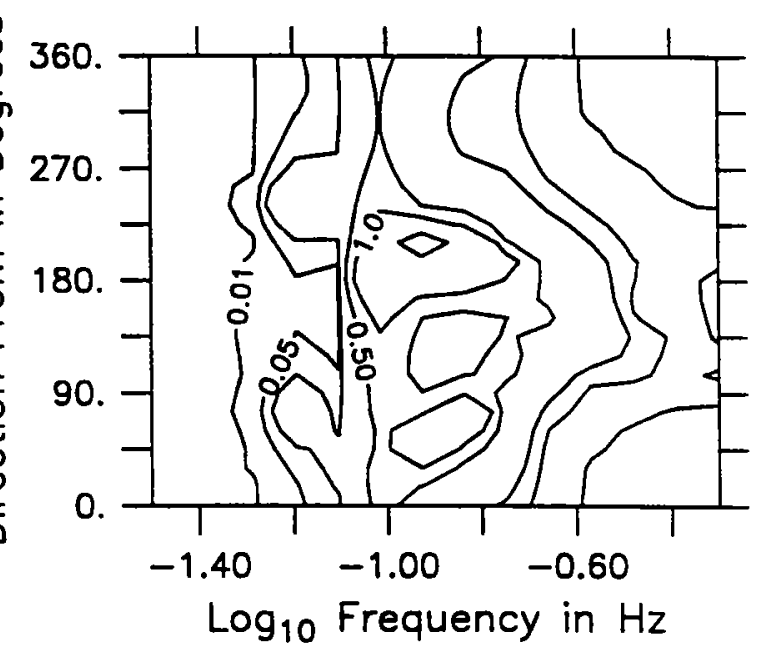

November 2,1991 $18 Z$

Figure 3.4.6: Directional wave spectra, Seatex buoy. Contours are 0.01, 0.05, $0.1,0.5,1,5,10,50,100,500$. 


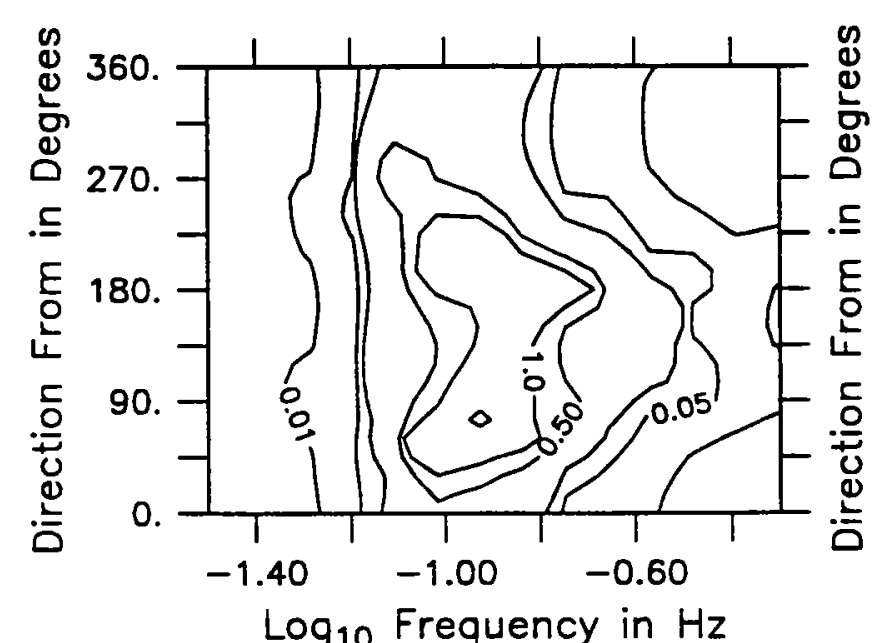

November 3,1991 OOZ

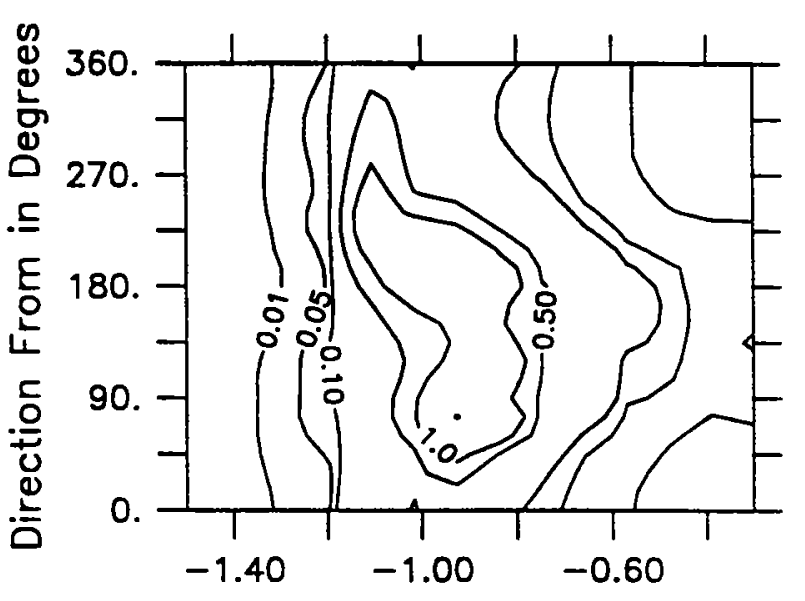

$\log _{10}$ Frequency in $\mathrm{Hz}$

November 3,1991 $06 Z$

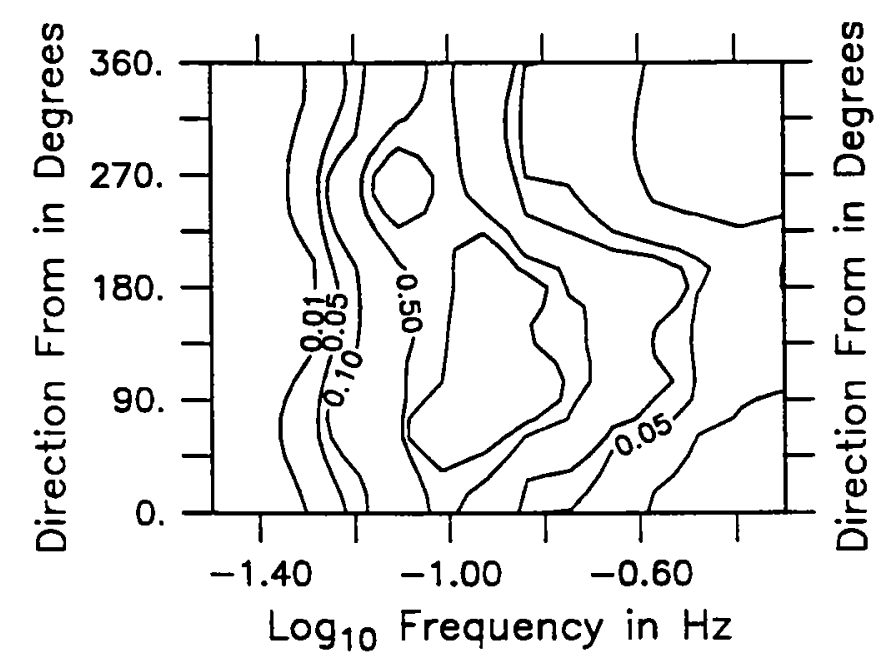

November 3,1991 $12 Z$

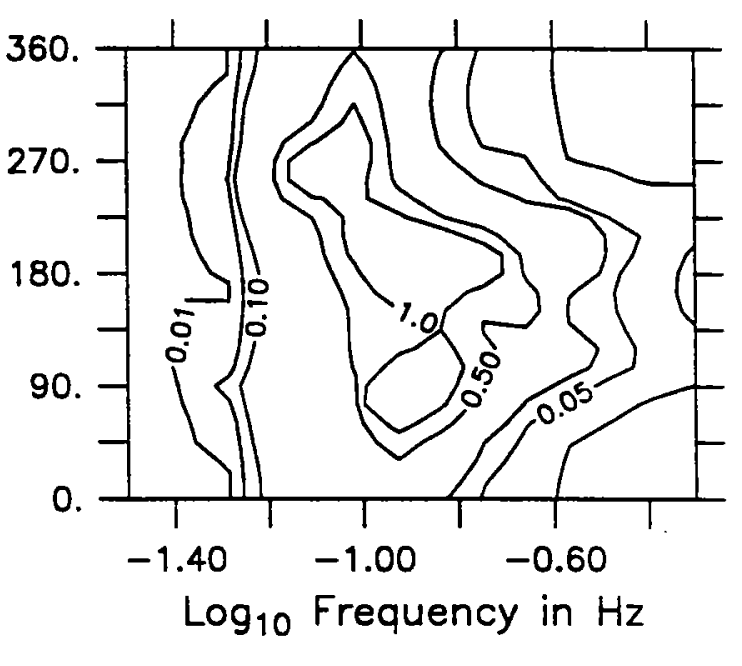

November 3,1991 $18 Z$

Figure 3.4.7: Directional wave spectra, Seatex buoy. Contours are 0.01, 0.05, $0.1,0.5,1,5,10,50,100,500$. 


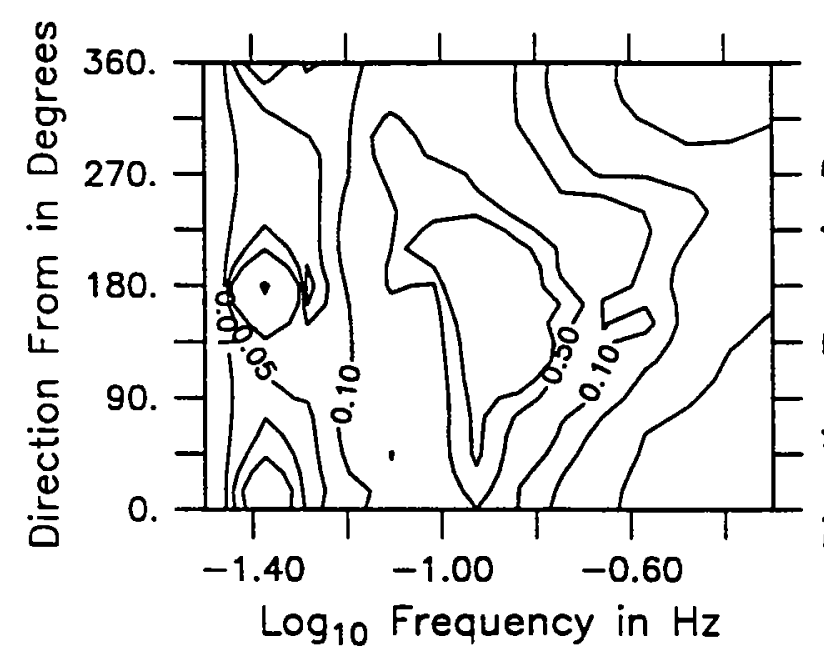

November 4,1991 OOZ

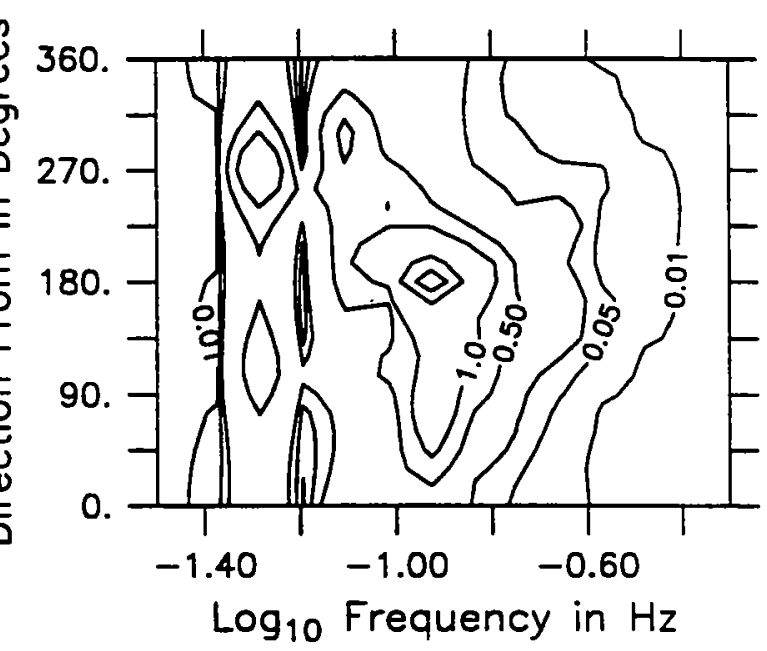

November 4,1991 O6Z

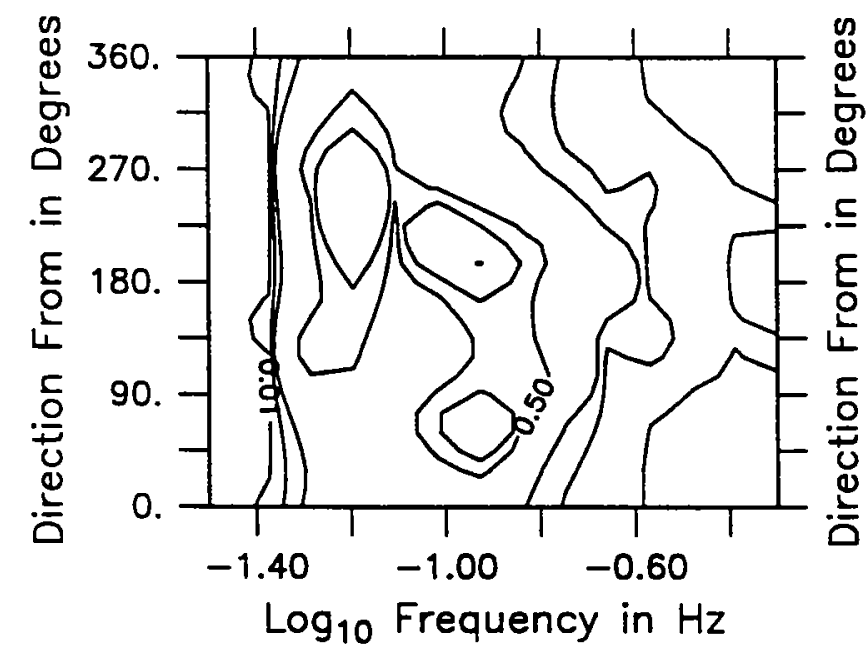

November 4,1991 $12 Z$

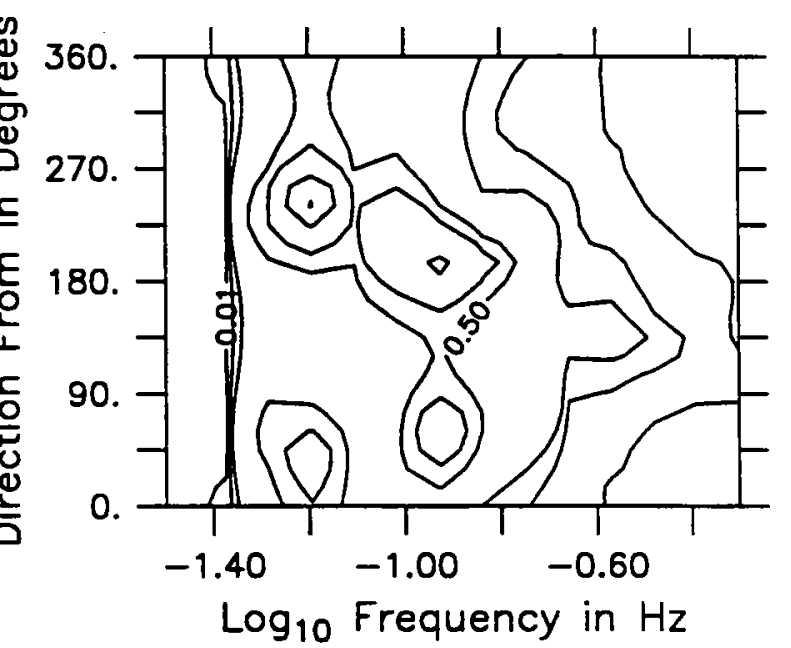

November 4,1991 $18 Z$

Figure 3.4.8: Directional wave spectra, Seatex buoy. Contours are 0.01, 0.05, $0.1,0.5,1,5,10,50,100,500$. 


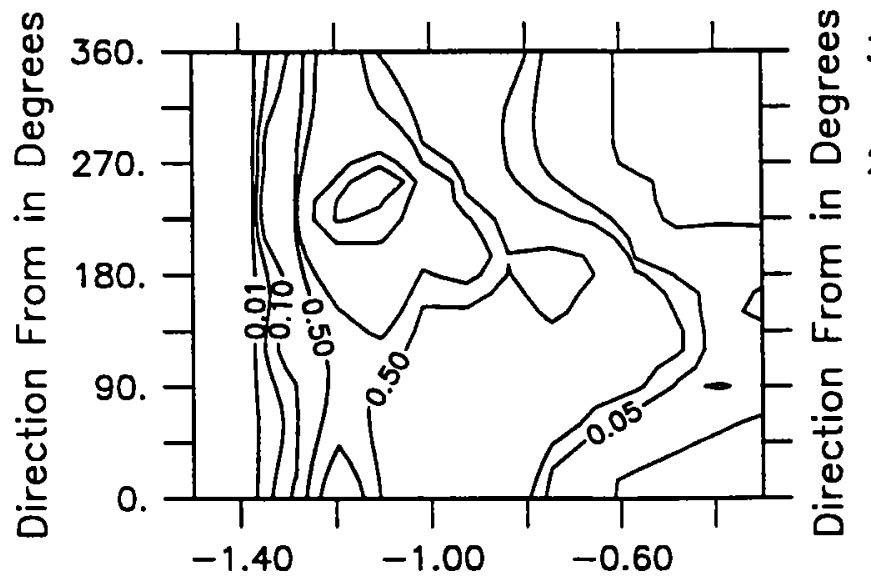

$\log _{10}$ Frequency in $\mathrm{Hz}$

November 5,1991 OOZ

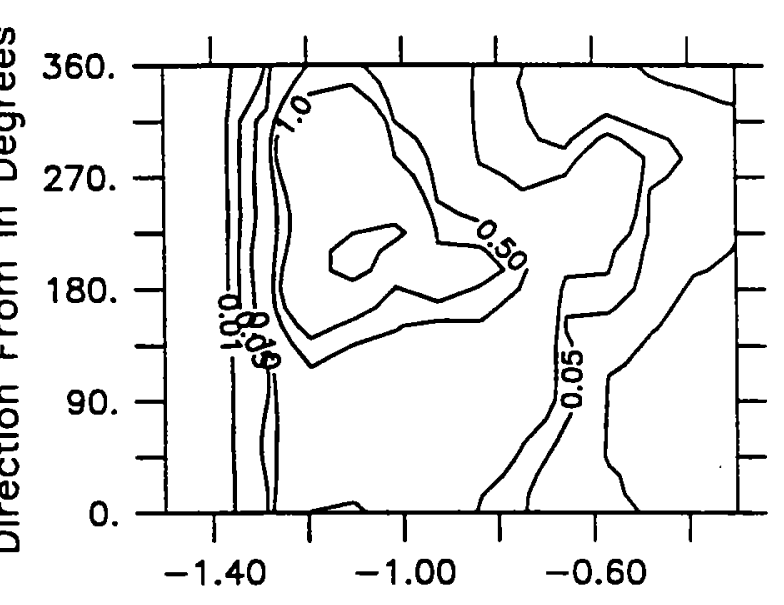

$\log _{10}$ Frequency in $\mathrm{Hz}$

November 5,1991 O6Z

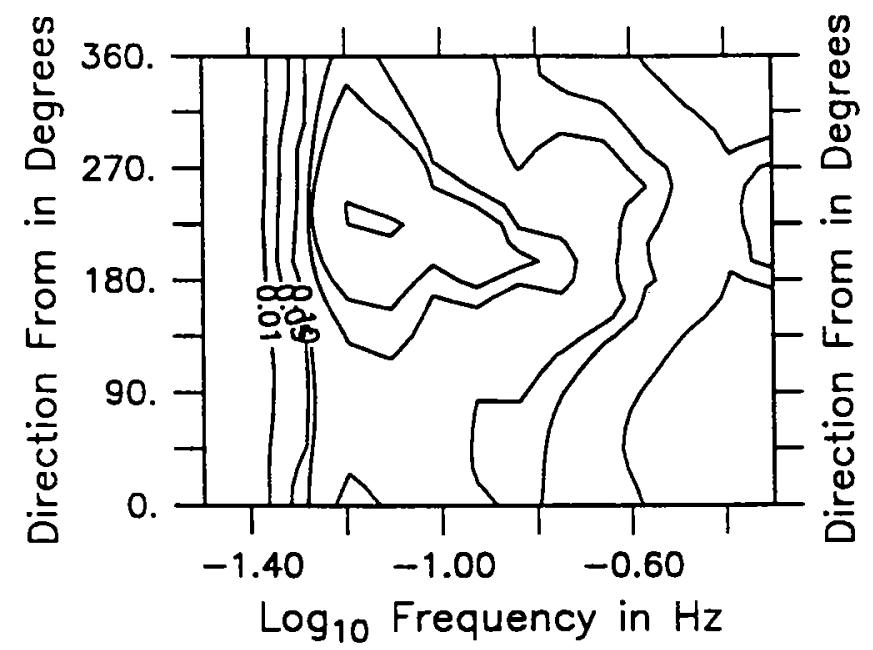

November 5,1991 $12 Z$

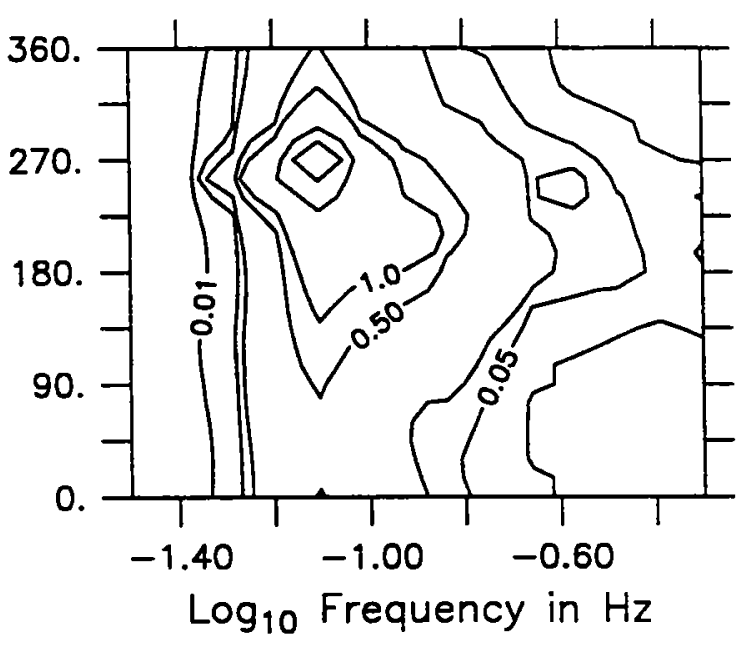

November 5,1991 $18 Z$

Figure 3.4.9: Directional wave spectra, Seatex buoy. Contours are 0.01, 0.05, $0.1,0.5,1,5,10,50,100,500$. 


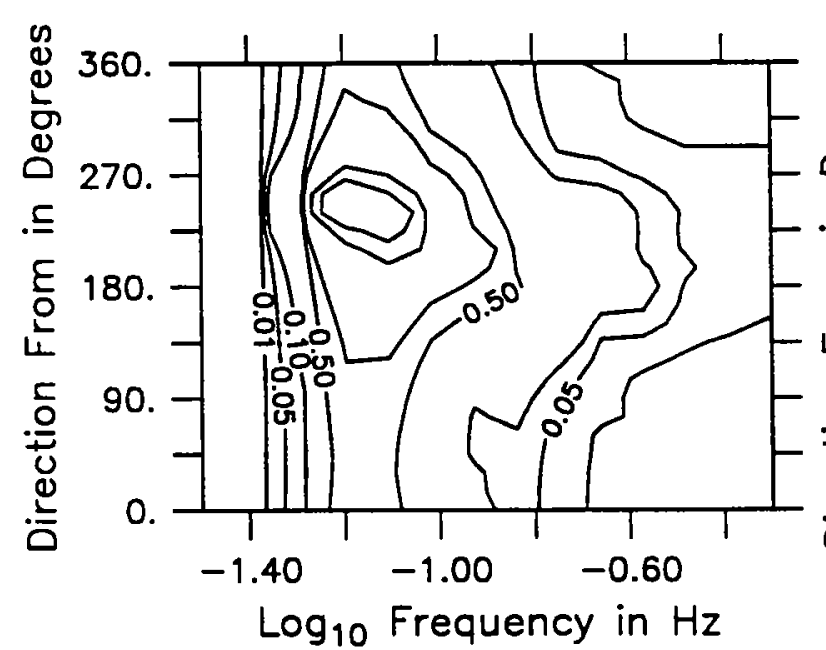

November 6,1991 OOZ

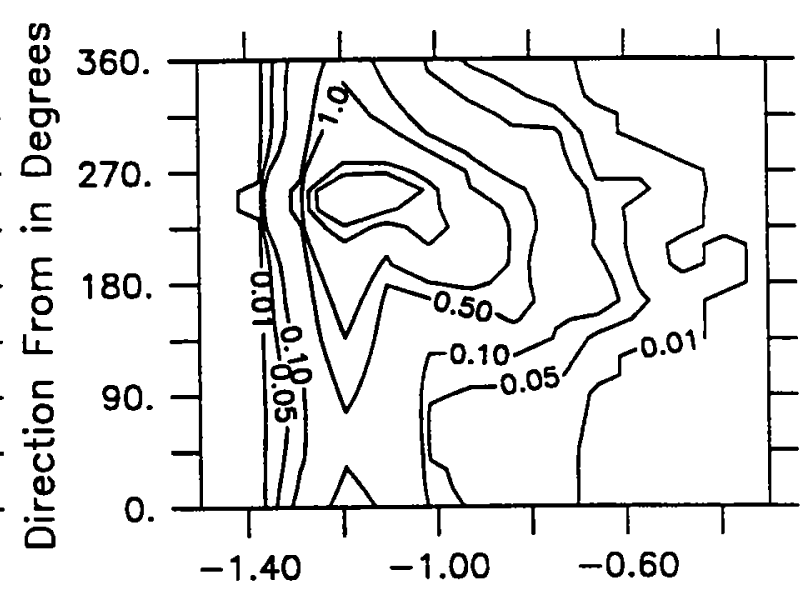

$\log _{10}$ Frequency in $\mathrm{Hz}$

November 6,1991 O6Z

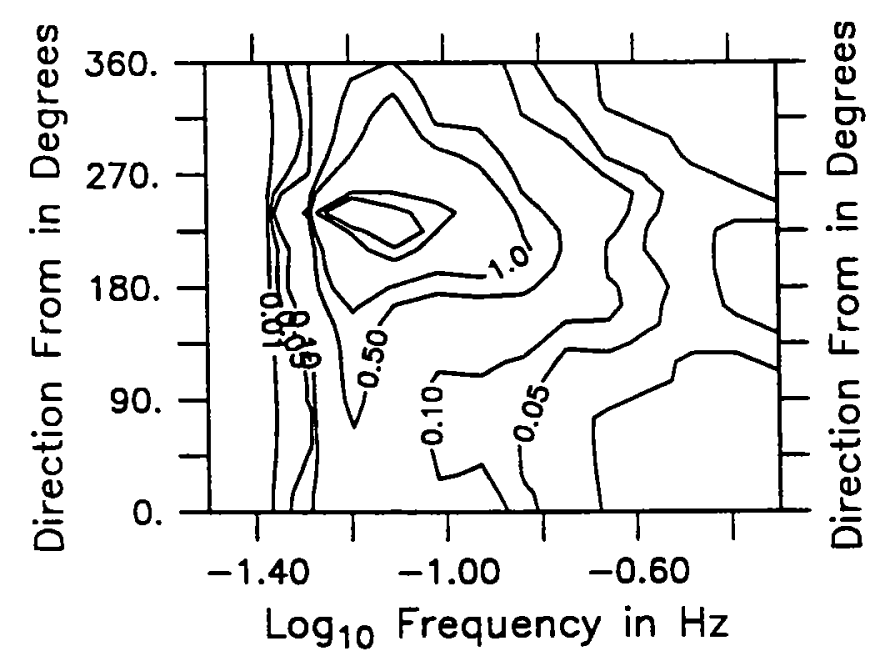

November 6,1991 $12 Z$

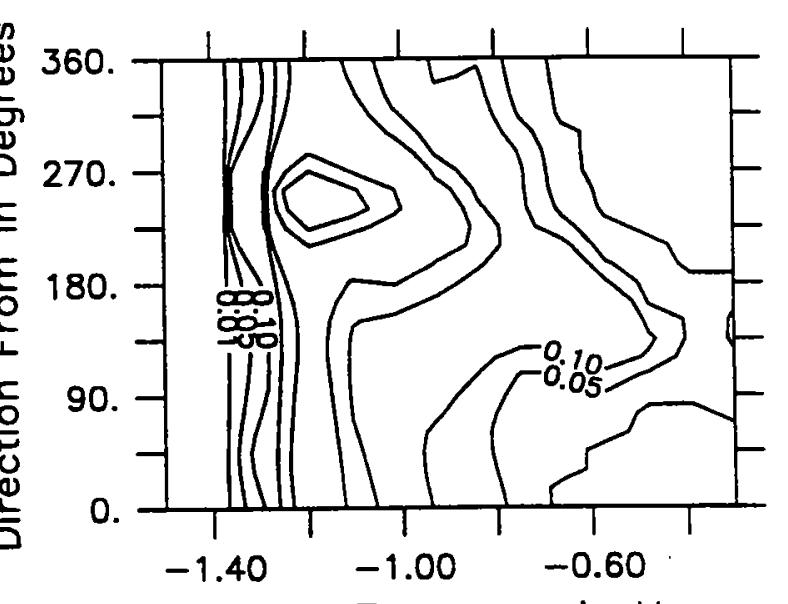

$\log _{10}$ Frequency in $\mathrm{Hz}$

November 6,1991 $18 Z$

Figure 3.4.10: Directional wave spectra, Seatex buoy. Contours are 0.01, $0.05,0.1,0.5,1,5,10,50,100,500$. 


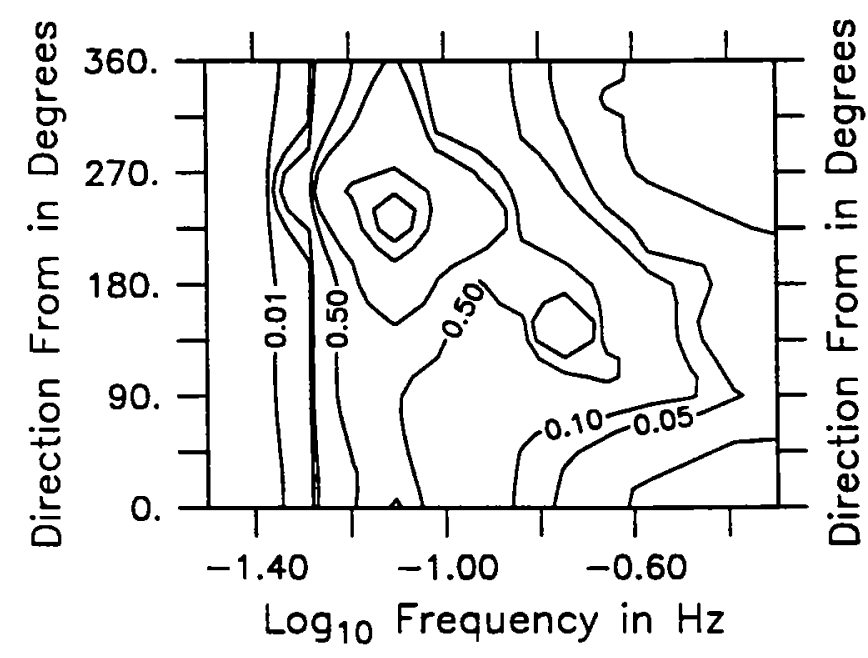

November 7,1991 OOZ

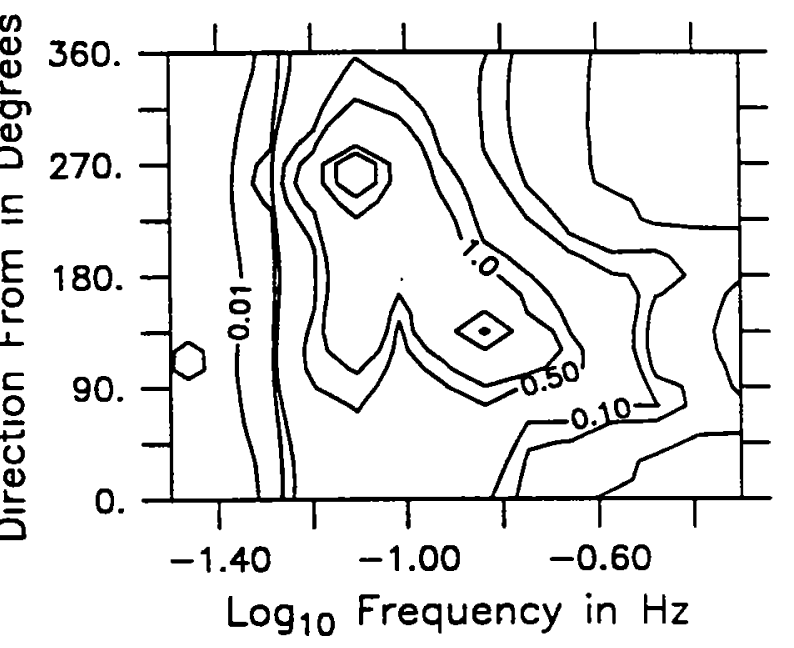

November 7,1991 $06 Z$

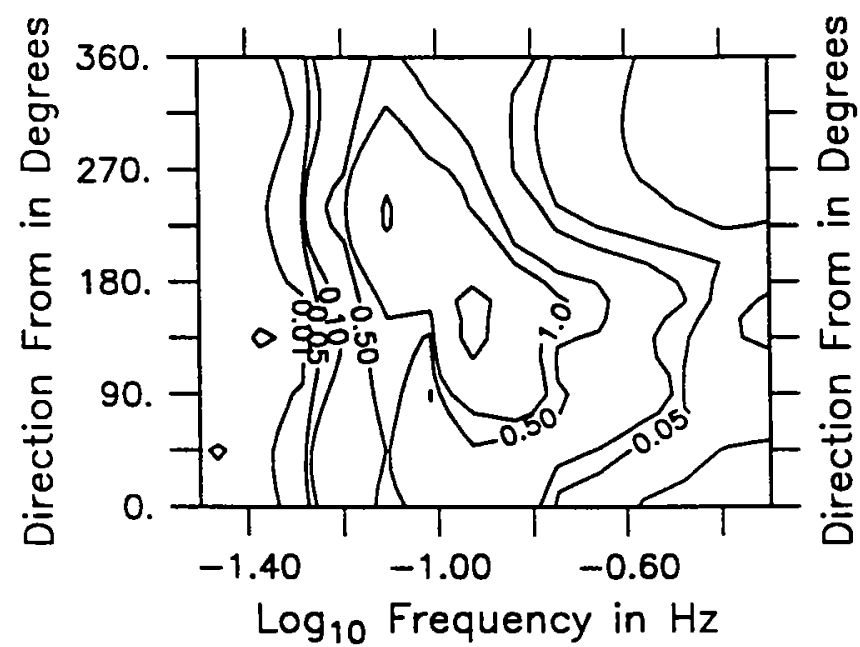

November 7,1991 $12 \mathrm{Z}$

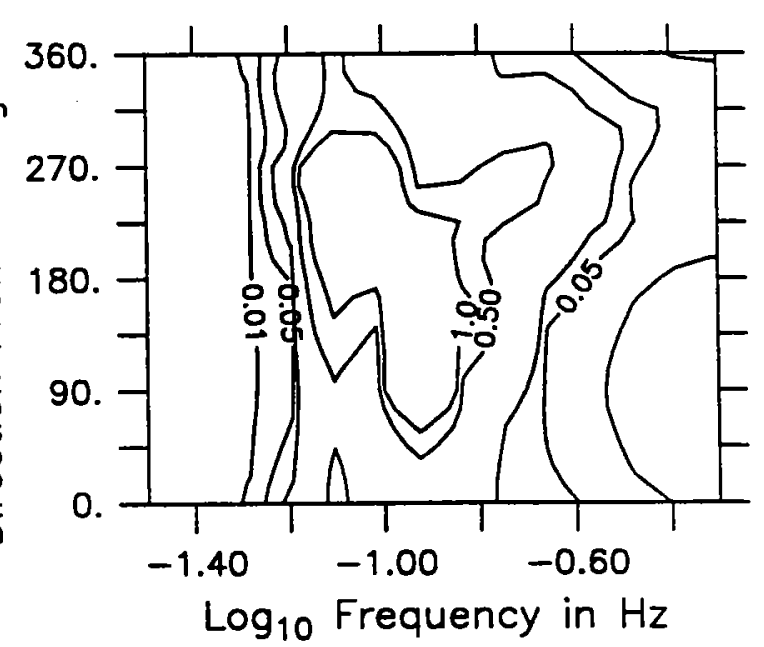

November $7,199118 Z$

Figure 3.4.11: Directional wave spectra, Seatex buoy. Contours are 0.01, $0.05,0.1,0.5,1,5,10,50,100,500$. 


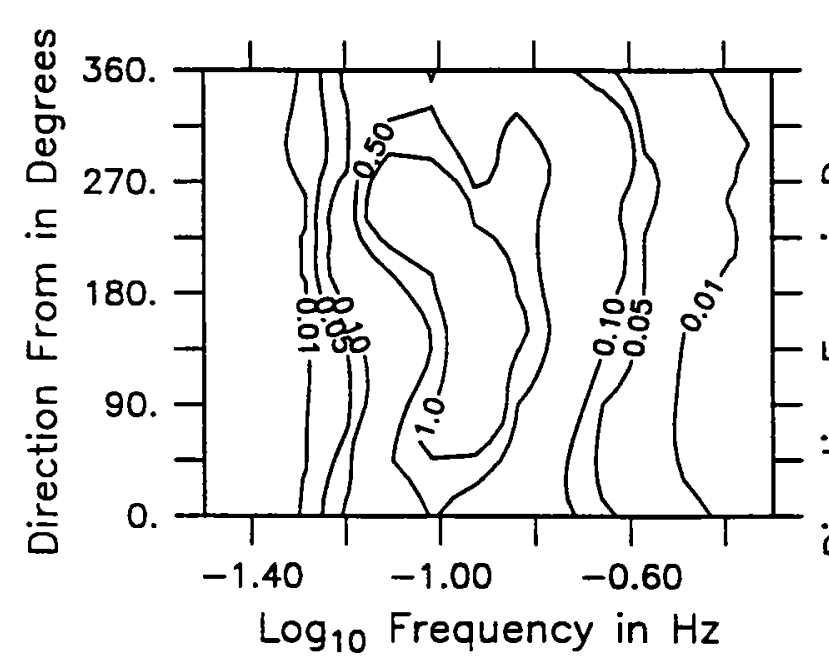

November 8,1991 00Z

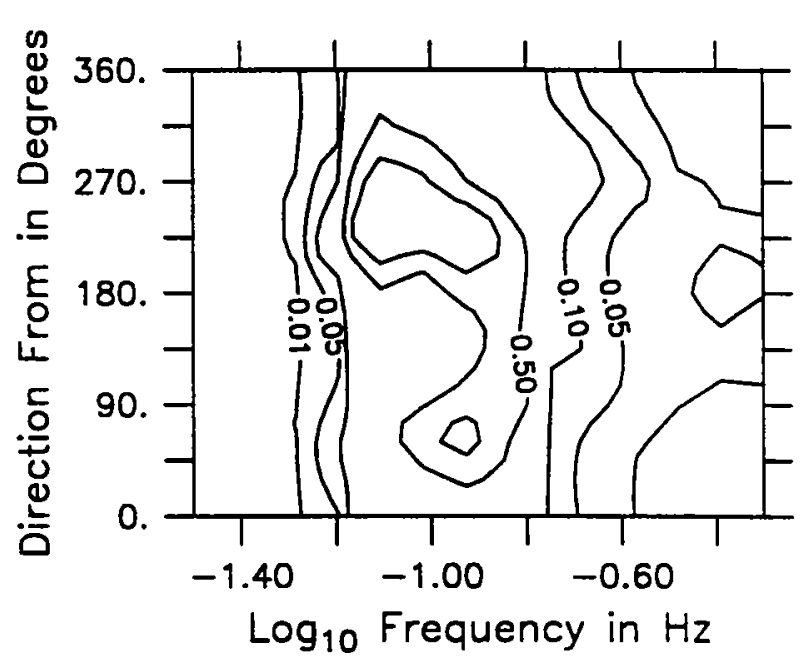

November 8,1991 O6Z

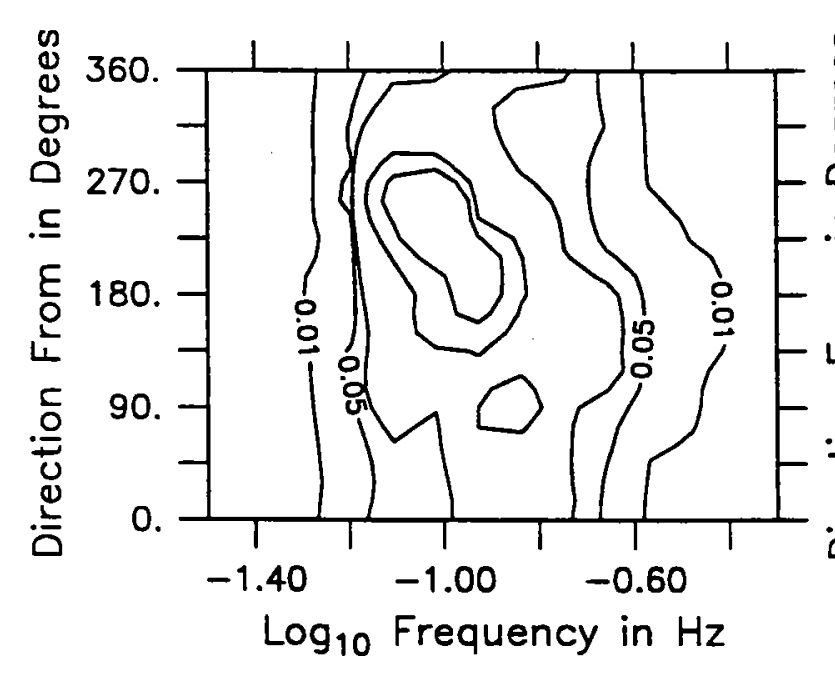

November $8,199112 Z$

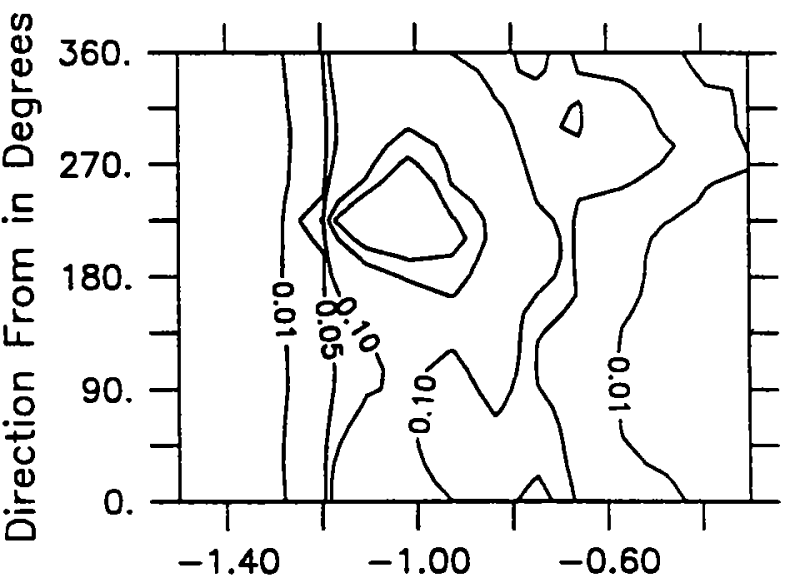

$\log _{10}$ Frequency in $\mathrm{Hz}$

November 8,1991 $18 Z$

Figure 3.4.12: Directional wave spectra, Seatex buoy. Contours are 0.01, $0.05,0.1,0.5,1,5,10,50,100,500$. 


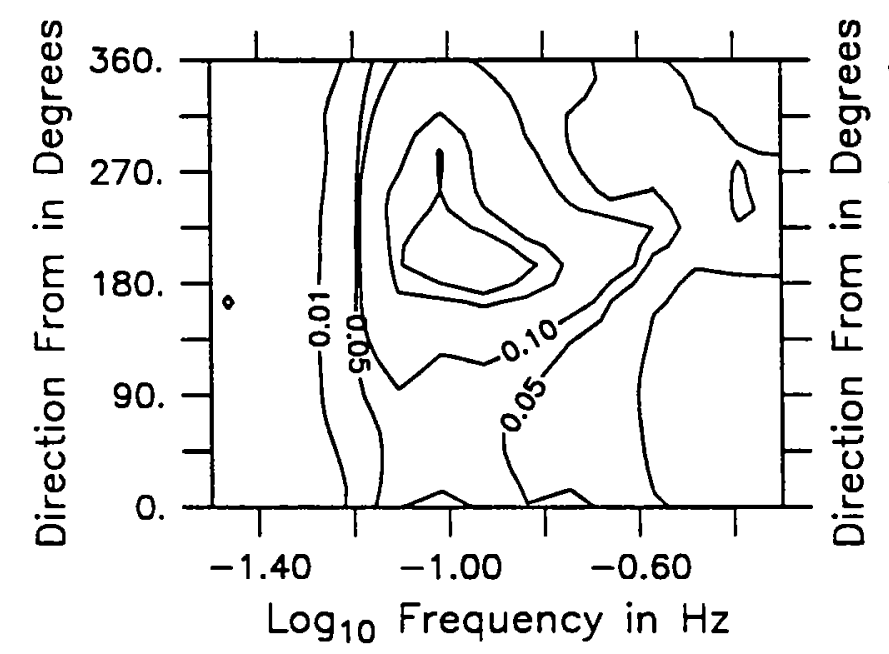

November 9,1991 00Z

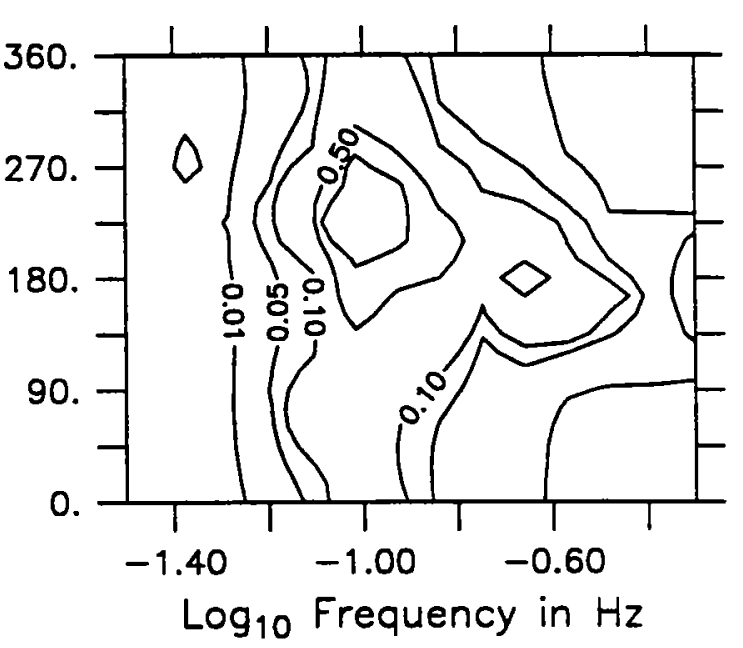

November 9,1991 06Z

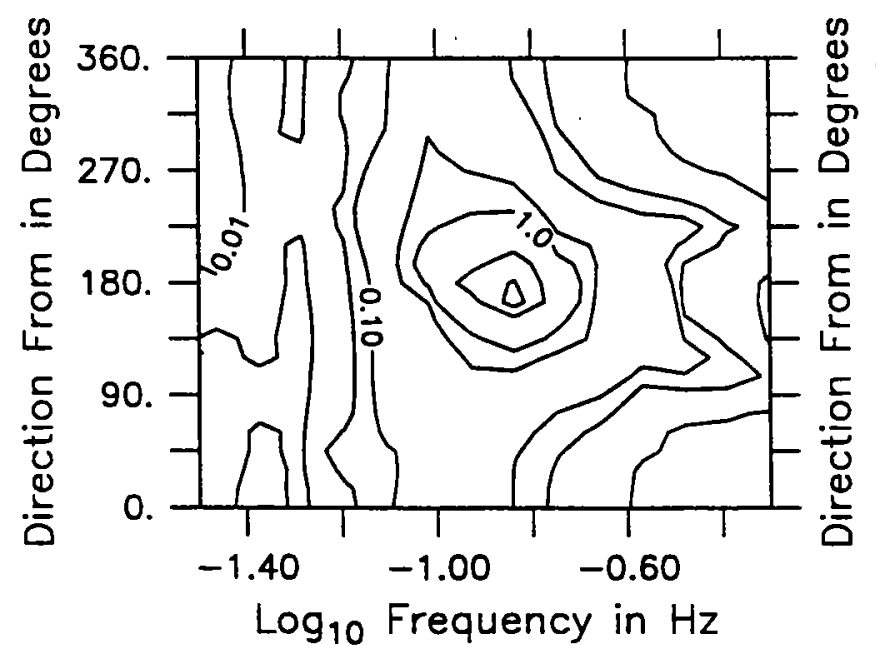

November 9,1991 $12 Z$

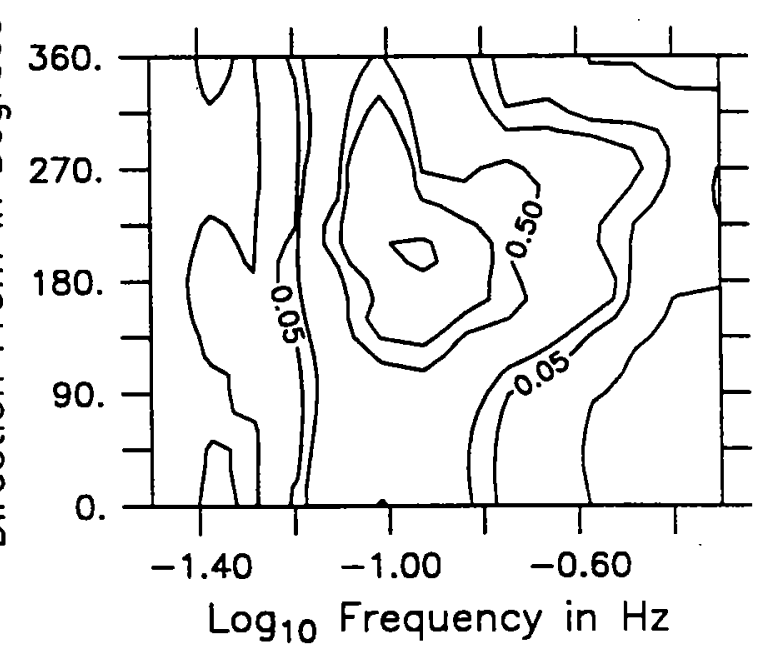

November $9,199118 Z$

Figure 3.4.13: Directional wave spectra, Seatex buoy. Contours are 0.01, $0.05,0.1,0.5,1,5,10,50,100,500$. 

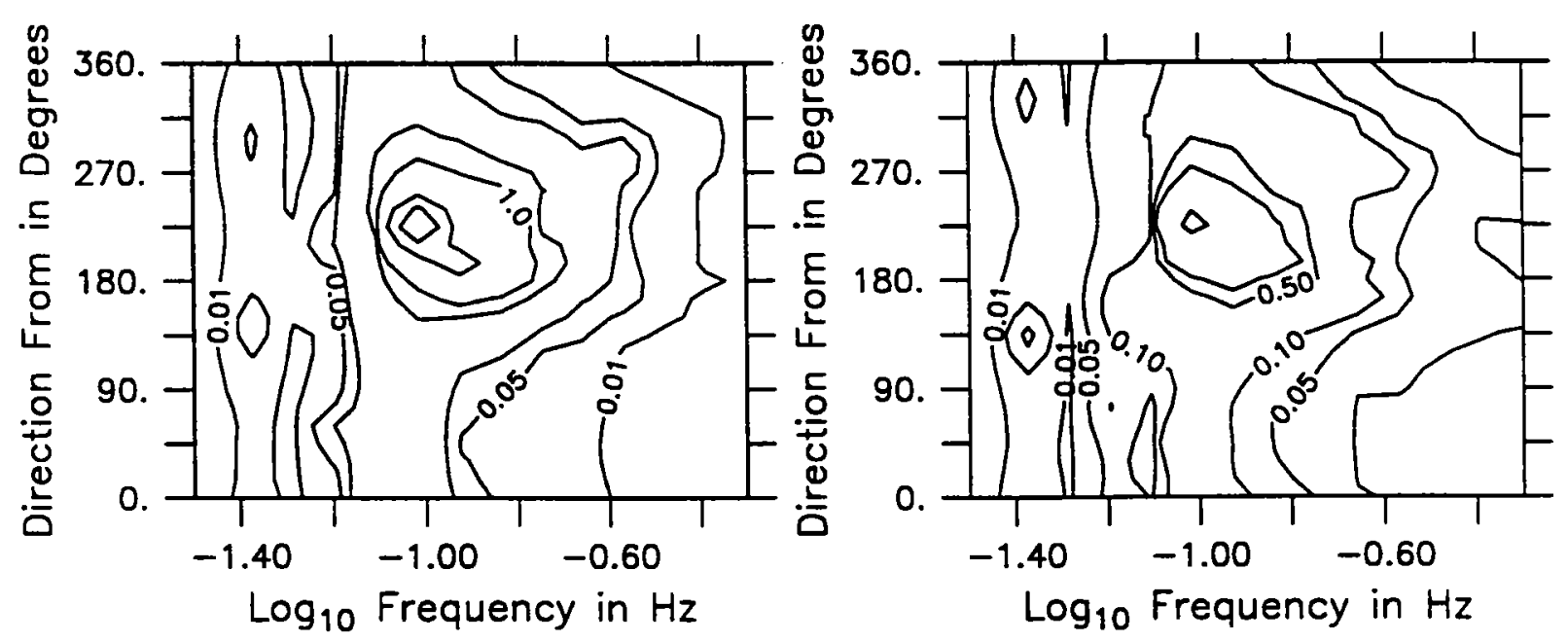

November 10,1991 $00 \mathrm{Z}$

November 10,1991 O6Z

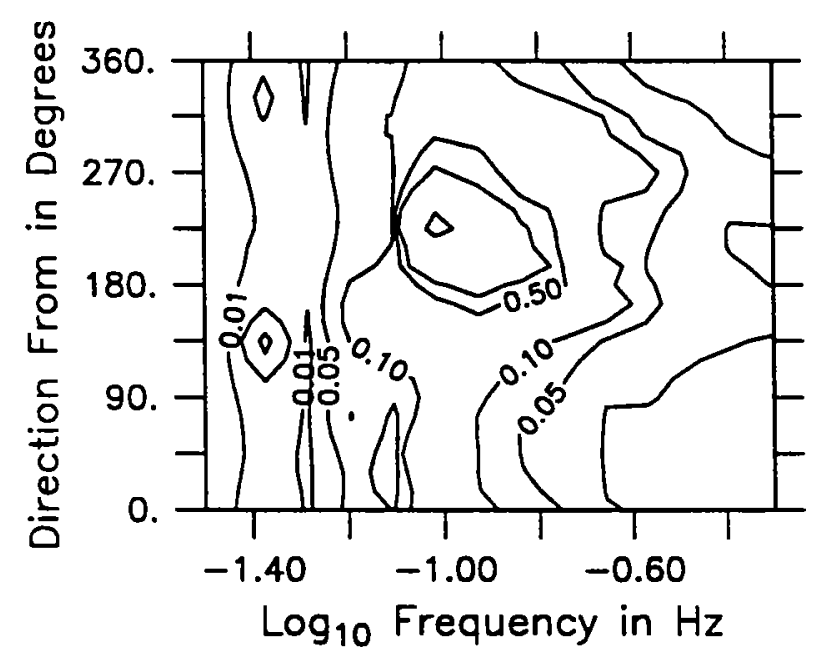

November 10,1991 $15 Z$

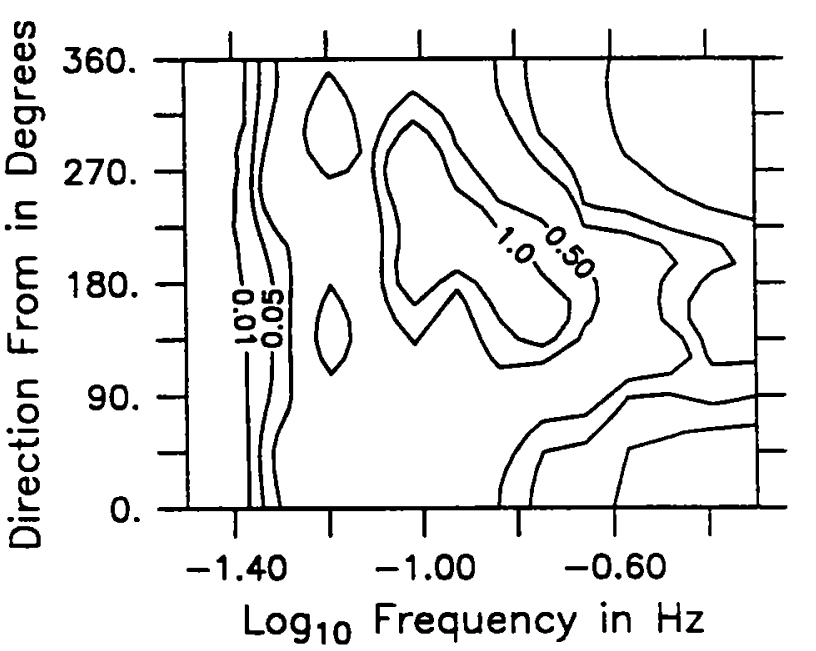

November 10,1991 $18 Z$

Figure 3.4.14: Directional wave spectra, Seatex buoy. Contours are 0.01, $0.05,0.1,0.5,1,5,10,50,100,500$. 


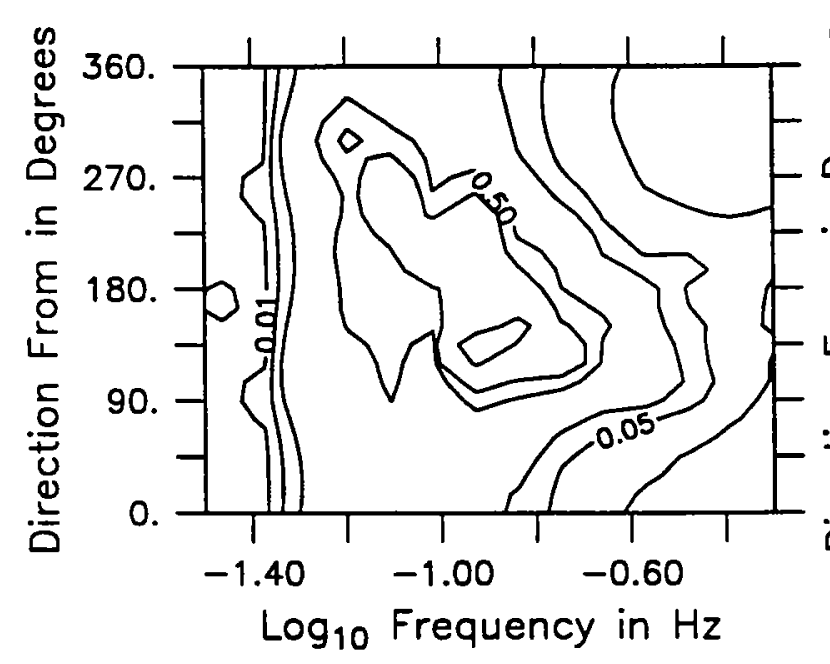

November 11,1991 $00 \mathrm{Z}$

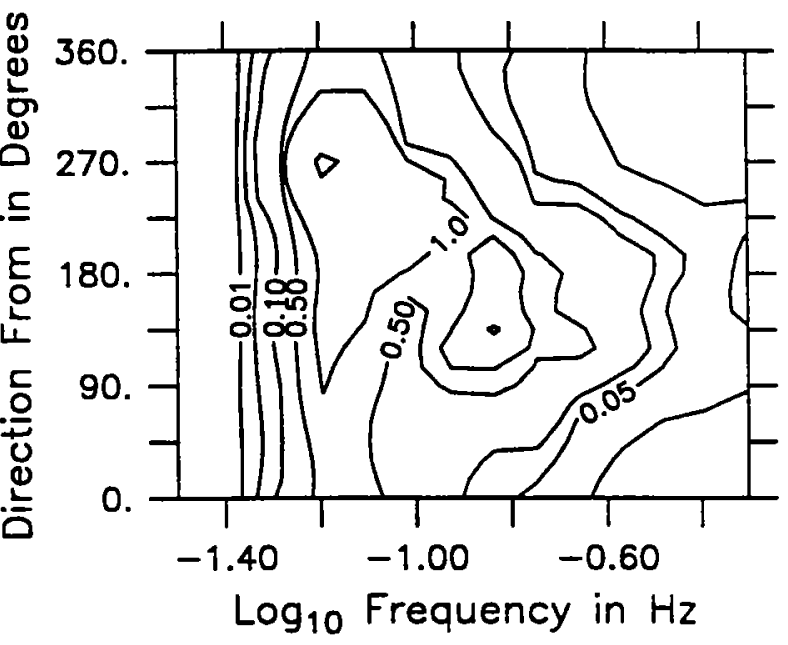

November 11,1991 $06 Z$

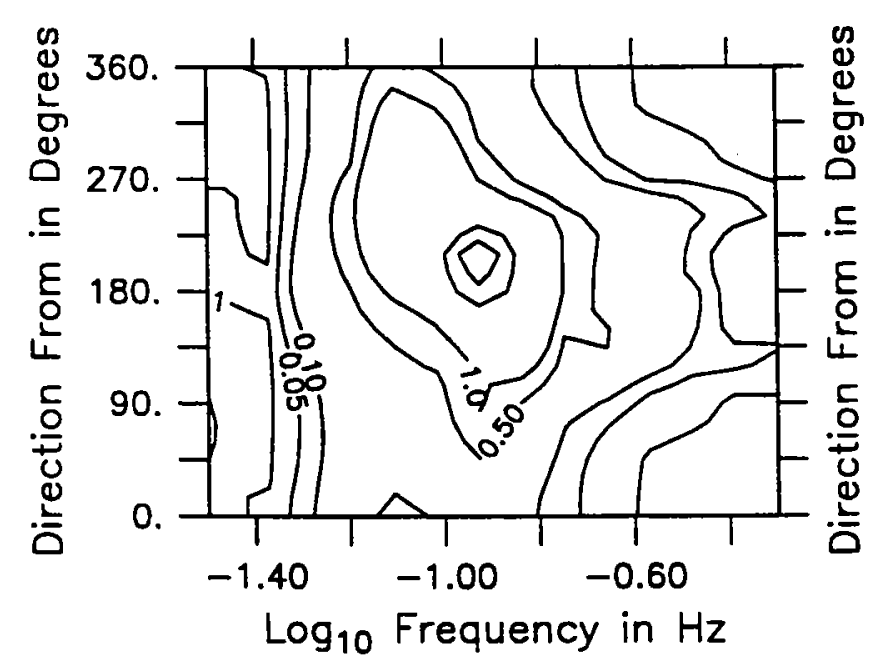

November $11,199112 Z$

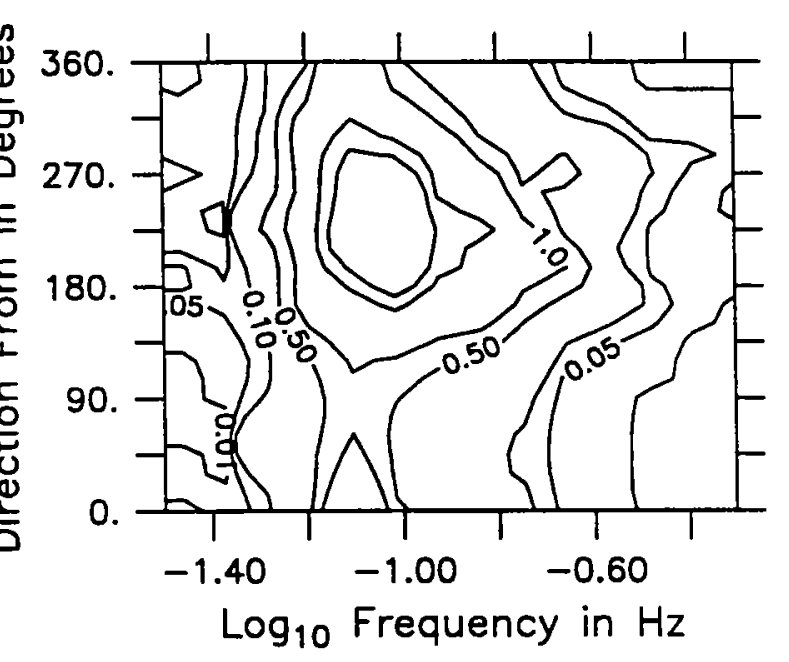

November 11,1991 $18 Z$

Figure 3.4.15: Directional wave spectra, Seatex buoy. Contours are 0.01, $0.05,0.1,0.5,1,5,10,50,100,500$. 


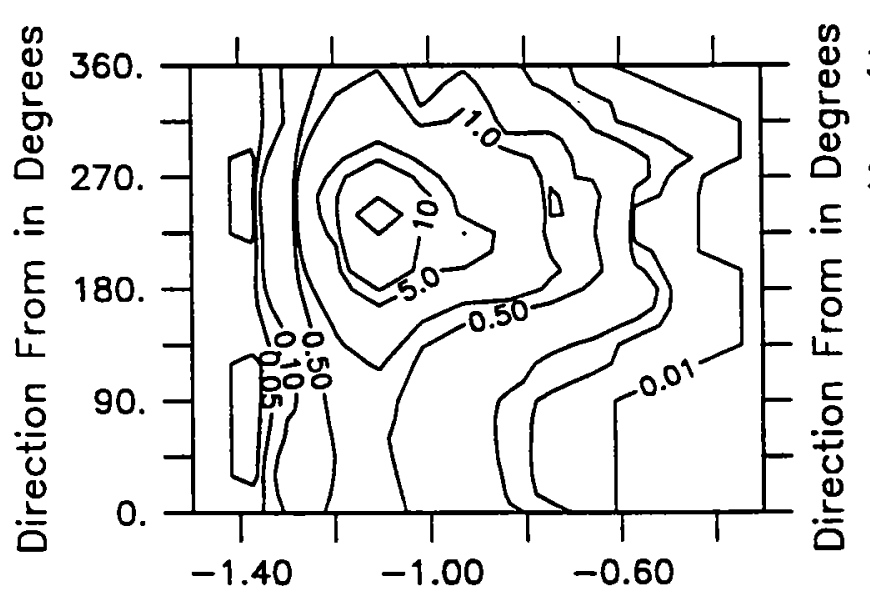

$\log _{10}$ Frequency in $\mathrm{Hz}$

November 12,1991 OOZ

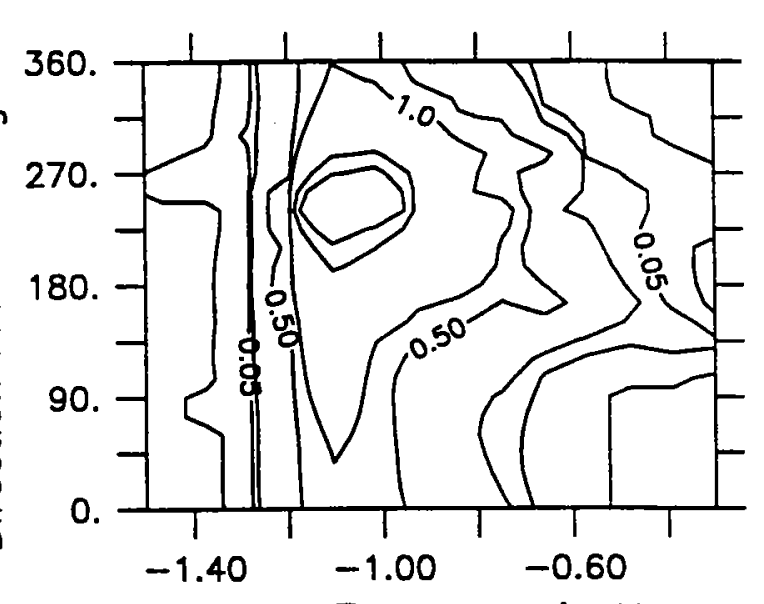

$\log _{10}$ Frequency in $\mathrm{Hz}$

November 12,1991 O6Z

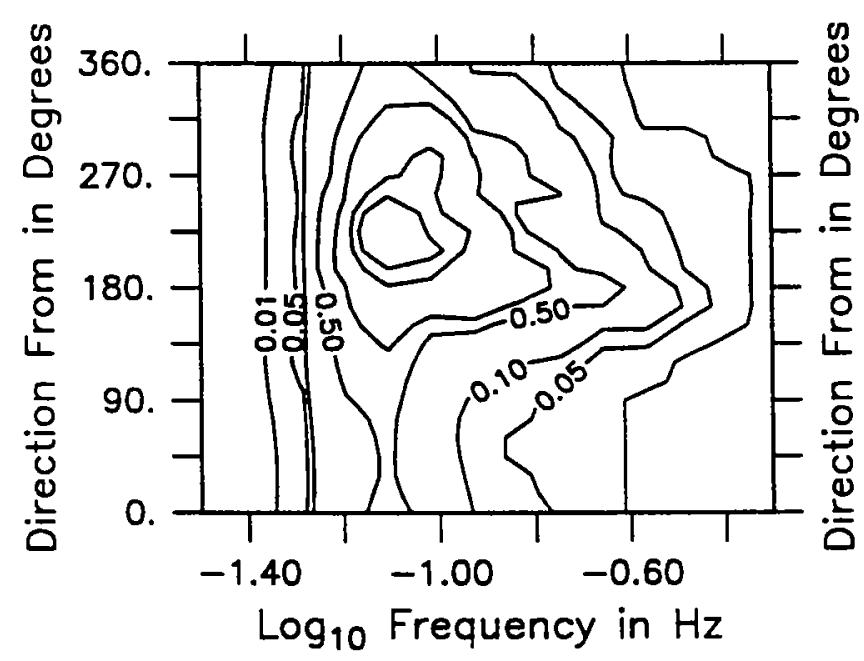

November $12,199112 Z$

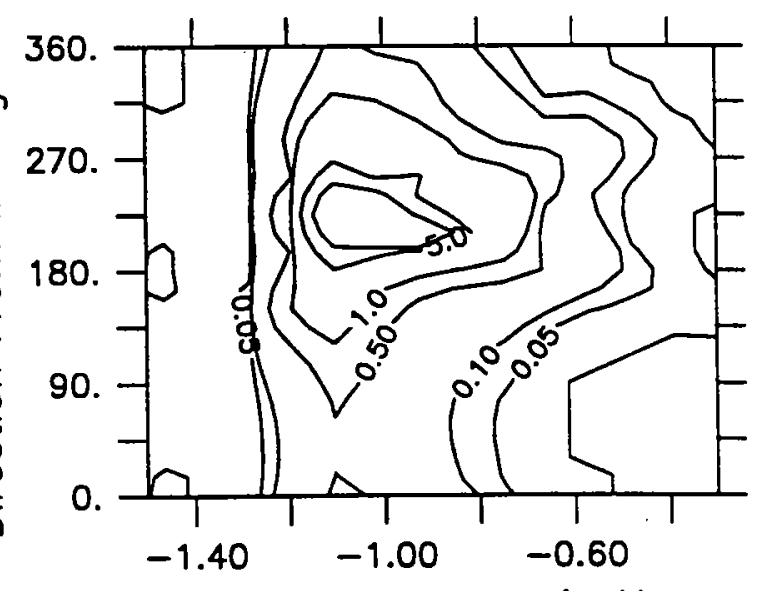

$\log _{10}$ Frequency in $\mathrm{Hz}$

November 12,1991 $18 Z$

Figure 3.4.16: Directional wave spectra, Seatex buoy. Contours are 0.01, $0.05,0.1,0.5,1,5,10,50,100,500$. 


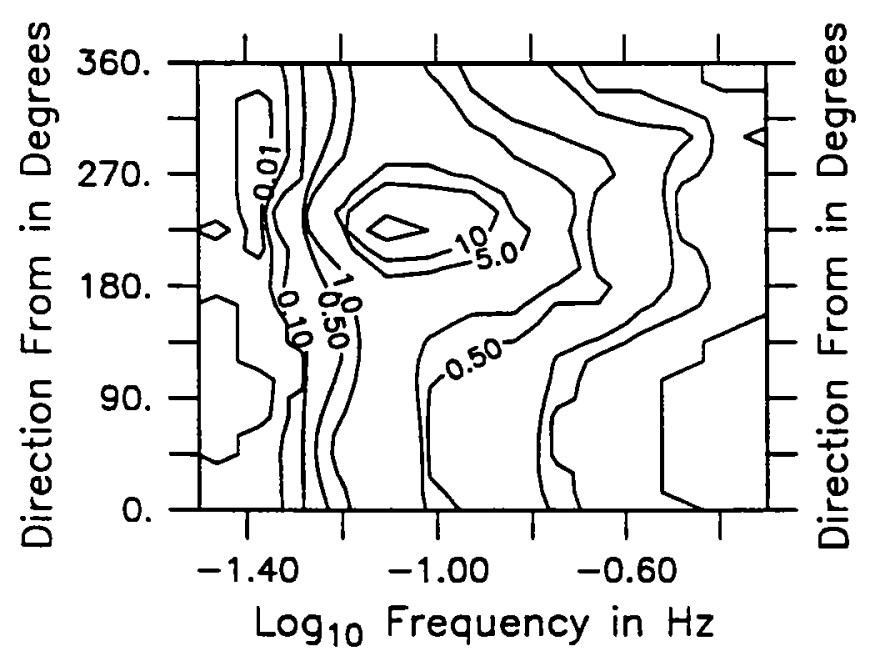

November 13,1991 00Z

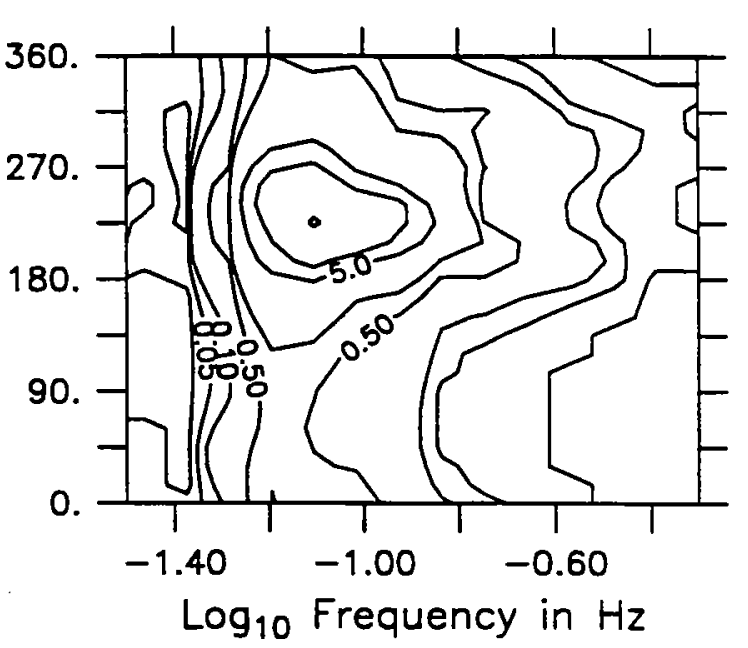

November 13,1991 O6Z

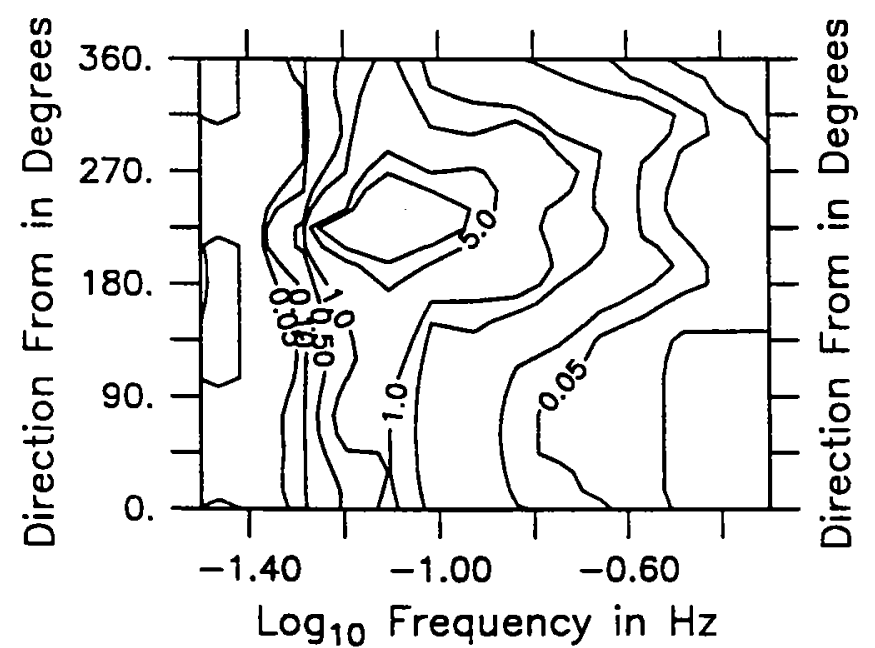

November 13,1991 $12 Z$

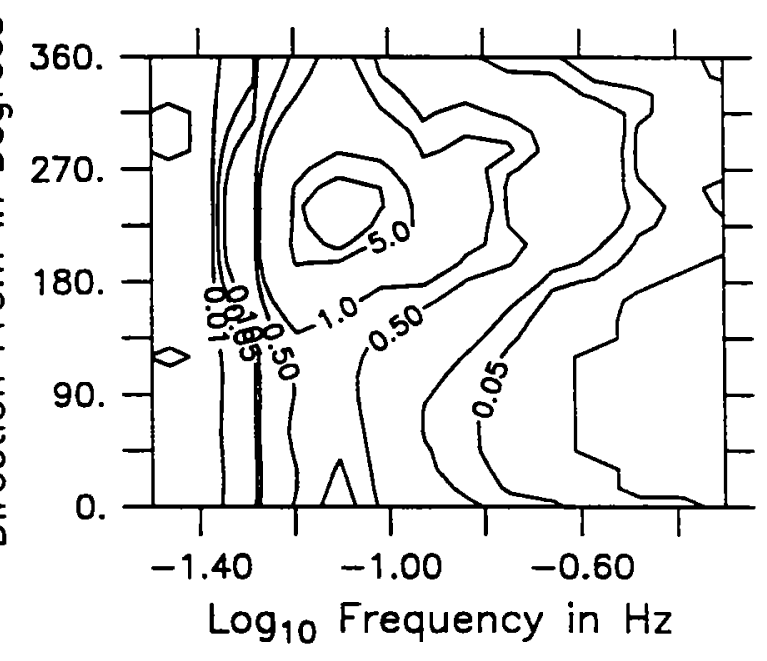

November 13,1991 $18 Z$

Figure 3.4.17: Directional wave spectra, Seatex buoy. Contours are 0.01, $0.05,0.1,0.5,1,5,10,50,100,500$. 


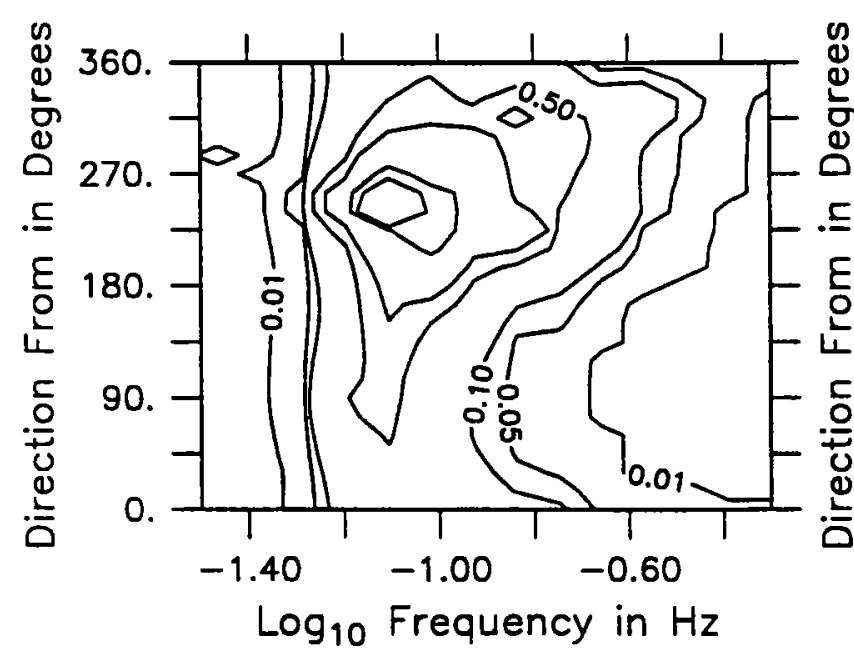

November 14,1991 OOZ

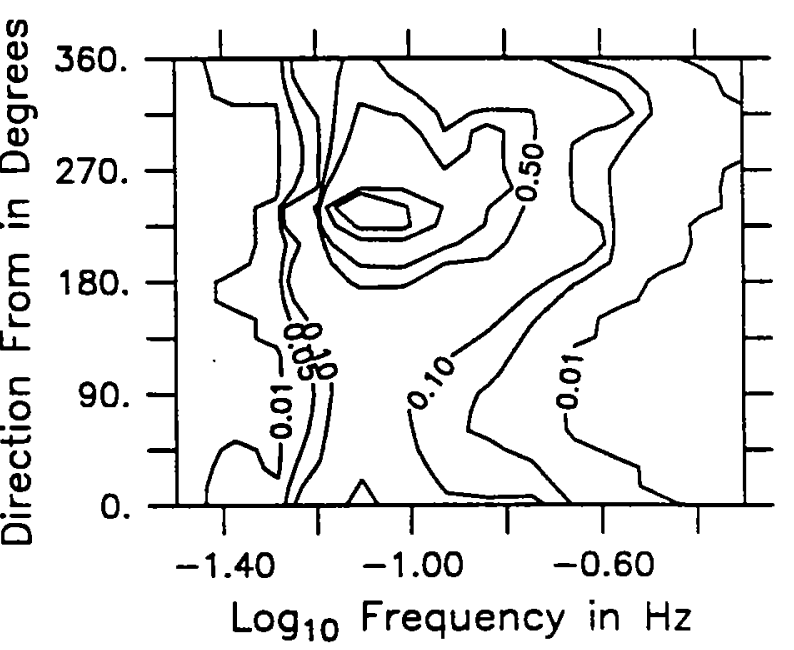

November 14,1991 O6Z

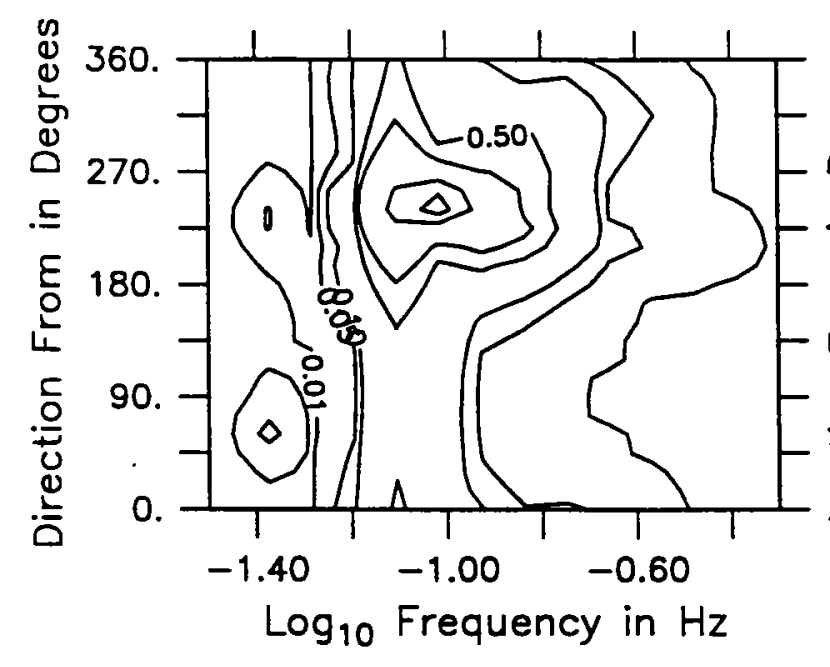

November 14,1991 $12 Z$

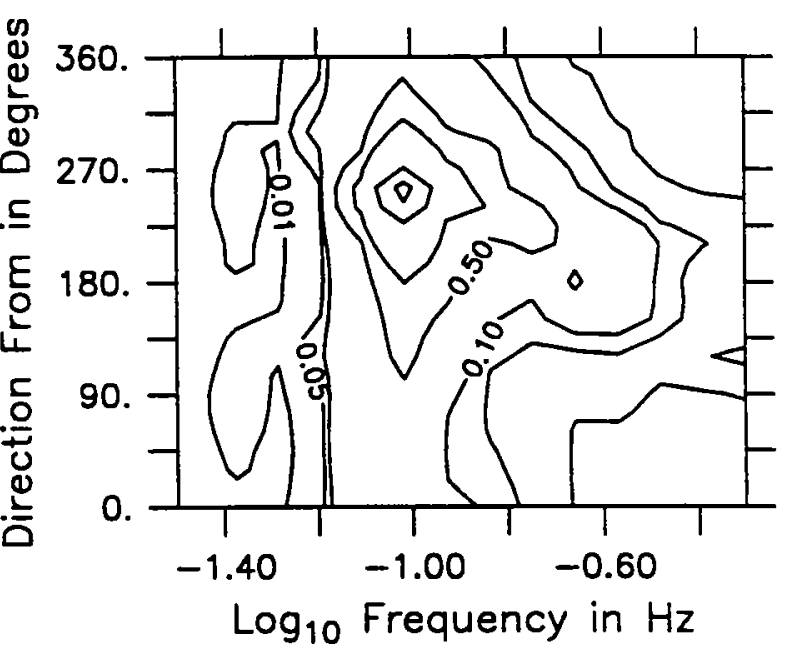

November 14,1991 $18 Z$

Figure 3.4.18: Directional wave spectra, Seatex buoy. Contours are 0.01, $0.05,0.1,0.5,1,5,10,50,100,500$. 


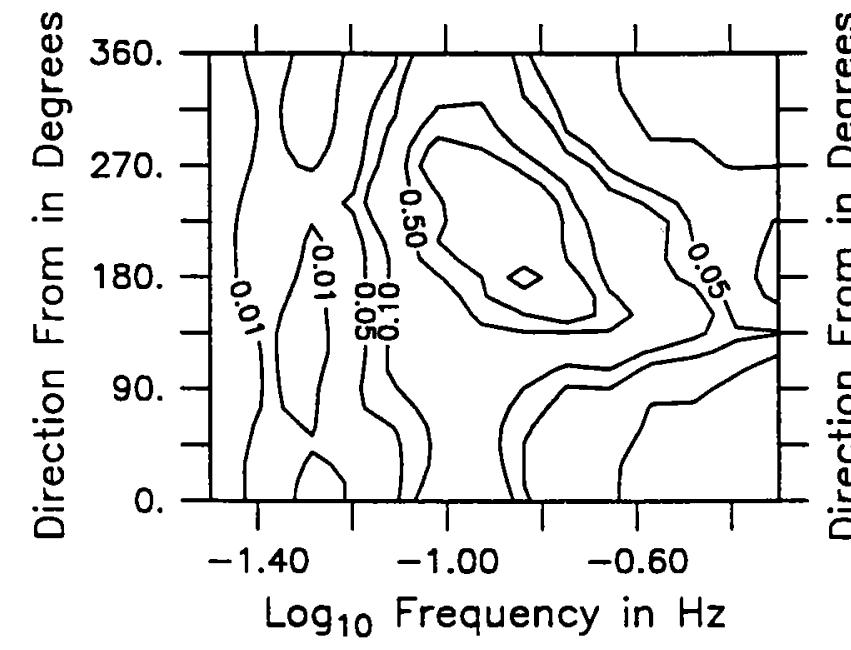

November 15,1991 00Z

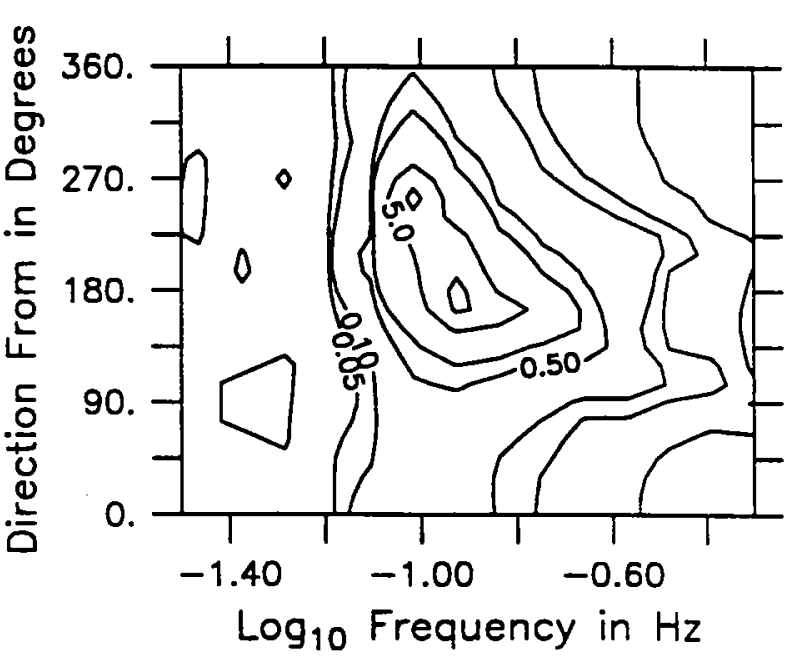

November 15,1991 O6Z

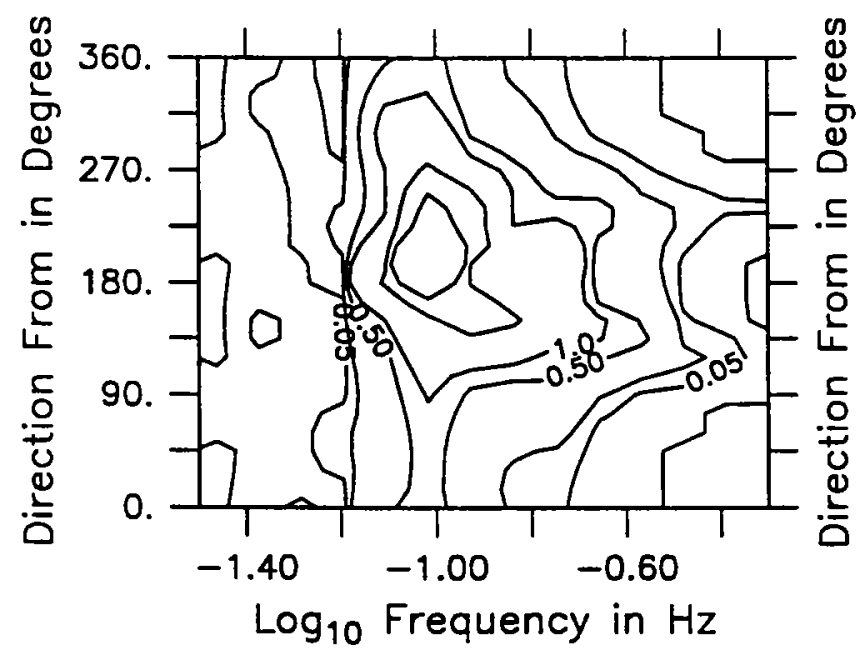

November $15,199112 Z$

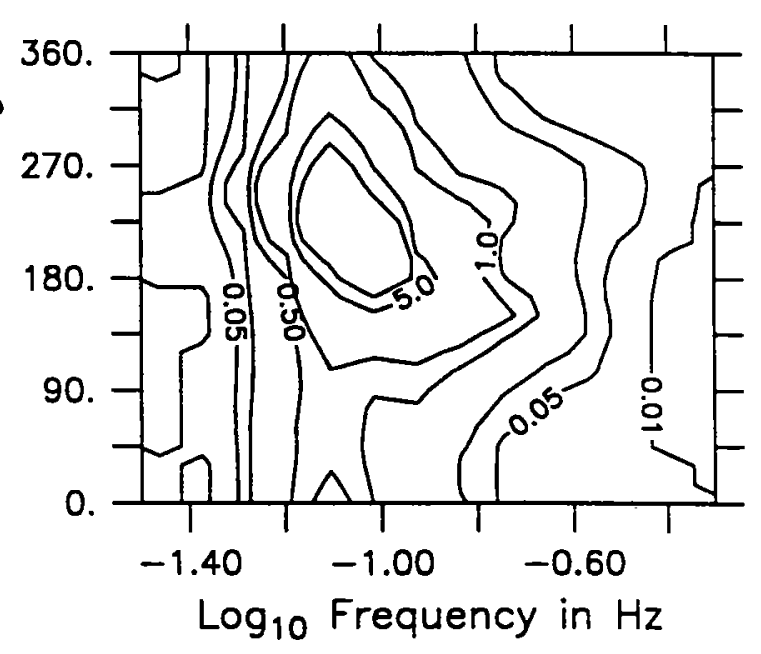

November 15,1991 $18 Z$

Figure 3.4.19: Directional wave spectra, Seatex buoy. Contours are 0.01, $0.05,0.1,0.5,1,5,10,50,100,500$. 


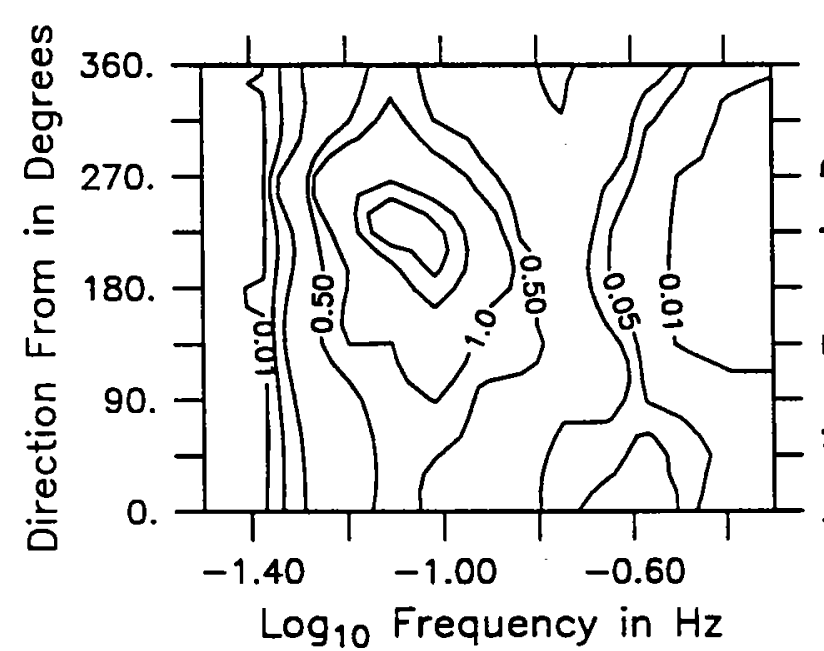

November 16,1991 00Z

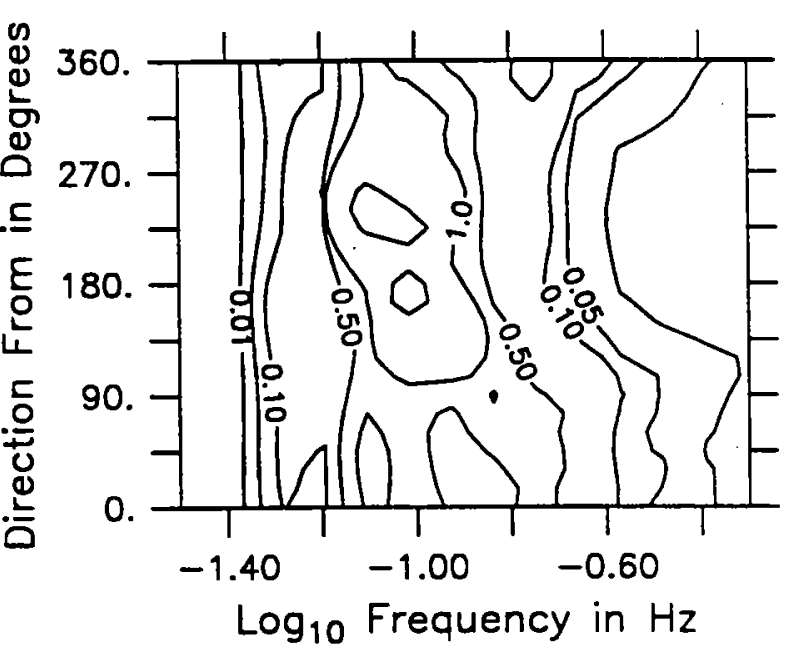

November 16,1991 06Z

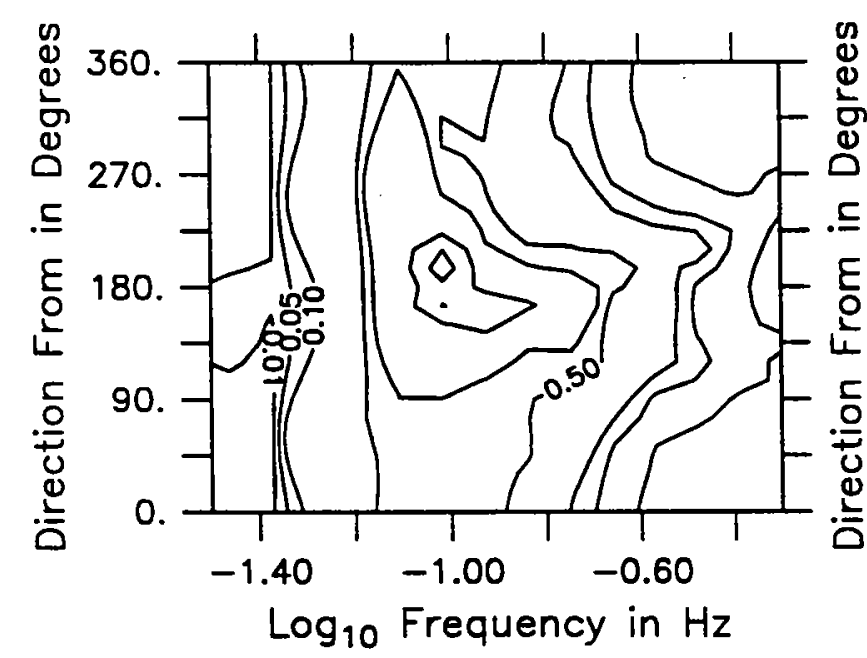

November 16,1991 $12 Z$

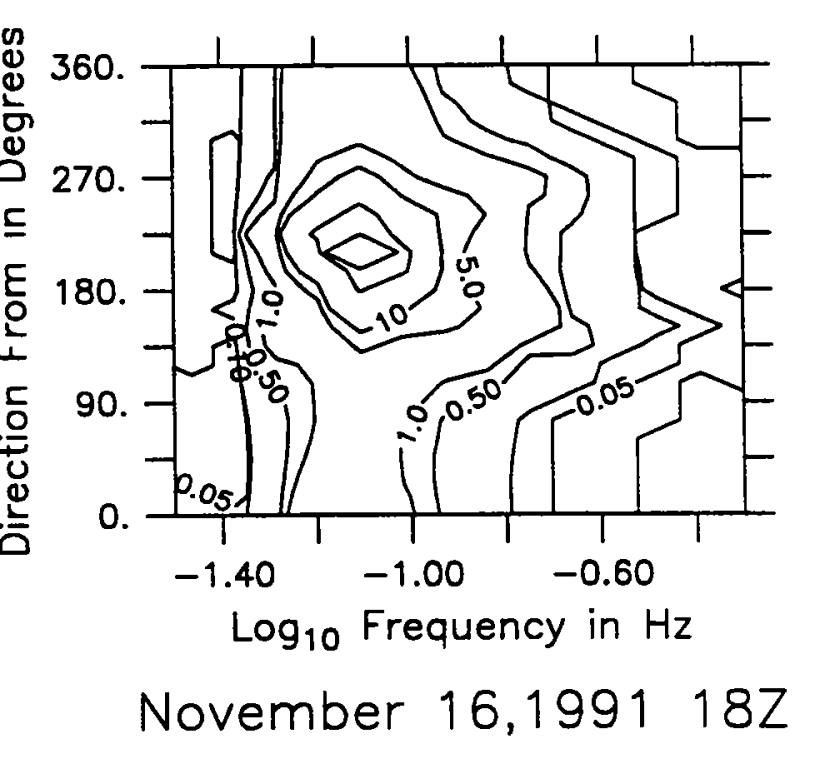

Figure 3.4.20: Directional wave spectra, Seatex buoy. Contours are 0.01, $0.05,0.1,0.5,1,5,10,50,100,500$. 


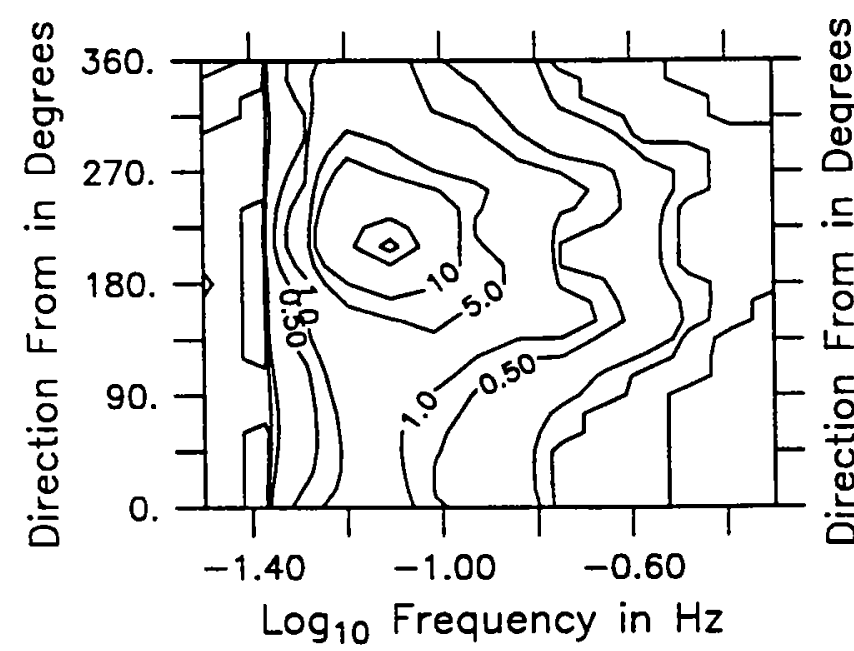

November 17,1991 00Z

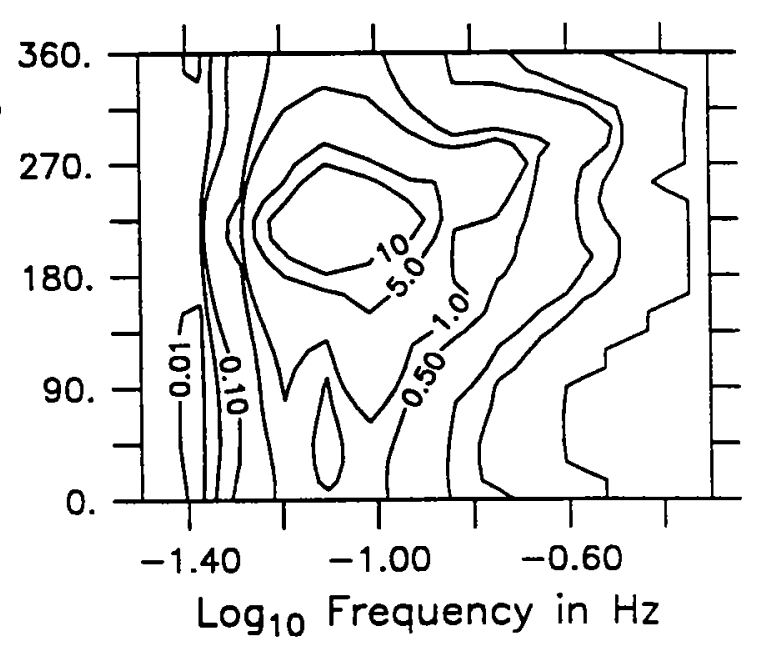

November 17,1991 06Z

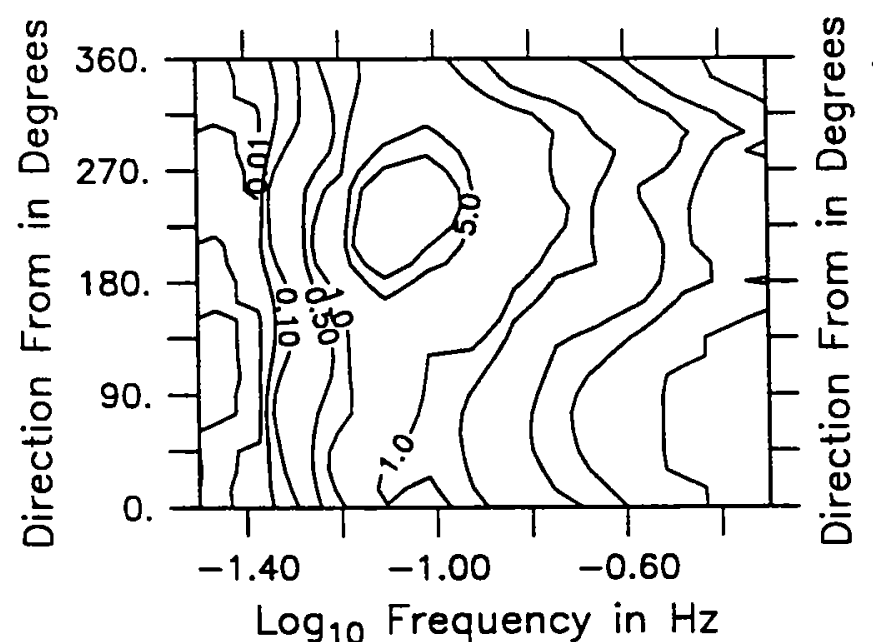

November 17,1991 $12 Z$

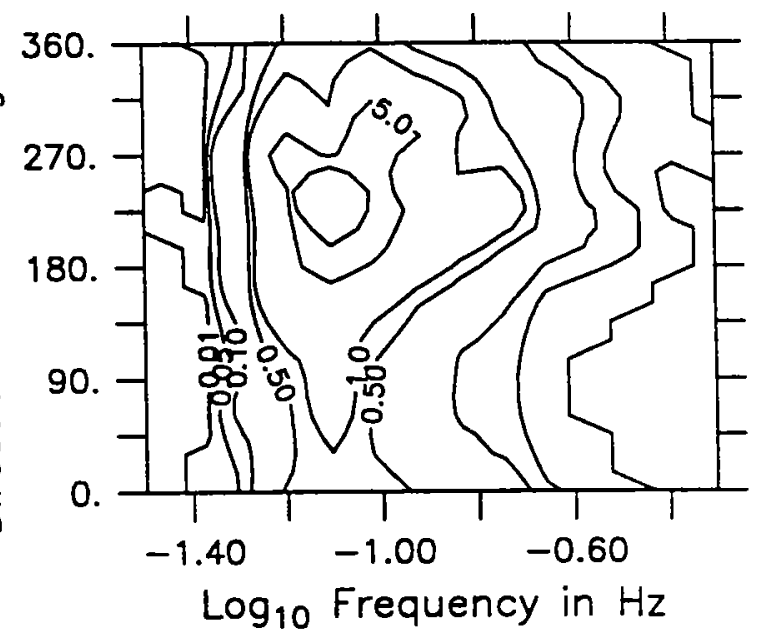

November 17,1991 $18 Z$

Figure 3.4.21: Directional wave spectra, Seatex buoy. Contours are 0.01, $0.05,0.1,0.5,1,5,10,50,100,500$. 


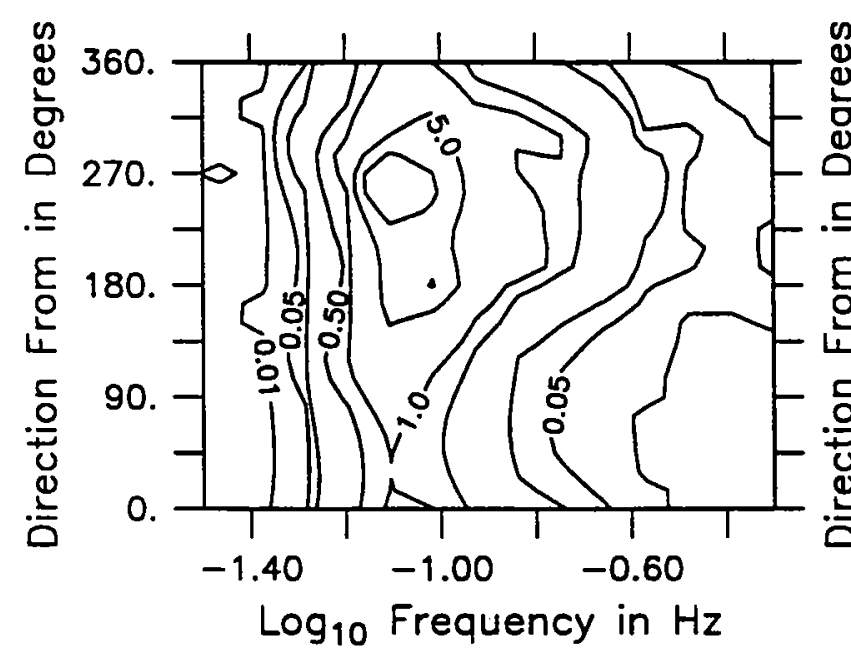

November 18,1991 OOZ

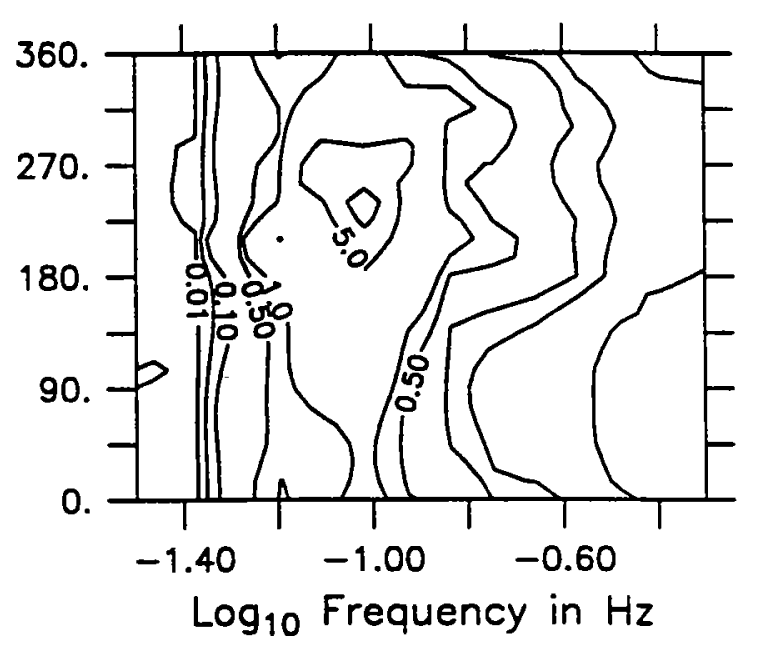

November 18,1991 06Z

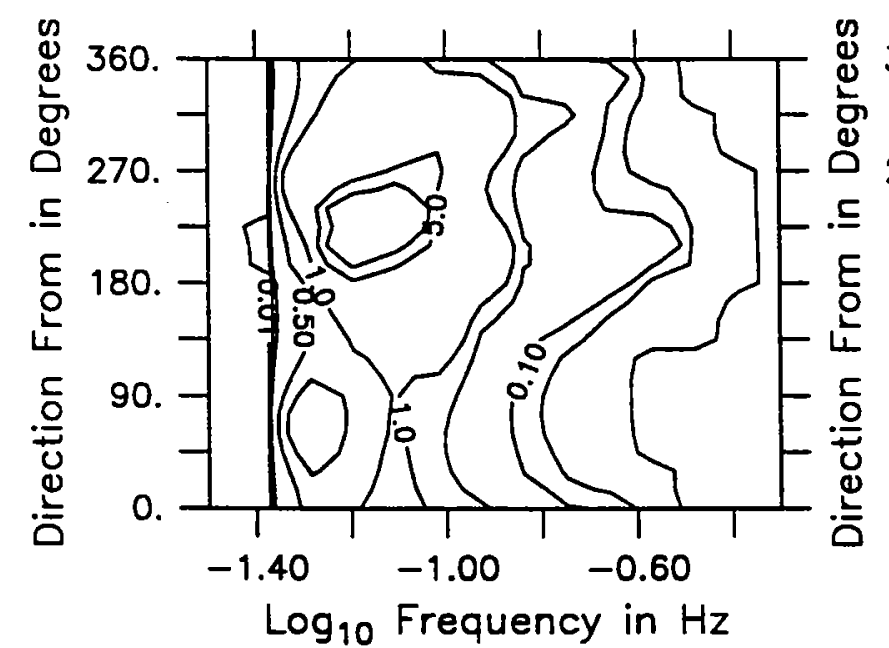

November 18,1991 $12 Z$

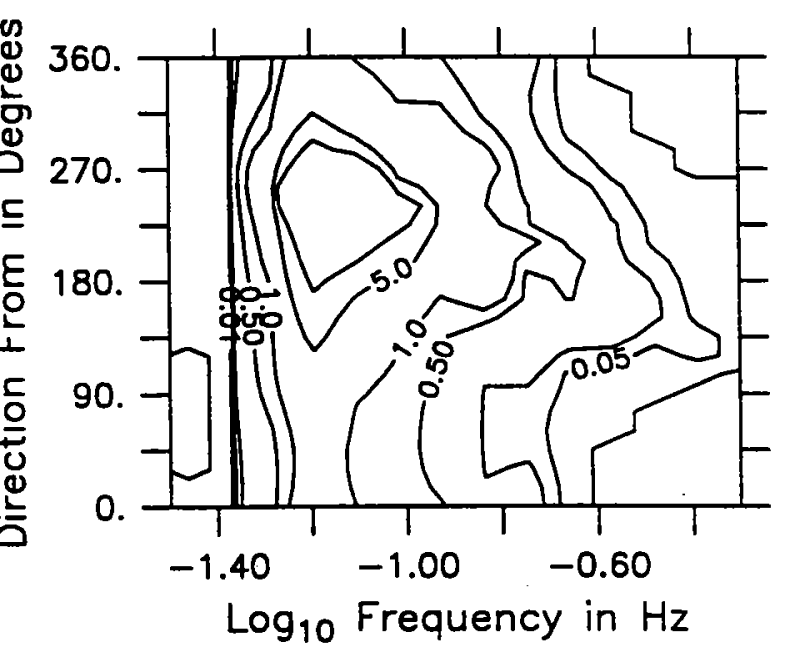

November $18,199118 Z$

Figure 3.4.22: Directional wave spectra, Seatex buoy. Contours are 0.01, $0.05,0.1,0.5,1,5,10,50,100,500$. 


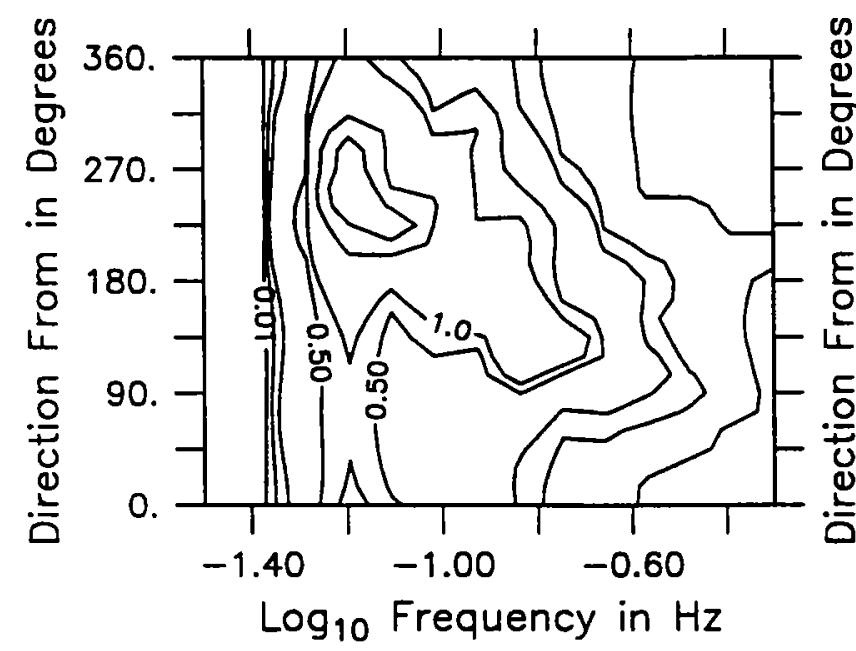

November 19,1991 OOZ

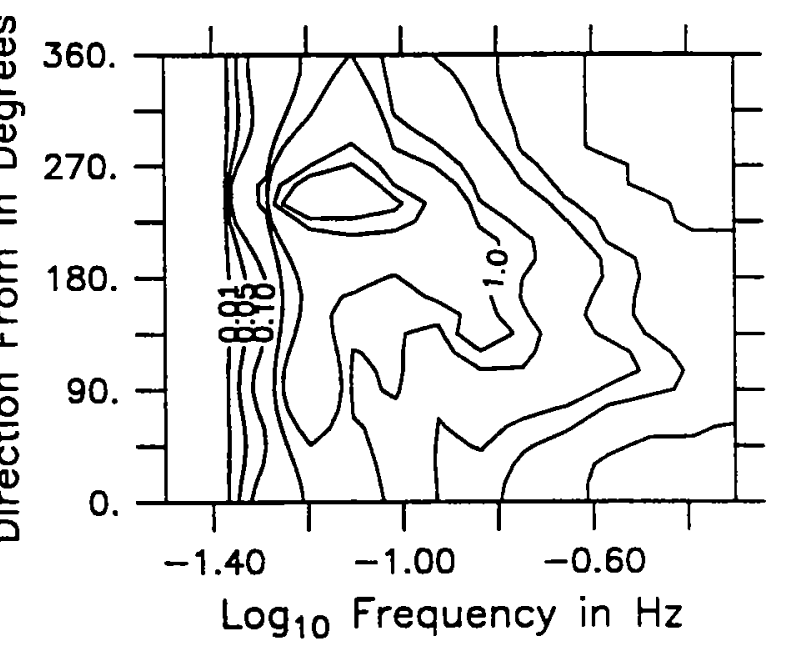

November 19,1991 O6Z

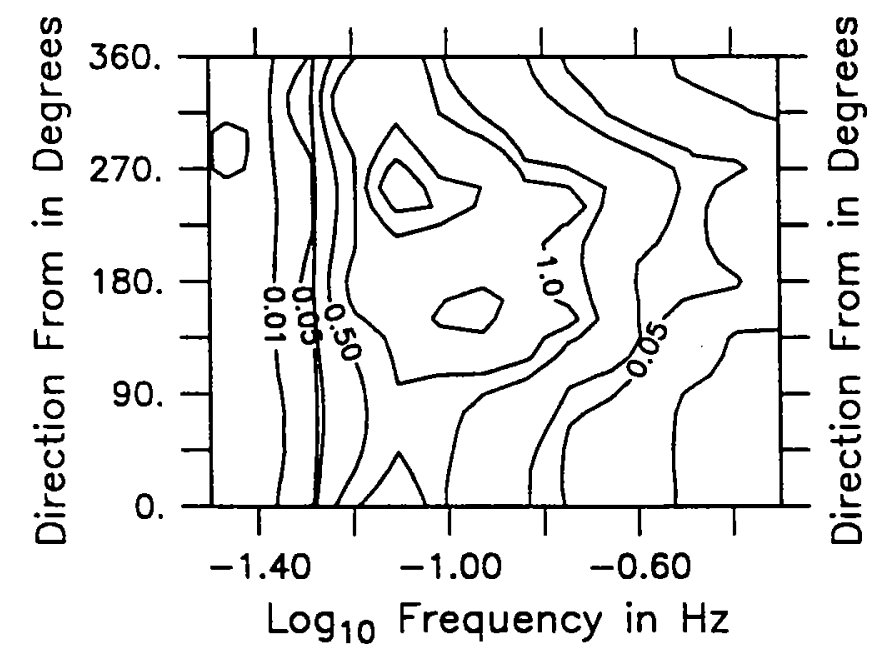

November 19,1991 $12 Z$

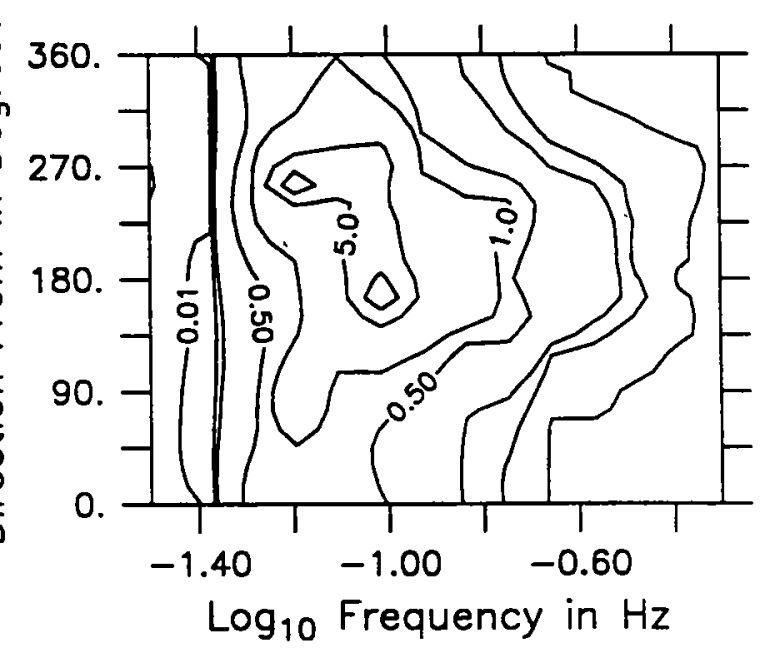

November 19,1991 $18 Z$

Figure 3.4.23: Directional wave spectra, Seatex buoy. Contours are 0.01, $0.05,0.1,0.5,1,5,10,50,100,500$. 


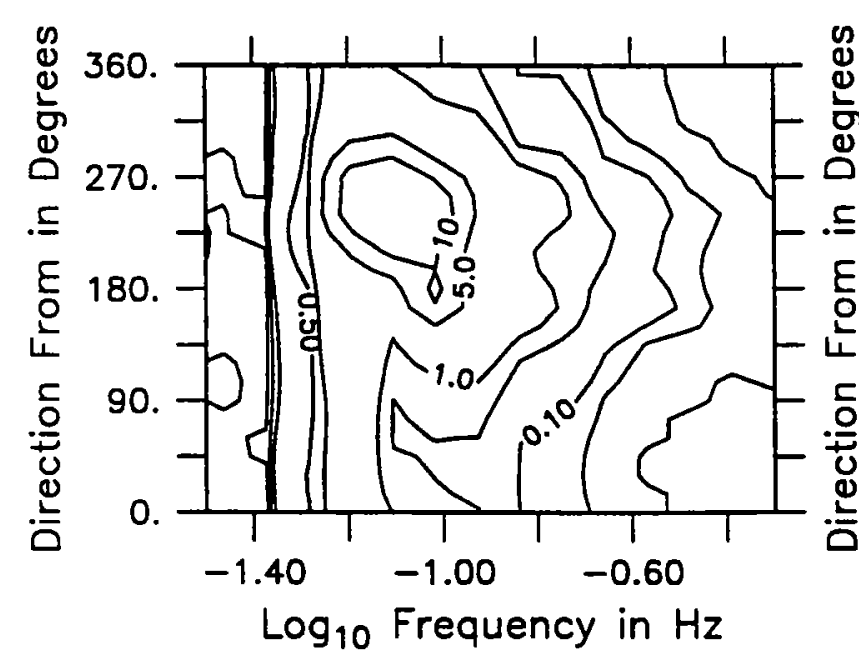

November 20,1991 00Z

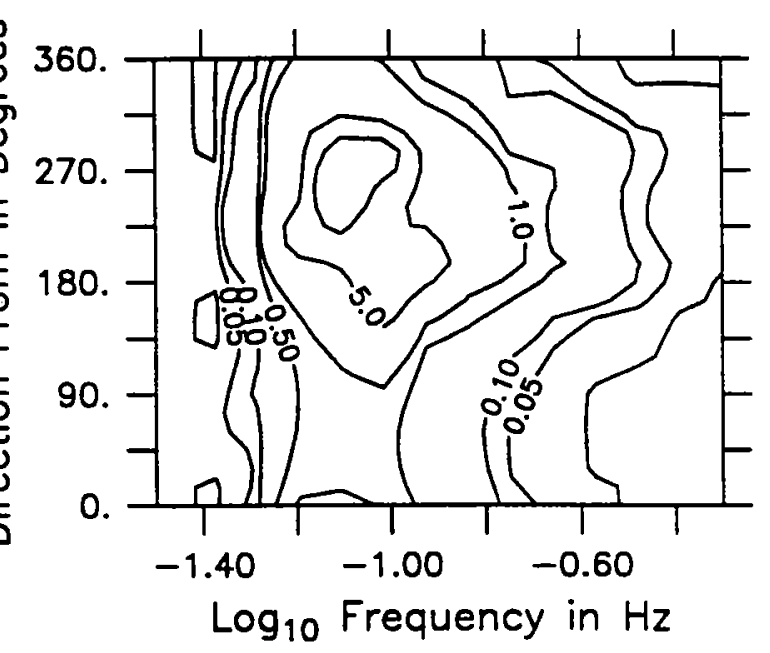

November 20,1991 06Z

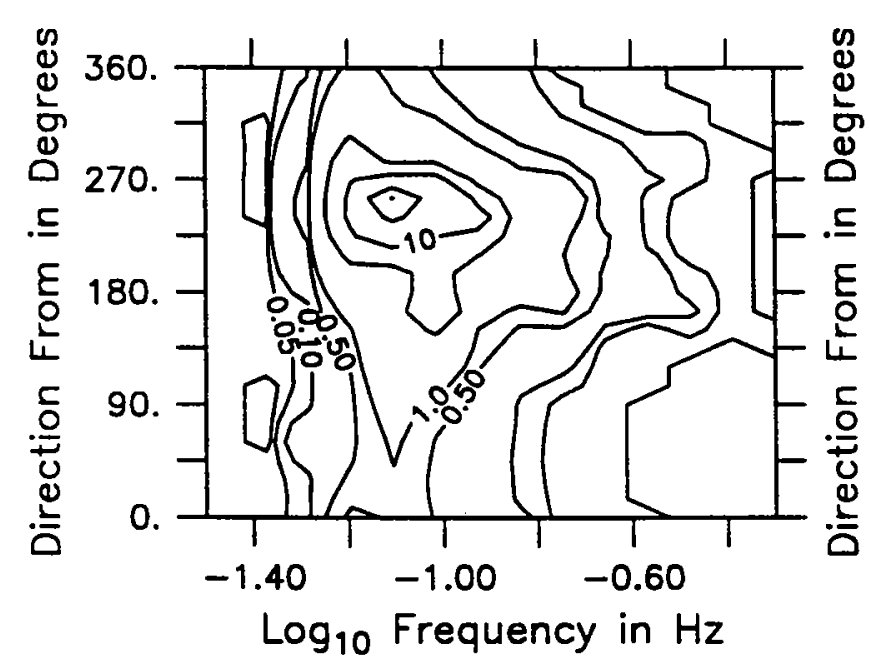

November $20,199112 Z$

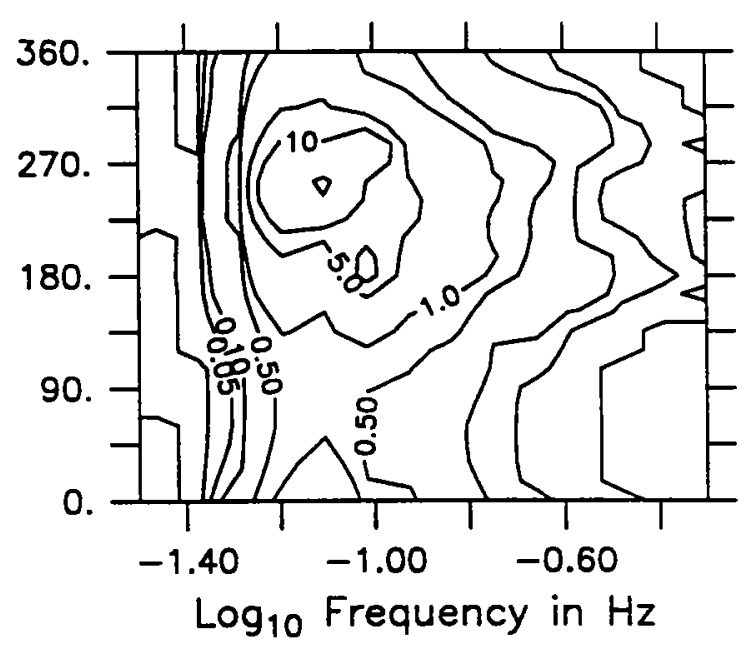

November 20,1991 18Z

Figure 3.4.24: Directional wave spectra, Seatex buoy. Contours are 0.01, $0.05,0.1,0.5,1,5,10,50,100,500$. 


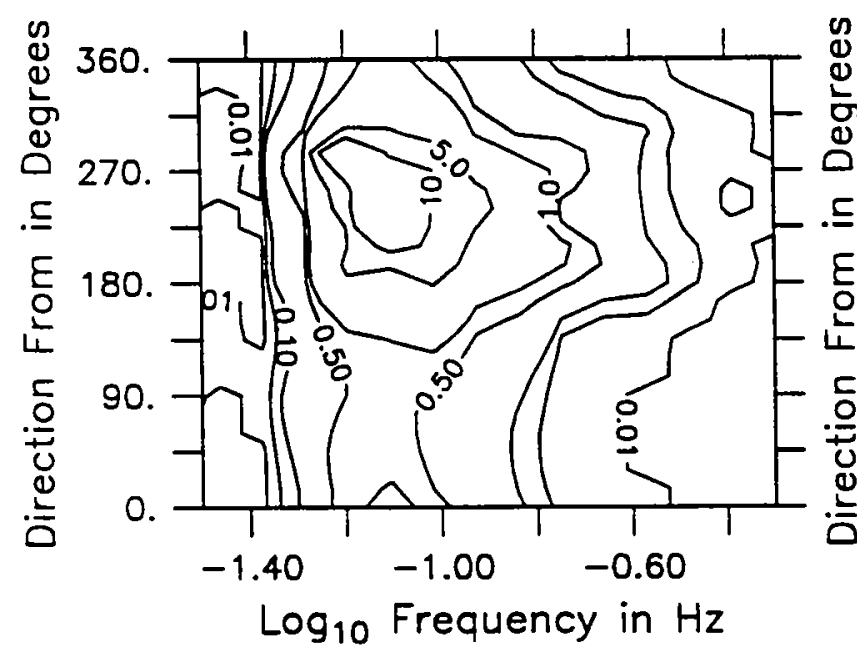

November 21,1991 00Z

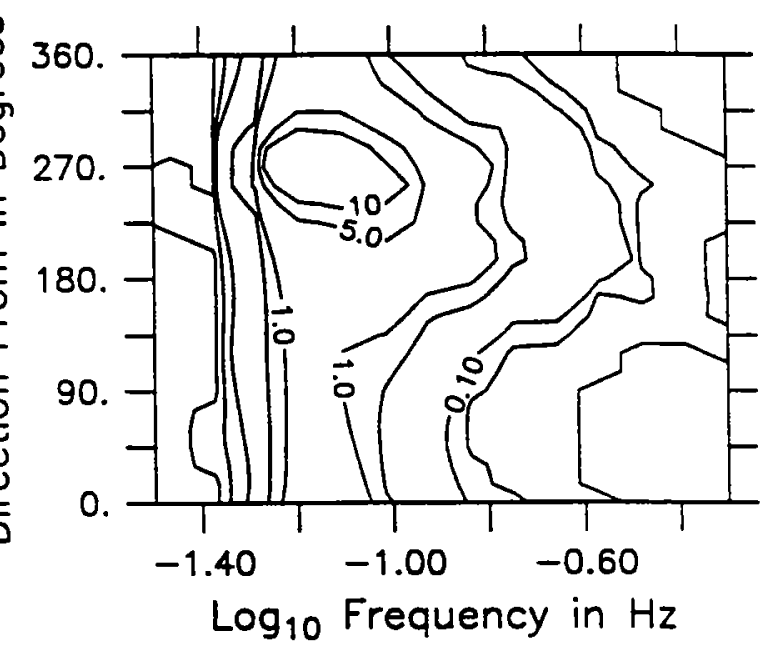

November 21,1991 06Z

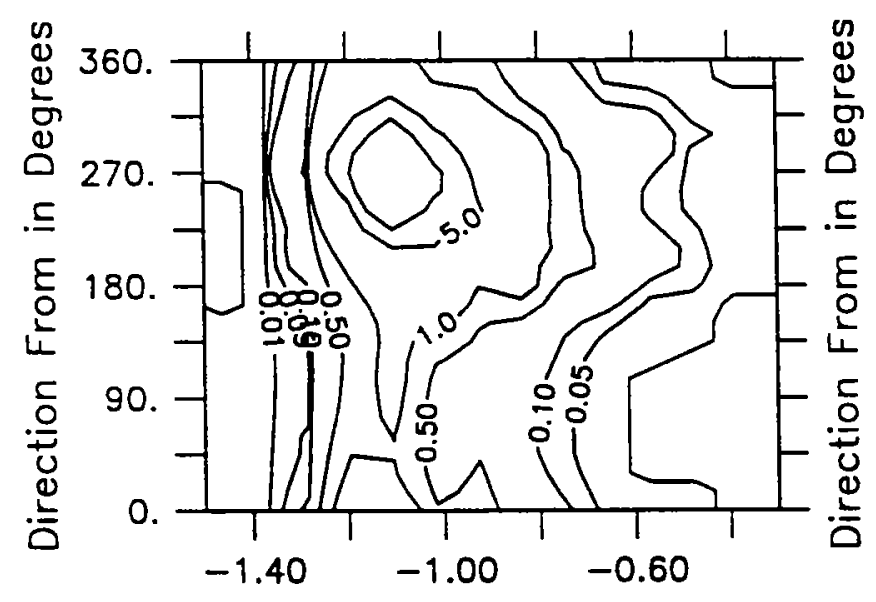

$\log _{10}$ Frequency in $\mathrm{Hz}$

November $21,199112 Z$

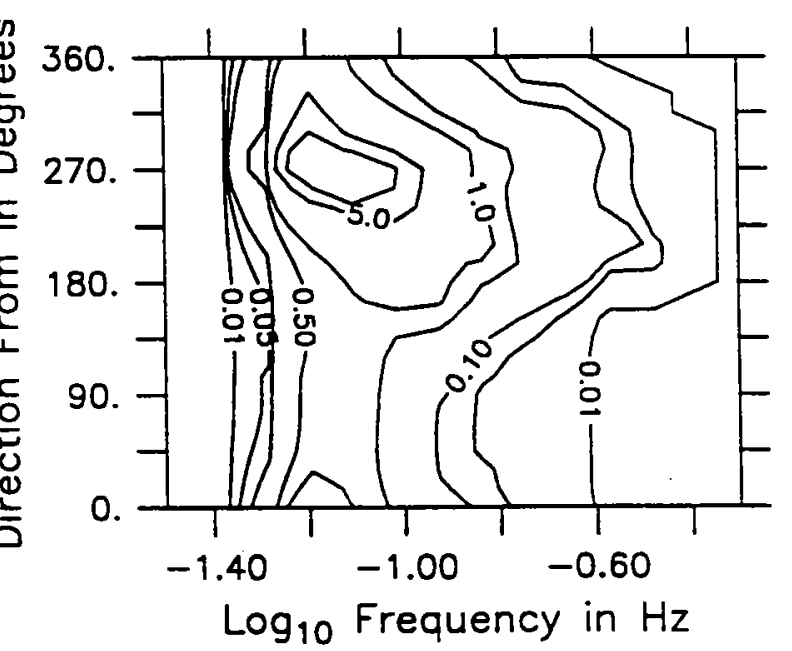

November 21,1991 $18 Z$

Figure 3.4.25: Directional wave spectra, Seatex buoy. Contours are 0.01, $0.05,0.1,0.5,1,5,10,50,100,500$. 


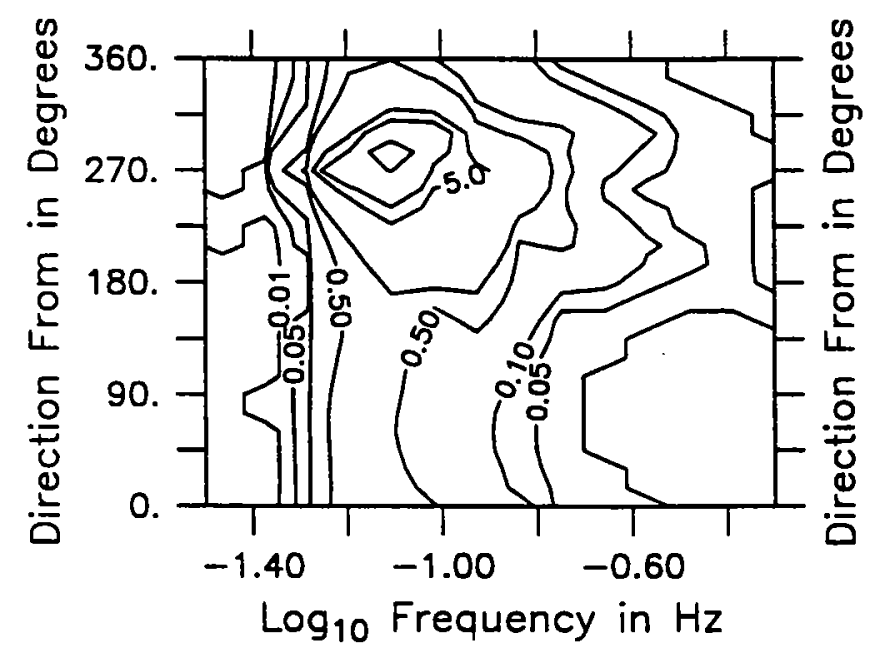

November 22,1991 OOZ

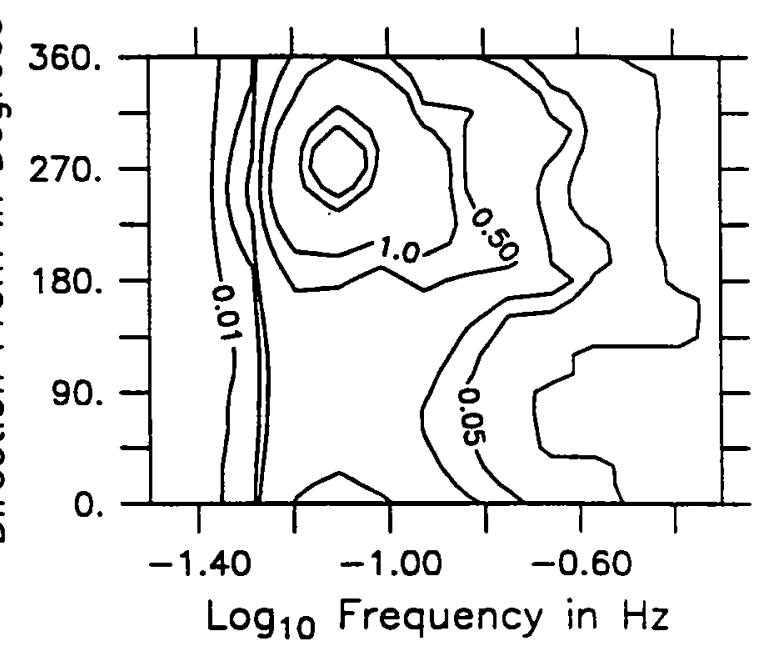

November 22,1991 O6Z

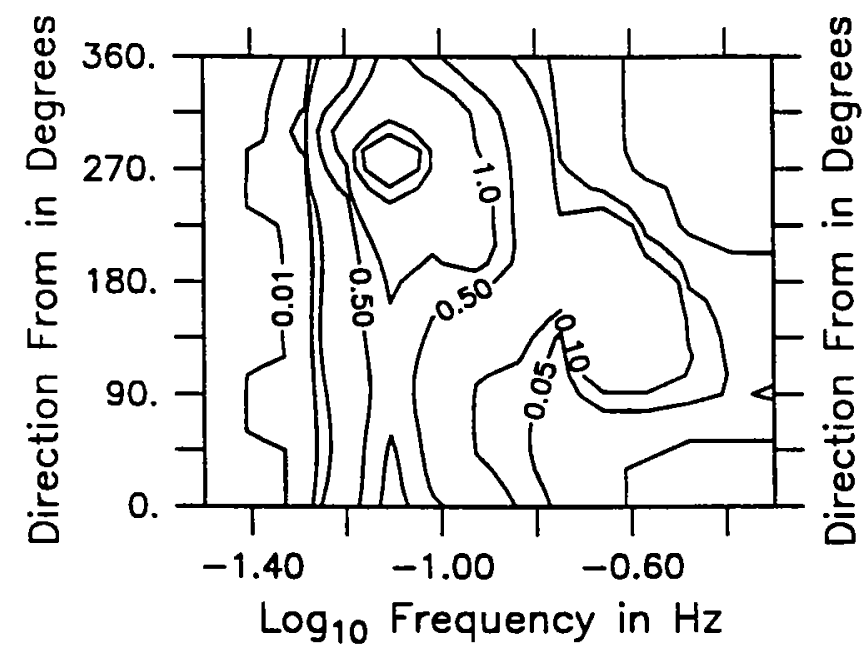

November 22,1991 $12 Z$

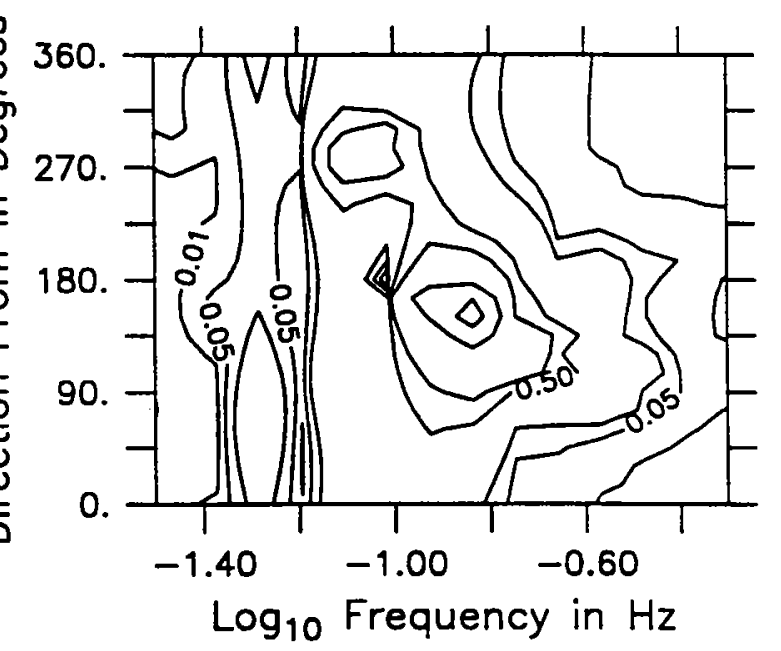

November 22,1991 $18 \mathrm{Z}$

Figure 3.4.26: Directional wave spectra, Seatex buoy. Contours are 0.01, $0.05,0.1,0.5,1,5,10,50,100,500$. 


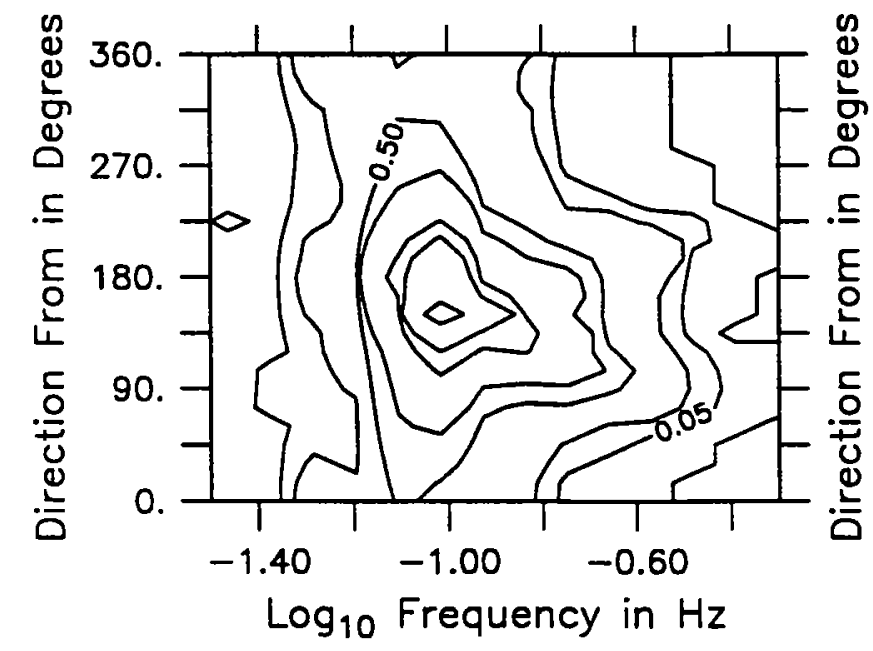

November 23,1991 OOZ

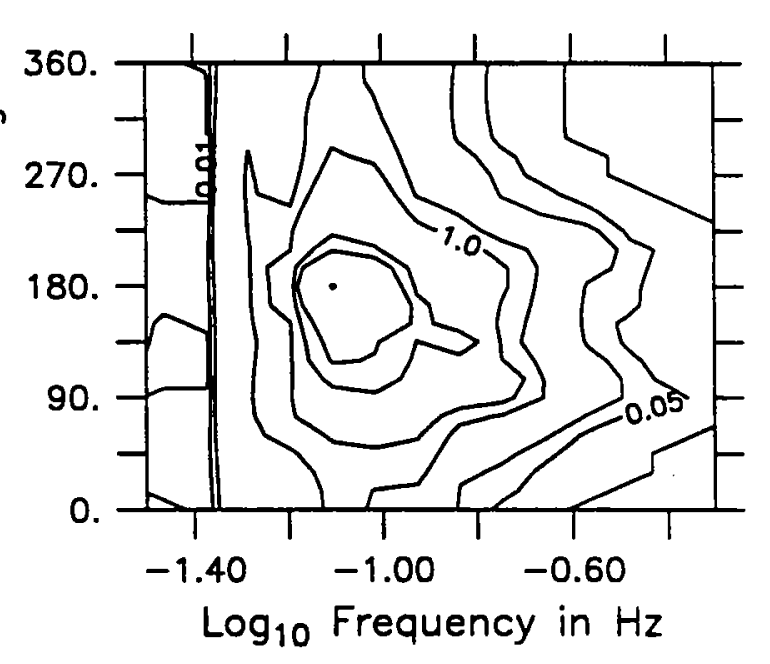

November 23,1991 06Z

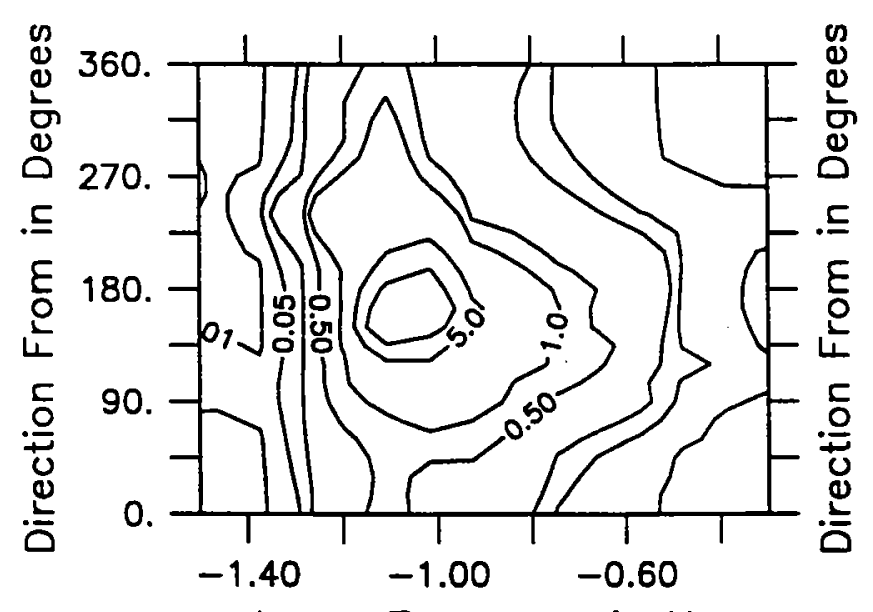

$\log _{10}$ Frequency in $\mathrm{Hz}$

November 23,1991 $12 Z$

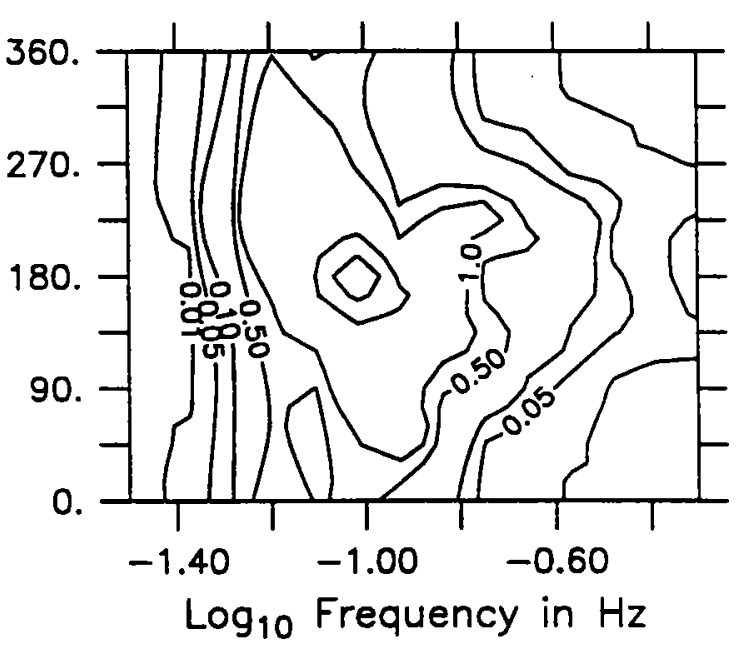

November 23,1991 18Z

Figure 3.4.27: Directional wave spectra, Seatex buoy. Contours are 0.01, $0.05,0.1,0.5,1,5,10,50,100,500$. 


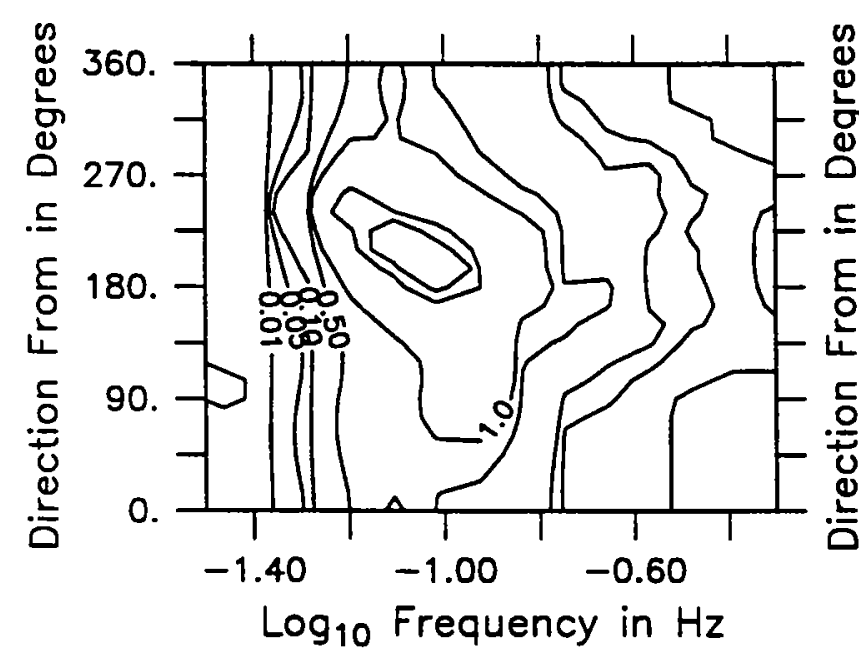

November 24,1991 OOZ

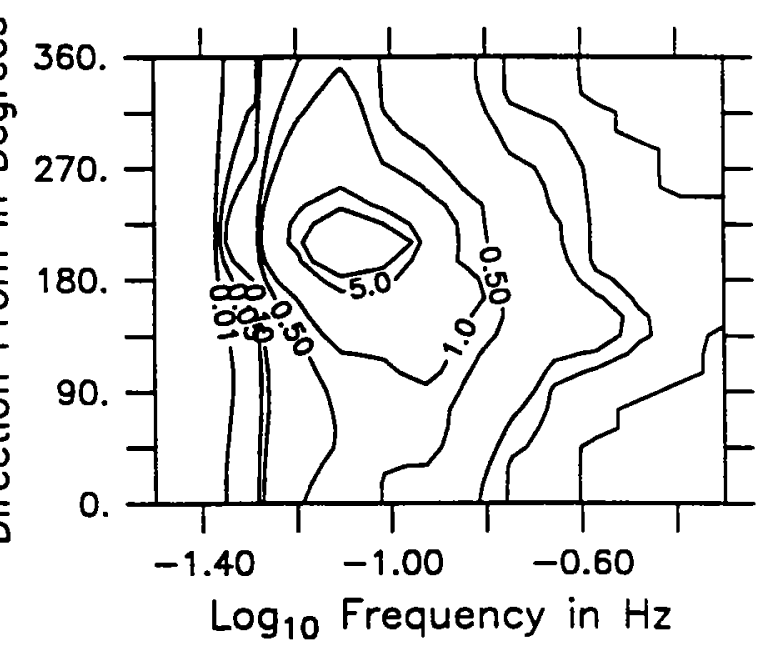

November 24,1991 O6Z

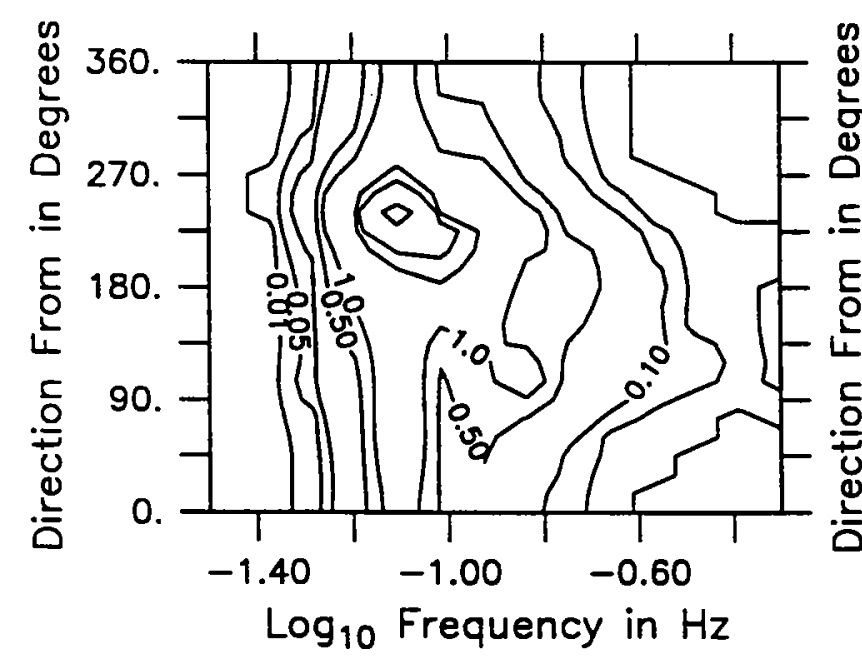

November 24,1991 $12 Z$

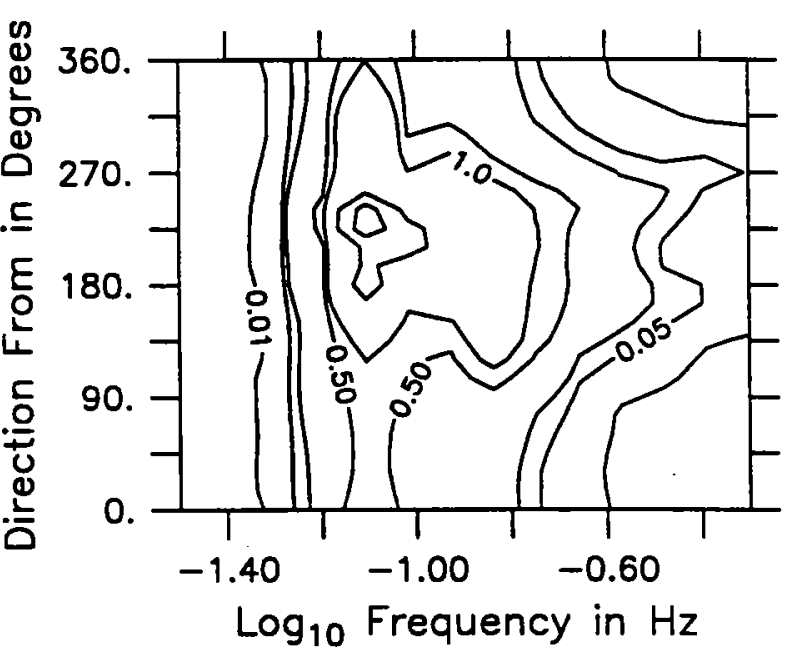

November 24,1991 $18 Z$

Figure 3.4.28: Directional wave spectra, Seatex buoy. Contours are 0.01, $0.05,0.1,0.5,1,5,10,50,100,500$. 


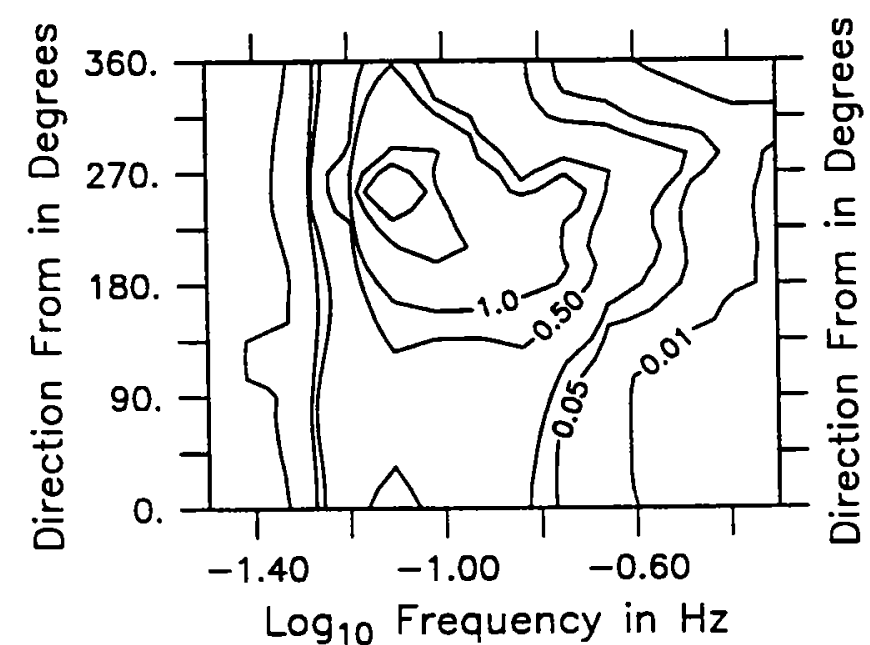

November 25,1991 00Z

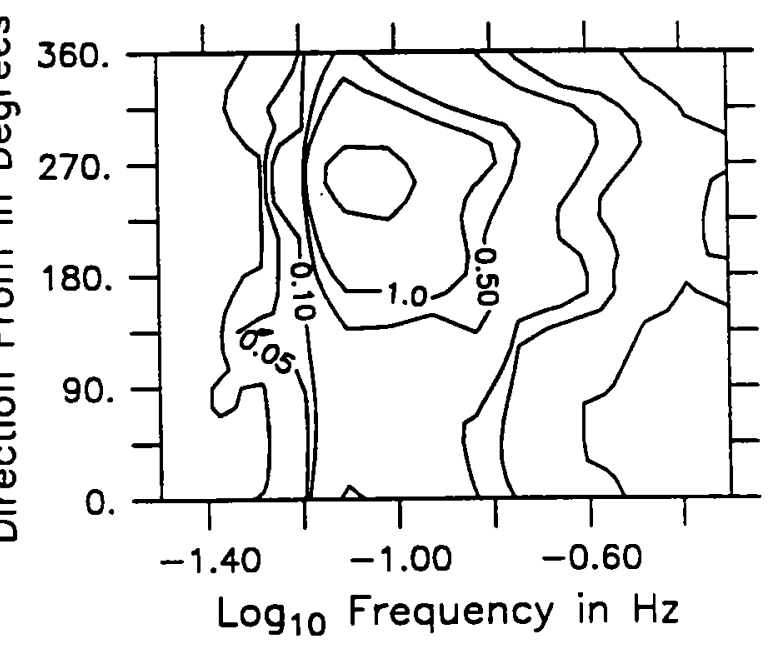

November 25,1991 O6Z

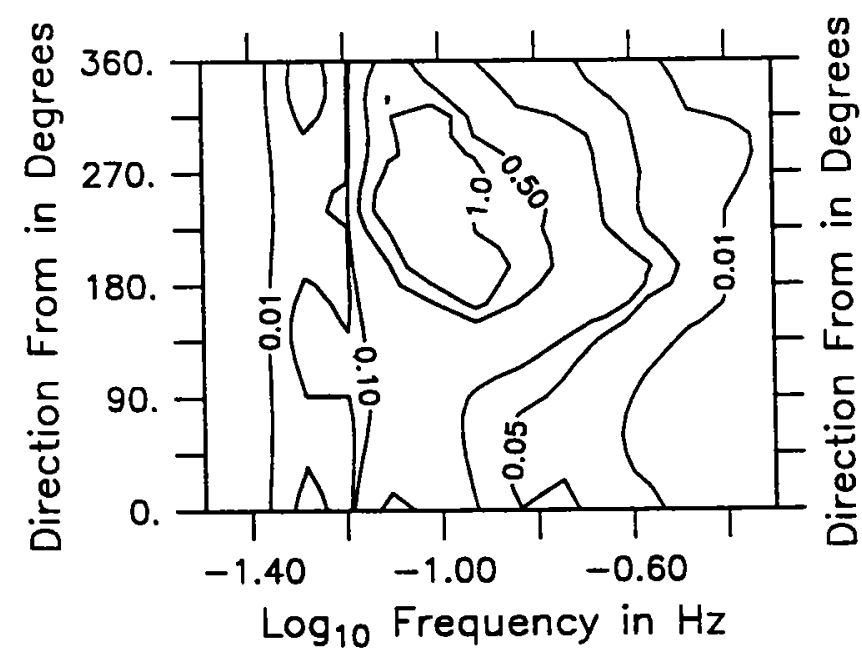

November 25,1991 $12 Z$

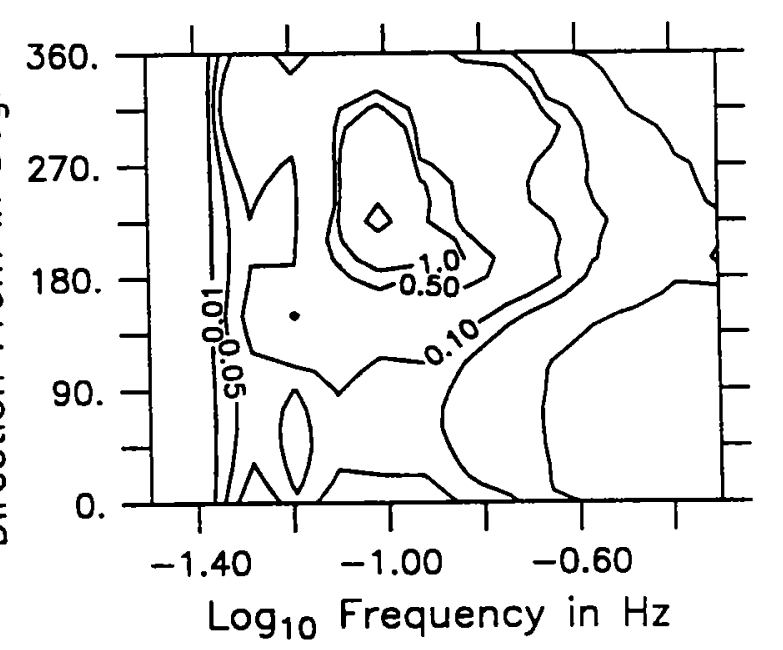

November 25,1991 $18 Z$

Figure 3.4.29: Directional wave spectra, Seatex buoy. Contours are 0.01, $0.05,0.1,0.5,1,5,10,50,100,500$. 


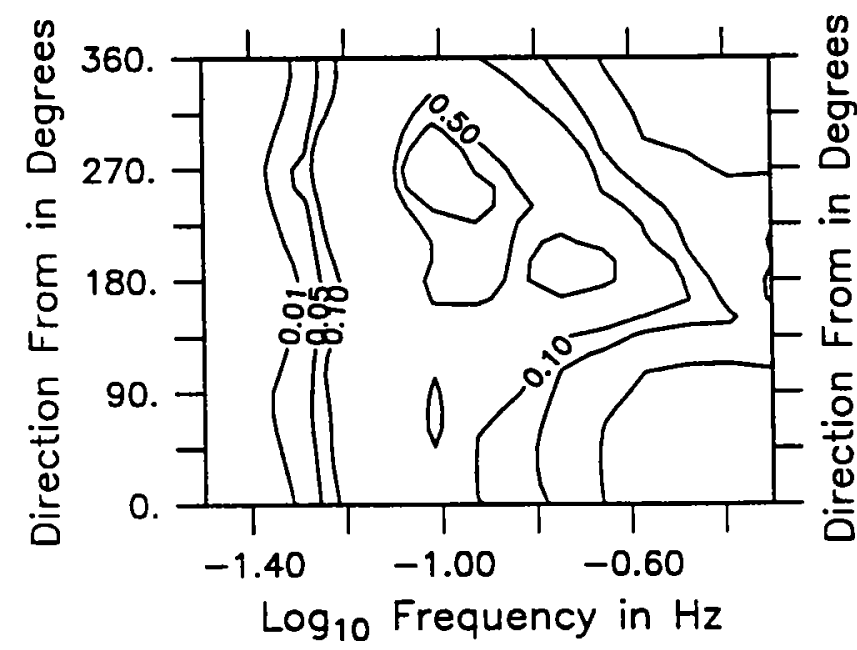

November 26,1991 00Z

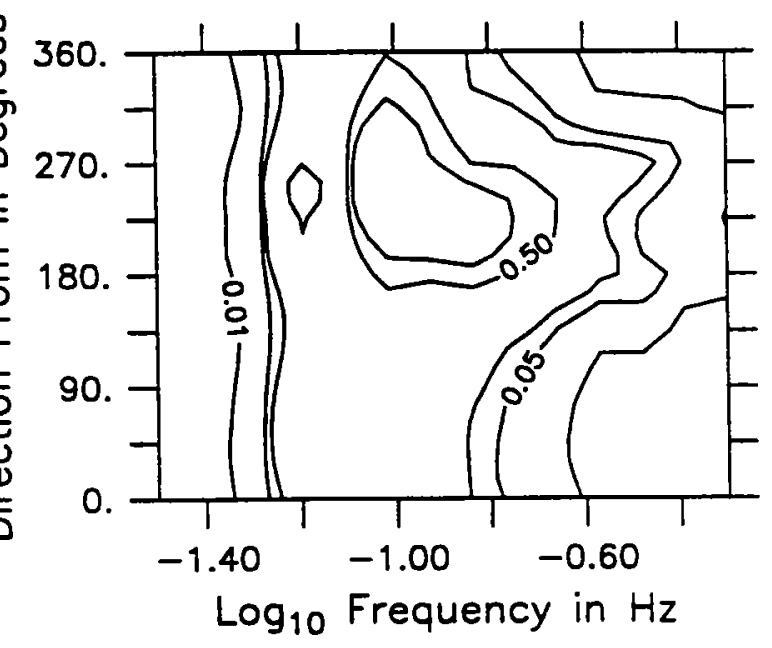

November 26,1991 O6Z

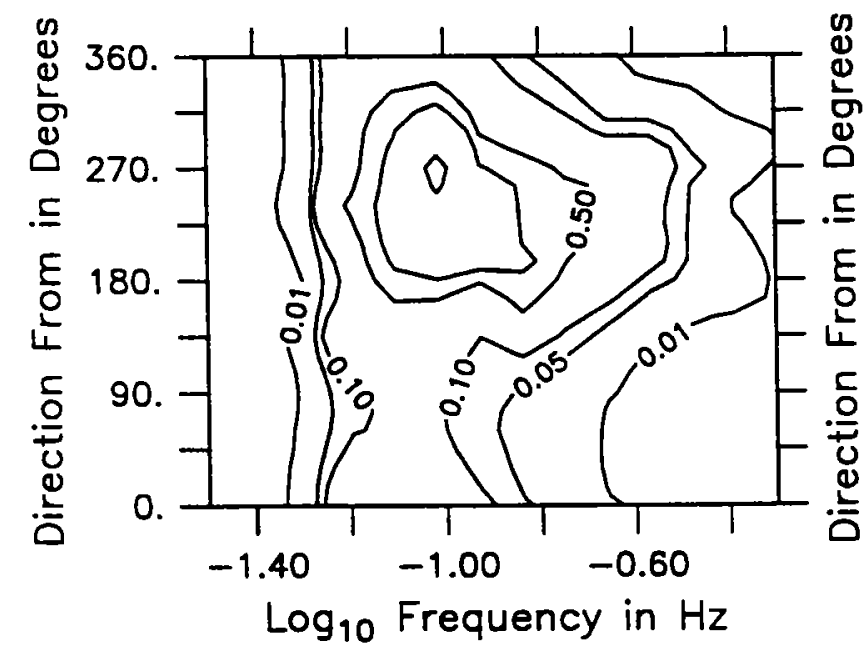

November 26,1991 $12 Z$

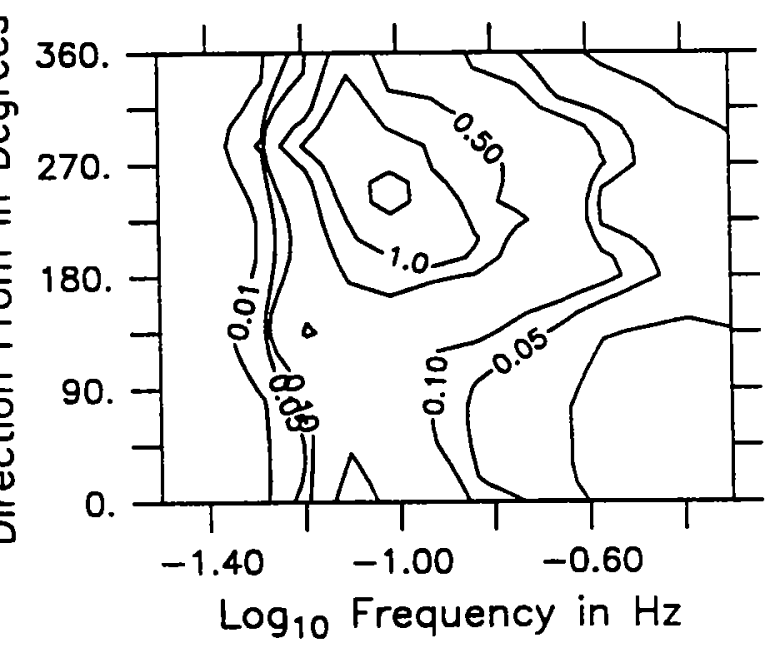

November 26,1991 $18 Z$

Figure 3.4.30: Directional wave spectra, Seatex buoy. Contours are 0.01, $0.05,0.1,0.5,1,5,10,50,100,500$. 


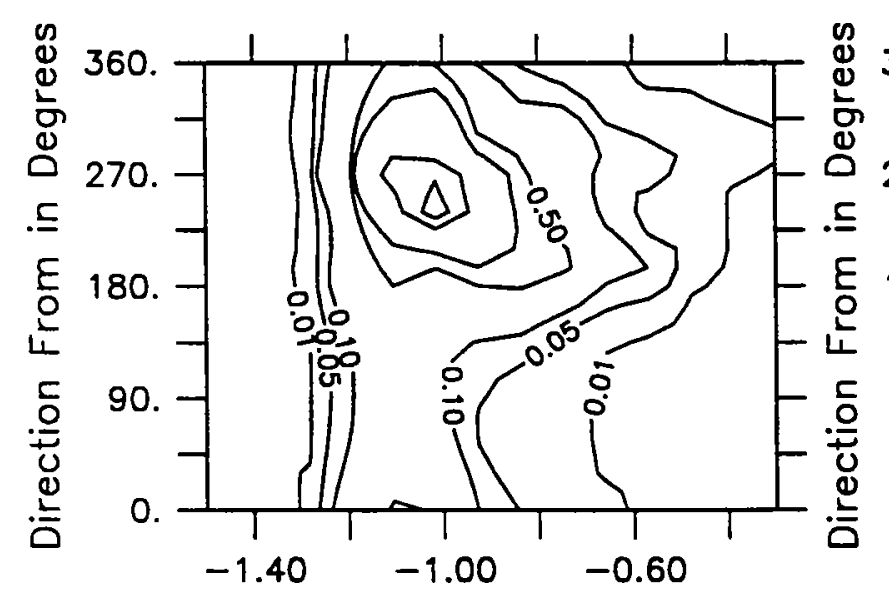

$\log _{10}$ Frequency in $\mathrm{Hz}$

November 27,1991 OOZ

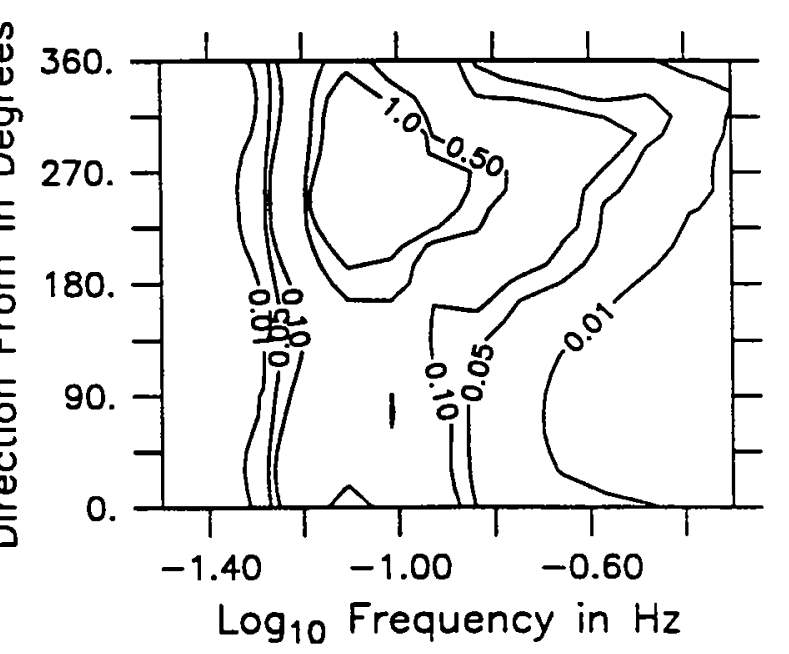

November 27,1991 O6Z

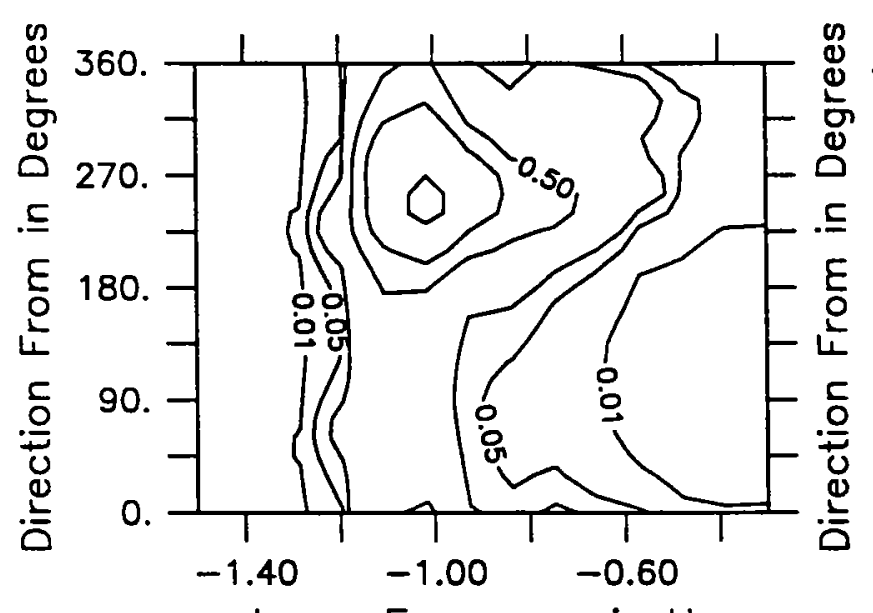

$\log _{10}$ Frequency in $\mathrm{Hz}$

November 27,1991 $12 Z$

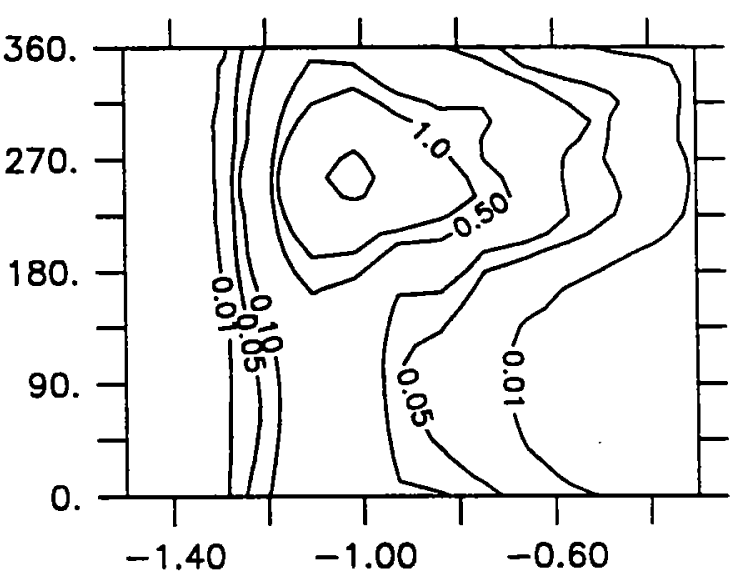

$\log _{10}$ Frequency in $\mathrm{Hz}$

November 27,1991 $18 Z$

Figure 3.4.31: Directional wave spectra, Seatex buoy. Contours are 0.01, $0.05,0.1,0.5,1,5,10,50,100,500$. 


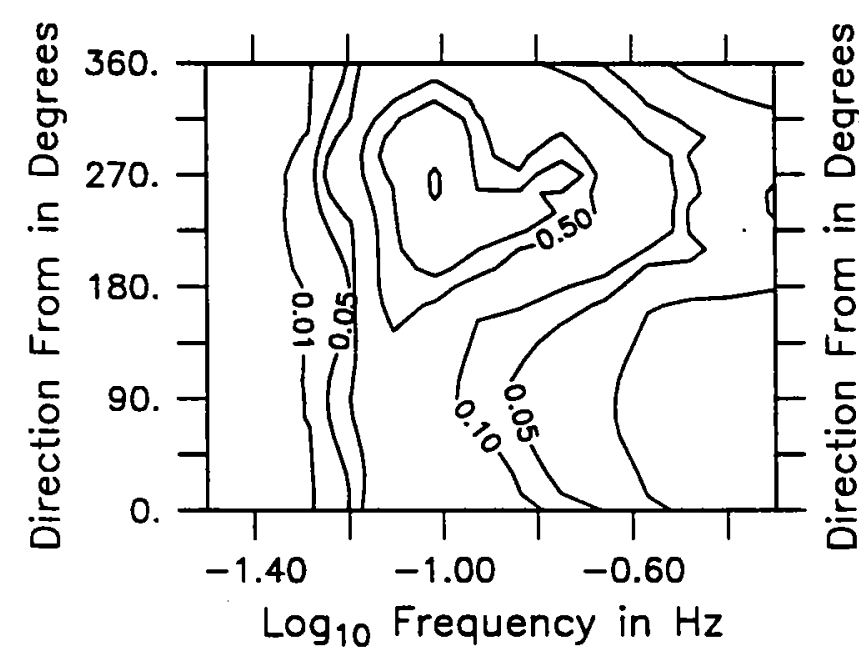

November 28,1991 OOZ

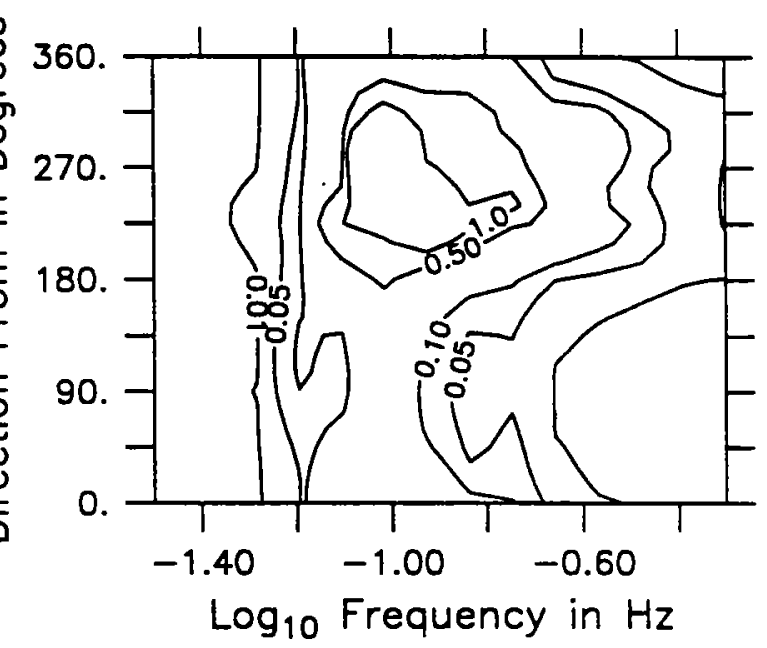

November 28,1991 O6Z

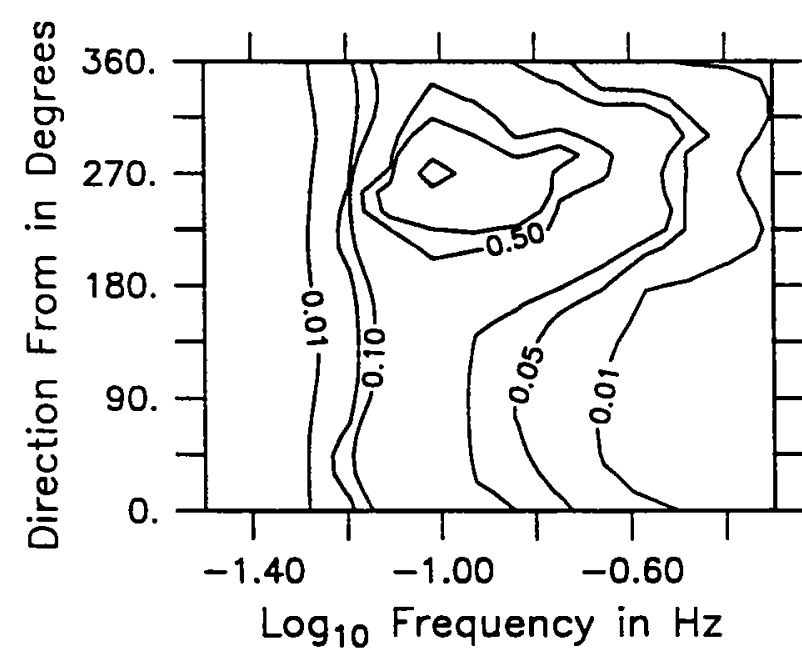

November $28,199112 Z$

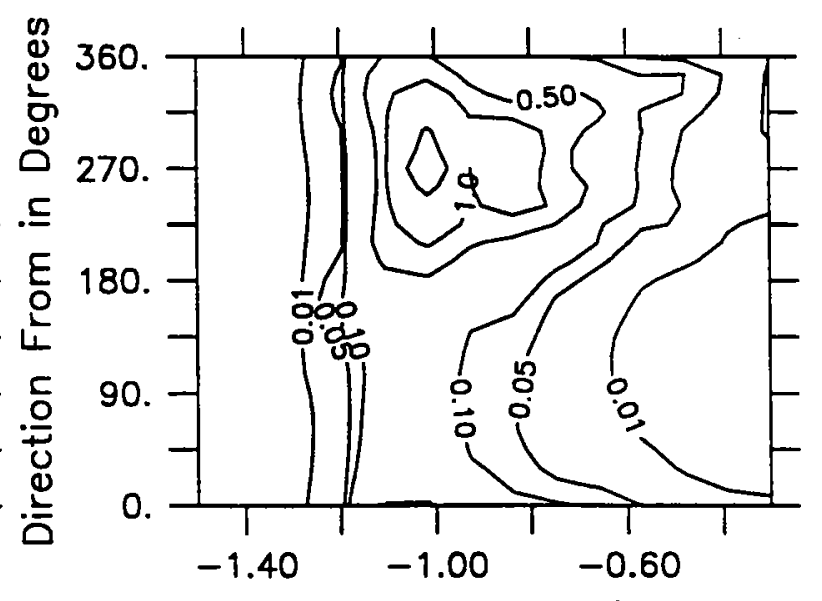

$\log _{10}$ Frequency in $\mathrm{Hz}$

November 28,1991 $18 Z$

Figure 3.4.32: Directional wave spectra, Seatex buoy. Contours are 0.01, $0.05,0.1,0.5,1,5,10,50,100,500$. 


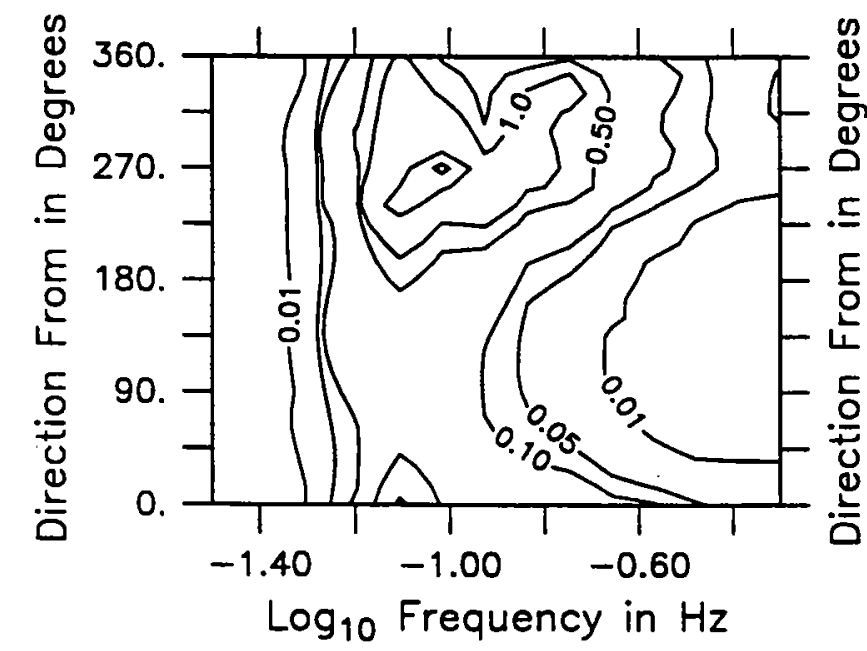

November 29,1991 00Z

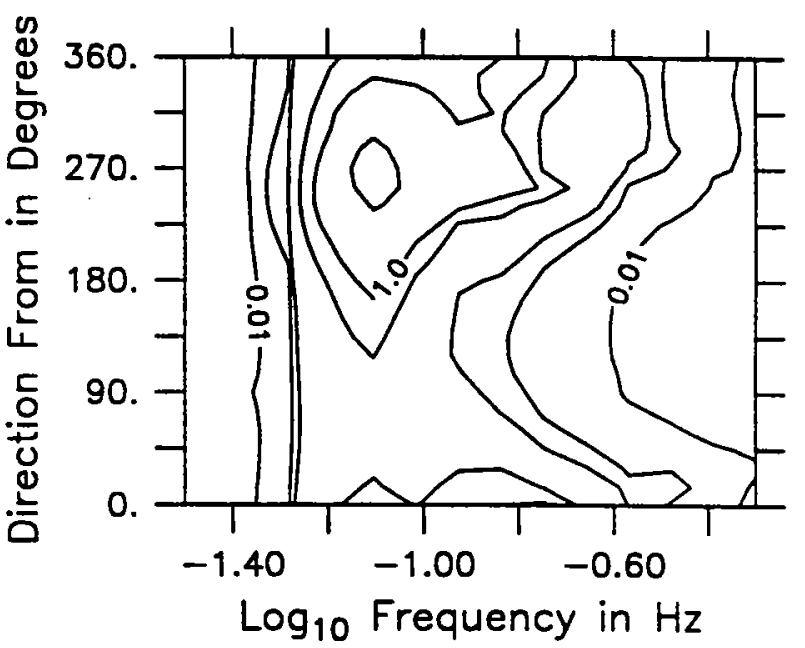

November 29,1991 O6Z

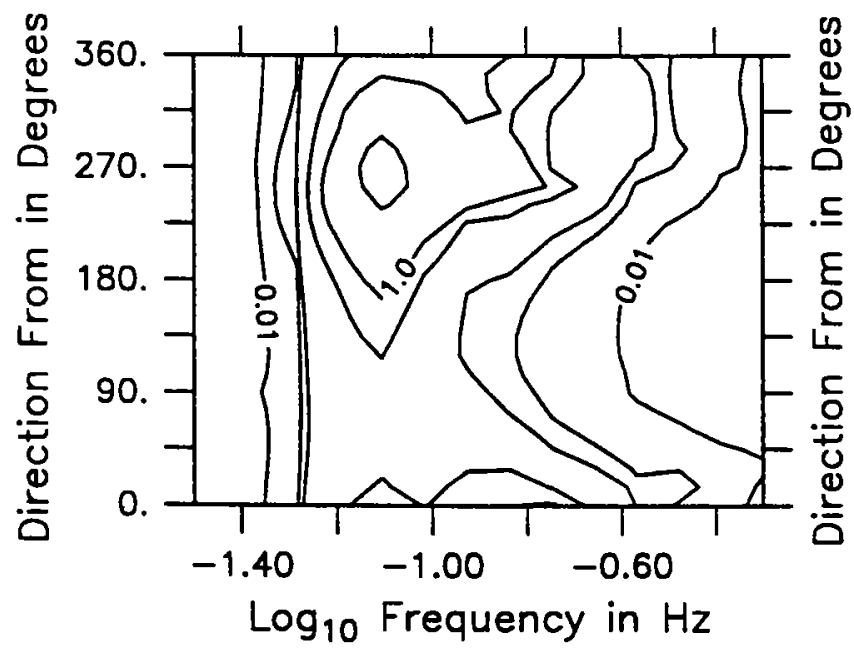

November 29,1991 $12 Z$

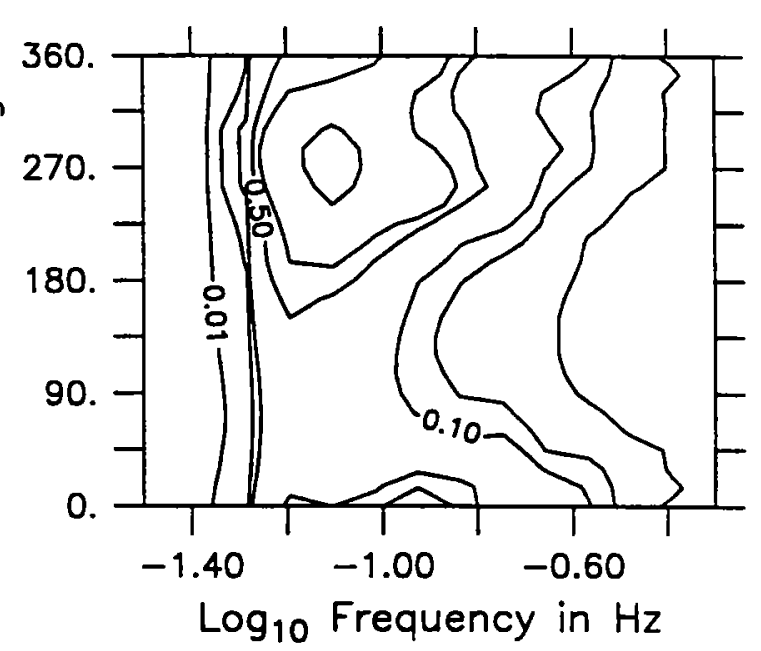

November 29,1991 $18 Z$

Figure 3.4.33: Directional wave spectra, Seatex buoy. Contours are 0.01, $0.05,0.1,0.5,1,5,10,50,100,500$. 


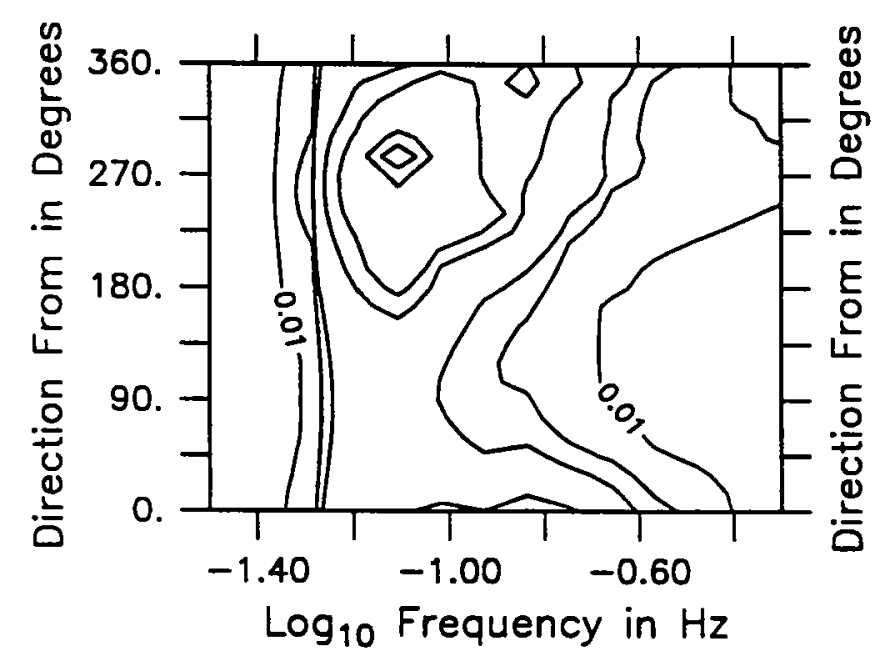

November 30,1991 00Z

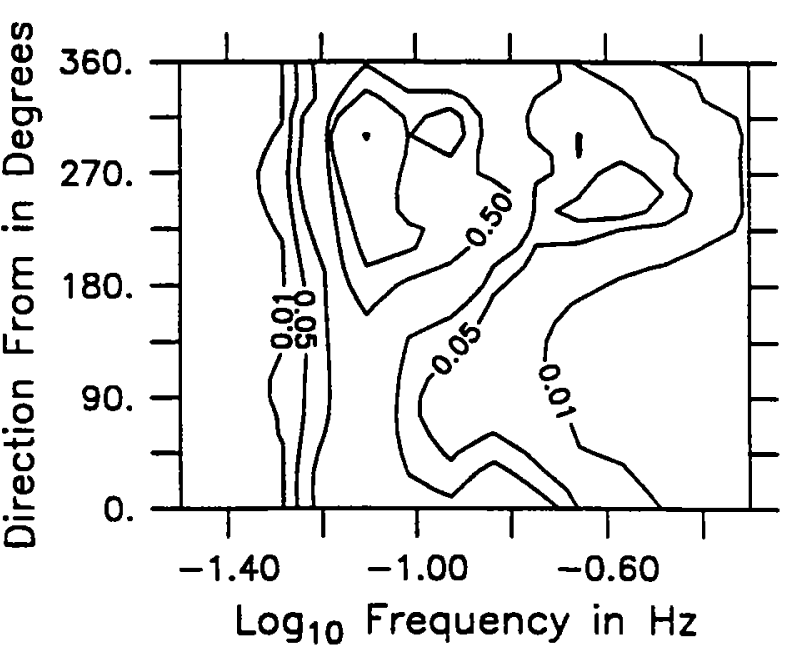

November 30,1991 06Z

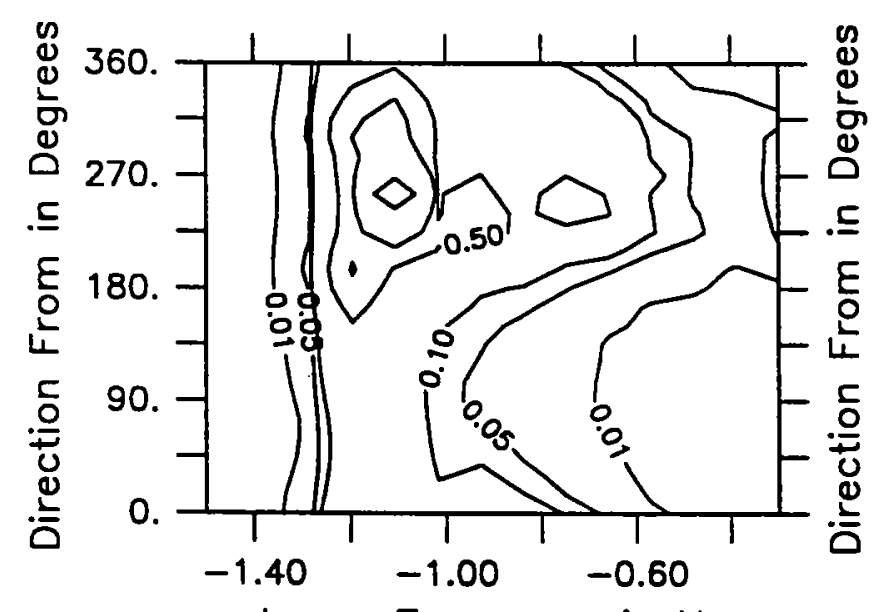

$\log _{10}$ Frequency in $\mathrm{Hz}$

November $30,199112 Z$

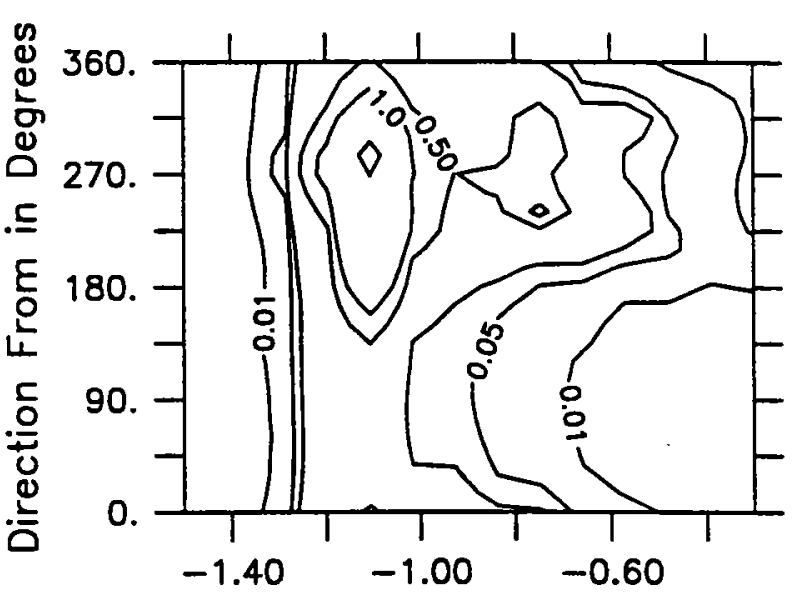

$\log _{10}$ Frequency in $\mathrm{Hz}$

November 30,1991 18Z

Figure 3.4.34: Directional wave spectra, Seatex buoy. Contours are 0.01, $0.05,0.1,0.5,1,5,10,50,100,500$. 


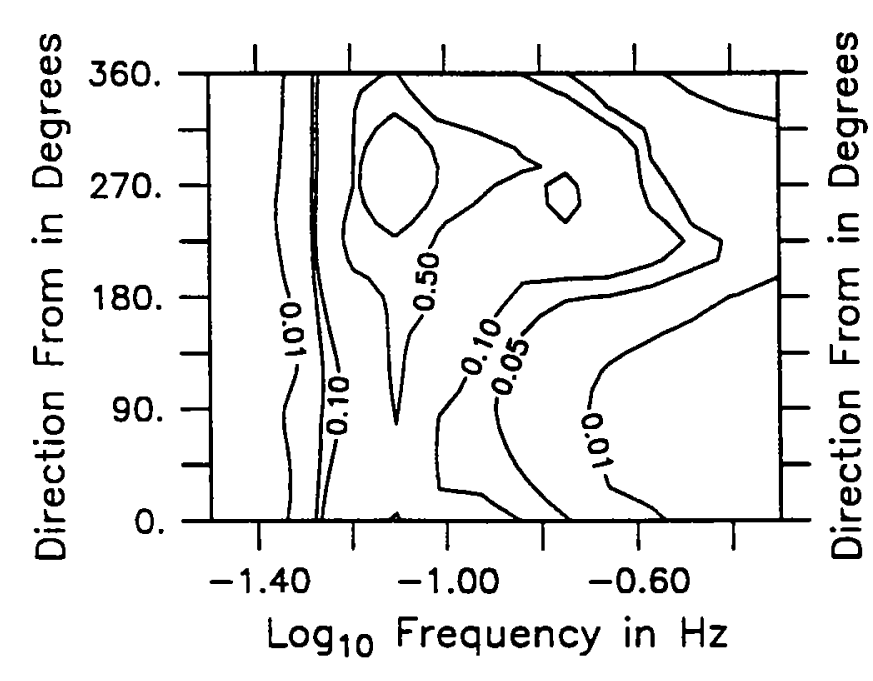

December 1,1991 OOZ

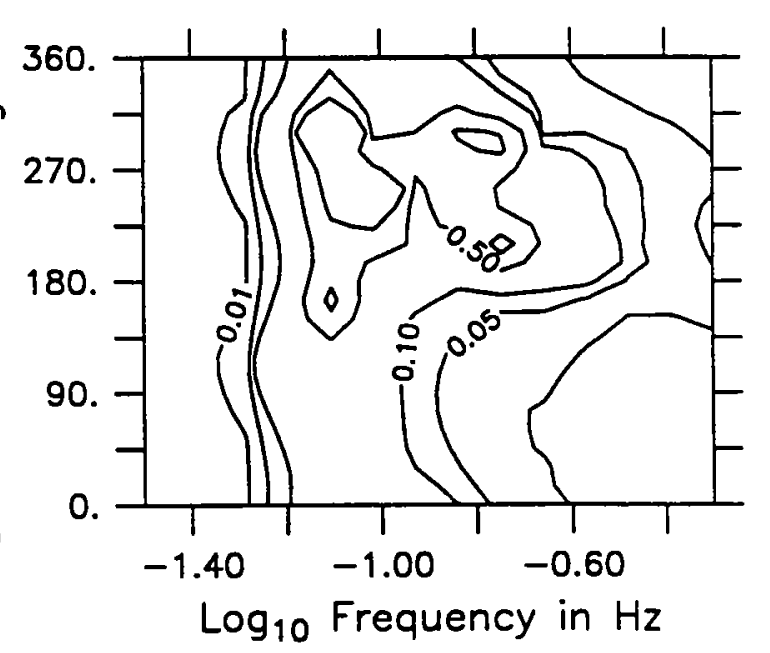

December 1,1991 06Z

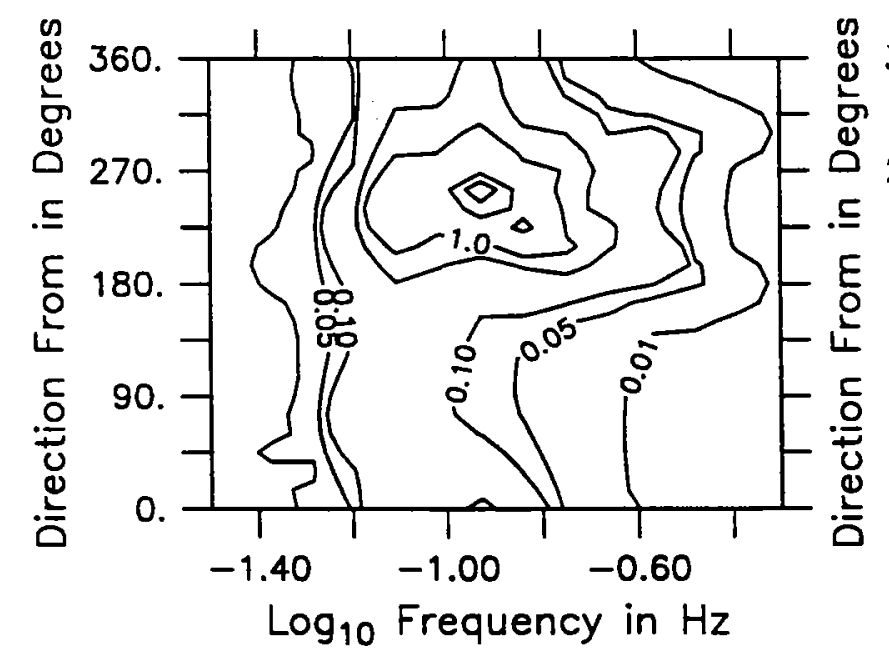

December 1,1991 $12 Z$

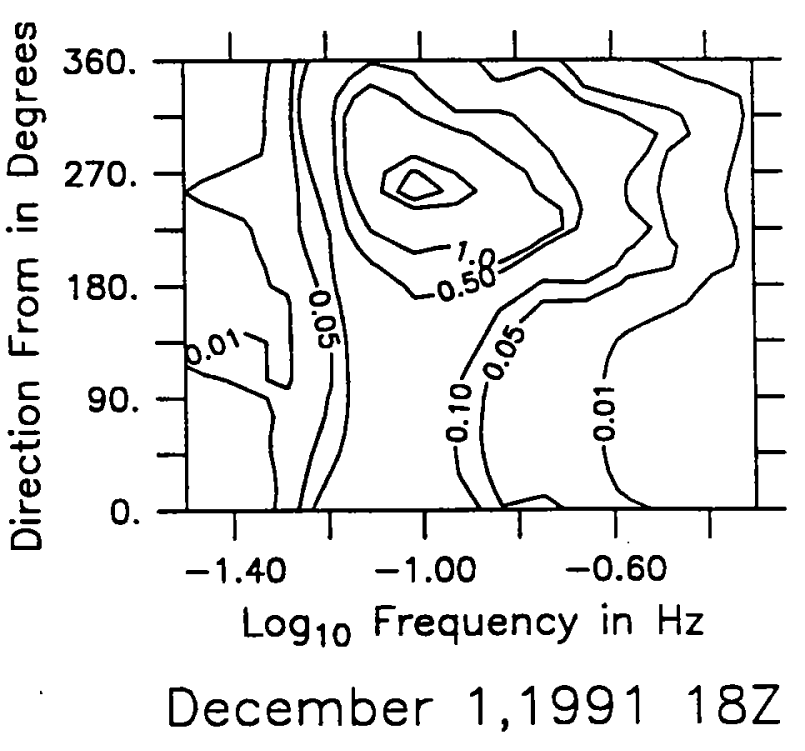

Figure 3.4.35: Directional wave spectra, Seatex buoy. Contours are 0.01, $0.05,0.1,0.5,1,5,10,50,100,500$. 


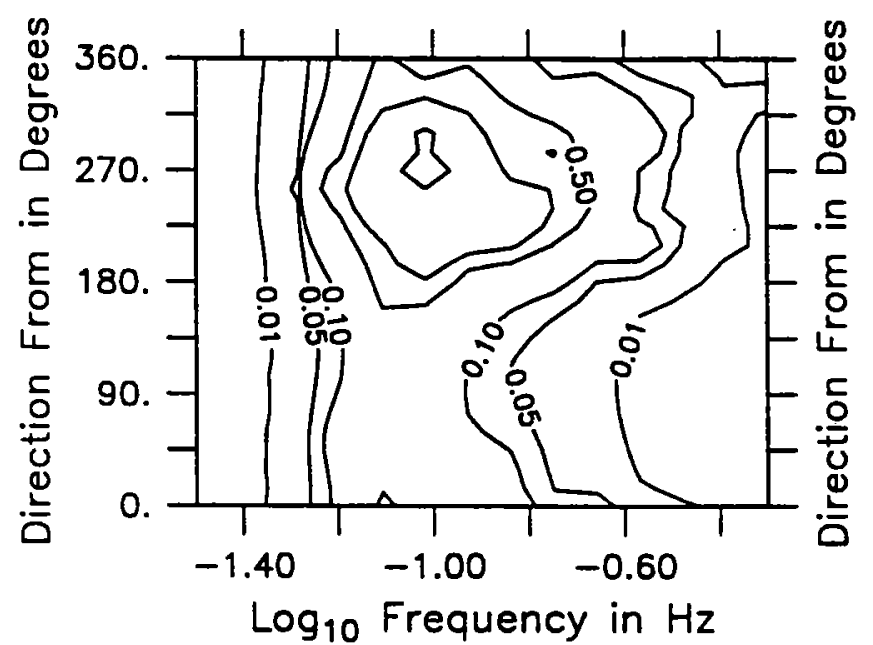

December 2,1991 OOZ

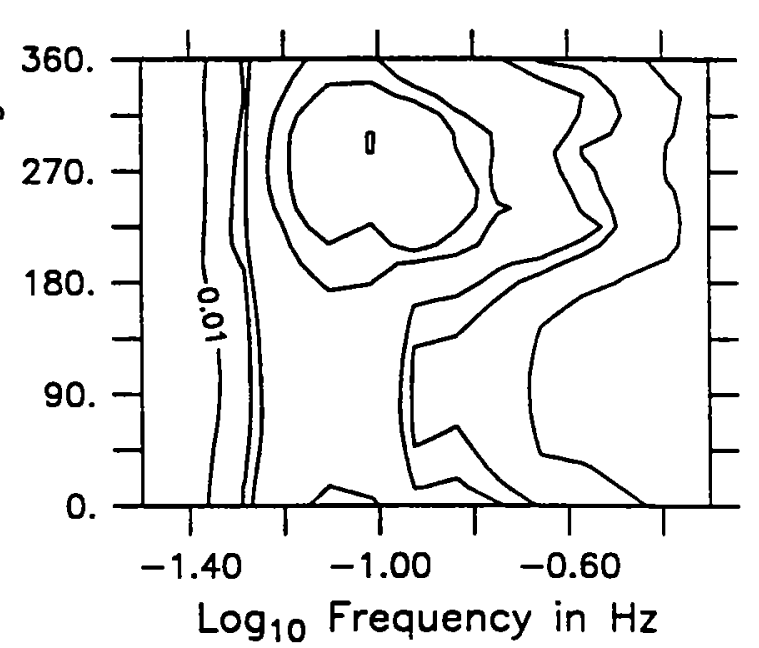

December 2,1991 O6Z

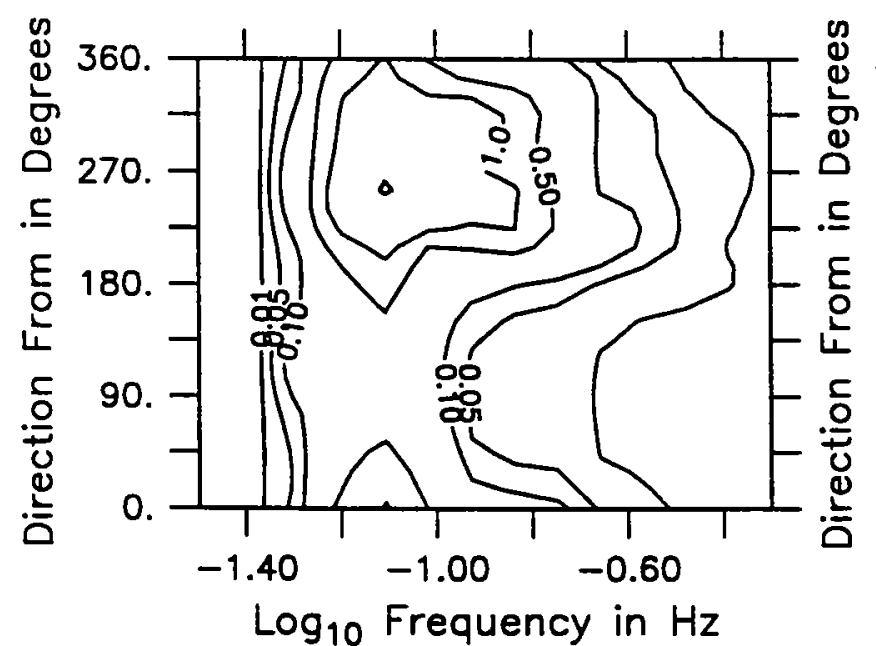

December 2,1991 $12 Z$

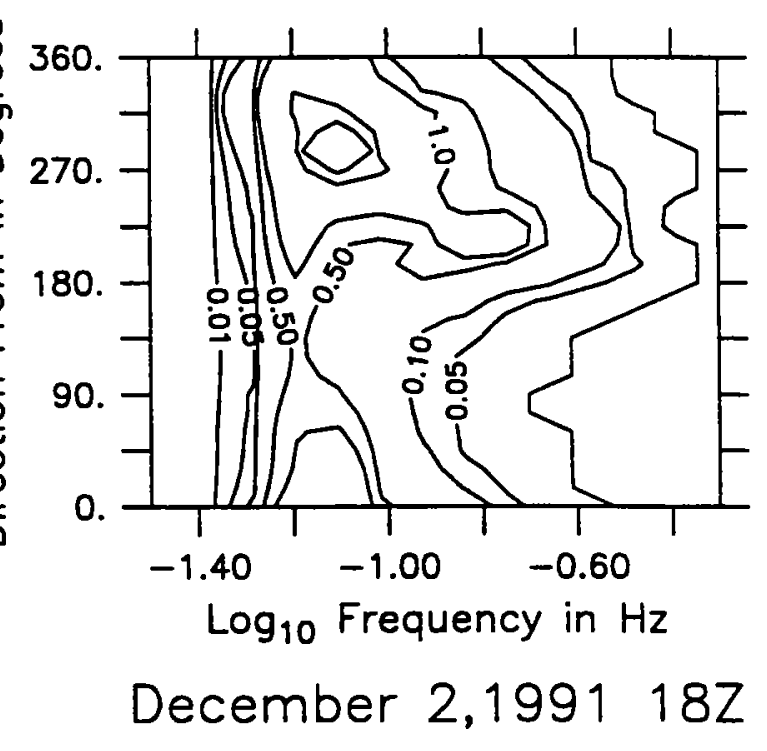

Figure 3.4.36: Directional wave spectra, Seatex buoy. Contours are 0.01, $0.05,0.1,0.5,1,5,10,50,100,500$. 


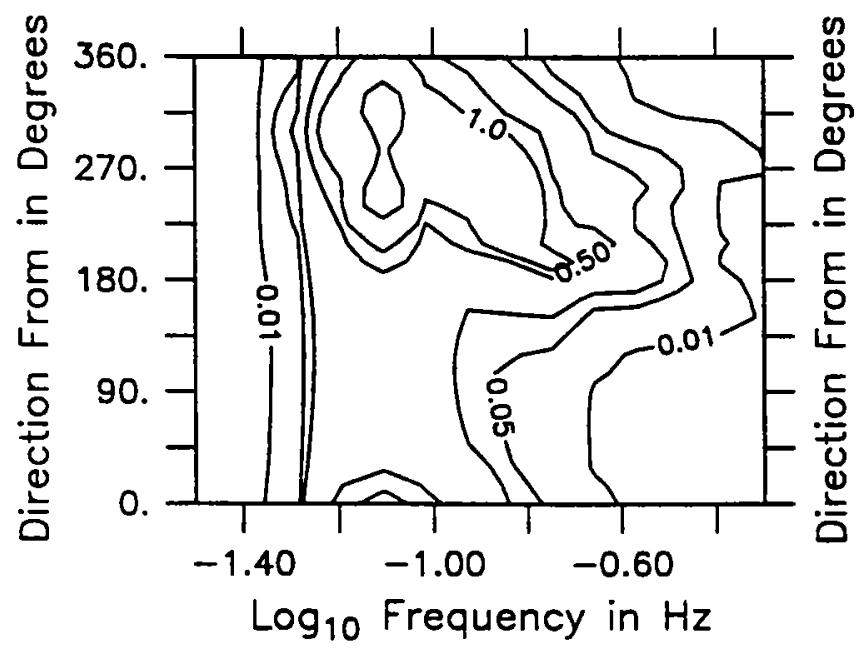

December 3,1991 OOZ

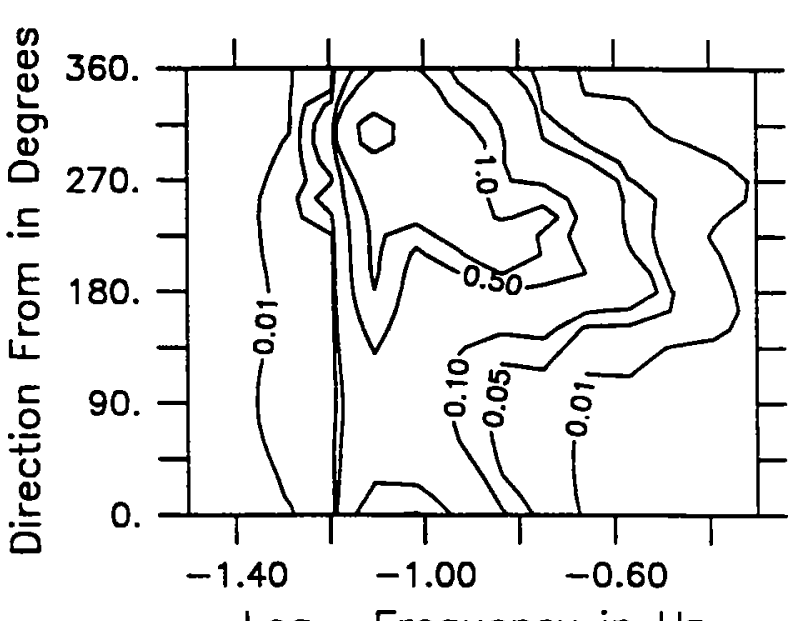

$\log _{10}$ Frequency in $\mathrm{Hz}$

December 3,1991 O6Z

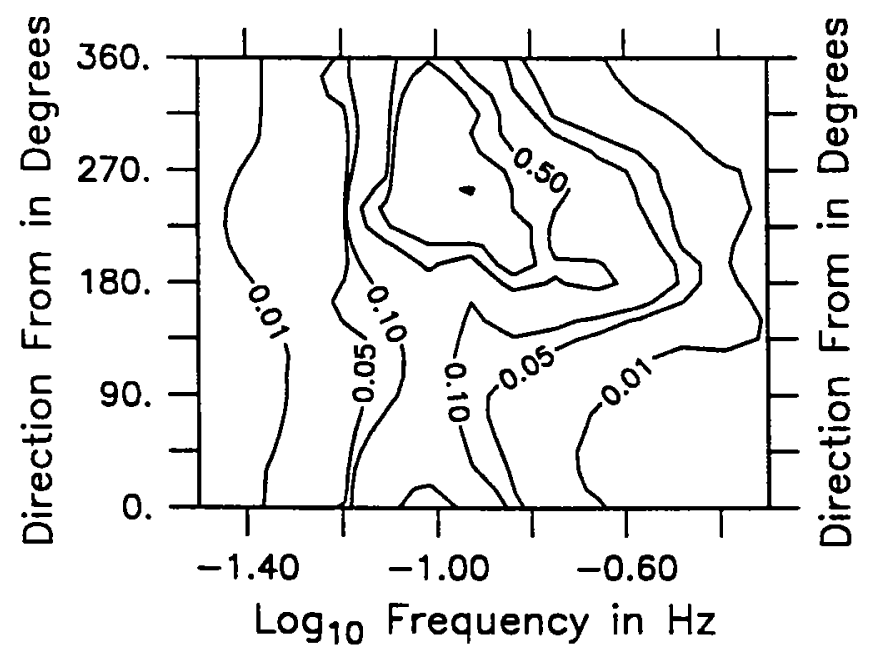

December 3,1991 $12 Z$

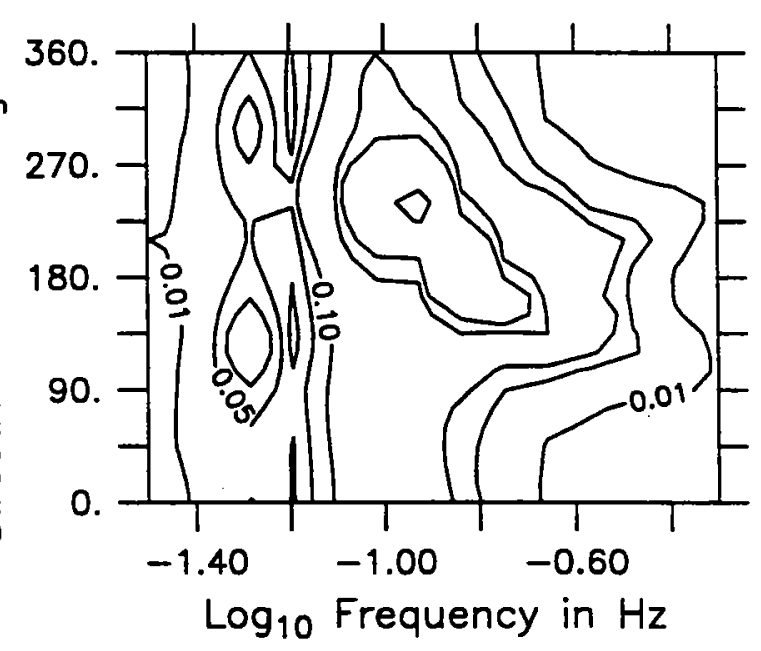

December 3,1991 $18 Z$

Figure 3.4.37: Directional wave spectra, Seatex buoy. Contours are 0.01, $0.05,0.1,0.5,1,5,10,50,100,500$. 


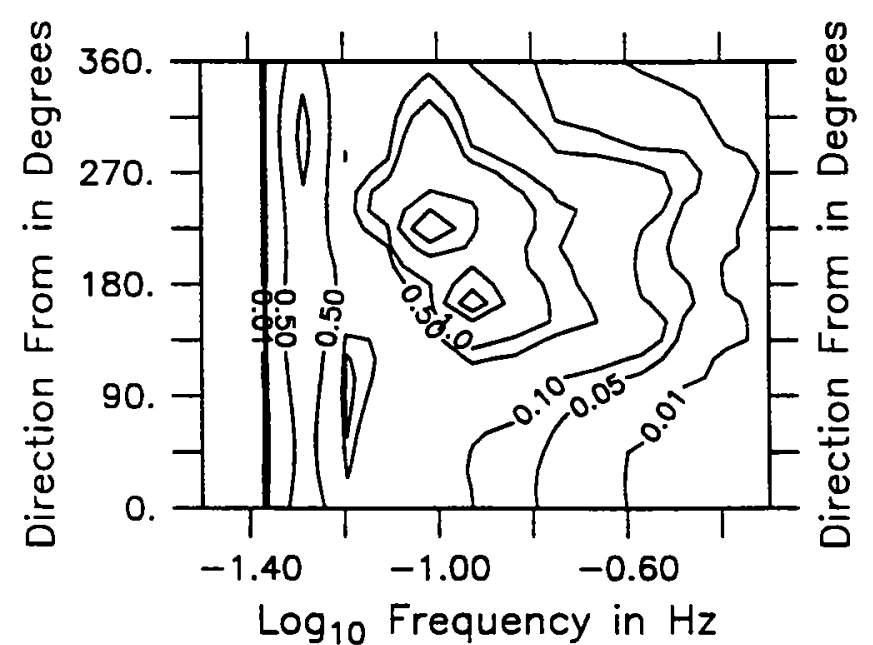

December 4,1991 OOZ

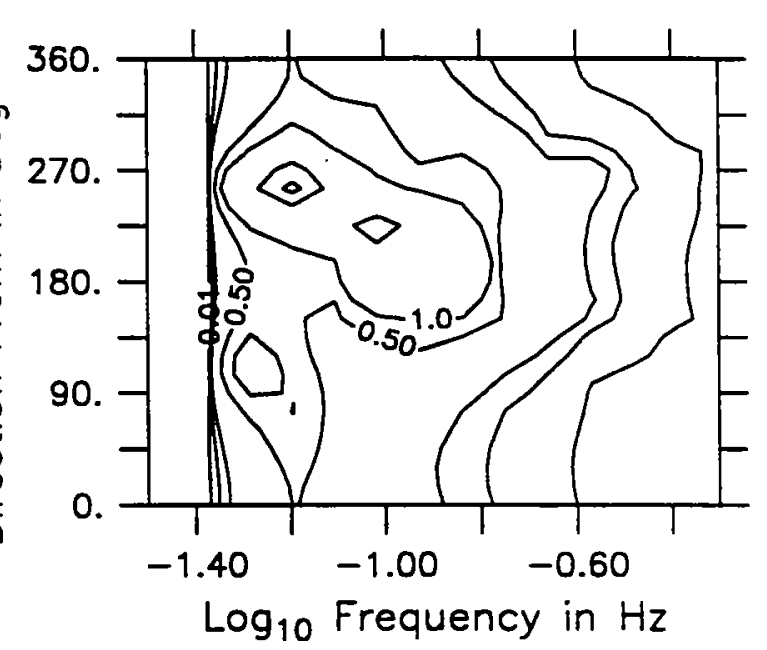

December 4,1991 $06 Z$

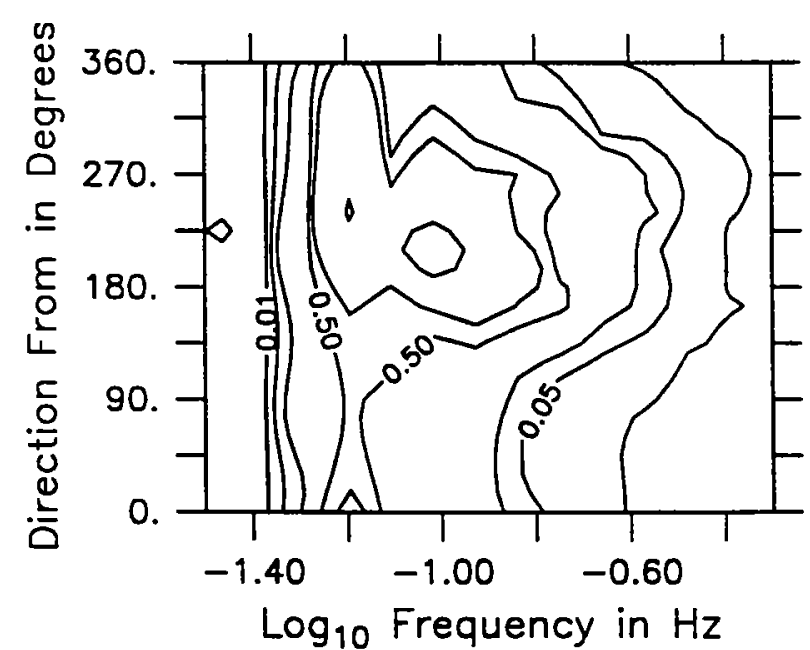

December 4,1991 $12 Z$

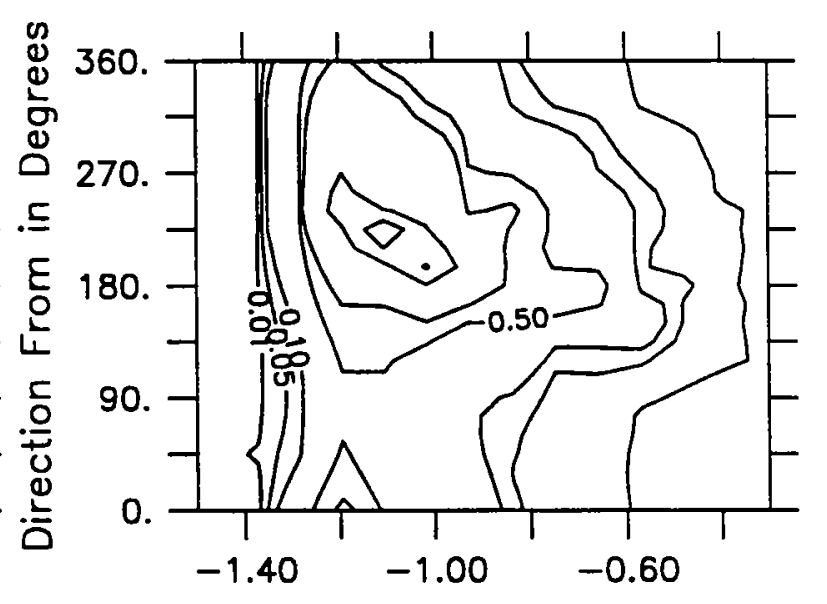

$\log _{10}$ Frequency in $\mathrm{Hz}$

December 4,1991 $18 Z$

Figure 3.4.38: Directional wave spectra, Seatex buoy. Contours are 0.01, $0.05,0.1,0.5,1,5,10,50,100,500$. 


\section{Acknowledgments}

The Endeco/YSI corporation donated an 1156 Wave Buoy for use in this experiment. The Seatex and discus moorings were designed by George Tupper, and the Endeco mooring was designed by Sean Kerry. The moorings were fabricated in the WHOI rigging shop by David Simoneau. John Kemp of the Ocean Acoustics Laboratory supervised the mooring deployment and recovery, which was carried out with expert help from Captain Clampitt and the crew of the Research Vessel Thomas Thompson. Commander Frank Scherber and the crew of the H.M.C.S. Huron recovered the Seatex Buoy. Melora Park-Samelson of the UOP Group undertook the primary processing and calibration tasks for the VAWR, VMCM, and TPOD data. Dick Payne and Bill Horn performed the pre and post-cruise calibrations of the IMET, VAWR, and temperature sensors. Mary Ann Lucas assisted with the final compilation of the manuscript.We would like to acknowledge assistance from Endeco/YSI and Seatex A/S during the course of the data analysis. This work was supported by the Ocean Acoustics Program (Code 324OA) of the Office of Naval Research under contract N00014-91-J1891. 


\section{References}

Barstow, S.E., G. Ueland, H.E. Krogstad, and B.A. Fossum, (1991) The WAVESCAN Second Generation Wave Buoy, IEEE J. Ocean. Eng., 16:254-266.

Clark, N.E., L. Eber, R.M. Laurs, J. A. Renner, and J.F.T. Saur, (1974) Heat exchange between ocean and atmosphere in the eastern North Pacific for 1961-1971. NOAA Technical Report, NMFS SSRF-682, U.S. Department of Commerce, Washington, D.C.

Gnanadesikan A., and E.A. Terray, (1994), A comparison of three wave-measuring buoys, in Magoon, O.T., and J. M. Helmsley, eds., Ocean Wave measurement and Analysis, ASCE, New York.

Krogstad, H.E., (1992), Calibration of the WAVESCAN Directional Wave Buoy, SINTEF Report available from Seatex A/S, Trondheim, Norway.

Large, W.G. and S. Pond, (1981) Open ocean momentum flux measurements in moderate to strong winds. J. Phys. Ocean., 11: 324-336.

Large, W.G. and S. Pond, (1982) Sensible and latent heat flux measurements over the ocean. J. Phys. Ocean., 12:464-482.

List, R.J., (1984), Smithsonian Meteorological Tables, Smithsonian Institution Press, Washington, D.C., 572 pp.

Lygre A. and H.E. Krogstad (1986), Maximum Entropy Estimation of the Directional Distribution in Ocean Wave Spectra, J. Phys. Ocean., 16:20522060. 
Appendix 1: Cruise Participants

a. Deployment Cruise

Raymond Burge

John Cartmill

Harry Deferrari

Paul Bouchard

John Boutheilette

Anand Gnanadesikan

John Kemp

Eric Lamarre

Neil McPhee

Ken Melville

Michael Rebozo

Jacob Roginsky

Anatole Rozenberg

Joseph Steele

Ming Su

George Tupper

Bryan Way

Neil Williams

Martin Wilson

b. Recovery Cruise

John Boutheilette

Raymond Burge

John Cartmill

Harry Deferrari

Carlton Grant

Anand Gnanadesikan

John Kemp

Ken Melville

Michael Rebozo

Ming Su

George Tupper

Neil Williams
NOARL

NOARL

U.Miami

W.H.O.I.

W.H.O.I.

W.H.O.I.

W.H.O.I.

M.I.T.

W.H.O.I.

M.I.T.

U.Miami

U.Miami

M.I.T.

U.Conn.

NOARL

W.H.O.I.

W.H.O.I.

U.Miami

U.Conn.

W.H.O.I.

NOARL

NOARL

U.Miami

W.H.O.I.

W.H.O.I.

W.H.O.I.

M.I.T.

U.Miami

NOARL

W.H.O.I.

U.Miami

(Chief Scientist)

(a)

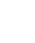




\section{Appendix 2: Chronology of Events}

All times noted are UTC

Deployment Cruise: R/V Thomas Thompson Cruise No. TT004.

Date Time

29 Oct $91 \quad 0121 \quad$ Underway on Cruise TT004 from Seattle

30 Oct $91 \quad 0858 \quad$ Arrive at mooring area

0948 Commence bottom survey using hydrosweep.

1450-1803 Release Testing on wire.

1840 Commence launch of Miami Acoustics Mooring.

2319 Anchor over for Miami Acoustics Mooring

31 Oct 91 0015-0130 Anchor Position Survey

0220 Launching sonabuoy, listening to Acoustics mooring.

0315-0415 Release testing on wire.

0457-0523 CTD Cast.

0537 Deploy Acoustic spar buoy (W.K. Melville). Tethered to ship.

0550-0649 Release Testing on wire.

0705 Recover Acoustic spar buoy.

1535 Commence launching Discus mooring. (WHOI mooring \#920).

2109 Anchor over, Discus mooring.

2200-2300 Meteorological observations to compare ship readings with buoy.

2305 Begin Anchor Position Survey.

1 Nov $910045 \quad$ Finish anchor position survey. 
0222 Commence launching Seatex mooring. (WHOI mooring \#921)

0520 Anchor over, Seatex mooring.

0643 Commence CTD cast.

0709 Deploy Acoustic spar buoy (Time back not recorded).

$0712 \quad$ CTD Aboard

1752 Begin anchor position survey.

1906 Finish anchor position survey.

2145-2350 Release testing on wire.

2 Nov $910130 \quad$ Commence launching Endeco mooring (WHOI mooring \#923).

0450 Anchor over, Endeco mooring.

0512 Anchor on bottom, Endeco mooring.

0535 Begin anchor position survey.

$0807 \quad$ Finish anchor position survey.

1600 Small boat launch to remove two temporary floats from Endeco buoy.

1609 Small boat aboard, floats successfully removed.

1740 Bubble population spar buoy (M. Su) deployed, tethered to ship.

2040 Bubble population spar buoy recovered.

2040 Breaking wave tripod buoy (E Monahan, UConn) deployed, tethered to ship.

2204 Breaking wave tripod buoy recovered.

2240 Acoustic spar buoy deployed, tethered to ship.

3 Nov $91 \quad 0210 \quad$ Acoustic spar buoy recovered. 
0225 Bubble population spar buoy deployed, tethered to ship.

0547 Bubble population spar buoy recovered.

0626-0636 CTD Cast.

1638 Acoustic spar buoy deployed, tethered to ship.

2017 Acoustic spar buoy recovered.

2025 Bubble population spar buoy deployed, tethered to ship.

4 Nov $91 \quad 0200 \quad$ Bubble population spar buoy recovered.

0203-0223 CTD cast.

0525 Set course for Seattle.

5 Nov $91 \quad 1700 \quad$ Arrive Seattle.

\section{Moorings at Sea Recording Data.}

1 Dec $91 \quad 1340 \quad$ Seatex adrift.

3 Dec $91 \quad 1900 \quad$ G. Tupper contacts Commander Johnson, (Royal Canadian Navy) at Esquimault, B.C. for possible recovery assistance.

4 Dec $91 \quad 1949 \quad$ Seatex buoy recovered by HMCS Huron.

2100 Commitment made to divert HMCS Huron, 170 miles from buoy, to attempt recovery.

5 Dec $910000 \quad$ IMET data collection shut down due to insufficient sun.

2 Jan $92 \quad 0700-0800$ Sometime during this hour the met tower on the Endeco buoy broke. Later examination revealed a faulty weld.

Recovery Cruise: R/V: Thomas Thompson Cruise No. TT005

5 Jan $920452 \quad$ Underway on Cruise TT005 from Seattle. 
$\begin{array}{rll}6 \text { Jan } 92 & 1622 & \text { Release fired, Miami Acoustics Mooring. } \\ 2201 & \text { Miami Acoustics Mooring recovered. }\end{array}$

7 Jan 92 0238-0311 CTD cast near Discus Mooring.

$1418 \quad$ Release fired. Discus Mooring.

1846 Discus Mooring recovery completed.

2052 Bubble population spar buoy deployed, tethered to ship.

2222 Bubble population spar buoy recovered.

2311 Release fired, remaining part of Seatex mooring.

8 Jan $92 \quad 0121 \quad$ Remaining Seatex subsurface mooring recovery completed.

1804 Release fired, Endeco mooring.

2106 Endeco mooring recovery completed.

2148 Bubble population spar buoy deployed, tethered to ship.

9 Jan $92 \quad 0100 \quad$ Bubble population spar buoy recovered.

$0200 \quad$ Underway to Seattle.

$0745 \quad$ Arrive Seattle. 


\section{Appendix 3: CTD Cast Information}

1. Pre-deployment Casts R/V Thomas G. Thompson Cruise TT004 Leg 1

Station TT004001 Thu Oct 31 04:58:05 1991

Latitude N49 12.2409 to N49 12.3439

Longitude W131 43.8676 to W131 43.5234

Station TT004002 Fri Nov 01 06:49:11 1991

Latitude N49 11.8471 to N49 11.8288

Longitude W131 54.6433 to W131 54.4354

Station TT004003 Sat Nov 02 05:38:10 1991

Latitude N49 08.4530 to N49 08.6263

Longitude W131 45.5396 to W131 45.4347

Station TT004004 Sun Nov 03 06:12:54 1991

Latitude N49 25.1633 to N49 25.4107

Longitude W131 42.0551 to W131 41.9707

Station TT004005 Mon Nov 04 02:09:29 1991

Latitude N49 16.0861 to N49 16.0843

Longitude W131 33.9778 to W131 33.7746

2. Post-deployment Casts R/V Thomas G. Thompson Cruise TT005 Leg 1

Station TT005001 Tue Jan 7 03:14:46 1992

Latitude N49 15.3600

Longitude W131 51.9404

Station TT005002 Wed Jan 8 04:47:53 1992

Latitude N49 08.9403

Longitude W131 46.7333 


\section{Appendix 4: The Seatex Mooring Failure}

The Seatex buoy was set on 1 November at 0520Z. On 1 December, information from system Argos made it clear that the Seatex buoy was adrift. The buoy was recovered by the HMCS Huron at $1949 \mathrm{Z}$ on 4 December. The Canadian Navy then transported the buoy to the marine facility at the University of Washington, Seattle.

A schematic of the surface expression of the mooring is shown below in Figure A.3.1. A nylon tether with attached floats came up to the surface and lay along the surface for about 70 meters. This tether was then attached to a stainless steel chain which was attached to a clamp on the buoy. The clamp was in turn attached to a stainless steel rod which ran through the buoy. The buoy hull consisted of two floatation elements, each of which was a half-toroid (sliced vertically) which were clamped around the central well with an outer steel band. rod ran in between the two halves of the floatation hull with the clamps keeping it in place.

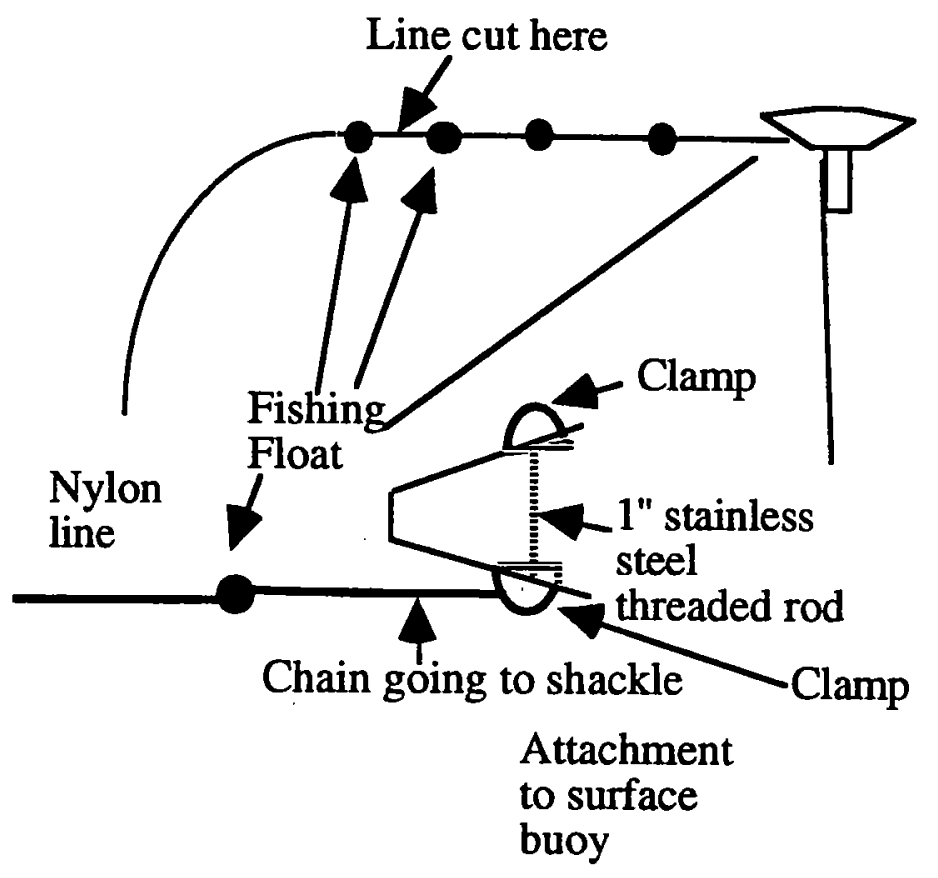

Figure A.4.1: Figure Schematic of the surface expression of the Seatex mooring and of the attachment of the mooring line to the buoy. 
When the buoy was examined on the dock at Seattle, it became clear that something very unusual had occurred. The entire assemblage for attaching the mooring, including the stainless steel rod and both clamps, was missing, as was a similar rod and clamp assembly on the other side of the buoy to which no lines had been attached. The floatation elements are jacketed with very soft plastic which can be scratched with a blunt instrument. The hull showed no signs of the stainless steel threaded rod having worked free on either side.

Upon recovery, it was discovered that the surface line had been cut just above the last float. Analysis of the line end, carried out by Bryce Prindle at WHOI, revealed that the line had been cut by something which produced strong tensile and torsional forces. The cutting instrument was blunt, indicating the line was probably not cut with a knife or by fish teeth. Some yarns in the cut end retained their original structure and were fused together, indicating possible tensile failure. The yarns in the mooring line were tightly wrapped around a central mass of fibers, suggesting strong rotational motion was involved in the failure.

At this point the most likely hypothesis is that the surface line was cut by a propellor. Possibly in an effort to unfoul the boat which cut the line, or else as a calculated act of theft, the clamps and threaded rod assemblies on the buoy were then removed intentionally. This would explain the lack of damage to the floatation hull. 


\section{Appendix 5: MATLAB Code for Calculating Directional Wave Spectra from the Seatex Buoy}

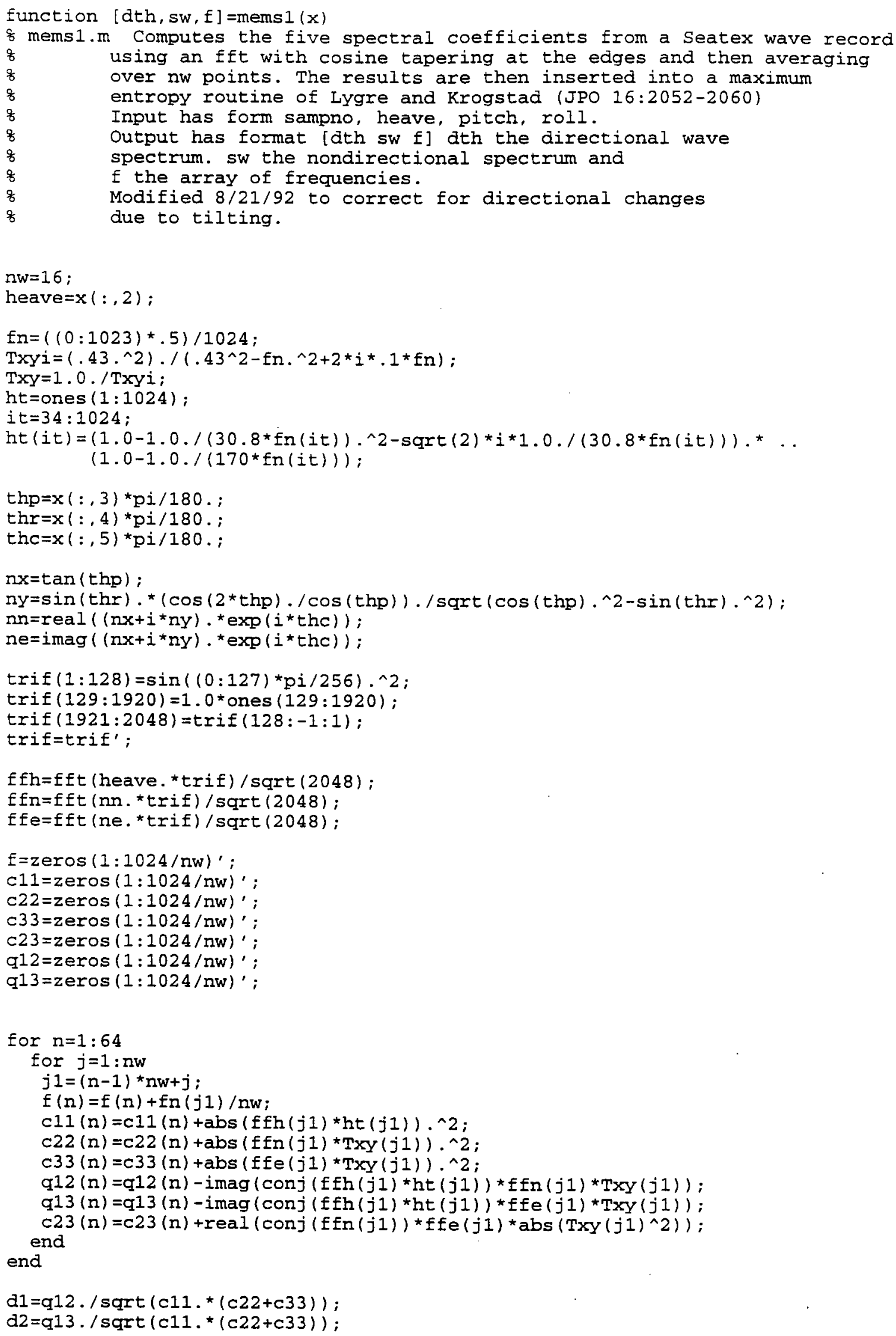




\section{DOCUMENT LIBRARY}

Distribution List for Technical Report Exchange - May 5, 1994

University of California, San Diego

SIO Library 0175C (TRC)

9500 Gilman Drive

La Jolla, CA 92093-0175

Hancock Library of Biology \& Oceanography

Alan Hancock Laboratory

University of Southern California

University Park

Los Angeles, CA 90089-0371

Gifts \& Exchanges

Library

Bedford Institute of Oceanography

P.O. Box 1006

Dartmouth, NS, B2Y 4A2, CANADA

Commander

International Ice Patrol

1082 Shennecossett Road

Groton, CT 06340-6095

NOAA/EDIS Miami Library Center

4301 Rickenbacker Causeway

Miami, FL 33149

\section{Library}

Skidaway Institute of Oceanography

10 Ocean Science Circle

Savannah, GA 31411

Institute of Geophysics

University of Hawaii

Library Room 252

2525 Correa Road

Honolulu, HI 96822

Marine Resources Information Center

Building E38-320

MIT

Cambridge, MA 02139

Library

Lamont-Doherty Geological Observatory

Columbia University

Palisades, NY 10964

\section{Library}

Serials Department

Oregon State University

Corvallis, OR 97331

Pell Marine Science Library

University of Rhode Island

Narragansett Bay Campus

Narragansett, RI 02882
Working Collection

Texas A\&M University

Dept. of Oceanography

College Station, TX 77843

Fisheries-Oceanography Library

151 Oceanography Teaching Bldg.

University of Washington

Seattle, WA 98195

Library

R.S.M.A.S.

University of Miami

4600 Rickenbacker Causeway

Miami, FL 33149

Maury Oceanographic Library

Naval Oceanographic Office

Building 1003 South

1002 Balch Blvd.

Stennis Space Center, MS 39522-5001

Library

Institute of Ocean Sciences,

P.O. Box 6000

Sidney, B.C. V8L 4B2

CANADA

Library

Institute of Oceanographic Sciences

Deacon Laboratory

Wormley, Godalming

Surrey GU8 5UB

UNITED KINGDOM

The Librarian

CSIRO Marine Laboratories

G.P.O. Box 1538

Hobart, Tasmania

AUSTRALIA 7001

Library

Proudman Oceanographic Laboratory

Bidston Observatory

Birkenhead

Merseyside L43 7 RA

UNITED KINGDOM

IFREMER

Centre de Brest

Service Documentation - Publications

BP 7029280 PLOUZANE

FRANCE 



\begin{tabular}{|c|c|c|c|}
\hline $\begin{array}{l}\text { REPORT DOCUMENTATION } \\
\text { PAGE }\end{array}$ & 1. REPORT NO. WHOI-94-18 & 2 & 3. Recipient's Accession No. \\
\hline \multirow{2}{*}{\multicolumn{3}{|c|}{$\begin{array}{l}\text { 4. Title and Subtitle } \\
\text { Meteorological and Oceanographic Data Collected during the ASREX } 91 \\
\text { Field Experiment }\end{array}$}} & $\begin{array}{l}\text { 5. Report Date } \\
\text { August } 1994\end{array}$ \\
\hline & & & a \\
\hline \multicolumn{3}{|c|}{$\begin{array}{ll}\text { 7. Author(s) } & \text { Nancy R. Galbraith, Anand Gnanadesikan, George H. Tupper, Bryan S. Way, and } \\
& \text { Eugene A. Terray }\end{array}$} & $\begin{array}{l}\text { 8. Performing Organization Rept. No. } \\
\text { WHOI-94-18 }\end{array}$ \\
\hline \multirow{2}{*}{\multicolumn{3}{|c|}{$\begin{array}{l}\text { 9. Performing Organization Name and Address } \\
\text { Woods Hole Oceanographic Institution } \\
\text { Woods Hole, Massachusetts } 02543\end{array}$}} & 10. Project/TaskWork Unit No. \\
\hline & & & $\begin{array}{l}\text { 11. Contract(C) or Grant(G) No. } \\
\text { (C) N00014-91-J-1891 } \\
\text { (G) }\end{array}$ \\
\hline \multirow{2}{*}{\multicolumn{3}{|c|}{$\begin{array}{l}\text { 12. Sponsoring Organization Name and Address } \\
\text { Office of Naval Research }\end{array}$}} & $\begin{array}{l}\text { 13. Type of Report \& Period Covered } \\
\text { Technical Report }\end{array}$ \\
\hline & & & 14. \\
\hline
\end{tabular}

\section{Supplementary Notes}

This report should be cited as: Woods Hole Oceanog. Inst. Tech. Rept., WHOI-94-18.

\section{Abstract (Limit: 200 words)}

The 1991 Acoustic Surface Reverberation Experiment (ASREX 91) took place in November and December off the coast of British Columbia. As part of this experiment, three moorings were deployed to characterize the environmental background. The moorings consisted of a meteorological/oceanographic mooring designed to measure surface meteorology, current and temperature in the upper 120 meters, and nondirectional wave parameters and two wave moorings which were instrumented with pitch-roll buoys to characterize the directional wave spectrum. This report presents results from these three moorings. The conditions seen during the experiment were extremely rough, with wind speeds at $3.4 \mathrm{~m}$ above the water surface reaching a maximum of $22 \mathrm{~m} / \mathrm{s}$ and wave heights reaching a maximum of over 10 meters. The air-sea flux of heat was strongly cooling, and the mixed layer deepened over the course of the experiment from approximately 40 to approximately 70 meters. Spectra of the temperature showed a strong semidiurnal tidal signal associated with temperature excursions of several degrees $\mathrm{C}$. The velocity signal showed strong inertial oscillations with amplitudes of $30-50 \mathrm{~cm} / \mathrm{s}$. Weaker low-frequency and semidiurnal tidal signals were also seen. The waves were very strong with significant wave heights of 5-6 meters persisting for up to 2 weeks at a time. Waves were generally out of the south or the west.

\section{Document Analysis a. Descriptors}

Meteorology: North Pacific

Oceanography: North Pacific

Moored Instrument Measurements

b. Identifiers/Open-Ended Terms

\section{c. COSATI Field/Group}

18. Availability Statement

Approved for public release; distribution unlimited.

\begin{tabular}{|l|c|}
\hline $\begin{array}{c}\text { 19. Security Class (This Report) } \\
\text { UNCLASSIFIED }\end{array}$ & $\begin{array}{c}\text { 21. No. of Pages } \\
118\end{array}$ \\
\hline 20. Security Class (This Page) & 22. Price \\
\hline
\end{tabular}


